\title{
Accelerated Development of Zr- Containing New Generation Ferritic Steels for Advanced Nuclear Reactors
}

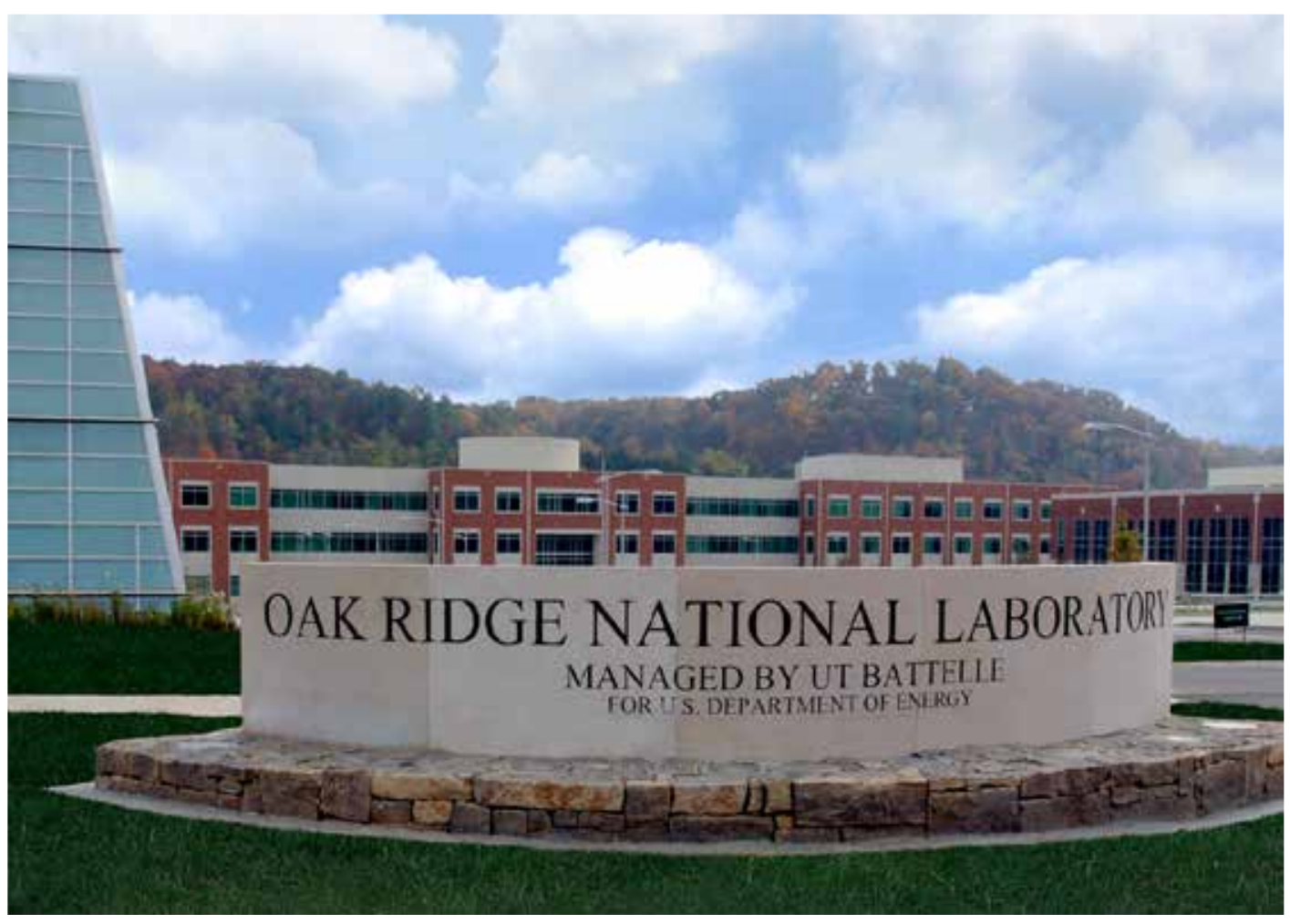

Approved for public release. Distribution is unlimited.
Lizhen Tan, Ying Yang Oak Ridge National Laboratory

Kumar Sridharan University of WisconsinMadison

December 2015 


\section{DOCUMENT AVAILABILITY}

Reports produced after January 1, 1996, are generally available free via US Department of Energy (DOE) SciTech Connect.

Website http://www.osti.gov/scitech/

Reports produced before January 1, 1996, may be purchased by members of the public from the following source:

National Technical Information Service

5285 Port Royal Road

Springfield, VA 22161

Telephone 703-605-6000 (1-800-553-6847)

TDD 703-487-4639

Fax 703-605-6900

E-mail info@ntis.gov

Website http://www.ntis.gov/help/ordermethods.aspx

Reports are available to DOE employees, DOE contractors, Energy Technology Data Exchange representatives, and International Nuclear Information System representatives from the following source:

Office of Scientific and Technical Information

PO Box 62

Oak Ridge, TN 37831

Telephone 865-576-8401

Fax 865-576-5728

E-mail reports@osti.gov

Website http://www.osti.gov/contact.html

This report was prepared as an account of work sponsored by an agency of the United States Government. Neither the United States Government nor any agency thereof, nor any of their employees, makes any warranty, express or implied, or assumes any legal liability or responsibility for the accuracy, completeness, or usefulness of any information, apparatus, product, or process disclosed, or represents that its use would not infringe privately owned rights. Reference herein to any specific commercial product, process, or service by trade name, trademark, manufacturer, or otherwise, does not necessarily constitute or imply its endorsement, recommendation, or favoring by the United States Government or any agency thereof. The views and opinions of authors expressed herein do not necessarily state or reflect those of the United States Government or any agency thereof. 
Nuclear Energy Enabling Technologies (NEET) Reactor Materials FY 2012 Award

M2CA-12-TN-OR_0402-0210

\title{
ACCELERATED DEVELOPMENT OF ZR-CONTAINING NEW GENERATION FERRITIC STEELS FOR ADVANCED NUCLEAR REACTORS
}

\author{
PI: $\quad$ Lizhen Tan (Oak Ridge National Laboratory) \\ Collaborators: Kumar Sridharan (University of Wisconsin-Madison) \\ Ying Yang (Oak Ridge National Laboratory)
}

Date Published: December 2015

Prepared by

OAK RIDGE NATIONAL LABORATORY

Oak Ridge, Tennessee 37831-6283

managed by

UT-BATTELLE, LLC

for the

US DEPARTMENT OF ENERGY

under contract DE-AC05-00OR22725 



\section{CONTENTS}

Page

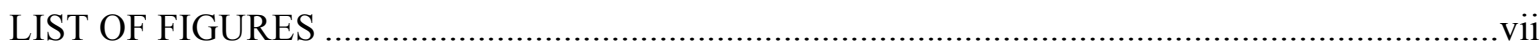

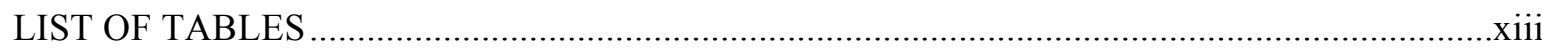

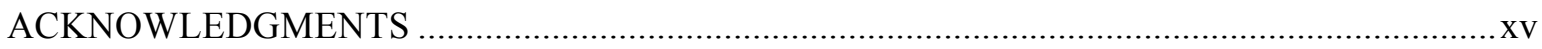

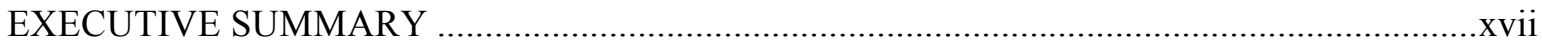

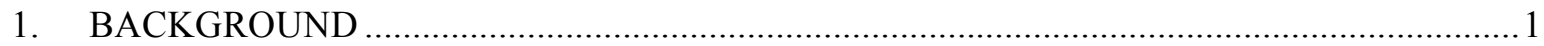

2. COMPUTATIONAL THERMODYNAMICS AIDED ALLOY DESIGN .............................

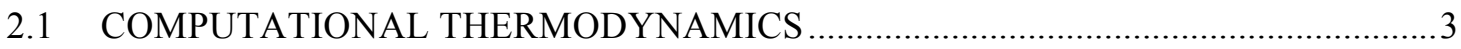

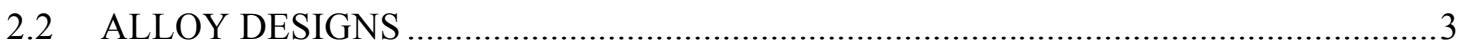

2.2.1 9Cr FM Steels (T-Alloys) ….......................................................................

2.2.2 Intermetallic-Strengthened Fe-Cr-Zr Alloys (Z-Alloys)...................................5

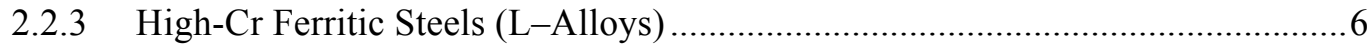

3. ALLOY FABRICATION AND MICROSTRUCTURAL CHARACTERIZATION ............... 8

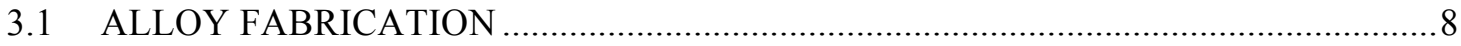

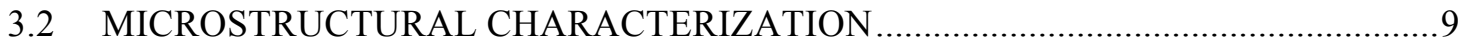

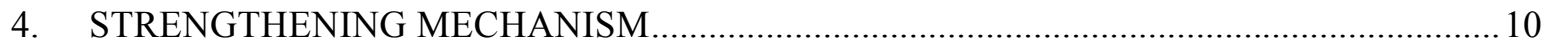

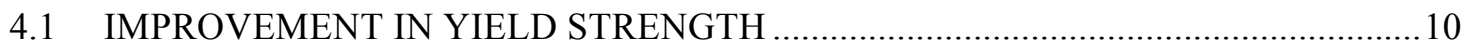

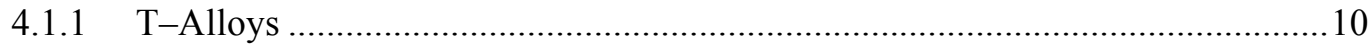

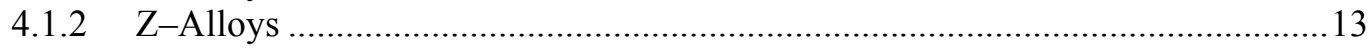

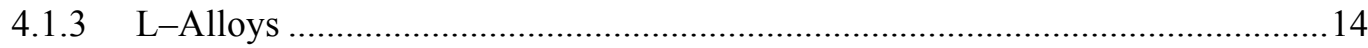

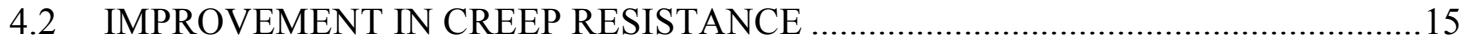

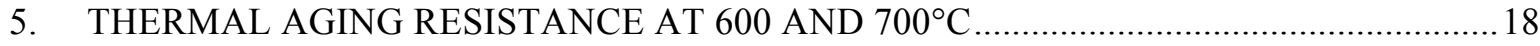

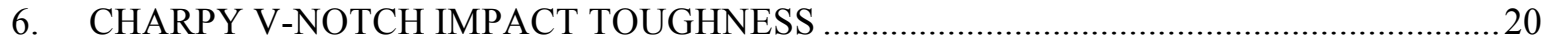

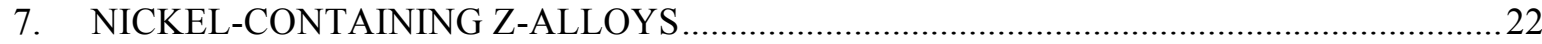

7.1 THERMODYNAMIC MODELING OF FE-CR-ZR-NI SYSTEM .............................22

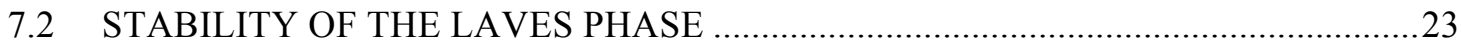

7.3 MICROSTRUCTURAL CHARACTERIZATION OF NI-CONTAINING ALLOYS ..24

8. RADIATION RESISTANCE EVALUATED BY ION IRRADIATION ...............................28

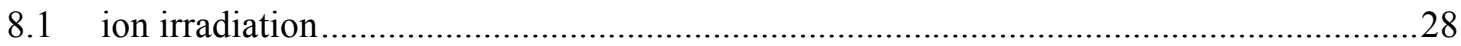

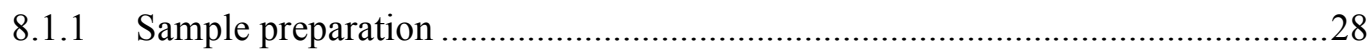

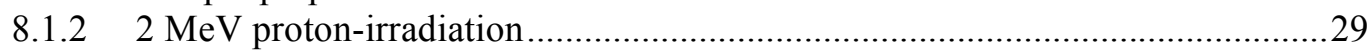

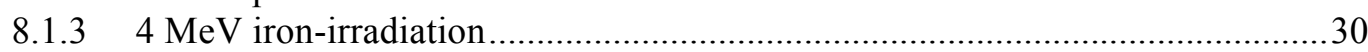

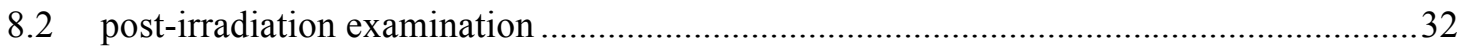

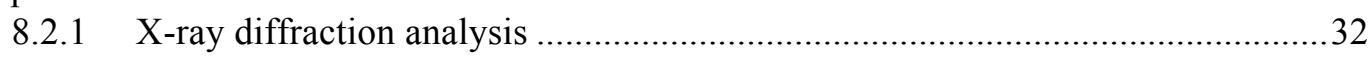

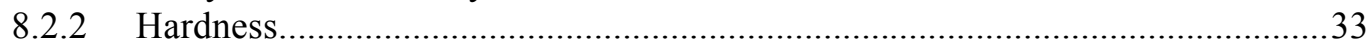

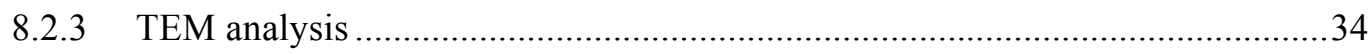

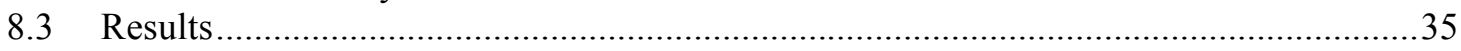

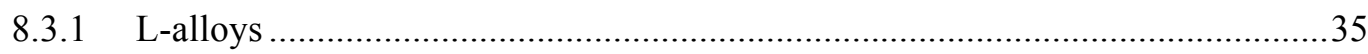

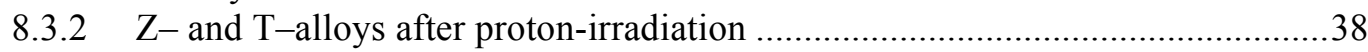

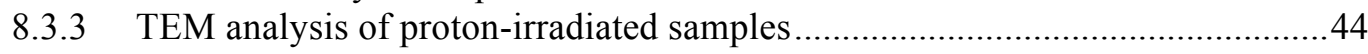

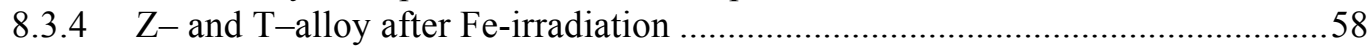

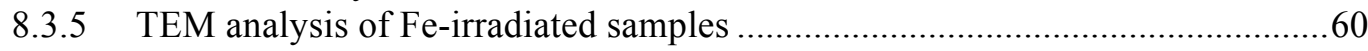

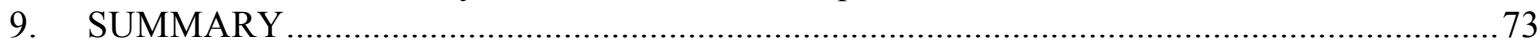

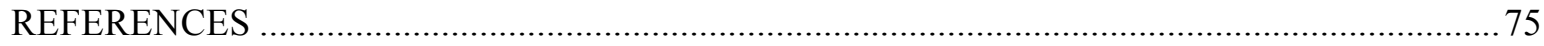





\section{LIST OF FIGURES}

\section{Figure}

Figure 1. Calculated temperature-dependent mole fraction of phases in a T-alloy as compared to P91.

Figure 2. Calculated temperature-dependent mole fraction of phases in Z-alloys (a) Z6, (b) Z7 and

(c) Z9.

Figure 3. Calculated temperature-dependent mole fraction of phases in L-alloys of LTZ1 and

LNTZ.......

Figure 4. Specification of type SS-3 specimen (unit: inch).

Figure 5. Typical tensile stress-strain curves of the T-alloys in the AR and TMT conditions.........11

Figure 6. Temperature-dependent yield strength and total elongation of T-alloys as compared with P91

Figure 7. Secondary electron images (SEIs) of T-alloys.

Figure 8. Bright-field (BF) TEM images of a T-alloy as compared with P91....

Figure 9. Temperature-dependent yield strength and total elongation of $Z$-alloys as compared with

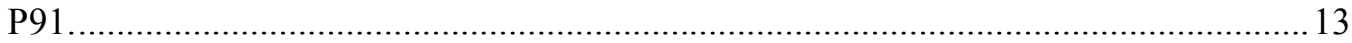

Figure 10. Backscattered electron images (BEIs) of Z-alloys (e.g., Z4, Z7, and Z9) showing eutectic network confined ferritic matrix cells.

Figure 11. Temperature-dependent yield strength and total elongation of L-alloys in the AR and TMT conditions as compared to P91....

Figure 12. Backscattered electron images (BEIs) of alloy LNTZ in the AR and aged $\left(700^{\circ} \mathrm{C}\right.$ for

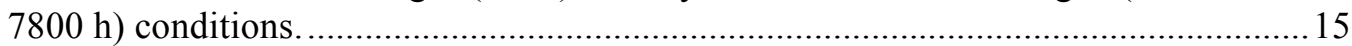

Figure 13. Larson-Miller parameter plot of the tested $\mathrm{T}$ - and $\mathrm{Z}$-alloys as compared with $\mathrm{P} 91 \ldots . . .15$

Figure 14. Creep curves of T-alloy and Z-alloy as compared with the data of $\mathrm{P} / \mathrm{T} 91$ at $650^{\circ} \mathrm{C}$ and $110 \mathrm{MPa}$.

Figure 15. Microstructural comparison between the gauge and tab sections of a creep ruptured T-alloy at $650^{\circ} \mathrm{C}$ and $110 \mathrm{MPa}$.

Figure 16. Microstructure of the gauge section of a creep ruptured $\mathrm{Z}$-alloy at $650^{\circ} \mathrm{C}$ and $110 \mathrm{MPa}$.

Figure 17. Changes of yield strength (YS), tensile strength (TS), and total elongation (EL) at room temperature of the $\mathrm{T}-$ and $\mathrm{Z}$-alloys after aging at 600 and $700^{\circ} \mathrm{C}$ for 5,906 and 5,236 h, respectively.....

Figure 18. Changes of yield strength (YS), tensile strength (TS), and total elongation (EL) at room temperature of the $\mathrm{T}-$ and $\mathrm{Z}$-alloys after aging at 600 and $700^{\circ} \mathrm{C}$ for $10,200 \mathrm{~h}$............ 19

Figure 19. Specification of half-size Charpy V-notch specimen...............................................20

Figure 20. Charpy V-notch impact tested data and fitted curves of T-alloys in the T-L orientation

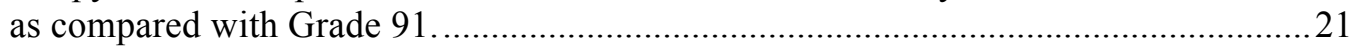

Figure 21. Partial isothermal section of $\mathrm{Fe}-\mathrm{Ni}-\mathrm{Zr}$ at $1,000^{\circ} \mathrm{C}$ : (a) experimental, (b) calculated..... 22

Figure 22. The mole fraction of the $\mathrm{C} 14$ and $\mathrm{C} 15$ Laves phase vs. temperature in the $\mathrm{Fe}-12 \mathrm{Cr}-6 \mathrm{Zr}$ base alloy with different additions of $\mathrm{Ni}$. The solid, dashed and dotted lines denote 0.5 , 2 and $4 \mathrm{wt} \% \mathrm{Ni}$, respectively. The black and red colors denote the $\mathrm{C} 14$ and $\mathrm{C} 15$ structure, respectively....................................................................................... 23

Figure 23. The dissolved $\mathrm{Ni}$ in the $\mathrm{C} 14$ and $\mathrm{C} 15$ Laves phase vs. temperature in the $\mathrm{Fe}-12 \mathrm{Cr}-6 \mathrm{Zr}$ base alloy with different additions of $\mathrm{Ni}$. The solid, dashed and dotted lines denote 0.5 , 2 and $4 \mathrm{wt} \% \mathrm{Ni}$, respectively. The black and red colors denote the $\mathrm{C} 14$ and $\mathrm{C} 15$

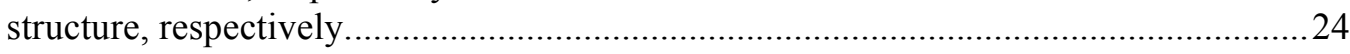

Figure 24. BEIs of Fe-12Cr-6Zr base alloy with additions of (a) 0.5 and (b) $4 \mathrm{wt} \% \mathrm{Ni} \ldots \ldots \ldots \ldots \ldots . . .25$ Figure 25. EBSD IQ and IPF maps of Fe-12Cr-6Zr alloys with $(\mathrm{a}-\mathrm{b}) 0.5$ and $(\mathrm{c}-\mathrm{d}) 4 \mathrm{wt} \% \mathrm{Ni}$......26 


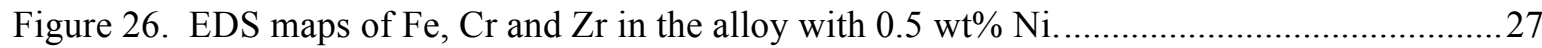

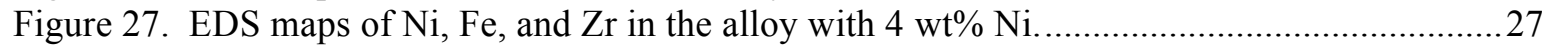

Figure 28. As received ferritic steel samples (left) and after polishing and punching into $3-\mathrm{mm}$ disks (right).

Figure 29. Sample and thermocouple arrangement in the irradiation stage with 6 samples ready for $2 \mathrm{MeV}$ proton irradiation at $420^{\circ} \mathrm{C}$ up to $1 \mathrm{dpa}$.

Figure 30. Damage depth profile in $\mathrm{Fe}-10 \mathrm{Cr}$ irradiated with $2 \mathrm{MeV}$ protons to a level of $1 \mathrm{dpa}$ at $15 \mu \mathrm{m}$. Calculation was performed using SRIM-2012.03 assuming the displacement threshold energies to be $40 \mathrm{eV}$ for all elements.

Figure 31. Temperature and current profile for $2 \mathrm{MeV}$ proton-irradiation up to $1.1 \mathrm{e} 18 \mathrm{p} / \mathrm{cm}^{2}$ (0.1dpa) and $1.1 \mathrm{e} 19 \mathrm{p} / \mathrm{cm}^{2}(1 \mathrm{dpa})$ at $420{ }^{\circ} \mathrm{C}$

Figure 32. Damage and Fe-implantation profile of $4 \mathrm{MeV} \mathrm{Fe}^{2+}$-irradiated $\mathrm{Fe}-10 \mathrm{Cr}$ alloy up to $5 \mathrm{e} 16$ $\mathrm{Fe} / \mathrm{cm}^{2}=50 \mathrm{dpa}_{\text {peak. }}$. The damage level was calculated using SRIM 2012-03, assuming $\mathrm{E}_{\mathrm{d}}(\mathrm{Cr}, \mathrm{Fe})=40 \mathrm{eV}$ under the Kinchin-Pease model.

Figure 33. Temperature and current profile for $4 \mathrm{MeV} \mathrm{Fe}$-irradiation up to $5 \mathrm{e} 16 \mathrm{Fe} / \mathrm{cm}^{2}$ at $400^{\circ} \mathrm{C} .31$

Figure 34. Indentation depths (left, A) and a photograph of the indenter (right, B) used in this study.

Figure 35. L-alloy sample arrangement and appearance before and after $2 \mathrm{MeV}$ proton irradiation at $420^{\circ} \mathrm{C}$ up to $0.1 \mathrm{dpa}$. Discoloration of the samples was observed after irradiation. .......35

Figure 36. XRD patterns of LTZ1 alloy at various proton damage levels. The possible Ti-rich

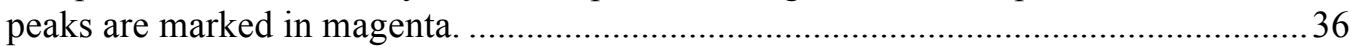

Figure 37. STEM image of LTZ1 alloy before proton irradiation at (a) low and (b) high

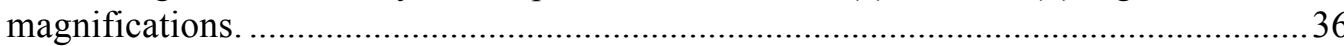

Figure 38. (a) STEM image and (b) EDS mapping of LTZ1 alloy irradiated with protons up to 0.1 dpa.

Figure 39. (a) STEM image and (b) EDS line scan of LTZ1 alloy irradiated with protons up to 1 dpa.

Figure 40. (a) STEM image and (b) EDS line scan of LT1 sample irradiated with protons up to 1 dpa.

Figure 41. Change of Vickers microhardness (25 gf) as compared to the non-implanted ( $0 \mathrm{dpa})$ counterparts for advanced alloys as a function of proton-irradiation damage level. .....38

Figure 42. XRD patterns for T12 alloy at various proton damage levels.

Figure 43. XRD patterns of T-alloys irradiated with $2 \mathrm{MeV}$ protons at $420^{\circ} \mathrm{C}$ up to $1 \mathrm{dpa}$. Main peaks at $2 \theta \sim 45^{\circ}, 65^{\circ}$, and $82^{\circ}$ correspond to diffraction from $\mathrm{CrFe}$ (PDF04-0334099).....

Figure 44. XRD patterns of Z3 alloy at various proton damage levels. The possible Zr-rich peaks are marked in red.

Figure 45. XRD patterns of Z-alloys irradiated with $2 \mathrm{MeV}$ protons at $420^{\circ} \mathrm{C}$ up to $1 \mathrm{dpa}$. Main peaks at $2 \theta \sim 45^{\circ}, 65^{\circ}$, and $82^{\circ}$ correspond to diffraction from $\mathrm{CrFe}$ (PDF04-0334099).....

Figure 46. Surface images of proton-irradiated Z8 ferritic steel.

Figure 47. Surface heights of the proton-irradiated T22 sample obtained by the in-situ SPM imaging.

Figure 48. Raw indentation and depth responses for un-irradiated Z8 steel (shown here as an example).

Figure 49. Projection for hardness vs. contact depth for proton-irradiated steel samples (red) as compared to un-irradiated base material (blue).

Figure 50. SEM characterization of un-irradiated Z6 alloy: (a) low-magnification secondaryelectron image overview; (b) high-magnification secondary-electron image of the eutectic zone; (c) EDS spectrum from full area of (a) and quantification results (error < 
$\pm 0.1 \%$ ); (d) EDS spectra from the "brighter" (red square) and "darker" (green diamond) phases in (b), all with beam voltage of $20 \mathrm{kV}$.

Figure 51. Cross-sectional TEM of un-irradiated Z6 alloy in the eutectic zone: (a) lowmagnification STEM-HAADF image; (b) zoom-in image of box b in (a) showing phase interface and grain boundary; (c, d) EDS line-scan profiles along arrows c and d in (b), respectively.....

Figure 52. Microstructure of the Fe-Cr phase in the eutectic zone of the un-irradiated Z6 alloy: (a) HAADF image viewed along [111] zone axis with (1-3) representing a few long dislocation lines and arrows pointing to short dislocation threads; (b) bright-field TEM image of the grain boundary shown in Figure 51(b) with defects and/or strain field noticed near the boundary; (c) diffraction pattern shows a small misorientation angle of the boundary.

Figure 53. (d-f) WBDF TEM images of the same grain in (a) using different g vectors. All images were recorded in $(\mathrm{g}, 3.1 \mathrm{~g})$ condition. One possible combination of Burgers vectors of the dislocation lines shown as (1), (2), and (3) is: $b^{(1)}=[1 \overline{1} 1] / 2, b^{(2)}=[0 \overline{1} 0]$, and $b^{(3)}=$ $[111] / 2$, allowing $b^{(1)}=b^{(2)}+b^{(3)}$.

Figure 54. (g) HRSTEM image of short dislocation threads with an inset FFT pattern suggests no extra phase relates with the dislocation. The interplanar spacing $d_{(110)}=1.97 \AA$ accords with that of $\alpha-\mathrm{Fe}(B C C)$. (h) HRSTEM image of a white-spot. (i,j) EDS line-scan profiles along arrows in $(\mathrm{g})$ and $(\mathrm{h})$, respectively.

Figure 55. Microstructure of $\mathrm{Zr} / \mathrm{W}$-rich Laves phase in the eutectic zone of the un-irradiated Z6 alloy: (a) bright-field TEM image shows severely faulted bands divided by defect-free bands; (b, c) selected area diffraction patterns from circles b and c in (a), respectively, together with enlarged view of diffraction patterns along $\mathrm{c}^{*}$ axis.

Figure 56. (d, e) Aberration-corrected HRSTEM images of faulted and defect-free region, respectively. (f, g) Enlarged atom-resolved images and structural model of faulted $\beta$ $\mathrm{Fe}_{2} \mathrm{Zr}$ and pristine $\beta$ '- $\mathrm{Fe}_{2} \mathrm{Zr}$ phases, respectively.

Figure 57. Microstructure of un-irradiated T12 alloy: (a) secondary-electron image with the same magnification as Figure 50(b); (b) EDS spectrum from full area of (a) with beam voltage of $20 \mathrm{kV}$

Figure 58. Cross-sectional TEM of un-irradiated T12 alloy: (a) low-magnification STEM-HAADF image; (b) zoom-in image of box b in (a) showing tangled dislocation lines in an elongated subgrain with an arrow pointing to dislocation arrays on a boundary; (c) HRSTEM image of dislocation lines with an inset FFT pattern suggesting no extra phase relates with the dislocation. The interplanar spacing $d_{(110)}=2.06 \AA$ and $d_{(002)}=$ $1.41 \AA$ accords with that of $\alpha-\mathrm{Fe}$ (BCC). (d) EDS line-scan profiles along arrow in (c).

Figure 59. Characterization of precipitates in un-irradiated T12 alloy: (a) STEM-HAADF image of a precipitate; (b) EDS line-scan profiles along arrow in (a); (c) HRSTEM image and corresponding FFT pattern of the precipitate in (a). The interplanar spacing $d_{(220)}=$ $1.59 \AA$ and $d_{(311)}=1.35 \AA$ accords well with that of $\mathrm{TiC}$ or $\mathrm{TaC}$ (rocksalt). ..................51

Figure 60. Surface morphology and cross-sectional microstructure of irradiated Z6 alloy: (a1,a2) low-magnification secondary-electron image; $(\mathrm{b} 1, \mathrm{~b} 2)$ high-magnification secondaryelectron image; (c) low-magnification STEM-HAADF image of cross-sectional specimen. Notice that (a), (b), and (c) have the same magnifications as of Figure 50(a), Figure 50(b), and Figure 50(a), respectively.

Figure 61. Characterization of eutectic structure in proton-irradiated Z6 alloy: (a) STEM-HAADF image; (b) EDS line-scan profiles along arrow in (a) with left axis as weight percent of $\mathrm{Cr}, \mathrm{Fe}, \mathrm{Zr}$, and $\mathrm{W}$ and right axis as atomic ratio between $\mathrm{O}$ and $(\mathrm{Cr}+\mathrm{Fe}+\mathrm{Zr}+\mathrm{W}) ;(\mathrm{c}, \mathrm{d})$ 
HRSTEM images and corresponding FFT patterns of $\mathrm{Fe}-\mathrm{Cr}$ phase and $\mathrm{Zr} / \mathrm{W}$-rich phase

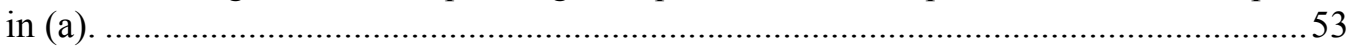

Figure 62. Characterization of defect microstructure in $\mathrm{Fe}-\mathrm{Cr}$ matrix grains of proton-irradiated Z6 alloy: (a) STEM-HAADF image of a grain boundary and defects inside grains; (b) EDS line-scan profiles along arrow in (a); (c, d) bright-field TEM images of unknown defects using beam directions slightly off [011] and [002] zone axes, respectively; (e) EDS line-scan profiles along arrow in (c).

Figure 63. Preliminary characterization of surface oxidation of proton-irradiated Z6 alloy: (a) STEM-HAADF image of eutectic structure near surface; (b) STEM-HAADF image of surface with multiple types of oxides; (c) EDS line-scan profiles along arrow in (a); (d) HRSTEM image of oxidized Zr-rich phase; (e) HRSTEM image and FFT pattern of a $\mathrm{ZrO}_{2}$ particle within Fe-Cr matrix grain in (b); (f) HRSTEM image and FFT pattern of a $\mathrm{Cr}_{2} \mathrm{O}_{3}$ debris on surface in (b); (g, h) EDS point spectra measured from phases (e) and (f), respectively with the spectrum of $\mathrm{Fe}-\mathrm{Cr}$ matrix grain in blue................................55

Figure 64. Surface morphology and cross-sectional microstructure of proton-irradiated T12 alloy: (a1) secondary-electron image with the same magnification as Figure 60(b); (b) lowmagnification STEM-HAADF image of cross-sectional specimen with the same magnification as Figure 58(a).

Figure 65. Cross-sectional TEM of proton-irradiated T12 alloy: (a) STEM-HAADF image showing elongated subgrains and sparse precipitates; (b) EDS line-scan profiles along the arrow in (a).

Figure 66. Characterization of precipitates in proton-irradiated T12 alloy: (a) STEM-HAADF image of elongated subgrain, with several precipitates within subgrain and on grain boundary; (b) EDS spectrum from a precipitate pointed by arrow b in (a); (c, e) HRSTEM image, FFT pattern, and EDS spectrum from a (TaTi)C precipitate pointed by arrow c,e in (a); (d, f) HRSTEM image, FFT pattern, and EDS spectrum from a $(\mathrm{CrW}) \mathrm{C}$ precipitate pointed by arrow d,f in (a). Blue: spectrum of $\mathrm{Fe}-\mathrm{Cr}$ matrix grain.

Figure 67. X-ray diffraction patterns of Fe-irradiated T-alloys at $400^{\circ} \mathrm{C}$ up to $50 \mathrm{dpa}$. Main peaks at $2 \theta \sim 45^{\circ}, 65^{\circ}$, and $82^{\circ}$ correspond to diffraction from $\mathrm{CrFe}$ (PDF04-033-4099)..........58

Figure 68. X-ray diffraction patterns of Fe-irradiated Z-alloys at $400^{\circ} \mathrm{C}$ up to $50 \mathrm{dpa}$. Main peaks at $2 \theta \sim 45^{\circ}, 65^{\circ}$, and $82^{\circ}$ correspond to diffraction from $\mathrm{CrFe}$ (PDF04-033-4099)..........59

Figure 69. Sample surface images taken of Fe-irradiated T12 alloy............................................59

Figure 70. Projection for hardness vs contact depth for Fe-irradiated Z6 alloy (red) as compared to un-irradiated base material (blue).

Figure 71. Low magnification STEM-HAADF image of the as received Z6 alloy, showing an overview of the sample: darker grains correspond to the ferrite phase, brighter grains correspond to the Laves phase.

Figure 72. STEM-ABF micrograph of the one grain of the as received Z6 alloy imaged along the [100] zone axis. Dislocation lines are visible at the center of the grain as well as close to grain boundaries.

Figure 73. Size distribution of the dislocation lines in the Z6 as received alloy.

Figure 74. TEM-BF micrographs of the two grains (circled in red) used for defect analysis in the Fe-irradiated Z6 alloy.

Figure 75. STEM-ABF micrograph of one grain of the Fe-irradiated Z6 alloy imaged along the [110] ZA. On the bottom left corner the habit planes of the loops, as viewed in this imaging condition is shown, as taken from Yao et al. [27].

Figure 76. STEM-ABF micrographs (the same region and grain) of the Fe-irradiated Z6 alloy

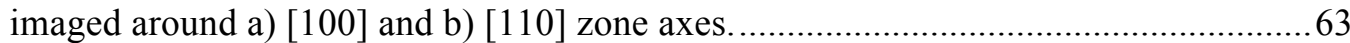

Figure 77. Size distribution for dislocation loops formed in Fe-irradiated Z6 alloy. 
Figure 78. HRSTEM images acquired on dislocation lines and a loop found in the Fe-irradiated Z6 alloy, when the grain was oriented along the [111] ZA. No significant structural rearrangement was observed.

Figure 79. Typical RIS profile across a grain boundary separating two ferritic grains in the Feirradiated Z6 alloy: a) STEM-ADF image; b) EDS compositional profile following the orange line in a) with red and black lines denoting $\mathrm{Fe}$ and $\mathrm{Cr}$, respectively.

Figure 80. Overview of the Fe-irradiated Z6 alloy and Laves phase: a) low magnification STEMABF micrograph with a dashed white line representing the approximate depth after which defects caused by irradiation are not visible anymore, corresponding to the maximum damage range of $\sim 2.1 \mu \mathrm{m}$. Grains of the Laves phase within the region bounded by red arrows $(0.8-1.7 \mu \mathrm{m})$ underwent amorphization. b) and c) are the SADP corresponding to the grains indicated by $\mathrm{b}$ and $\mathrm{c}$ in the STEM micrograph.......65

Figure 81. HRSTEM image of one crystalline grain of the Laves phase close to the top surface of the Fe-irradiated Z6 alloy.

Figure 82. STEM-ABF micrographs of a crystalline Laves phase grain in the Fe-irradiated Z6 alloy.....

Figure 83. Low magnification STEM-ABF image of the as received T12 alloy, showing an overview of the sample with the martensitic structure.

Figure 84. STEM micrographs of the as received T12 alloy: a) HAADF image showing different precipitates found in the as received alloy (arrows of different colors indicated precipitates with different composition) found in the sample; b) BF-ABF STEM micrograph of dislocations line inside a lath (imaged on the [100] ZA).

Figure 85. STEM-EDS analysis of the bright precipitates in the as received T12 alloy: a) STEMHAADF image showing different precipitates dispersed inside the grain of the steel matrix; b) STEM-HAADF at higher magnification of one precipitates; c) EDS linescan profiles showing $\mathrm{C}, \mathrm{Ta}$ and $\mathrm{Ti}$ enrichment in the precipitate.

Figure 86. STEM-ADF images of bright precipitates at gain boundary of the as received T12 alloy, which are enriched with $\mathrm{W}$ and $\mathrm{Cr}$, as compared to the matrix. Red dots represent the point from which EDS signals were acquired.

Figure 87. STEM-HAADF image of the precipitates indicated by black arrows in Figure 84 . Those precipitate are heavily enriched in titanium and carbon and only slightly in tantalum. 68

Figure 88. TEM-BF micrographs of the two grains (circled in red) used for defect analysis in the Fe-irradiated T12 alloy.

Figure 89. ABF-STEM images of dislocation loops in a grain of the Fe-irradiated T12 alloy, imaged on the [100] ZA. Similar to the case of Fe-irradiated Z6 alloy, loops are determined to be of the $<100>\{100\}$ type.

Figure 90. Size distribution for dislocation loops formed in Fe-irradiated T12 alloy.

Figure 91. STEM-HAADF micrographs of the Fe-irradiated T12 alloy at (a) low magnification and $(b, c)$ high magnification of the region encircled in (a). High density of precipitate particles was observed and their composition varied considerably. Typically, precipitates inside grains were enriched in $\mathrm{Ti}$ and $\mathrm{Ta}$, while precipitates on grain boundaries were enriched in $\mathrm{W}$ and $\mathrm{Cr}$.

Figure 92. STEM-HAADF micrograph showing different precipitates at various depths inside the Fe-irradiated T12 alloy....

Figure 93. STEM-HAADF micrograph of different precipitates found at grain boundaries in the Feirradiated T12 alloy. Red dots represent the point from which EDS signals were acquired.

Figure 94. STEM-EDS analysis of precipitates at grain boundaries outside the Fe-irradiation range: a) STEM-ADF image and b) EDS line-scan profile showing the particle enriched in W and $\mathrm{Cr}$ without the presence of $\mathrm{Ti}$ or $\mathrm{Ta}$. 


\section{LIST OF TABLES}

Table

Page

Table 1. Nominal compositions (wt.\%) of the tested T-, Z-, and L-alloys................................. 8

Table 2. Chemical analysis results (wt.\%) of $\mathrm{O}, \mathrm{N}$ and $\mathrm{S}$ in the $\mathrm{T}-$, $\mathrm{Z}-$, and $\mathrm{L}-$ alloys.................... 9

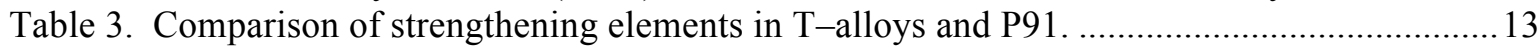

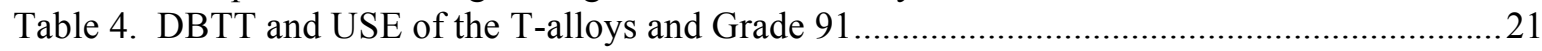

Table 5. Zygo parameters for surface roughness measurements of samples prior to ion

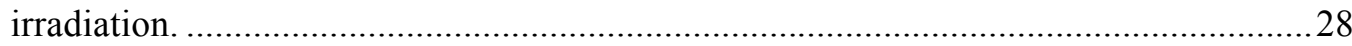

Table 6. Matrix of samples irradiated by $2 \mathrm{MeV}$ protons at $420^{\circ} \mathrm{C}$. Numbers in columns indicate the number of samples for each condition. ............................................................ 30

Table 7. Samples selected for the $4 \mathrm{MeV} \mathrm{Fe-irradiation} \mathrm{at} 400{ }^{\circ} \mathrm{C}$ up to $50 \mathrm{dpa}$. In most cases, the surface roughness increased by a factor of two after irradiation...................................32

Table 8. Samples selected for the nano-hardness measurements based on XRD and TEM

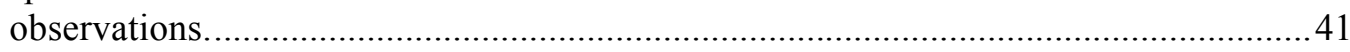

Table 9. Root-Mean-Squared (RMS) roughness values for proton-irradiated steel samples. ...........42

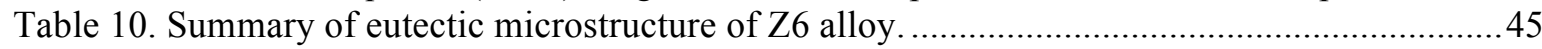

Table 11. Global composition of T12 alloy (error $< \pm 0.1 \%$ ).......................................................50

Table 12. Atomic percent composition of the black precipitates observed in the T12 as received

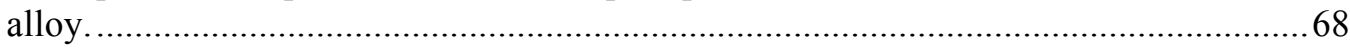





\section{ACKNOWLEDGMENTS}

This research was sponsored by the U.S. Department of Energy (DOE), Office of Nuclear Energy (NE), the Nuclear Energy Enabling Technologies (NEET) FY 2012 Award. This research was supported in part by the Office of Nuclear Energy, Science and Technology and by the Center for Nanophase Materials Sciences (CNMS), which is sponsored by the Scientific User Facilities Division, Office of Basic Energy Sciences, U.S. Department of Energy. We gratefully acknowledge the support provided by Sue Lesica of DOE-NE and Jeremy Busby of Oak Ridge National Laboratory (ORNL).

The authors are grateful to Eric Manneschmidt (ORNL) for mechanical tests, Tom Geer and Zhenggang $\mathrm{Wu}(\mathrm{ORNL})$ for sample preparation and characterization assistance, David Harper and Greg Cox (ORNL) for alloy fabrication, Kim Kriewaldt and Beata Tyburska-Püschel (the University of Wisconsin-Madison: UWM) for ion irradiation experiments and radiation hardening assessment, Alexander Mairove and Rigen Mo (UWM) for radiation-induced microstructural evolution characterization, Kelsey Amundson, McKinleigh McCabe and Dylan Clark (UWM) for general experimental assistance throughout the project. Philip Maziasz (ORNL) is appreciated for technical review of this report. 



\section{EXECUTIVE SUMMARY}

The mission of the Nuclear Energy Enabling Technologies (NEET) program is to develop crosscutting technologies for nuclear energy applications. Advanced structural materials with superior performance at elevated temperatures are always desired for nuclear reactors, which can improve reactor economics, safety margins, and design flexibility. They benefit not only new reactors, including advanced light water reactors (LWRs) and fast reactors such as the sodium-cooled fast reactor (SFR) that is primarily designed for management of high-level wastes, but also life extension of the existing fleet when component exchange is needed. Developing and utilizing the modern materials science tools (experimental, theoretical, and computational tools) is an important path to more efficient alloy development and process optimization.

Ferritic-martensitic (FM) steels are important structural materials for nuclear reactors due to their advantages over other applicable materials such as austenitic stainless steels, notably their resistance to void swelling, low thermal expansion coefficients, and higher thermal conductivity. However, traditional FM steels exhibit a noticeable yield strength reduction at elevated temperatures above $\sim 500^{\circ} \mathrm{C}$, which limits their applications in advanced nuclear reactors which target operating temperatures above this temperature. Although oxide-dispersion-strengthened (ODS) ferritic steels have shown excellent hightemperature performance, their exclusive fabrication technique of mechanical alloying lead to extremely high cost, limited product fabricability in terms of size and shape, as well as great difficulty with welding and joining, have limited or precluded their large-scale commercial applications. Zirconium has shown many benefits to Fe-based alloys such as grain refinement, improved phase stability, and reduced radiation-induced segregation. The ultimate goal of this project is, with the aid of computational modeling tools, to accelerate the development of Zr-bearing ferritic alloys that can be fabricated using conventional steelmaking methods. The new alloys are expected to have superior high-temperature creep performance and excellent radiation resistance as compared to Grade 91.

Using the Zr-bearing thermodynamic database that has been developed in this project, three groups of advanced ferritic alloys have been developed with the aid of computational alloy thermodynamics. The three groups advanced alloys include T-alloys (i.e., 9Cr ferritic-martensitic (FM) steels), Z-alloys (i.e., intermetallic-strengthened Fe-Cr-Zr alloys), and L-alloys (i.e., high-Cr ferritic steels). As compared to the $\mathrm{T}$-alloys, the $\mathrm{Z}$ - and L-alloys do not have the ferrite-austenite phase transformation during heating and cooling, leading to simplified alloy fabrication and possible capability of higher temperature use. Recently, effect of $\mathrm{Ni}$ alloying on phase stability in $\mathrm{Fe}-\mathrm{Cr}-\mathrm{Zr}-\mathrm{Ni}$ system, specifically on the stability of polymorphic Laves phase, was preliminarily assessed by computational alloy thermodynamics, coupled with selected experiments.

The designed alloys were fabricated using arc-melting and drop-casting, followed by hot rolling and conventional heat treatments. The control capability of impurities such as $\mathrm{S}, \mathrm{O}, \mathrm{N}$, and $\mathrm{C}$, especially for the presence of $\mathrm{Zr}$, $\mathrm{Ti}$, and $\mathrm{Ta}$ in alloys, was confirmed by a larger heat of $\mathrm{L}$-alloy production using vacuum-induction melting from a commercial vendor. A comprehensive experimental studies have been conducted on the developed alloys to evaluate their hardness, tensile properties, creep resistance, Charpy impact toughness, and aging resistance, as well as resistance to proton and heavy ion $\left(\mathrm{Fe}^{2+}\right)$. Relevant microstructure characterization was conducted using optical microscopy, SEM, EBSD, XRD, TEM, and EDS. Vicker's microhardness and nanoindentation technique were employed to measure radiation hardening. The project has been primarily focused on the T-and Z-alloys because the L-alloys exhibited the lowest strength and the highest radiation hardening among the three groups of alloys.

As compared to $\mathrm{P} 91$, the T-alloys exhibited $\sim 300$ to $100 \mathrm{MPa}$ increases in yield/tensile strength from room temperature to $\sim 750^{\circ} \mathrm{C}$. The $\mathrm{Z}$-alloys showed comparable or slightly lower yield strength than $\mathrm{P} 91$ 
at temperatures below $\sim 600^{\circ} \mathrm{C}$, above which the Z-alloys exhibited higher yield strength approaching the $\mathrm{T}$-alloys. Microstructural characterization and the modeling of strengthening elements suggest that the notable strength increase of the $\mathrm{T}$-alloys is primarily attributable to the significantly increased amount of ultrafine $\mathrm{MX}(\mathrm{M}=$ metal, $\mathrm{X}=\mathrm{C} / \mathrm{N})$ type nanoprecipitates. In contrast, the $\mathrm{Z}$-alloys are primarily strengthened by the network of eutectic structure. The $\mathrm{T}$ - and $\mathrm{Z}$-alloys had increased creep lives by 2 to 4 times of the $\mathrm{P} 91$ tested at $650^{\circ} \mathrm{C}$ and $110 \mathrm{MPa}$. The increased amount of MX nanoprecipitates in the Talloys helped pin the subgrains during creep. Many ultrafine particles $(\sim 10 \mathrm{~nm})$ were randomly formed in the Z-alloys during the creep test, which helped improve creep life without impairing creep ductility. Thermal aging at 600 and $700^{\circ} \mathrm{C}$ for up to $10,200 \mathrm{~h}$ indicated that aging-induced softening in $\mathrm{T}$-alloys, but slight aging hardening in $\mathrm{Z}$-alloys. The higher aging temperature resulted in greater softening in $\mathrm{T}-$ alloys, but less hardening or becoming softening in $\mathrm{Z}$-alloys. Alloying Ta in $\mathrm{T}$-alloys exhibited greater aging resistance. The minor $\mathrm{Zr}$ alloying in $\mathrm{T}$-alloys showed trivial beneficial effect on aging resistance. The decreasing amount of Laves phase in $\mathrm{Z}$-alloys resulted in the change of aging hardening to softening. Charpy V-notch impact tests showed the significant improvement in impact toughness of T-alloys as compared to P91. However, the impact toughness of Z-alloys was significantly lower, which needs to be further investigated and developed.

Ion irradiation experiments using proton and heavy ion $\left(\mathrm{Fe}^{2+}\right)$ have been conducted on the developed alloys to $\sim 1 \mathrm{dpa}$ at $420^{\circ} \mathrm{C}$ and $\sim 50 \mathrm{dpa}$ at $400^{\circ} \mathrm{C}$, respectively. Vicker's microhardness measurements indicated the largest radiation hardening of the L-alloys $(\sim 120 \%)$ and the smallest hardening of the $\mathrm{T}-$ alloys $(\sim 15-40 \%)$ after $\sim 1$ dpa irradiation. The Z-alloys exhibited a large variation in hardening $(\sim 30$ $90 \%$ ), suggesting a strong microstructure effect. XRD and STEM/EDS investigations suggested the formation of a large amount of radiation-induced precipitates in the L-alloys and a small amount in the Z-alloys, but negligible in the T-alloys, which is qualitatively consistent with the largest hardening of the L-alloys and the smallest hardening of the T-alloys. Detailed microstructural characterization was conducted on the Z6 and T12 alloys as representatives of the Z-and T-alloys. Proton-irradiation resulted in the disappearance of pre-existing large amount of short dislocation threads and the formation of many unknown polyhedron-shaped defects within the ferritic grains, but did not result in phase and chemistry changes to Laves phase in Z6 alloy. In contrast, Fe-irradiation resulted in predominant $<100>$ type dislocation loops in ferrite grains and amorphization of Laves phase within the zone of $>\sim 25 \mathrm{dpa}$. The effect of Laves phase amorphization on mechanical properties is not clear, but which may be beneficial radiation resistance improvement. Unlike the radiation-induced segregation (RIS) of slight Zr-enrichment at popular low-angle boundaries of the ferritic grains in proton-irradiated Z6 alloy, Fe-irradiation did not result in detectable RIS. Proton-irradiation did not result in significant changes to the microstructure of T12 alloy, except for the formation of $(\mathrm{Cr}, \mathrm{W})$-rich carbides with undefined crystal structure at grain boundaries. Fe-irradiation mainly resulted in a high density of predominant $<100>$ type dislocation loops in T12 alloy, which are about 1/3 in size but one order of magnitude higher in density than the loops in the Fe-irradiated Z6 alloy. RIS was not detected in the proton- and Fe-irradiated T12 alloy.

According to the experimental results, the TT-series alloys and Z-alloys showed promising mechanical properties and radiation resistance. The TT-series alloys exhibited superior strength and impact toughness with excellent microstructure stability under the ion irradiation conditions. Despite the superior high temperature strength and decent (or superior) radiation resistance of $Z$-alloys, this group of alloys requires further development to have balanced mechanical properties and radiation resistance, as well as to have better understanding of their underlying mechanisms. 


\section{BACKGROUND}

Nuclear power currently provides a significant fraction of the United States' non-carbon emitting electric power generation. In future years, nuclear power must continue to generate a significant portion of the nation's electricity to meet the growing power demand, carbon-free energy goals, and to ensure energy independence. New reactors will be an essential part of the expansion of nuclear power. However, given limits on new builds imposed by economics and industrial capacity, the extended service of the existing nuclear fleet will also be required. Advanced structural materials with superior performance at elevated temperatures are always desired for nuclear reactors because they can improve reactor economics, safety margins, and design flexibility. They benefit not only new reactors including advanced light water reactors (LWRs) and fast reactors such as sodium-cooled fast reactors (SFRs) primarily designed for management of high-level wastes, but these new materials also improve life extension of the existing fleet when component exchange is needed.

Ferritic-martensitic (FM) steels are an important category of structural materials because of their outstanding resistance to radiation-induced void swelling (e.g., $\sim 1$ vol.\% per 100 displacements-per-atom (dpa) in FM steels versus $\sim 1$ vol.\% per 10 dpa in austenitic stainless steels at temperatures above $300^{\circ} \mathrm{C}$ [1]), high thermal conductivity, and low thermal expansion coefficients compared to austenitic stainless steels [2]. The body-centered cubic (bcc) structure of ferrite provides the inherent resistance to void swelling compared to the face-centered cubic (fcc) structure of austenitic alloys [3]. The formation of martensite followed by the tempering treatment introduces a large amount of lath boundaries and dislocations into the ferrite matrix, leading to refined precipitates and increased strength with decent fracture toughness [4]. However, the dislocations and lath boundaries are not stable at elevated temperatures, resulting in softening due to the impaired pinning effect induced by the instability of precipitates [4,5]. Zirconium (Zr) has shown many benefits to Fe-based alloys, such as introduced ultrafine new phases, improved coarsening resistance of Zr-bearing phases [6], and reduced radiationinduced segregation (RIS) [7,8]. Thus, it is expected that $\mathrm{Zr}$ has a beneficial role in improving hightemperature performance. This project's goal is to develop Zr-bearing ferritic alloys aided by computational alloy thermodynamics.

In contrast to traditional experimental trial-error methods, computational alloy thermodynamics (a scientific approach to systematically study the relationship between thermodynamic properties and phase stability) provides effective and economic practices for alloy development. The primary microstructures of new alloys can be simulated on a desktop computer within a short period of time, which guides the design of new alloys for experimental verification and performance examination. To facilitate the development of Zr-bearing ferritic steels, a thermodynamic database of Fe-C-Cr-Mo-Nb-Ti-W-Zr had been developed in Year 1 of this project. The computational thermodynamics tool helped the design of Zr-bearing ferritic steels in three groups: (I) 9Cr FM (named as T-alloys), (II) intermetallic-strengthened ferritic alloys (named as Z-alloys), and (III) high- $\mathrm{Cr}(>12 \mathrm{Cr}$ ) ferritic steels (named as L-alloys).

During the course of alloy development and testing activities in the first two years of this project, the composition of T-alloys has been refined as $0.08-0.12 \mathrm{C}, 8.3-8.8 \mathrm{Cr},<1.0 \mathrm{Mn}, 0.10-0.25 \mathrm{~V}, 1.0-1.5 \mathrm{~W}$, $<0.15 \mathrm{Ni},<0.2 \mathrm{Si},<0.10 \mathrm{Nb} / \mathrm{Ta},<0.15 \mathrm{Ti},<0.06 \mathrm{Zr}$; Z-alloys as $8-12 \mathrm{Cr}, 3-8 \mathrm{Zr}, 1-2 \mathrm{~W},<0.5 \mathrm{Mo}$, $<1.0 \mathrm{Mn},<0.5 \mathrm{Si}$; and L-alloys as $<0.02 \mathrm{C}, 15 \mathrm{Cr}, 1-3 \mathrm{~W},<1 \mathrm{Mo},<0.4 \mathrm{Nb},<0.5 \mathrm{Mn},<0.2 \mathrm{Si}$, and $<0.06 \mathrm{Zr}$ with $\mathrm{Fe}$ as balance. Development and investigation of $\mathrm{L}$-alloys were discontinued in the second year of this project because of their mediocre mechanical properties as compared to Grade 91 and their significant hardening after proton irradiation to $\sim 1 \mathrm{dpa}$ at $420^{\circ} \mathrm{C}[9,10]$. $\mathrm{T}$-alloys and $\mathrm{Z}$-alloys exhibited strength superior or comparable to Grade 91. Under the same proton irradiation as the L-alloys, T-alloys showed slightly lower hardening than Grade 91. In contrast, Z-alloys showed a large variation in hardening, suggesting noticeable alloy composition effect. 
This report summarizes the continued development and testing results of $\mathrm{T}$-alloys and $\mathrm{Z}$-alloys in the third year, as well as the accumulated results from the previous two years of this project. It describes the alloy design, strengthening mechanism, thermal aging resistance, Charpy V-notch impact toughness, effect of nickel on phase stability of Z-alloys, and radiation resistance of the developed alloys. 


\section{COMPUTATIONAL THERMODYNAMICS AIDED ALLOY DESIGN}

\subsection{COMPUTATIONAL THERMODYNAMICS}

Thermodynamic properties of phases in the Fe-C-Cr-Mo-Nb-Ti-W-Zr system were modeled for the development of Zr-bearing ferritic steels. Computational thermodynamics based on the CALPHAD (CALculation of PHAse Diagram) approach [11] is used to develop thermodynamic models of phases in this multicomponent system. The essence of this approach is to develop self-consistent thermodynamic models of phases which cannot only describe thermodynamic properties but also phase equilibria of materials. The most important component of computational thermodynamics is to develop the thermodynamic database that is a compilation of Gibbs Energy functions of phases in a system. For each Gibbs energy function, there are two components, thermodynamic models and model parameters. The most frequently used models are solution, compound energy formalism, and line compound [12]. The model selection is based on the crystal structures, defect types and ordering information of phases. Model parameters are optimized based on experimental data such as phase boundary and thermodynamic property measurements such as activity and enthalpy of formation. Successful thermodynamic modeling requires simultaneously satisfying different properties of phases using one set of Gibbs energy functions. For multicomponent systems where the experimental information is often lacking, the advantage of this approach is that the Gibbs energies of multicomponent phases can be derived from its constituent lower order systems through different geometric rules such as Redlich-Kister expansions [13]. Based on the obtained Gibbs energies, phase property such as fraction (mole, weight and volume), composition, solidus, liquidus at different temperatures and alloy compositions in an unknown system can be calculated by numerically finding the lowest energy minimum of the system. The software used in this work for computational thermodynamic calculation is Pandat [14].

\subsection{ALLOY DESIGNS}

Using the thermodynamic database and computational tool that were developed in Year 1 of this project [15], three series of alloys have been explored. A number of alloys have been designed in each alloy series. The detailed compositions of the alloys are not presented here due to potential proprietary concerns. Examples of the alloys in each alloy series can be found in the previous report [16].

\subsubsection{Cr FM Steels (T-Alloys)}

This group of alloys is designated as T-series alloys (Fe-9CrWMoVNbTaTiZr). The T-series FM steels have $9 \mathrm{wt} . \% \mathrm{Cr}$ and are alloyed with $\mathrm{W}$ and Mo for solution strengthening, which favors Laves phase, and $\mathrm{Nb}, \mathrm{Ta}$, $\mathrm{Ti}$, and $\mathrm{Zr}$ for precipitates (primarily MX-type) strengthening. The 9Cr FM steels are considered because they have lower $\delta$-ferrite formation tendency, lower $\alpha$ ' formation tendency under irradiation, and lower tendency to increase the ductile-brittle transition temperature (DBTT) under irradiation, as compared to $12 \mathrm{Cr}$ FM steels. The properties generated from this series of alloys will be compared to the commercial 9Cr FM steels such as P91 and/or T91.

The calculated temperature-dependent mole fraction of phases in a T-alloy, named as TTZ1, is shown in Figure 6. The calculated phase fraction of a NIMS heat of P91 [17] is plotted in the same scale in Figure 6 for comparison. Similar to P91, a conventional 9Cr FM alloy, the T-alloy is primarily composed of austenite at high temperatures with a decent range of austenite temperature window, at which normalization treatment is usually conducted, e.g., $\sim 1100^{\circ} \mathrm{C}$. The alloying of additional ferrite stabilizers in the T-alloy slightly reduced the austenite temperature window as compared to P91. Ferrite primarily exists at intermediate and lower temperatures, at which tempering is usually conducted, e.g., $\sim 750^{\circ} \mathrm{C}$. Similar to P91, this series of alloys experiences the ferrite-austenite phase transformation at temperatures 
between about 800 and $850^{\circ} \mathrm{C}$. Figure 6 shows a fraction of y-axis ranging from $0-0.025$ to facilitate the reading of phases with small fractions. Three precipitate phases, designated as MX (primarily carbides), $\mathrm{M}_{23} \mathrm{C}_{6}$ and Laves phase, are predicted in the T-alloy. In contrast, an additional phase, designated as Zphase, is predicted in P91 at low temperatures, which is transformed by consuming the preferable MX (primarily nitrides) precipitates. Comparing to P91 in Figure 6, the T-alloy satisfies the following alloy design expectations of this alloy series: 1) increased amount of $M X, 2$ ) reduced amount of $\mathrm{M}_{23} \mathrm{C}_{6}$, and 3) suppressed the formation of Z-phase.
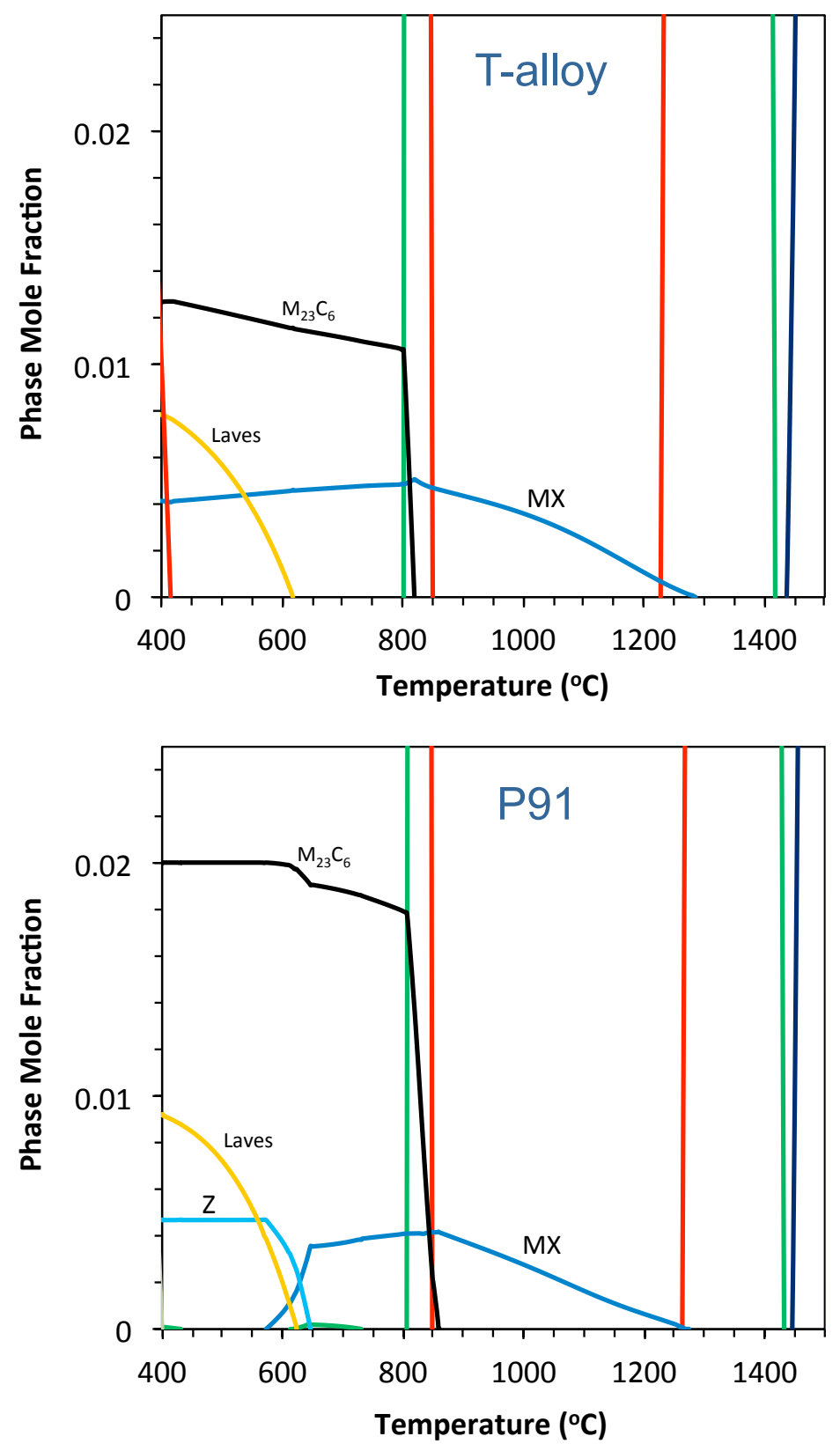

Figure 1. Calculated temperature-dependent mole fraction of phases in a T-alloy as compared to P91. 


\subsubsection{Intermetallic-Strengthened Fe-Cr-Zr Alloys (Z-Alloys)}

This group of alloys is designated as Z-series alloys (Fe-12CrZrWMo). The Z-series alloys are Febase ferritic alloys, primarily composed of $12 \mathrm{wt} . \% \mathrm{Cr}$ and different amounts of $\mathrm{Zr}$ with some alloying of $\mathrm{W}, \mathrm{Mo}, \mathrm{Si}, \mathrm{Mn}$, and $\mathrm{Ni}$. The $\mathrm{Z}$-series alloys develop $\mathrm{Fe}_{2} \mathrm{Zr}$-type Laves phase during solidification, leading to fine eutectic microstructures, and form intermetallics following thermomechanical treatment.

Based on the Fe-Cr-Zr ternary phase diagram, the eutectic composition of the Bcc_a2 (ferrite) and $\mathrm{Fe}_{2} \mathrm{Zr}$ Laves phases is $\sim 14 \mathrm{wt} \% \mathrm{Zr}$ [18]. Z-series alloys are designed to form in-situ composites of $\mathrm{Fe}_{2} \mathrm{Zr}$ and Bcc_a2 by forming ultra-fine eutectic microstructure from liquid. The $\mathrm{Fe}_{2} \mathrm{Zr}$ intermetallic compound is designed as a strengthening component, and the Bcc_a2 phase provides necessary toughness. The relative amount of each phase is critical to reach a balance of mechanical properties. The $\mathrm{Fe}_{2} \mathrm{Zr}$ phase has a hexagonal Laves_C14 structure. It should be noted that there is a substantial amount of Cr participating in the $\mathrm{Fe}_{2} \mathrm{Zr}$ C 14 Laves phase. In addition to $\mathrm{Cr}$ and $\mathrm{Zr}$, small amounts of $\mathrm{Mo}, \mathrm{W}, \mathrm{Si}, \mathrm{Mn}$, and Ni were also added to tune the properties of materials. The calculated temperature-dependent mole fraction of phases in Z-alloys with alloys Z6, Z7, and Z9 as examples are shown in Figure 9. The Z-alloys are located in the primary phase region of Bcc_a2. Their solidification path is Liquid $\rightarrow$ Bcc_A2 followed by the eutectic reaction of Liquid $\rightarrow \mathrm{Bcc} \_\overline{\mathrm{A}} 2+\mathrm{Fe}_{2} \mathrm{Zr}$. The major difference from $\mathrm{Z} 6$ to $\mathrm{Z} 9$ is the composition of $\mathrm{Zr}$ which decreases in sequence, directly leading to the sequential reduction of eutectic in microstructures. In alloy Z6, the polymorphic Laves_C15 (cubic) structure of $\mathrm{Fe}_{2} \mathrm{Zr}$ could form, depending on the heat treatment or testing temperature. In alloys Z7 and Z9, only Laves_C14 phase is stable. Compared to Talloys, Z-alloys do not have a ferrite-austenite phase transformation.

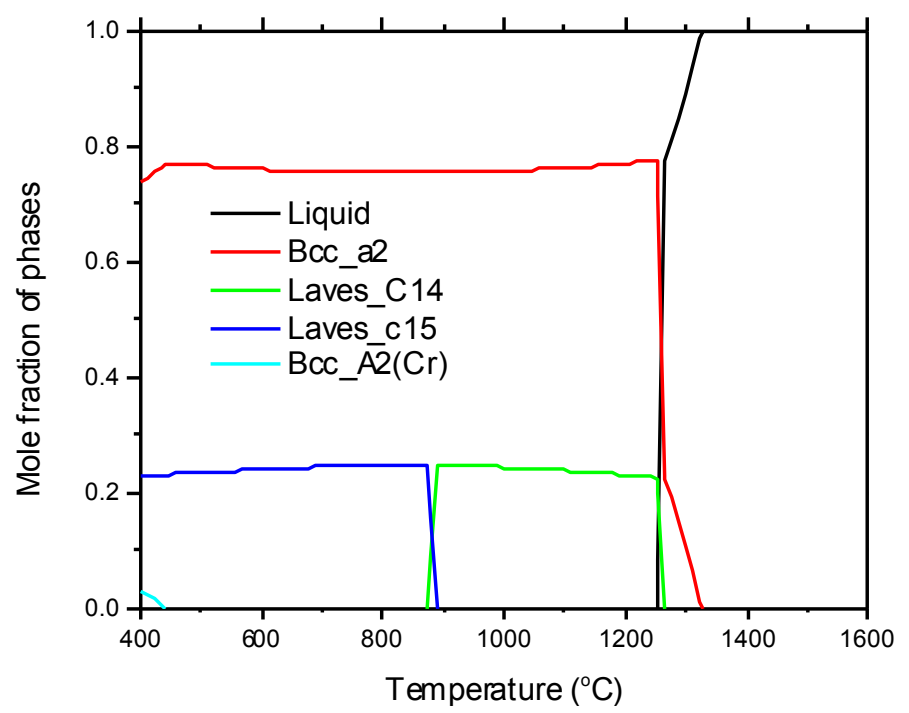

(a) 


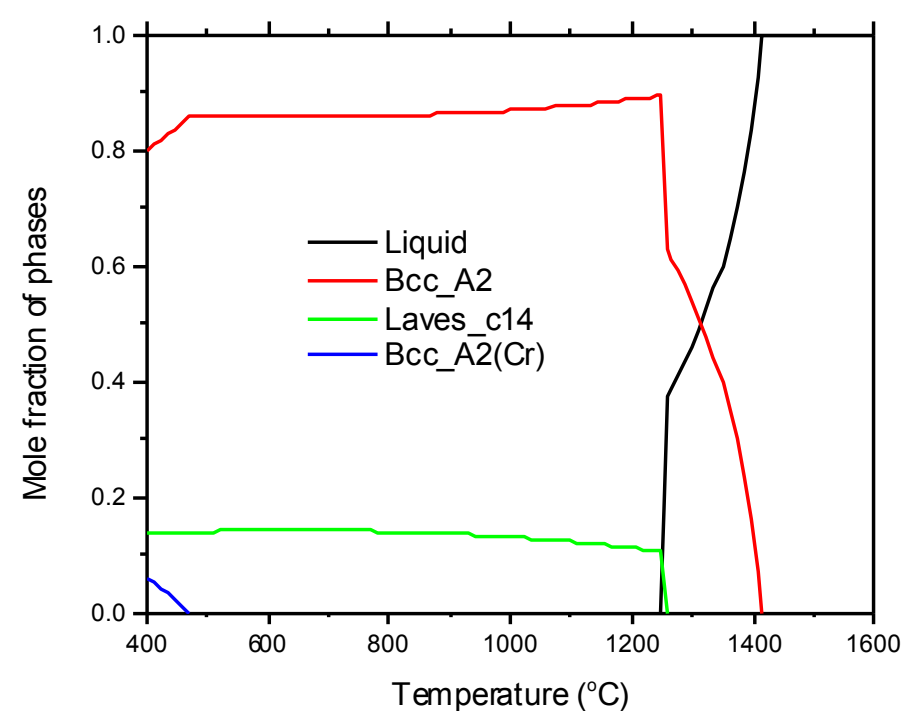

(b)

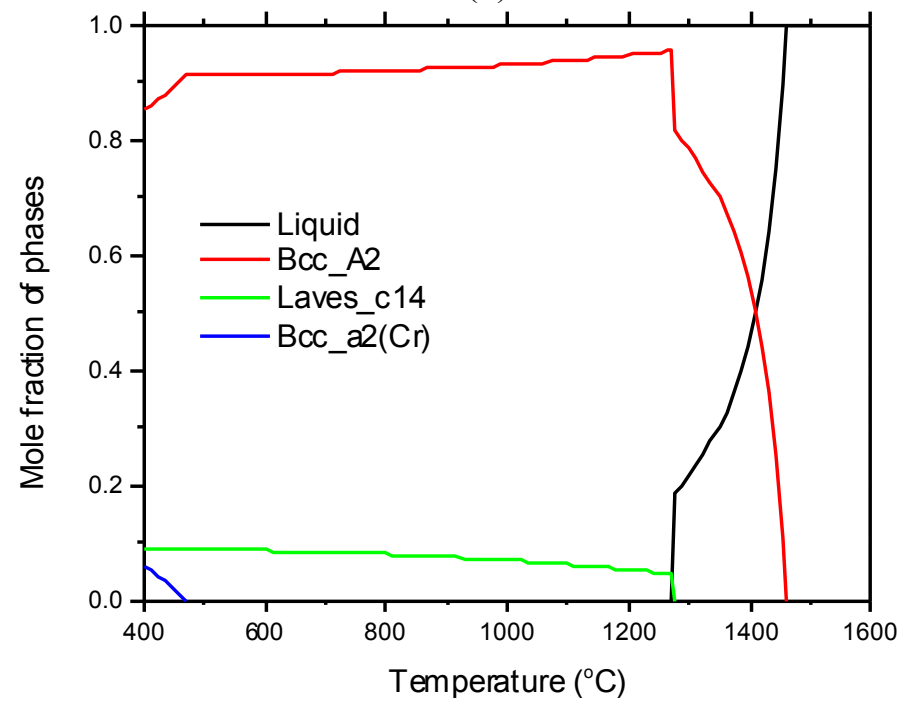

(c)

Figure 2. Calculated temperature-dependent mole fraction of phases in Z-alloys (a) Z6, (b) Z7 and (c) Z9.

\subsubsection{High-Cr Ferritic Steels (L-Alloys)}

This group of alloys is designated as L-series alloys (Fe-15CrWMoNbTiZr). The L-series alloys are Fe-base ferritic steels, having 15 wt.\% $\mathrm{Cr}$ and alloyed with $\mathrm{W}, \mathrm{Mo}, \mathrm{Nb}$, Ti, and $\mathrm{Zr}$. Carbonitrides of $\mathrm{Zr}$, $\mathrm{Ti}$ and $\mathrm{Nb}$ help grain refinement. Laves phase, primarily $\mathrm{Fe}_{2} \mathrm{~W}$-type, precipitates from the ferritic matrix through solid-state reaction during testing and services, which acts as secondary strengthening mechanism in addition to the primary solid solution strengthening. This series of alloys is anticipated to have better corrosion resistance than the lower $\mathrm{Cr}$ steels and less stress corrosion cracking (SCC) issues compared to 300 -series austenitic stainless steels.

Figure 8 shows the calculated temperature-dependent mole fraction of phases in L-alloys with alloys LTZ1 and LNTZ as examples. Similar to the Z-alloys, L-alloys are fully ferritic matrix below their melting points. The major difference between alloys LTZ1 and LNTZ is the amount of Laves phase and 
MX. Alloy LNTZ has an additional $\sigma$-phase. As compared to the Z-alloys with $12 \mathrm{Cr}$, the $15 \mathrm{Cr}$ L-alloys favor the formation of $\alpha_{-} \mathrm{Cr}$ phase at higher temperatures in greater amounts.
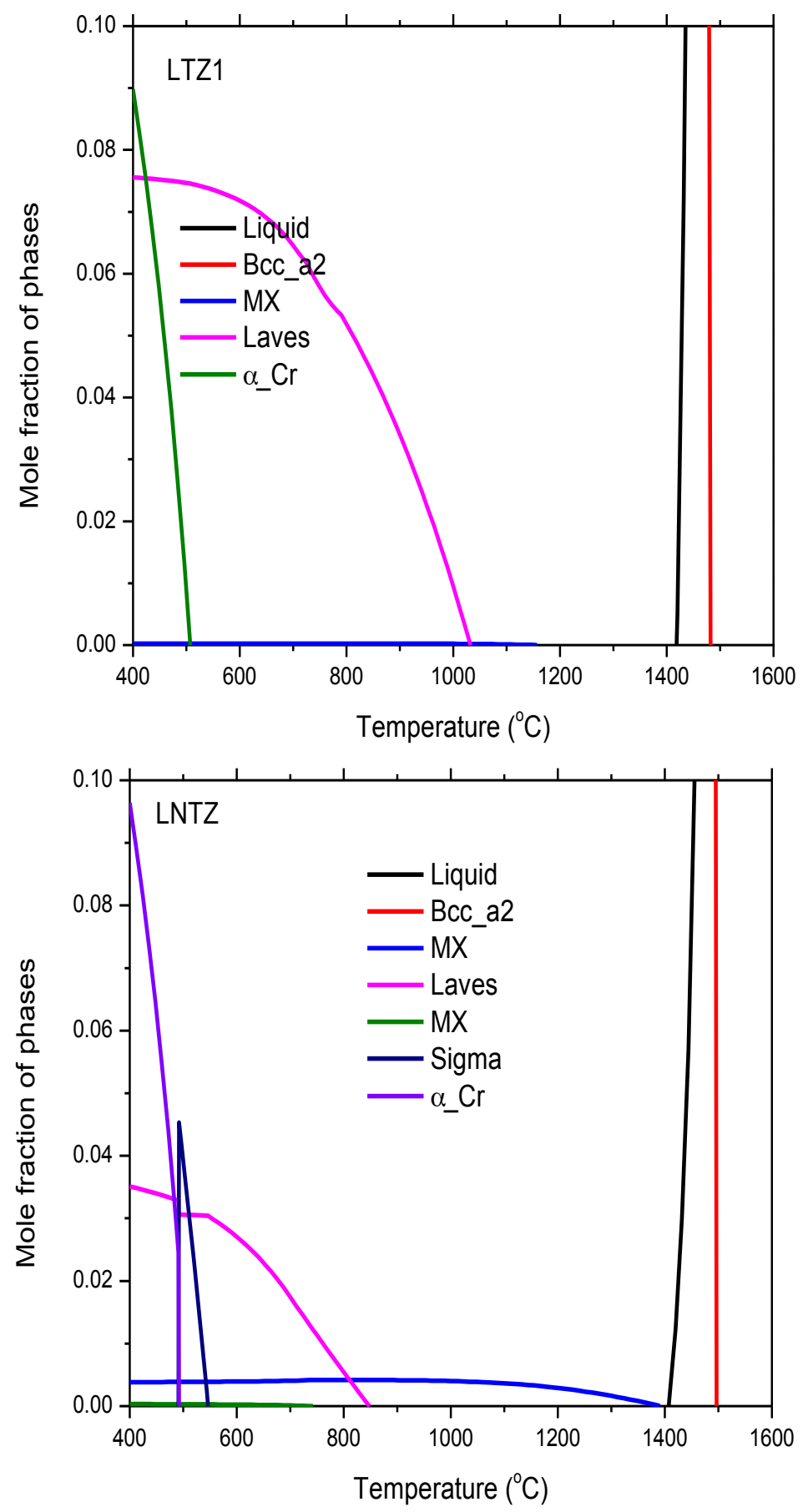

Figure 3. Calculated temperature-dependent mole fraction of phases in L-alloys of LTZ1 and LNTZ. 


\section{ALLOY FABRICATION AND MICROSTRUCTURAL CHARACTERIZATION}

\subsection{ALLOY FABRICATION}

Due to the similarity between the T-alloys and P91, the experience on steelmaking and welding of P91 can be directly borrowed for the T-alloys. The lack of ferrite-austenite phase transformation during heating and cooling in the Z- and L-alloys simplifies their steelmaking processes and allows for higher application temperatures as compared to FM steels. Lab-scale small heats with weight up to $\sim 0.9 \mathrm{~kg}$ were melted using arc-melting in argon back-filled atmosphere with titanium and zirconium getter, which were then drop-cast into $2.5 \times 2.5 \mathrm{~cm}^{2}$ cross-section bars. The nominal compositions of the fabricated three groups of alloys are listed in Table 1. The blanket cells in the Table denote the impurities controlled to be the minimum levels using best efforts.

Table 1. Nominal compositions (wt.\%) of the tested $T-, Z_{-}$, and $L_{-}$-alloys.

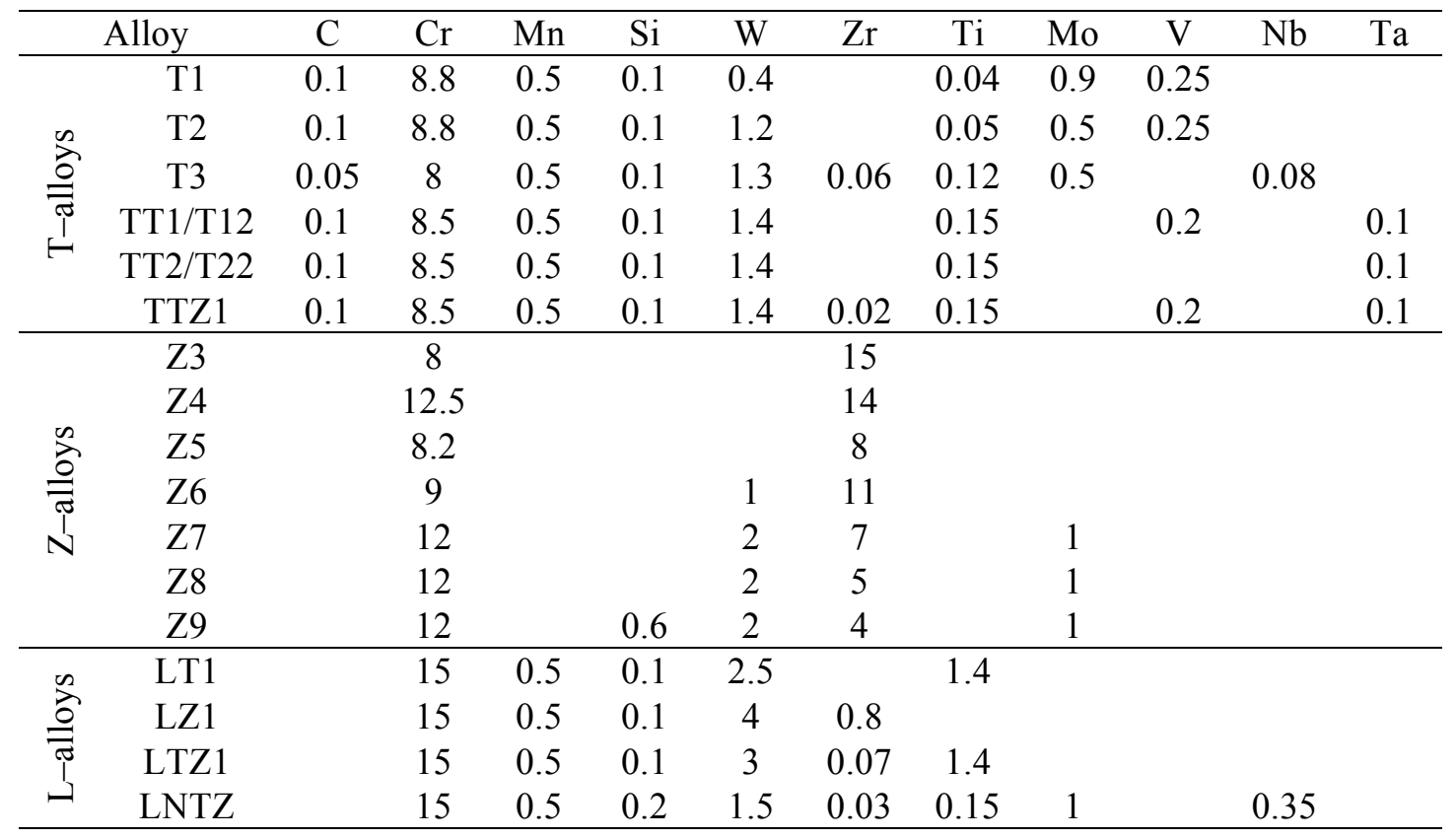

An example of impurity control results of the as-cast bars in terms of the amounts of impurities of oxygen $(\mathrm{O})$, sulfur $(\mathrm{S})$, and nitrogen $(\mathrm{N})$ is listed in Table 2. Among the alloys, only alloy T1 has intentionally alloyed nitrogen. The contents were analyzed using Instrumental Gas Analysis (IGA). Impurity S was well controlled to an acceptable low level, ranging from 21 to 33 ppm (part-per-million). However, impurity O level was more difficult to control, which ranged from 35 to $460 \mathrm{ppm}$. The variations in the impurity $\mathrm{O}$ level were not closely dependent on the alloyed amount of $\mathrm{Zr}$ and/or Ti that have high affinity to oxygen, which suggests the uncertainties of each arc-melting practice. The $\mathrm{N}$ level could be relatively well controlled down to $<10 \mathrm{ppm}$ by best effort. To examining impurity $\mathrm{O}$ level control capability for larger heats, alloy $\operatorname{LNTZ}(\sim 12.7 \mathrm{~kg})$ was fabricated using vacuum induction melting (VIM) by Carpenter Technology Corporation. The analyzed impurity results of alloy LNTZ heat may suggest that impurity $\mathrm{O}$ level can be well control at industrial facilities. Furthermore, the application of VIM or electro-slag remelting at industrial facilities is expected to further reduce the impurity content. 
Table 2. Chemical analysis results (wt.\%) of $O, N$ and $S$ in the $T-, Z_{-}$, and $L_{-}$-alloys.

\begin{tabular}{|c|c|c|c|c|}
\hline \multicolumn{2}{|c|}{ Alloy } & $\mathrm{O}$ & $\mathrm{N}$ & $\mathrm{S}$ \\
\hline \multirow{2}{*}{$\mathrm{T}$-alloys } & $\mathrm{T} 1$ & 0.0079 & 0.047 & 0.0021 \\
\hline & $\mathrm{T} 2$ & 0.0039 & $<0.001$ & 0.0024 \\
\hline \multirow{3}{*}{ Z-alloys } & $\mathrm{Z7}$ & 0.023 & 0.0052 & 0.0022 \\
\hline & Z8 & 0.0072 & 0.0034 & 0.0027 \\
\hline & Z9 & 0.0071 & 0.001 & 0.0033 \\
\hline \multirow{4}{*}{ L-alloys } & LT1 & 0.046 & 0.0051 & 0.0028 \\
\hline & LZ1 & 0.016 & 0.035 & 0.0029 \\
\hline & LTZ1 & 0.013 & $<0.001$ & 0.0026 \\
\hline & LNTZ & 0.0035 & 0.0019 & 0.001 \\
\hline
\end{tabular}

The as-cast bars of the alloys were subjected to homogenization heat treatment and hot rolling, followed by heat treatment and air cooling. A homogenization process, which was about 0.8 of the melting temperature of the alloys or as low as the normalization temperature, was conducted on the alloys to obtain homogenous chemical compositions in micro-volumes. Hot rolling was applied to the annealed ingots to achieve more than 50\% thickness reduction. Cross-rolling was also applied to improve the straightness of the work pieces and reduce textures developed during the rolling processing. Significant amounts of dislocations have been generated during the rolling, which not only increase alloy strength but also serve as nucleation sites of precipitates during the following processing and testing. The $\mathrm{Z}-$ and $\mathrm{L}-$ alloys were air cooled to room temperature after the hot rolling processing. In contrast, the $\mathrm{T}$-alloys were subjected to normalization at about $1100^{\circ} \mathrm{C}$ after the hot rolling to dissolve as much as possible precipitates in the austenite matrix. The normalized T-alloys were water quenched to ambient temperature and then tempered at $750^{\circ} \mathrm{C}$ followed by air-cooling. The times for the different types of heat treatments ranged from 15 to $60 \mathrm{~min}$. depending on the applied temperature and the thickness of the work pieces.

Other the above-mentioned conventional processing, preliminary thermomechanical treatment (TMT) was explored on some of the T-alloys. Hot-rolling with $>50 \%$ reduction was applied to the alloys at normalization temperature, after which the work pieces were quenched in water, followed by tempering at $750^{\circ} \mathrm{C}$ and air-cooling.

\subsection{MICROSTRUCTURAL CHARACTERIZATION}

Optical microscopy (OM), scanning electron microscopy (SEM), electron backscatter diffraction (EBSD), transmission electron microscopy (TEM), energy dispersive x-ray spectroscopy (EDS), and xray diffraction $(\mathrm{XRD})$ have been primarily employed to characterize the microstructures of the alloys in the as-fabricated and tested conditions. Different imaging modes have been employed to better elucidate microstructural distinctions, which are described in the following sections. 


\section{STRENGTHENING MECHANISM}

\subsection{IMPROVEMENT IN YIELD STRENGTH}

Type SS-3 miniature specimens were used to screen tensile properties of the alloys due to the limited heat size. The specification of this type of specimens is shown in Figure 4. The specimens were machined from the heats with specimen length parallel to the longitudinal direction of the heats. Tensile testing was conducted on the specimens at temperatures from ambient temperature up to $800^{\circ} \mathrm{C}$ in accordance with the American Society for Testing and Materials (ASTM) standard E8/E8M-13a, Standard Test Methods for Tension Testing of Metallic Materials, and E21/E21M-09, Standard Test Methods for Elevated Temperature Tension Tests of Metallic Materials. Tests were performed using an MTS tensile testing system with a load cell possessing $22 \mathrm{kN}(5,000 \mathrm{lbf})$ capacity, which is integrated in the load train and placed in the water-cooled zone below the hot zone of the furnace. Due to the small specimen size, an extensometer was not used during the tests. Tensile testing was performed at a crosshead speed of $0.0076 \mathrm{~mm} / \mathrm{s}(0.018 \mathrm{in} . / \mathrm{min})$, corresponding to a nominal strain rate of $0.001 \mathrm{~s}^{-1}$. The tensile testing system, load cells, and furnace thermocouples were regularly calibrated.
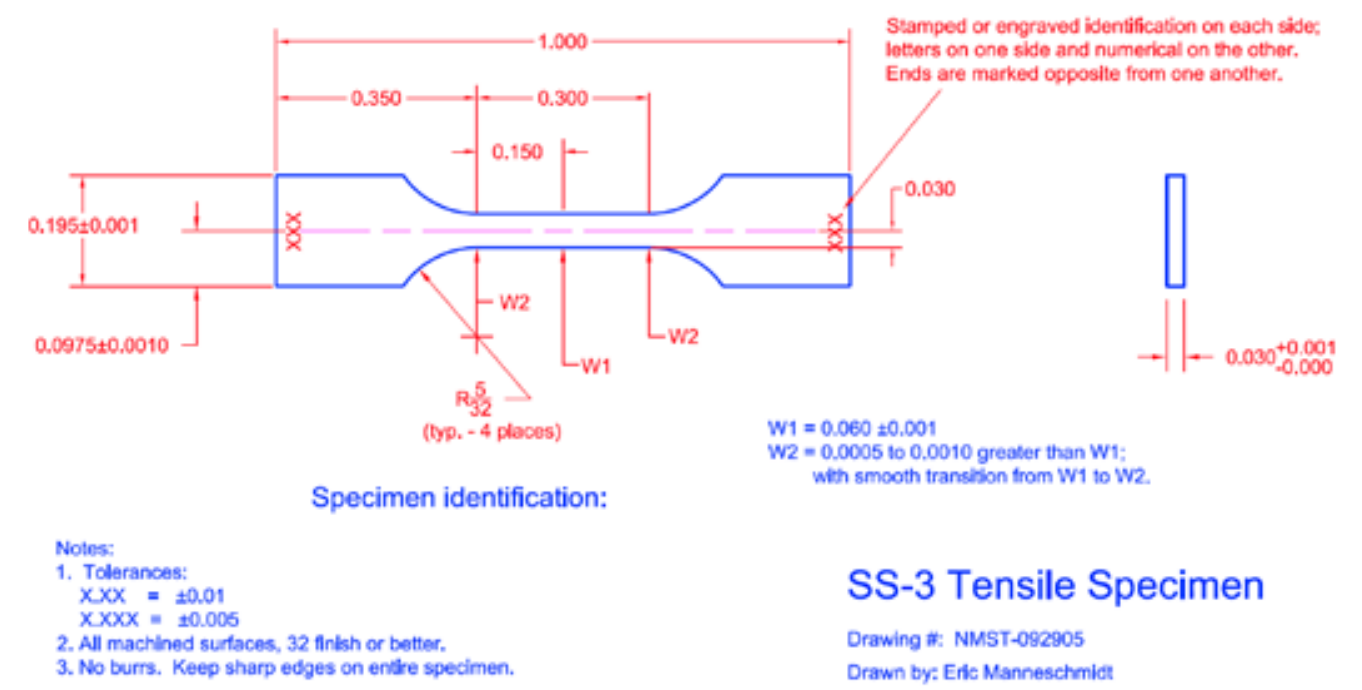

SS-3 Tensile Specimen

Drawing *: NMST-092805

Drawn by: Eric Manneschmidt

Figure 4. Specification of type SS-3 specimen (unit: inch).

\subsubsection{T-Alloys}

Examples of tensile stress-strain curves of alloys TT1 and TTZ1 in the as-received (AR) and a TMT conditions are shown in Figure 5. Only the testing temperatures of 24,400 and $700^{\circ} \mathrm{C}$ are included in this figure with each line denoting one alloy. The $400^{\circ} \mathrm{C}$ test temperature was included because $9-12 \mathrm{Cr} \mathrm{FM}$ steels usually exhibit the minimum total elongation around this temperature. Figure 5 indicates that the two T-alloys have very similar tensile properties with strength decreasing with the increasing testing temperature and the minimum total elongation at $400^{\circ} \mathrm{C}$ as compared to the testing at 24 and $700^{\circ} \mathrm{C}$. The minor Zr-bearing (0.02 wt.\%) in alloy TTZ1 as compared with alloy TT1 exhibited slight improvement in ductility at the test temperatures in both the AR and TMT conditions. The major difference in Figure 5 is that the elongations of the T-alloys in the TMT condition are significantly greater than the alloys in the AR condition. The uniform elongations of the TMT samples are also noticeably greater than those of the AR samples tested at room temperature. 

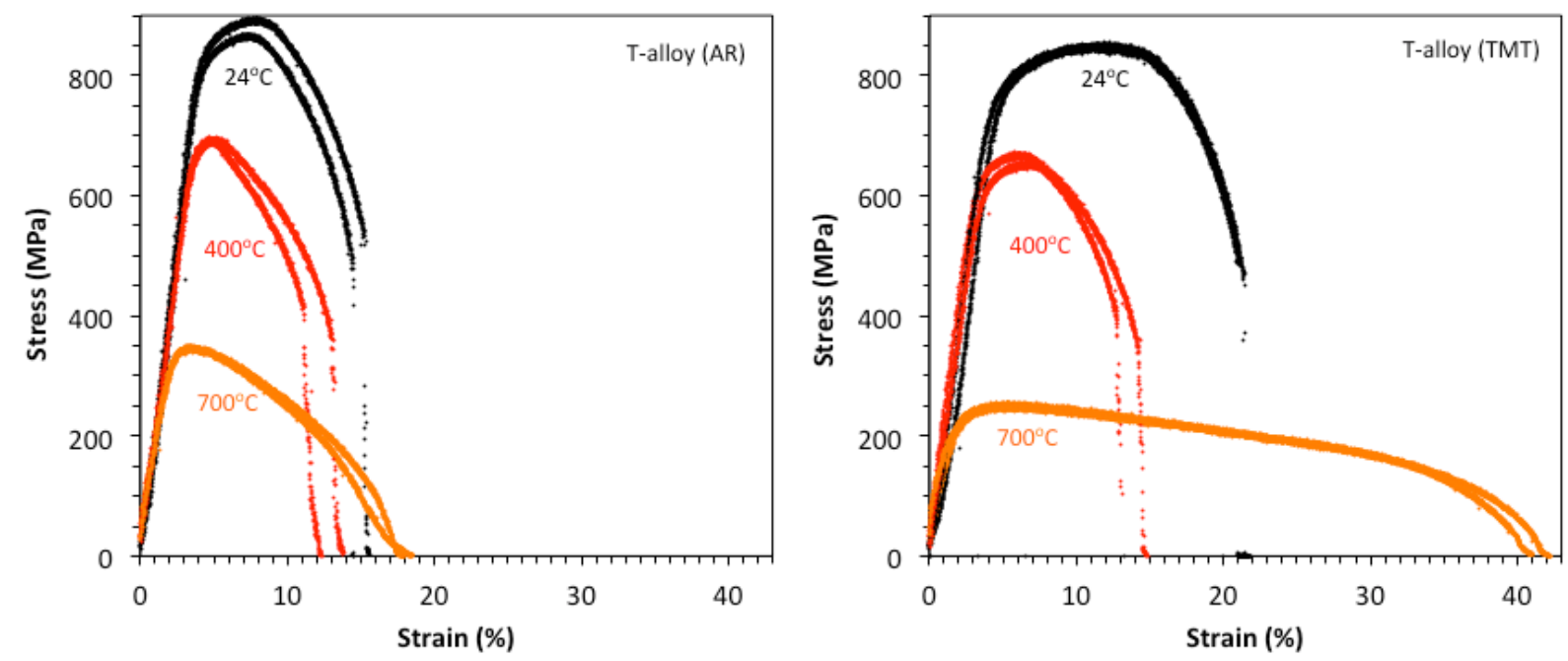

Figure 5. Typical tensile stress-strain curves of the T-alloys in the AR and TMT conditions.

To have a clear picture on the effect of testing temperature on strength and elongation, the testing results of yield strength and total elongation of the $\mathrm{T}$-alloys are plotted as a function of testing temperature up to $\sim 750^{\circ} \mathrm{C}$ as shown in Figure 6 with each line denoting one alloy. The results of P91 from the National Institute for Materials Science (NIMS) Creep Data Sheet No. 43 are included for comparison. In general, the six T-alloys exhibited similar yield strength that is higher than P91, e.g., up to $\sim 300 \mathrm{MPa}$ higher at room temperature and up to $\sim 100 \mathrm{MPa}$ higher at $700^{\circ} \mathrm{C}$. Similar to other general alloys, the increased strength was compensated by some reductions in total elongation. Considering the miniature size of type SS-3 specimens, which has a gauge cross-sectional area about 1/68 of the P91 as schematically shown in the inset of Figure 6, the total elongations at room temperature of the T-alloys comply with the minimum requirement of $10.96 \%(=32 t+10.00$, where $t=0.03 \mathrm{in}$.) according to the ASTM standard A335/A335M-11, Standard specification for seamless ferritic alloy-steel pipe for hightemperature service. Furthermore, the total elongation of the T-alloys in the TMT condition as shown in Figure 5 is close to $\mathrm{P} 91$ at room temperature.
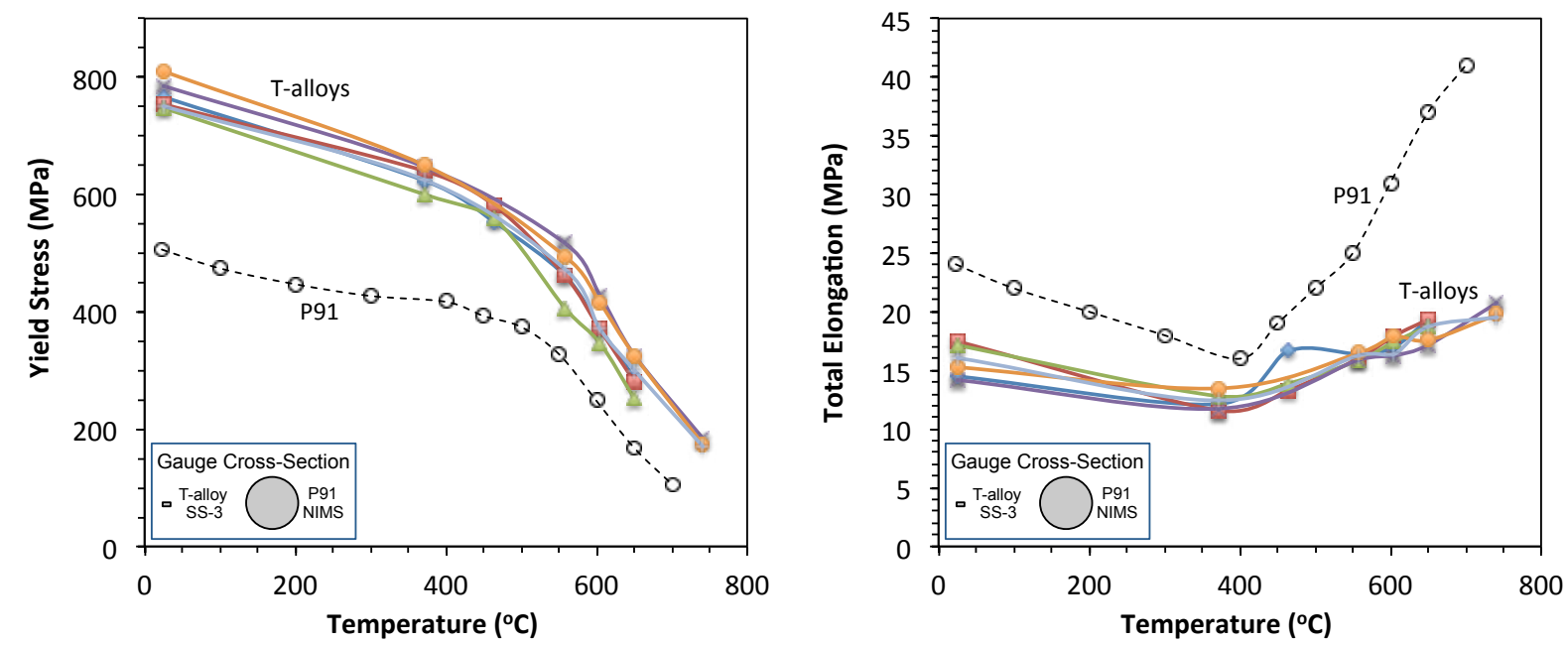

Figure 6. Temperature-dependent yield strength and total elongation of T-alloys as compared with P91. 
Microstructural characterization did not reveal noticeable difference caused by the trace amount of $\mathrm{Zr}$ addition, as shown in Figure 7 with fully developed lath structures in alloys TT1 and TTZ1. However, pronounced distinction was observed between T-alloys and P91 with Figure 8 as an example showing bright-field (BF) TEM images of a T-alloy as compared with P91. In addition to the few large particles $(\sim 50-100 \mathrm{~nm})$ decorating the prior-austenite grain boundary at the lower left corner of the T-alloy, a high density of ultrafine precipitates $(<10 \mathrm{~nm})$ dispersed in the matrix together with many free dislocations. In contrast, only a few precipitates $(\sim 20-100 \mathrm{~nm})$ are distributed in the matrix of P91.
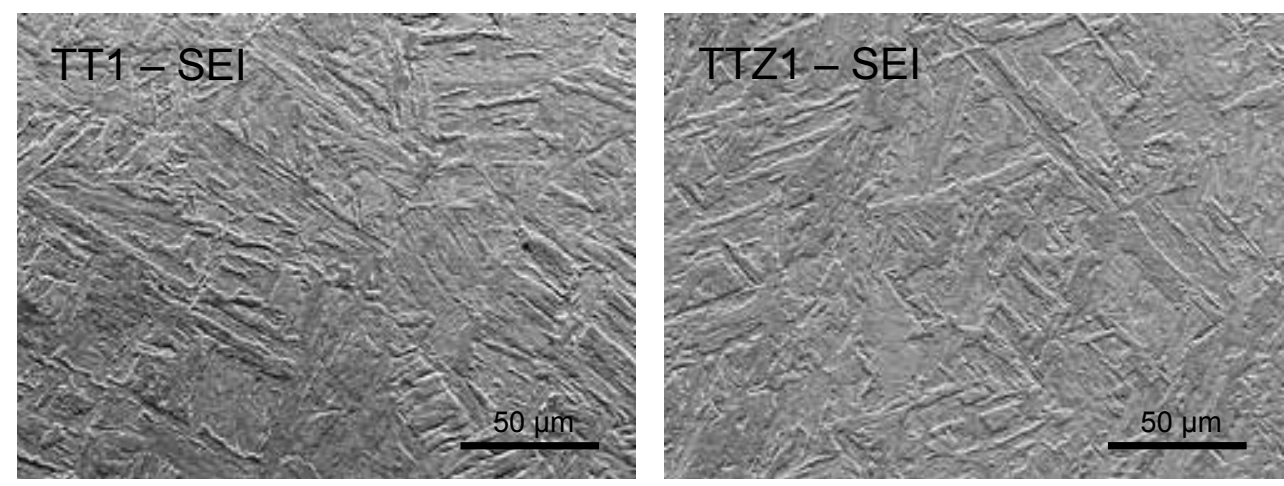

Figure 7. Secondary electron images (SEIs) of T-alloys.
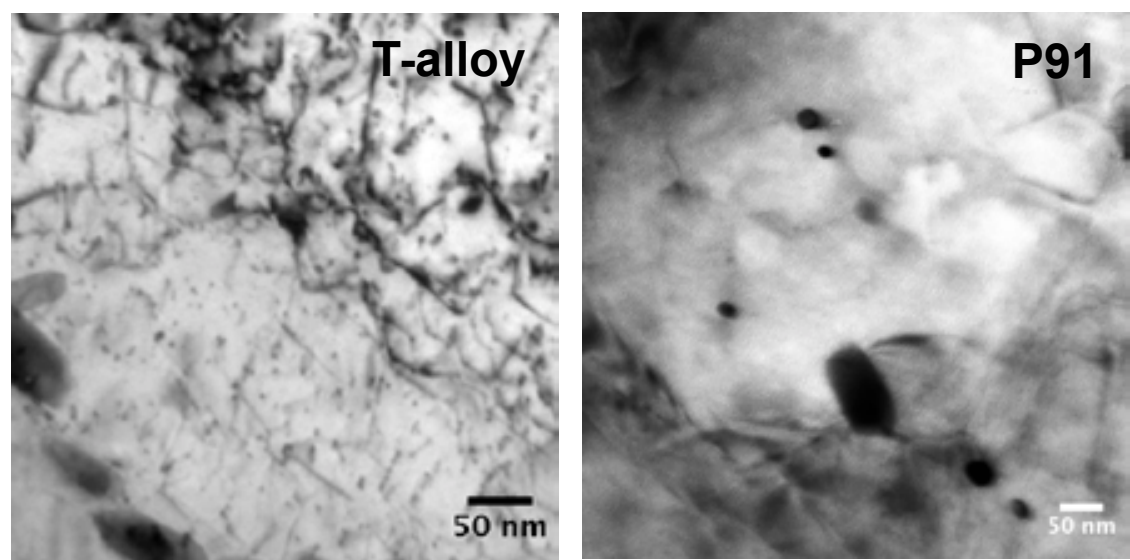

Figure 8. Bright-field (BF) TEM images of a T-alloy as compared with P91.

In general, there are three types of primary strengthening elements in FM steels, such as subgrain (lath) boundaries, precipitates, and free dislocations. The contribution of subgrain boundaries to strength can be estimated by $\sigma_{\text {sgb }}=k G b / \lambda_{\text {sgb }}$, where $k$ is a constant $(\approx 10), G$ is the shear modulus $(\approx 86 \mathrm{GPa}$ at room temperature $), b$ is the Burgers vector $(\approx 0.25 \mathrm{~nm})$, and $\lambda_{\text {sgb }}$ is the width of the lath boundaries. Precipitate strengthening is often estimated by the dispersed barrier model following Orowan mechanism as $\sigma_{\mathrm{ppt}}=\alpha M G b(N d)^{1 / 2}$, where $\alpha$ is the strength factor calculable according to Ref. [19], $M$ is Taylor factor $(\approx 2.9$ for body centered cubic), and $N$ and $d$ are the volume number density and diameter of the precipitates, respectively. Free dislocation strengthening can be estimated by $\sigma_{\mathrm{disl}}=0.5 M G b\left(\rho_{\mathrm{disl}}\right)^{1 / 2}$, where $\rho_{\text {disl }}$ is the density of free dislocations. The characterized size and density of the MX precipitates and the density of free dislocations and subgrain boundaries are listed in Table 3. The resultant strength from the three strengthening elements, estimated according to the respective equations, is also included for both a typical T-alloy and P91 in Table 3. The calculation suggests $768 \mathrm{MPa}$ and $521 \mathrm{MPa}$ for the T-alloy and P91 at room temperature, which are approximately consistent with the tensile tested results as 
shown in Figure 6. The strengthening contribution from the coarse particles of $\mathrm{M}_{23} \mathrm{C}_{6}$ is negligible because of its low density on the order of $10^{19} \mathrm{~m}^{-3}$ or less. The three strengthening elements exhibited different levels of increase in strength of the T-alloy as compared to P91. Subgrain boundaries have the highest contribution to strength in both of the steels. The notable strength increase of the T-alloy is primarily attributable to the significantly increased amount of ultrafine MX nanoprecipitates.

Table 3. Comparison of strengthening elements in T-alloys and P91.

\begin{tabular}{|c|c|c|c|}
\hline Size of $\mathrm{MX}(r, \mathrm{~nm})$ & $\sim 5$ & $\sim 20$ & $\sim 0.3$ times \\
\hline Density of $\mathrm{MX}\left(N, \mathrm{~m}^{-3}\right)$ & Close to $10^{23}$ & $10^{21}$ & $\sim 50$ times \\
\hline Density of dislocations $\left(\rho_{\text {disl }}, \mathrm{m}^{-2}\right)$ & $10^{14}$ & Close to $10^{14}$ & $\sim 5$ times \\
\hline Subgrain boundaries $\left(\lambda_{\mathrm{sgb}}, \mathrm{nm}\right)$ & 400 & 500 & $\sim 0.7$ times \\
\hline Dislocation strengthening: $\sigma_{\text {disl }}(\mathrm{MPa})$ & 312 & 220 & 92 \\
\hline Precipitate strengthening: $\sigma_{\mathrm{MX}}(\mathrm{MPa})$ & 451 & 195 & 256 \\
\hline Subgrain boundary strengthening: $\sigma_{\mathrm{sgb}}(\mathrm{MPa})$ & 538 & 430 & 108 \\
\hline Overall strength: $\sqrt{\sigma_{M X}^{2}+\sigma_{\text {disl }}^{2}+\sigma_{\text {sgb }}^{2}}(\mathrm{MPa})$ & 768 & 521 & 247 \\
\hline
\end{tabular}

\subsubsection{Z-Alloys}

Similar to Figure 6, the temperature-dependent yield strength and total elongation of the developed Zalloys as compared with P91 are shown in Figure 9. As compared with P91, the Z-alloys generally have comparable or slightly lower yield strength at temperatures below $\sim 600^{\circ} \mathrm{C}$, above which the $\mathrm{Z}$-alloys exhibited higher yield strength approaching the yield strength of T-alloys in Figure 6. In general, the Zalloys exhibited total elongation comparable to the $\mathrm{T}$-alloys at temperatures below $\sim 400^{\circ} \mathrm{C}$, above which the Z-alloys had superior total elongation approaching P91.
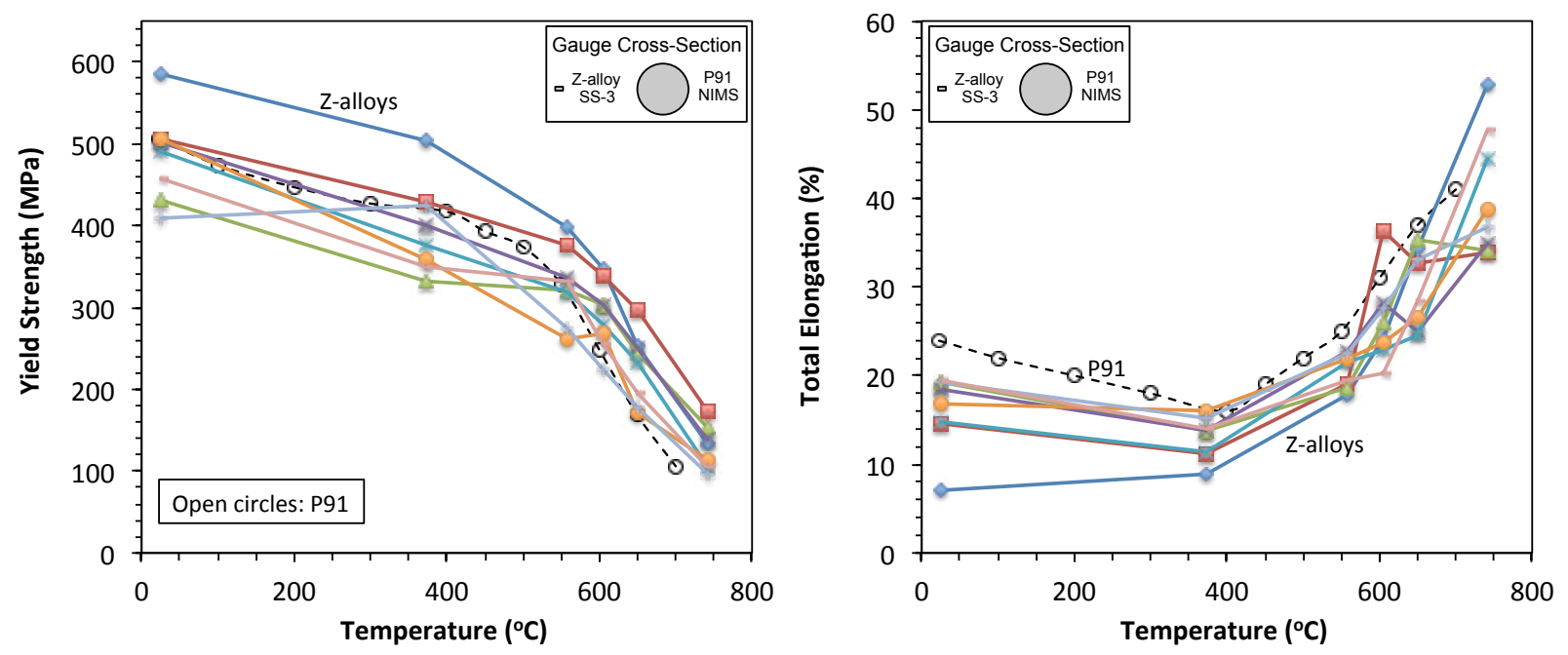

Figure 9. Temperature-dependent yield strength and total elongation of $Z$-alloys as compared with $\mathbf{P 9 1}$. 
The Z-alloys are primarily strengthened by the network of eutectic structure as shown in Figure 10. The eutectic structure is composed of Zr-bearing Laves phase in bright and ferrite phase in grey. The ferrite matrix is confined as cells by the eutectic network. Further information can be found in Ref. [20].
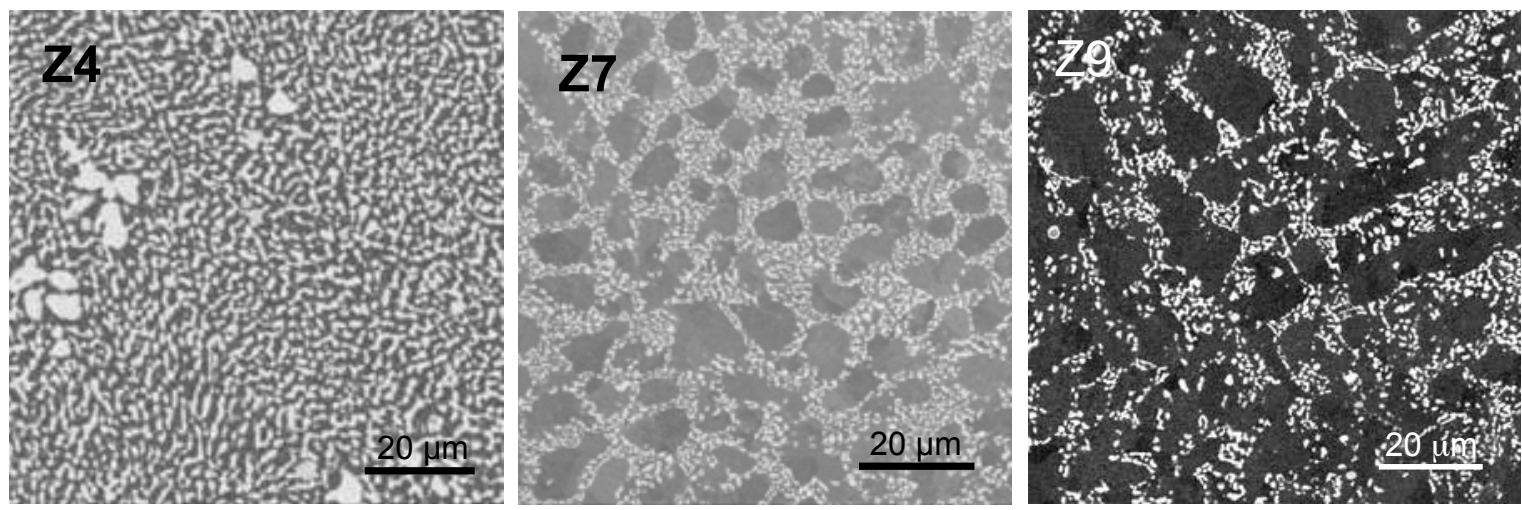

Figure 10. Backscattered electron images (BEIs) of Z-alloys (e.g., Z4, Z7, and Z9) showing eutectic network confined ferritic matrix cells.

\subsubsection{L-Alloys}

Temperature-dependent yield strength and total elongation of two L-alloys in the AR and TMT conditions are shown in Figure 11 with each line denoting one alloy in the respective condition. The data of P91 are included for comparison. The L-alloys in the AR condition had lower strength and higher total elongation than P91. The TMT increased the strength of the L-alloys to be comparable to P91 but decreased their total elongation lower than P91. This series of alloys is expected to precipitate Laves phase during thermal aging as shown in Figure 12 with the appearance of many bright particles in submicrometer sizes at boundaries and within matrix of alloy LNTZ after aging at $700^{\circ} \mathrm{C}$ for $7,800 \mathrm{~h}$.

Vicker's hardness measurements after the aging did not show noticeable changes from the AR condition, i.e., $176 \pm 4 \mathrm{HV} 1$ of the aged condition as compared with $179 \pm 10 \mathrm{HV} 1$ of the AR condition.
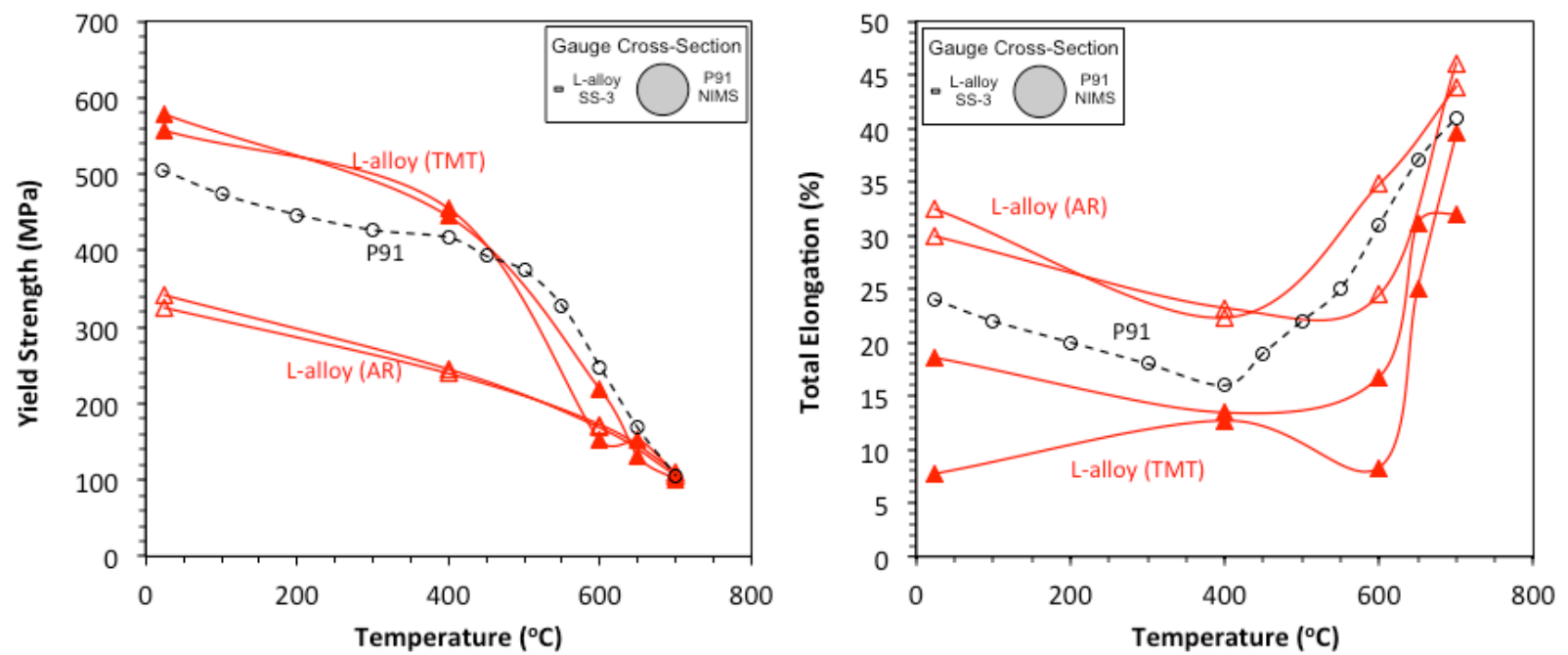

Figure 11. Temperature-dependent yield strength and total elongation of L-alloys in the AR and TMT conditions as compared to $\mathbf{P 9 1 .}$ 

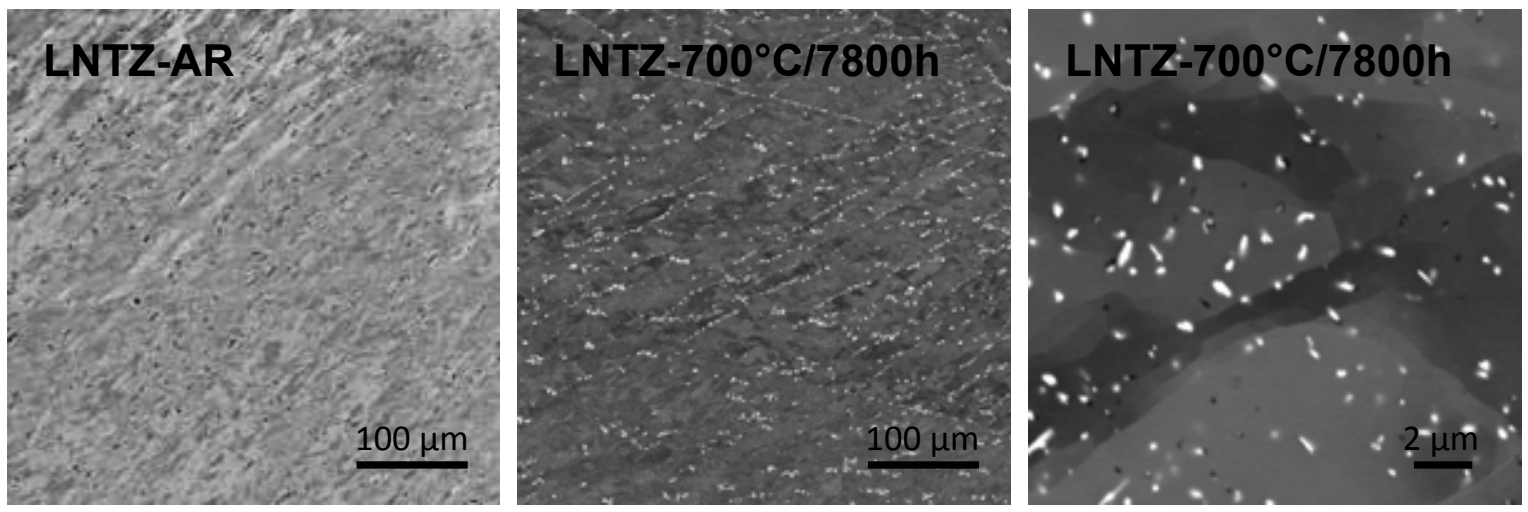

Figure 12. Backscattered electron images (BEIs) of alloy LNTZ in the AR and aged (700 ${ }^{\circ} \mathrm{C}$ for $\left.7800 \mathrm{~h}\right)$ conditions.

\subsection{IMPROVEMENT IN CREEP RESISTANCE}

Creep tests were conducted using the type SS-3 specimens primarily at 600 and $650^{\circ} \mathrm{C}$. The tests have been primarily conducted on the $\mathrm{T}$ - and $\mathrm{Z}$-alloys. The L-alloys were not included in the tests because of their mediocre tensile performance and remarkable radiation hardening (as described in the later section). Figure 13 shows the creep stress as a function of Larson-Miller parameter (LMP) of the tested specimens of T- and Z-alloys in open circles and triangles, respectively. The literature data of P91 from the National Institute for Materials Science (NIMS) Creep Data Sheet No. 43 are plotted in the figure with plus signs and a solid fitting line. Most of the tested specimens exhibited superior creep strength as compared to P91 at higher stress and lower LMP, corresponding to the lower test temperature and/or shorter creep lives. At the higher test temperature, the tested specimens exhibited comparable or slightly inferior creep strength. The significantly smaller test specimens, with a gauge cross-sectional area about $1 / 68$ of the P91 as schematically shown in the inset, may have impaired the creep resistance of the $\mathrm{T}-$ and $\mathrm{Z}$-alloys at the higher test temperature.

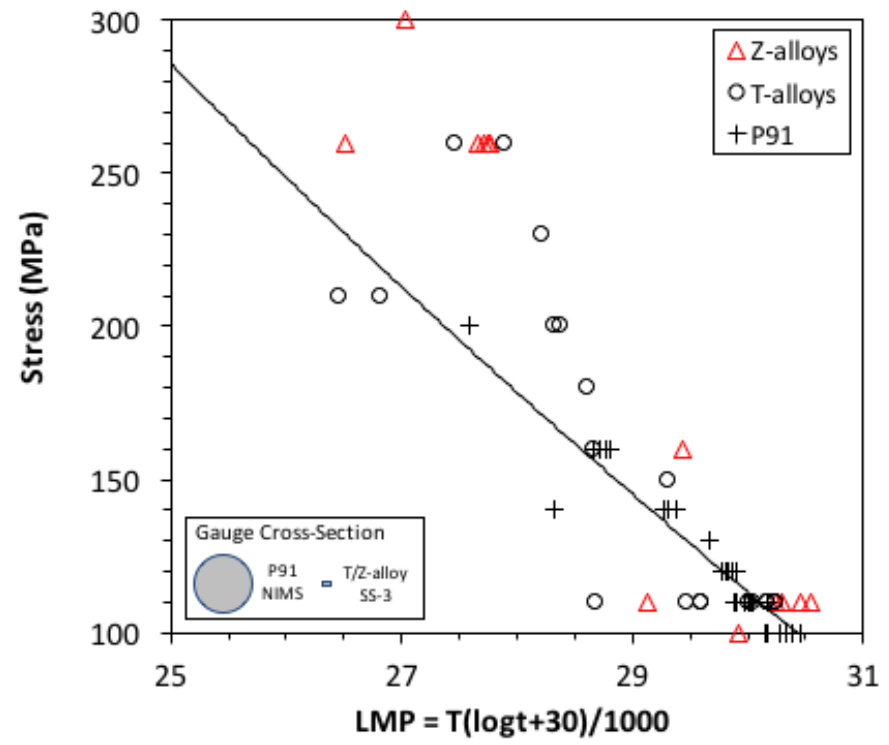

Figure 13. Larson-Miller parameter plot of the tested $\mathrm{T}$ - and Z-alloys as compared with P91. 
Figure 14 shows typical creep curves of a T-alloy and a Z-alloy tested at $650^{\circ} \mathrm{C}$ and $110 \mathrm{MPa}$. The data of P/T91 tested at the same condition are extracted from the NIMS Creep Data Sheet No. 43 and included in Figure 14. Noticeable improvement in creep life was observed for the T-alloys and Z-alloys as compared to $\mathrm{P} / \mathrm{T} 91$. In general, Z-alloys had longer creep life than T-alloys, as well as higher creep strain comparable to $\mathrm{P} / \mathrm{T} 91$. Similar to the tensile tests, the miniature type SS-3 specimen is expected to have constrained creep strain as compared to the $\mathrm{P} / \mathrm{T} 91$ because of the significantly smaller gauge cross-section area of type SS-3 specimen that is about 1/68 of the gauge cross-section area of the P/T91 specimen.

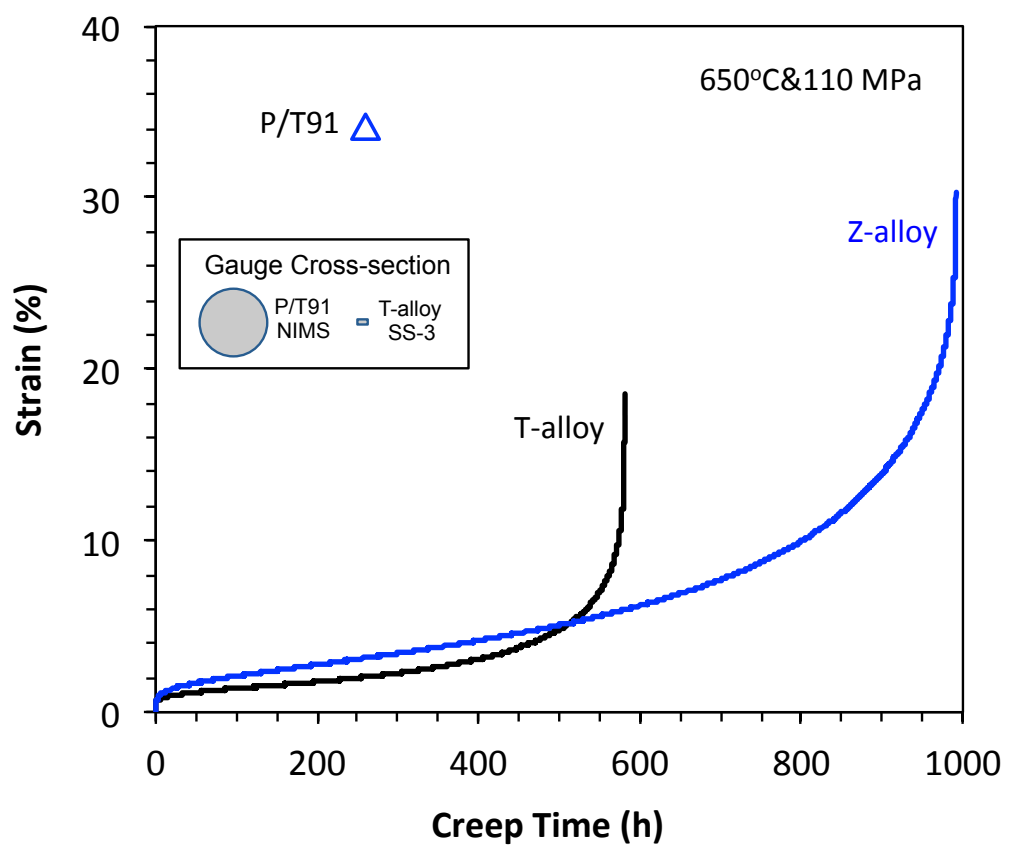

Figure 14. Creep curves of T-alloy and Z-alloy as compared with the data of $\mathrm{P} / \mathrm{T} 91$ at $650^{\circ} \mathrm{C}$ and $110 \mathrm{MPa}$.

Figure 15 shows the TEM images of the creep-ruptured T-alloy at $650^{\circ} \mathrm{C}$ and $110 \mathrm{MPa}$ at the tab and gauge sections in both BF and dark-field (DF) modes. The tab section, under negligible stress during the creep test, shows a narrow lath without noticeable recovery. Many nanoprecipitates exist in the matrix with some viewable particles pinning the right lath boundary. In contrast, the gauge section, under significant stress during the creep test, shows some recovery, e.g., $\sim 500 \mathrm{~nm}$ subgrains in the BF image of the gauge section. A large amount of dislocation line approximately perpendicular to $g_{200}$ formed in the subgrains. The DF image of the gauge section shows some nanoprecipitates in white but many nanoprecipitates in grey that are deviated from the diffraction condition. The nanoprecipitates at the gauge section have size and density comparable to those at the tab section. The observation indicates that subgrain recovery is still the primary softening mechanism of the T-alloys, which is similar to conventional FM steels. The greater creep life of T-alloys as compared to P/T91 suggests that the T-alloys have smaller recovery levels than P/T91. Detailed microstructural analysis is still needed to help understand the mechanism of the improved creep life of the T-alloys. 

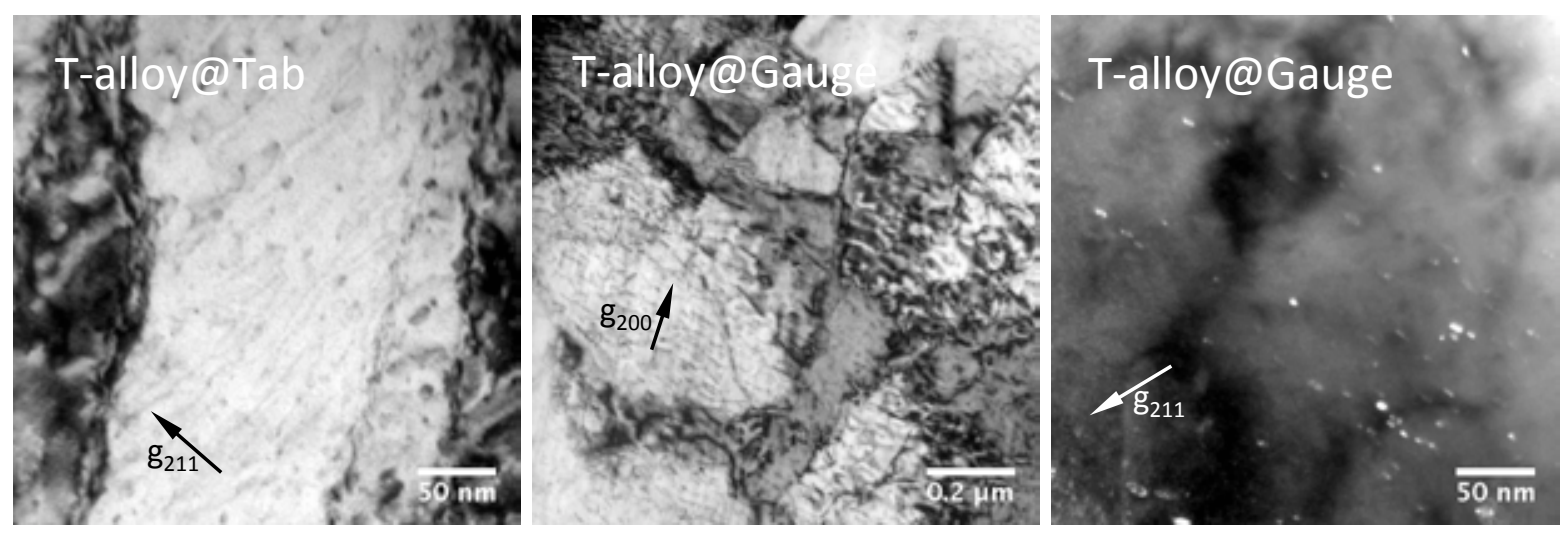

Figure 15. Microstructural comparison between the gauge and tab sections of a creep ruptured $\mathrm{T}$-alloy at $650^{\circ} \mathrm{C}$ and $110 \mathrm{MPa}$.

Figure 16 shows the $\mathrm{BF}$ image at the gauge section of the creep-ruptured Z-alloy tested at $650^{\circ} \mathrm{C}$ and $110 \mathrm{MPa}$. Many ultrafine particles with size about $10 \mathrm{~nm}$ are shown in the BF image with randomly orientated lattice fringes. The selected area diffraction pattern captured from this area shows a ring pattern of the particles on a [111] ferritic single grain matrix, which confirms the random orientation of the ultrafine particles. The ultrafine particles were formed during the creep test, which strengthened the alloy and extended its creep life. In the meantime, it seems that the dynamic precipitation of the ultrafine particles during the creep test did not impair creep strain.
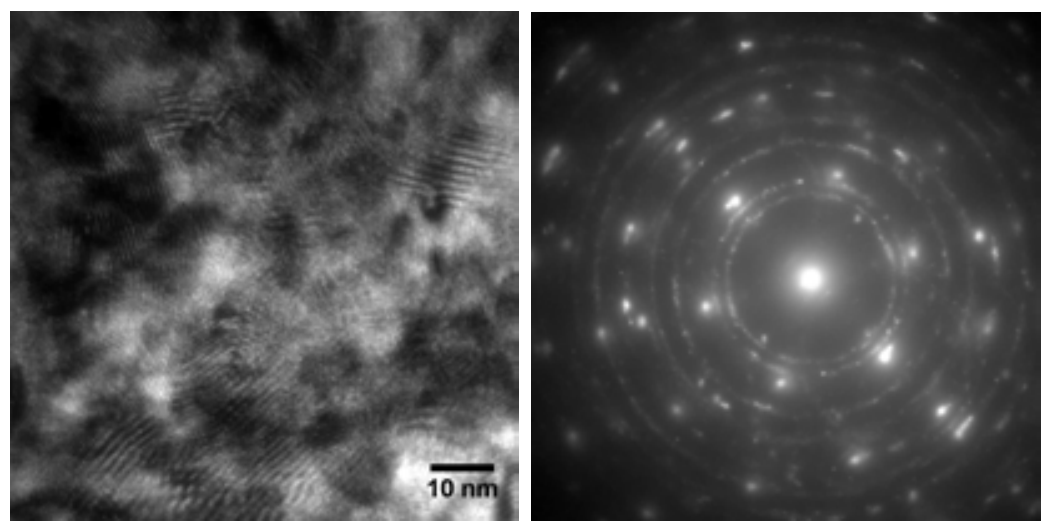

Figure 16. Microstructure of the gauge section of a creep ruptured Z-alloy at $650^{\circ} \mathrm{C}$ and $110 \mathrm{MPa}$. 


\section{THERMAL AGING RESISTANCE AT 600 AND $700^{\circ} \mathrm{C}$}

Type SS-3 specimens of T- and Z-alloys were sealed separately in argon back-filled quartz tubes which were aged in box furnaces at 600 and $700^{\circ} \mathrm{C}$. The 600 and $700^{\circ} \mathrm{C}$ thermal aging had achieved up to $10,200 \mathrm{~h}$. Tensile tests of the aged specimens were conducted at room temperature and the aging temperature (i.e., 600 and $700^{\circ} \mathrm{C}$ ). Their tensile properties are compared to the control condition without the aging.

Figure 17 and Figure 18 show the changes of yield strength, tensile strength, and total elongation at room temperature of the aged specimens as compared to the control specimens. The T-alloys exhibited softening with reduced yield/tensile strength and increased total elongation after the aging at 600 and $700^{\circ} \mathrm{C}$. The higher aging temperature resulted in greater softening. Alloy TTZ1 with a small amount of $\mathrm{Zr}$ alloying into alloy TT1 led to reduction in the softening at both 600 and $700^{\circ} \mathrm{C}$. In contrast, alloy Z6 showed some $(\sim 10 \%)$ hardening after the aging at both 600 and $700^{\circ} \mathrm{C}$ for $5,000 \sim 6,000 \mathrm{~h}$. The aging temperatures did not result in noticeable difference in the hardening. However, the higher aging temperature $\left(700^{\circ} \mathrm{C}\right)$ tended to have hardening without impairing total elongation of alloy Z6. The longer time $(10,200 \mathrm{~h})$ aged $\mathrm{T}$-alloys were subjected to a secondary normalization and tempering treatments prior to the aging at $600^{\circ} \mathrm{C}$. The aging resulted in up to $\sim 20 \%$ reductions in strength accompanied with $<14 \%$ increases in total elongation, which is comparable or slightly superior to the $5,906 \mathrm{~h}$ aging at $600^{\circ} \mathrm{C}$ of the T-alloys. The significant distinction between the T3t and the TT-series suggests the beneficial effect of Ta alloying on improving aging resistance. In contrast, slight aging hardening was observed in the $\mathrm{Z}$-alloys with some reductions in total elongation at $600^{\circ} \mathrm{C}$. The higher aging temperature at $700^{\circ} \mathrm{C}$ tended to diminish radiation hardening with somewhat greater reductions in total elongation of the $\mathrm{Z}-$ alloys. With the decreasing amount of Laves phase from $\mathrm{Z} 6$ to $\mathrm{Z} 9$ alloys, the $\mathrm{Z}$-alloys changed from aging hardening to aging softening. Unlike the aging softening in the $\mathrm{T}$-alloys, however, the aging softening in $\mathrm{Z} 9$ alloy was accompanied with reduction of total elongation.
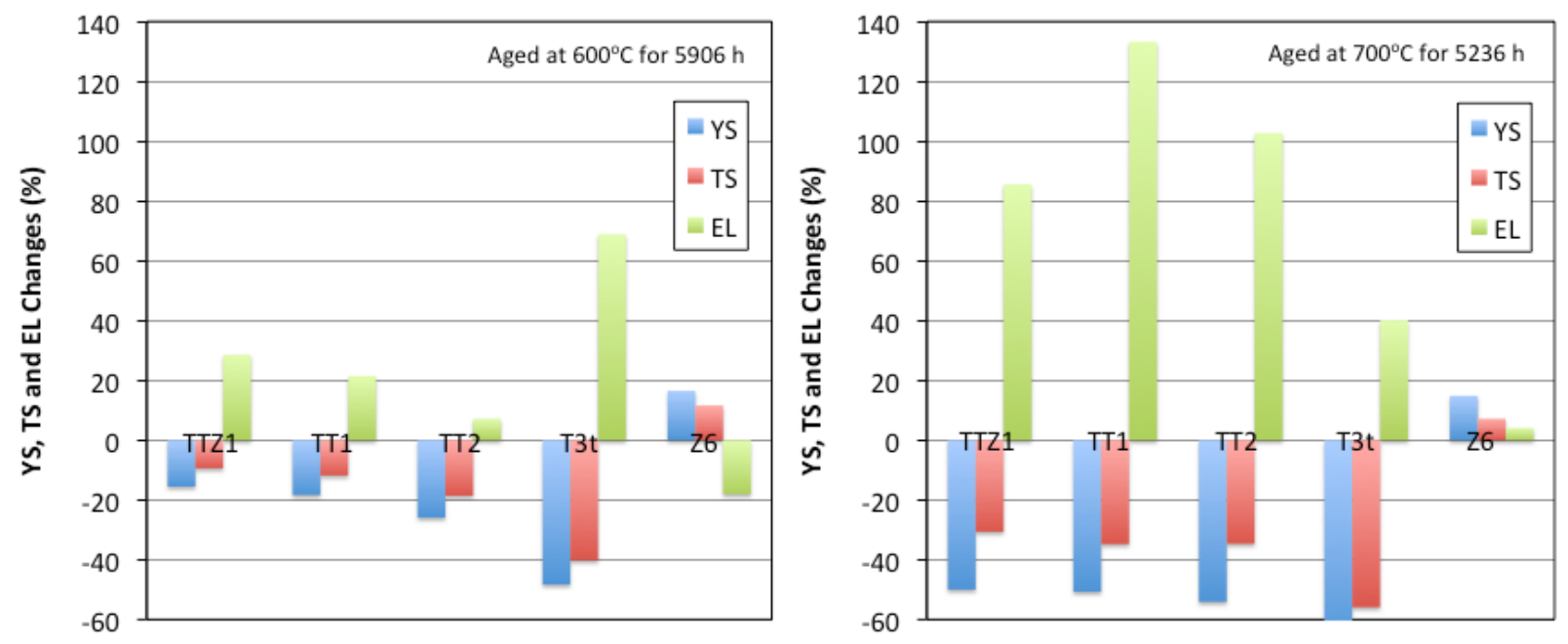

Figure 17. Changes of yield strength (YS), tensile strength (TS), and total elongation (EL) at room temperature of the $T$ - and $Z$-alloys after aging at 600 and $700^{\circ} \mathrm{C}$ for 5,906 and $5,236 \mathrm{~h}$, respectively. 

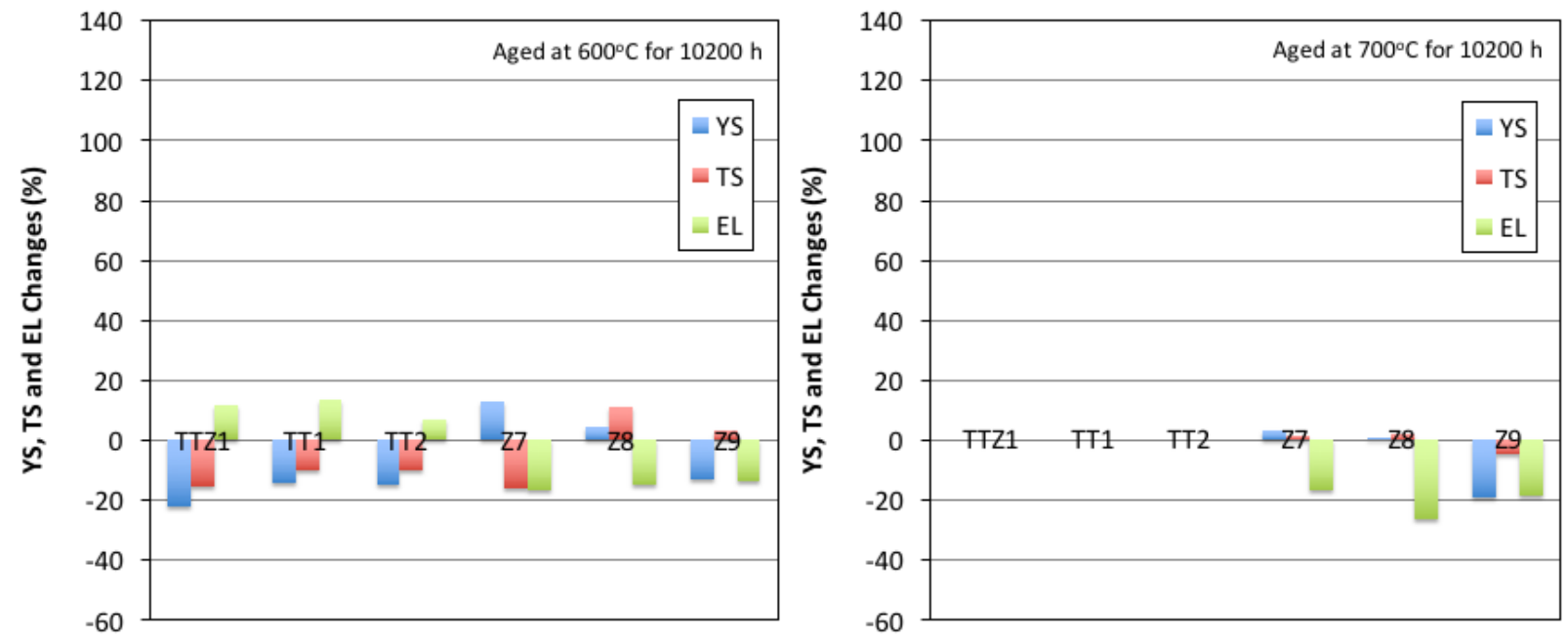

Figure 18. Changes of yield strength (YS), tensile strength (TS), and total elongation (EL) at room temperature of the $T$ - and $Z$-alloys after aging at 600 and $700^{\circ} \mathrm{C}$ for $10,200 \mathrm{~h}$. 


\section{CHARPY V-NOTCH IMPACT TOUGHNESS}

Charpy impact resistance is an important property of ferritic steels, which influences the application condition of the materials. Charpy impact tests were conducted on a Tinius Olsen Charpy $300 \mathrm{ft}-\mathrm{lb}$ machine according to ASTM Standard E23-12c, Standard Test Methods for Notched Bar Impact Testing of Metallic Materials. The measurement calibration of the Charpy machine is performed annually through testing of specimens with certified values to verify the accuracy of the machine. The certified specimens are obtained from the National Institute of Standards and Technology (NIST). Half-size Charpy V-notch specimens with a specification shown in Figure 19 were used to screen the absorbed impact energies at temperatures ranging from $-150^{\circ} \mathrm{C}$ to $300^{\circ} \mathrm{C}$ to determine ductile-brittle transition temperature (DBTT) and upper-shelf energy (USE) of the developed alloys. The specimens were primarily tested in the T-L (transverse-longitudinal) orientation with V-notch aligned with the longitudinal direction because this orientation usually gives the worst impact toughness as compared to the other specimen orientations, e.g., the L-T orientation with V-notch aligned with the transverse direction.

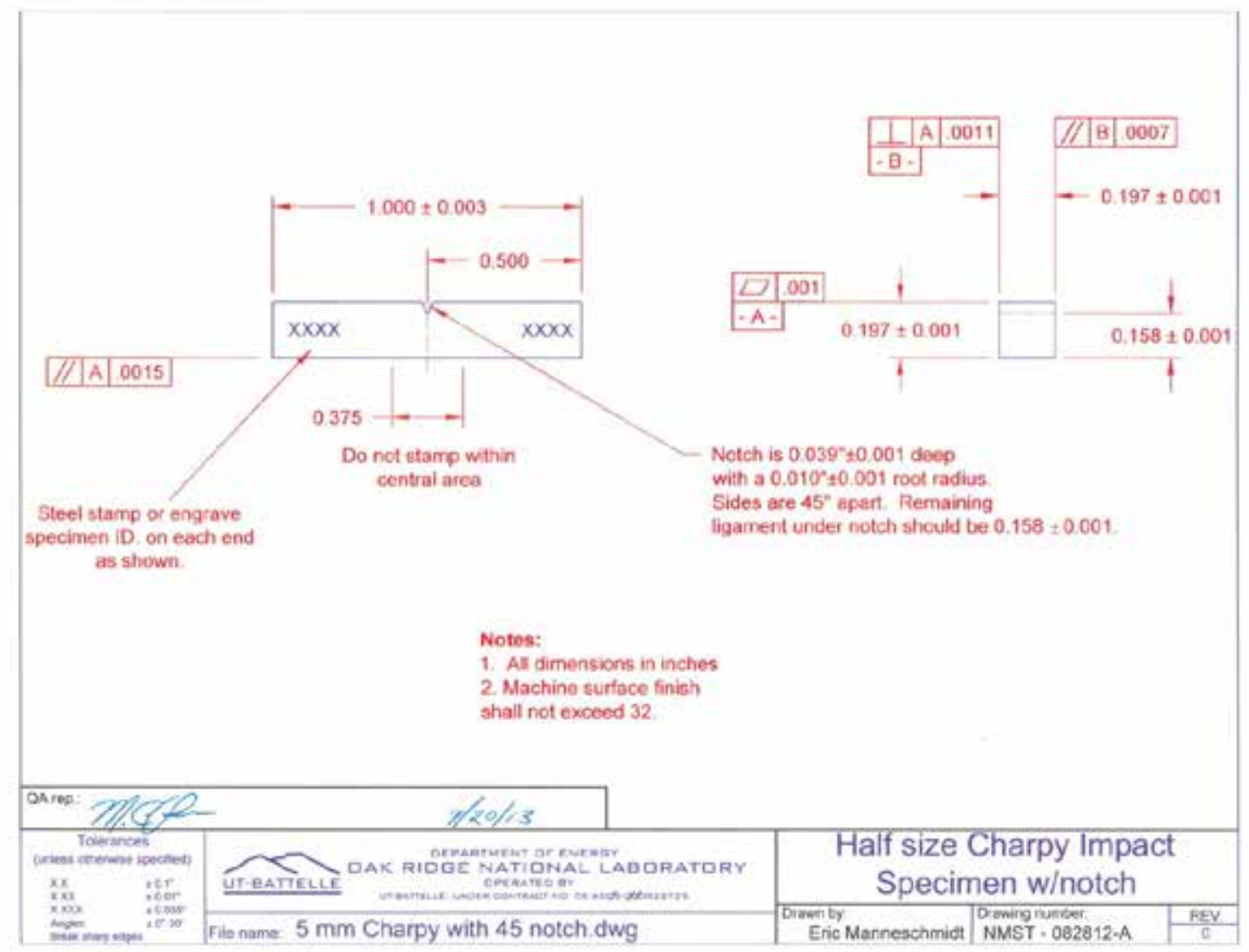

Figure 19. Specification of half-size Charpy V-notch specimen.

The tested results of two T-alloys are plotted in Figure 20. The literature data of Grade 91 using the same type of half-size Charpy V-notch specimens in the same T-L orientation are included for comparison [21]. To obtain DBTT and USE, impact energy-temperature curves were generated by fitting the data with a hyperbolic tangent function $E=a+b \tanh \left[\left(T-T_{0}\right) / c\right]$, where $T$ is test temperature and $a$, $b, c$ and $T_{0}$ are regression coefficients. In this study, $T_{0}$ is the mathematical DBTT, corresponding to the 
mean value of USE and lower-shelf energy (LSE), i.e., 1/2USE assuming LSE $=0$ in this study. In comparison, engineering DBTT is determined at $6.5 \mathrm{~J}$ for the half-size specimen $(5 \times 5 \times 25 \mathrm{~mm})$, lower than the $41 \mathrm{~J}$ criterion for full-size specimen $(10 \times 10 \times 55 \mathrm{~mm})$ [22]. The analyzed results of the two T-alloys and Grade 91 are summarized in Table 4. As compared to Grade 91, the T-alloys have about $25^{\circ} \mathrm{C}$ lower DBTT in terms of the mathematic DBTT at $1 / 2 \mathrm{USE}$ and about $12^{\circ} \mathrm{C}$ lower DBTT in terms of the engineering DBTT at $6.5 \mathrm{~J}$. In the meantime, the USE of the T-alloys is about double that of the Grade 91, which suggested significant improvement in Charpy impact toughness of the T-alloys.

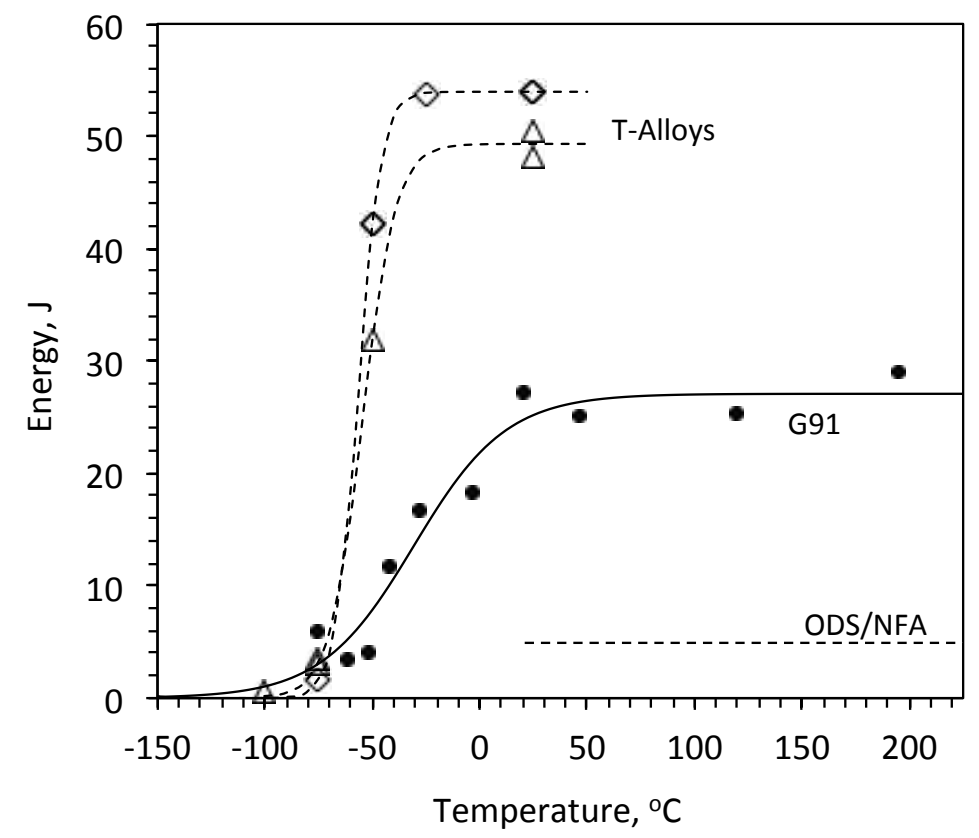

Figure 20. Charpy V-notch impact tested data and fitted curves of T-alloys in the T-L orientation as compared with Grade 91.

Table 4. DBTT and USE of the T-alloys and Grade 91.

\begin{tabular}{cccc}
\hline Alloy & Mathematic DBTT & Engineering DBTT & USE \\
\cline { 2 - 4 } Sample & $(1 / 2 \mathrm{USE}),{ }^{\circ} \mathrm{C}$ & $(6.5 \mathrm{~J}),{ }^{\circ} \mathrm{C}$ & $\mathrm{J}$ \\
\hline T-alloys & -56.7 & -67.1 & 54.0 \\
& -54.6 & -69.1 & 49.3 \\
Grade 91 & -30.7 & -55.5 & 27.1 \\
\hline
\end{tabular}

A few Z-alloy half-size Charpy V-notch specimens tested at room temperature exhibited USE comparable to or lower than the general USE of 12-14Cr oxide-dispersion-strengthened (ODS) or nanostructured ferritic alloys (NFA) at about $5 \mathrm{~J}$ as shown with dashed horizontal line in Figure 20. Extensive development is needed to improve the toughness of this type of ferritic alloys ( $Z$-alloys). 


\section{NICKEL-CONTAINING Z-ALLOYS}

\subsection{THERMODYNAMIC MODELING OF FE-CR-ZR-NI SYSTEM}

The $\mathrm{Fe}_{2} \mathrm{Zr}$ Laves phase has dihexagonal $\mathrm{C} 36$ structure at high temperature and cubic $\mathrm{C} 15$ structure at low temperature. When $\mathrm{Cr}$ is added, the hexagonal $\mathrm{C} 14$ structure can also be stabilized. These polytypes are related to each other because the basic unit layer of these phases is the same, while the stacking sequence of the unit layer is different in each structure. Despite the excellent high-temperature strength of the Laves phases, the low ductility and brittle fracture characteristics at ambient temperature are the main limitations for structural applications. The high hardness and brittle fracture of Laves phase are due to the complex atomic configuration of each unit layer, interplanar locking, and lack of operating slip systems at ambient temperature. In view of this problem, the dual-phase alloying concept based on a soft solid solution matrix reinforced with hard Laves phase particles has been proposed for practical alloy development, as employed in this study. New Fe-Cr-Zr ferritic alloys with the C14 Laves phase as the strengthening component have been developed. These new alloys show one order of magnitude higher enhancement on high-temperature tensile and creep strength over conventional P91 ferritic/martensitic steels. Despite the success in high-temperature mechanical properties, these alloys suffer from the low fracture toughness at ambient temperature. Thermodynamic modeling and experimental investigation identified the hexagonal $\mathrm{C} 14$ structure as the prevalent structure in $\mathrm{Fe}-\mathrm{Cr}-\mathrm{Zr}$ alloys. The literature review suggested that the fracture toughness of $\mathrm{C} 14$ structure is lower than that of $\mathrm{C} 15$ structure, which was attributed to the fact that the cubic $\mathrm{C} 15$ structure has more operating slip system, therefore is more deformable than the hexagonal C14 structure. Following this concept, Ni was proposed to be added into the current $\mathrm{Fe}-\mathrm{Cr}-\mathrm{Zr}$ alloy, with the goal to convert the hexagonal $(\mathrm{Fe}, \mathrm{Cr})_{2} \mathrm{Zr}$ _C14 Laves phase into the cubic $(\mathrm{Fe}, \mathrm{Cr}, \mathrm{Ni})_{2} \mathrm{Zr} \_\mathrm{C} 15$ structure.
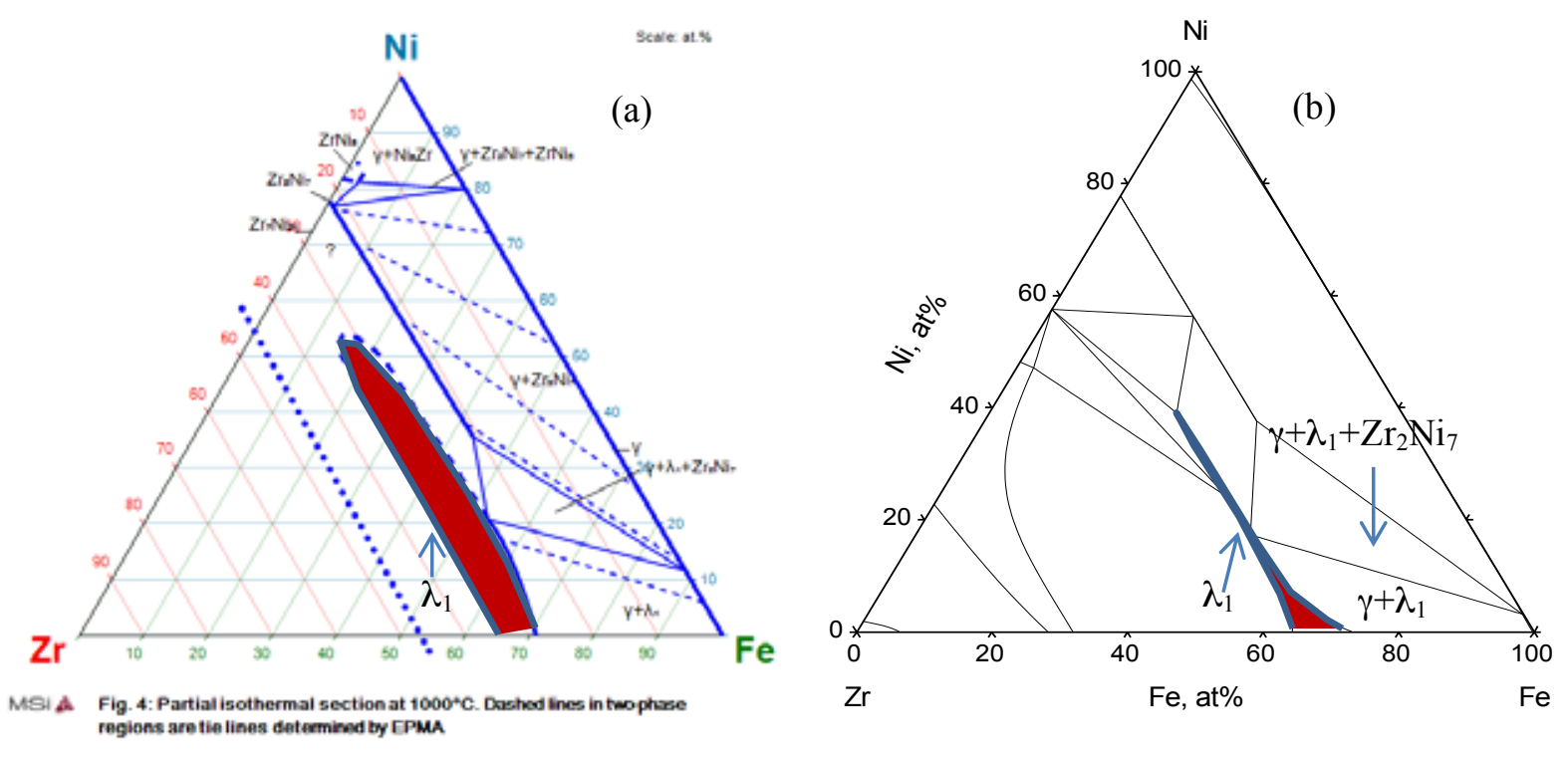

Figure 21. Partial isothermal section of Fe-Ni-Zr at $1,000^{\circ} \mathrm{C}$ : (a) experimental, (b) calculated.

The partial isothermal section of $\mathrm{Fe}-\mathrm{Ni}-\mathrm{Zr}$ at $1,000^{\circ} \mathrm{C}$ is shown in Figure $21 \mathrm{a}$, in which the $\lambda 1$ phase is the $(\mathrm{Fe}, \mathrm{Ni})_{2} \mathrm{Zr} \_\mathrm{C} 15$ phase. Clearly, Ni stabilizes the $\mathrm{C} 15$ structure. The solubility of $\mathrm{Ni}$ in $\mathrm{Fe}_{2} \mathrm{Zr} \mathrm{C}_{-} 15$ phase can be up to 20 at. $\%$ for the $\mathrm{Bcc}(\mathrm{Fe}, \mathrm{Cr})+\mathrm{Fe}_{2} \mathrm{Zr} \_\mathrm{C} 15$ two-phase region. A preliminary thermodynamic model on $(\mathrm{Fe}, \mathrm{Ni})_{2} \mathrm{Zr}$ _C15 Laves phase has been developed in this study. The calculated 
partial isothermal section is shown in Figure 21b. The region relevant to this study is the $\gamma+\lambda_{1}$ and $\gamma+\lambda_{1}+\mathrm{Zr}_{2} \mathrm{Ni}_{7}$ phase equilibria.

\subsection{STABILITY OF THE LAVES PHASE}

By incorporating the newly developed thermodynamic model of (Fe,Ni) ${ }_{2} \mathrm{Zr}$ C15_Laves phase into the OCTANT (Ornl Computational Thermodynamics for Nuclear Technology) thermodynamic database, the stability of relevant phases in Fe-Cr-Ni-Zr alloys can be calculated. Although the thermodynamic description for the $\mathrm{Fe}-\mathrm{Cr}-\mathrm{Ni}-\mathrm{Zr}$ quaternary system is still preliminary due to the lack of experimental validation, it provides important trend analysis of the $\mathrm{Ni}$ effect on the stability of the Laves phases in the $\mathrm{Fe}-\mathrm{Cr}-\mathrm{Zr}$ alloys. Based on thermodynamic calculation results, three $\mathrm{Fe}-\mathrm{Cr}-\mathrm{Zr}$ alloys with different $\mathrm{Ni}$ concentrations were designed for experimental study. They are Fe-12Cr-6Zr base alloys with addition of $0.5,2$ and $4 \mathrm{wt} \% \mathrm{Ni}$, respectively. The detailed compositions of the alloys are not presented here due to potential proprietary concerns. The amount of Laves phase in $\mathrm{C} 14$ and $\mathrm{C} 15$ structures in these alloys is plotted as a function of temperature in Figure 22. At $0.5 \mathrm{wt} \% \mathrm{Ni}$, the hexagonal $\mathrm{C} 14$ phase is the major one, plotted as the solid black line. It forms from liquid through the eutectic reaction of Liquid $\rightarrow \mathrm{Bcc}(\mathrm{Fe}, \mathrm{Cr})+\mathrm{Fe}_{2} \mathrm{Zr} \mathrm{C} 14$. The $\mathrm{C} 14$ Laves phase is decomposed into the $\mathrm{C} 15$ structure at temperatures below $900^{\circ} \mathrm{C}$ (the sold red line). The formation of C14 and $\mathrm{C} 15$ Laves phase in the alloy with $0.5 \mathrm{wt} \% \mathrm{Ni}$ is similar to that in Fe-Cr-Zr alloys without $\mathrm{Ni}$ addition. At $2 \mathrm{wt} \% \mathrm{Ni}$, the $\mathrm{C} 15$ phase is the primary Laves phase formed from the eutectic reaction Liquid $\rightarrow \mathrm{Bcc}\left(\mathrm{Fe}, \mathrm{Cr}\right.$ ) $+\mathrm{Fe}_{2} \mathrm{Zr} \_\mathrm{C} 15$ (the red dashed line), suggesting that the increasing Ni concentration greatly stabilizes the $\mathrm{C} 15$ structure. The $\mathrm{C} 14$ structure is now the secondary phase formed at low temperature. With further addition of $\mathrm{Ni}, 4 \mathrm{wt} \%$, there is no dramatic change in terms of phase stability and amounts.

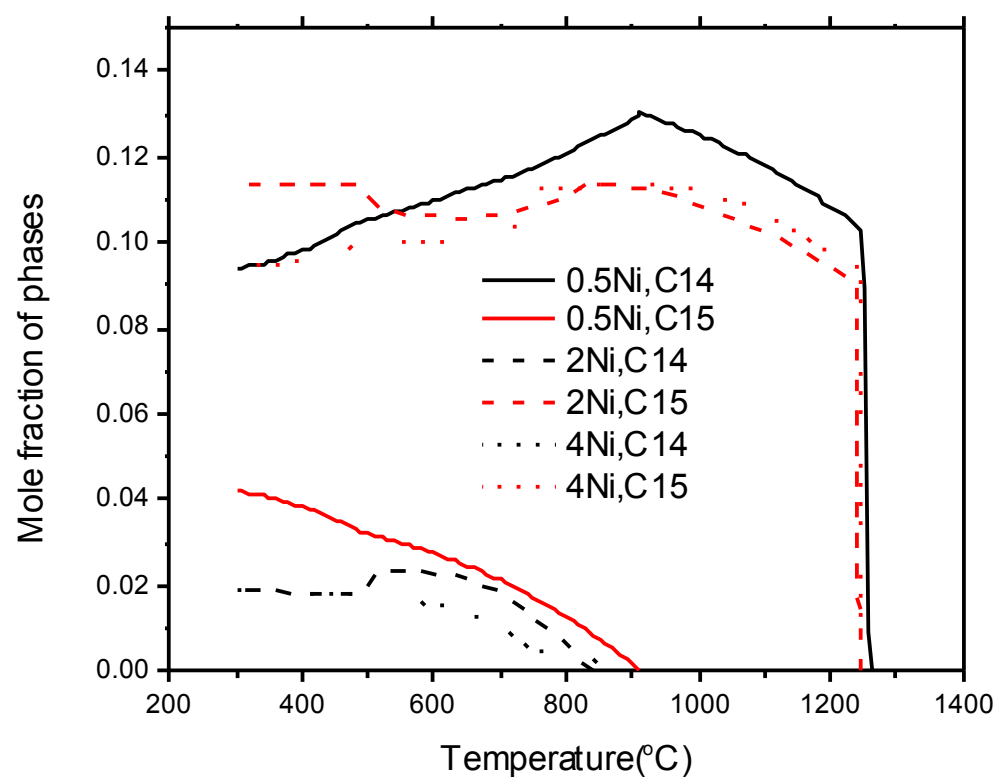

Figure 22. The mole fraction of the C14 and C15 Laves phase vs. temperature in the Fe-12Cr-6Zr base alloy with different additions of $\mathrm{Ni}$. The solid, dashed and dotted lines denote $0.5,2$ and $4 \mathrm{wt} \% \mathrm{Ni}$, respectively. The black and red colors denote the $\mathrm{C} 14$ and $\mathrm{C} 15$ structure, respectively.

It has been shown that by increasing the $\mathrm{Ni}$ content from 2 to $4 \mathrm{wt} \%$, no additional Laves phase can form. This is because the $\mathrm{C} 15$ structure has a large solubility of Ni. Figure 23 plots the solubility of Ni in the $\mathrm{C} 14$ and $\mathrm{C} 15$ structure as a function of temperature for $0.5,2$ and $4 \mathrm{wt} \% \mathrm{Ni}$ alloys. Again, the solid, 
dashed and dotted lines denote $0.5,2$ and $4 \mathrm{wt} \% \mathrm{Ni}$, respectively. The black and red color denotes the $\mathrm{C} 14$ and $\mathrm{C} 15$ structure, respectively. For the $0.5 \mathrm{wt} \%$ alloy, the dissolved $\mathrm{Ni}$ in both $\mathrm{C} 14$ and $\mathrm{C} 15$ structures is due to the limited $\mathrm{Ni}$ available from the bulk composition. In $2 \mathrm{wt} \%$ alloy, the dissolved $\mathrm{Ni}$ in the $\mathrm{C} 15$ structure is significantly increased, while that in $\mathrm{C} 14$ structure remains at a minimum. When further increasing the $\mathrm{Ni}$ content to $4 \mathrm{wt} \%$, the dissolved Ni in $\mathrm{C} 15$ structure is continuously rising, while that in the $\mathrm{C} 14$ structure is still at a minimum. The amount of dissolved $\mathrm{Ni}$ in the $\mathrm{C} 15$ structure is determined by the solubility of $\mathrm{Ni}$ in this structure. As shown in the isothermal section of $\mathrm{Fe}-\mathrm{Ni}-\mathrm{Zr}$ at $1,000^{\circ} \mathrm{C}$, the solubility of $\mathrm{Ni}$ in $\mathrm{Fe}_{2} \mathrm{Zr} \_\mathrm{C} 15$ phase can be up to 20 at.\% for the $\mathrm{Bcc}(\mathrm{Fe}, \mathrm{Cr})+\mathrm{Fe}_{2} \mathrm{Zr} \_\mathrm{C} 15$ two-phase region. Therefore, the $\mathrm{Ni}$ behavior in the $(\mathrm{Fe}, \mathrm{Cr})_{2} \mathrm{Zr}$ Laves phase is inherited from the Fe-Ni-Zr ternary

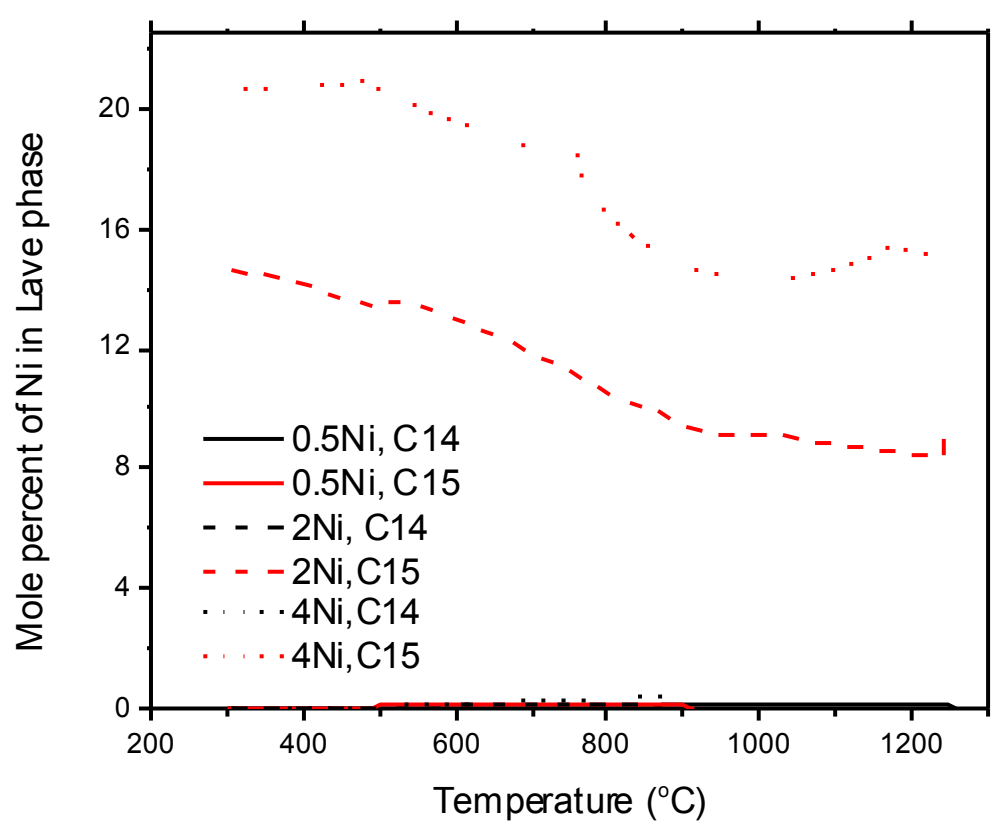

Figure 23. The dissolved $\mathrm{Ni}$ in the $\mathrm{C} 14$ and $\mathrm{C} 15$ Laves phase vs. temperature in the $\mathrm{Fe}-12 \mathrm{Cr}-6 \mathrm{Zr}$ base alloy with different additions of $\mathrm{Ni}$. The solid, dashed and dotted lines denote $0.5,2$ and $4 \mathrm{wt} \% \mathrm{Ni}$, respectively. The black and red colors denote the $\mathrm{C} 14$ and $\mathrm{C} 15$ structure, respectively.

\subsection{MICROSTRUCTURAL CHARACTERIZATION OF NI-CONTAINING ALLOYS}

Scanning electron microscopy (SEM) coupled with energy dispersive x-ray spectroscopy (EDS) and electron-backscattered diffraction (EBSD) was used for morphology, composition, and orientation analyses. SEM/EDS/EBSD was performed using a JEOL JSM 6500F microscope with a field emission gun (FEG), equipped with EDAX EDS and EBSD systems. The accelerating voltage was $20 \mathrm{kV}$, and the working distance was 12 to $17 \mathrm{~mm}$. EBSD maps were measured on a hexagonal grid with a step size of $\leq 0.5 \mu \mathrm{m}$. The camera operated in $2 \times 2$ binning mode at $\sim 100$ frames per second (fps). These parameters were chosen to keep the EBSD analysis time within reasonable limits taking into account the large size of the scanned areas.

Figure $24 \mathrm{a}$ and $\mathrm{b}$ shows the backscattered electronic image (BEI) of the $\mathrm{Fe}-12 \mathrm{Cr}-6 \mathrm{Zr}$ base alloy with 0.5 and $4 \mathrm{wt} \% \mathrm{Ni}$, respectively. The BEI of the alloy with $2 \mathrm{wt} \% \mathrm{Ni}$ is shown here due to the similarity to these two alloys. The indents in the micrograph of $4 \mathrm{wt} \%$ alloy were caused by hardness measurements, which were also used to align the EBSD scans. Both micrographs consist of the large 
primary ferrite phase surrounded by a network of $\mathrm{Bcc}(\mathrm{Fe}, \mathrm{Cr})+\mathrm{Fe}_{2} \mathrm{Zr}$ eutectic. The phase with the bright white feature is the $\mathrm{Fe}_{2} \mathrm{Zr}$ phase. The grey and dark features are ferrite matrix in slightly different grain orientations. With increasing Ni content from 0.5 to $4 \mathrm{wt} \%$, no significant changes in the amount of primary and eutectic phases have been observed.

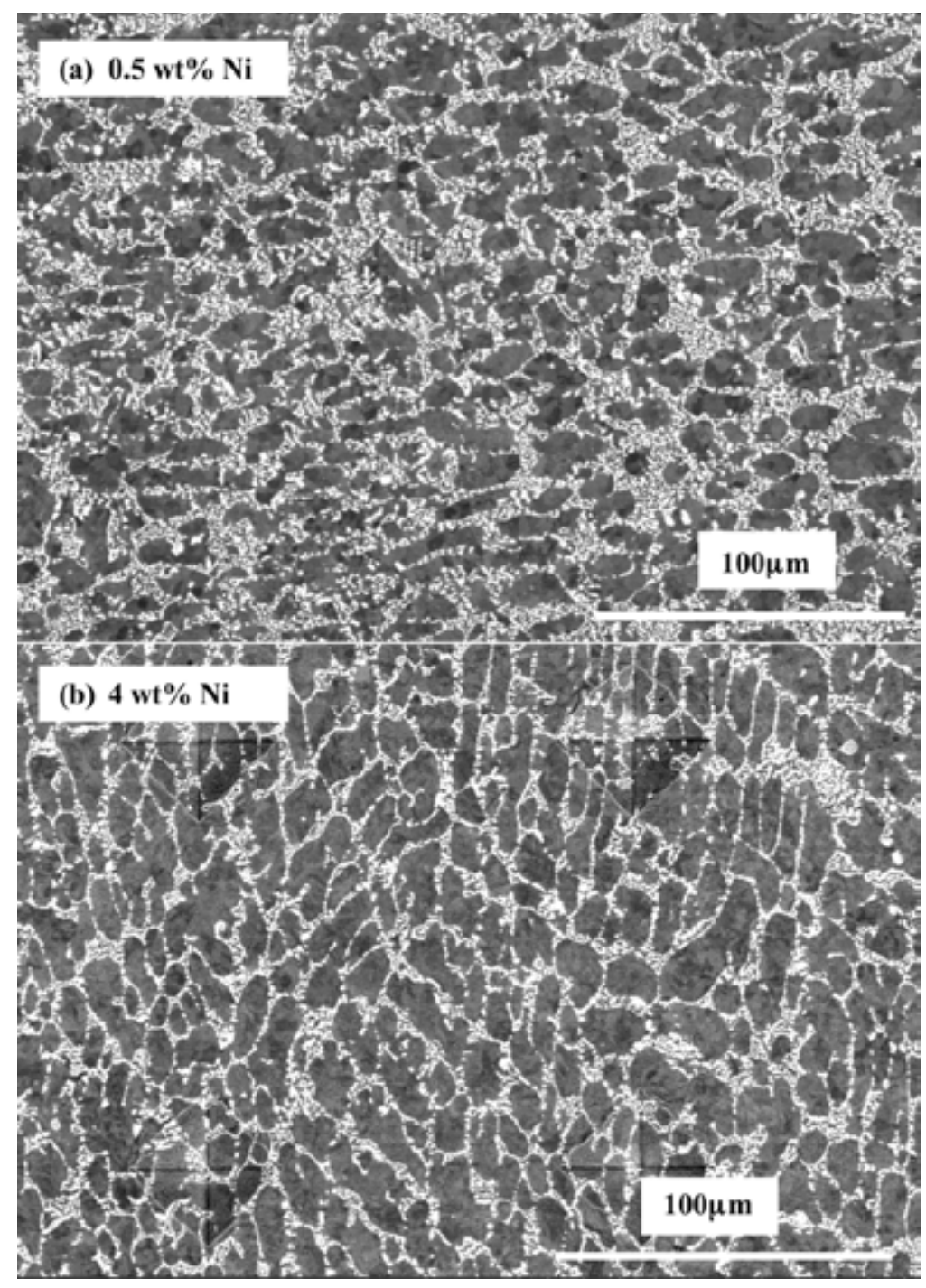

Figure 24. BEIs of Fe-12Cr-6Zr base alloy with additions of (a) 0.5 and (b) $4 \mathrm{wt} \% \mathrm{Ni}$.

The EBSD maps in the forms of image quality (IQ) and inverse pole figure (IPF) for alloys with 0.5 and $4 \mathrm{wt} \% \mathrm{Ni}$ are shown in Figure $25 \mathrm{a}-\mathrm{d}$. The phases of $\mathrm{Bcc}(\mathrm{Fe}), \mathrm{Fe}_{2} \mathrm{Zr} \mathrm{C}_{-} 14$, and $\mathrm{Fe}_{2} \mathrm{Zr} \mathrm{C} 15$ were used during the EBSD mapping. The IQ maps describe the quality of the collected EBSD patterns, which is strongly affected by the perfection of the crystal lattice in the diffracting volume. Lower IQ corresponds to lower contrast in the IQ images, which is associated with disortions to the crystal lattice. The IQ maps in Figure $25 \mathrm{a}$ and $\mathrm{c}$ indicate that low IQ regions are primarily associated with the Laves phases in the eutectic network, as well as the grain and subgrain boundaries. The low IQ of the Laves phase is likely because of its complex crystal structure as compared to the matrix ferritic $\mathrm{Bcc}(\mathrm{Fe})$ phase. The alloy with $4 \mathrm{wt} \% \mathrm{Ni}$ shows a denser eutectic network and more subgrains in the primary/matrix phase than the alloy with $0.5 \mathrm{wt} \% \mathrm{Ni}$. The alloys have been produced by the same processing and yielded greater hardness of the alloy with $4 \mathrm{wt} \% \mathrm{Ni}$ as compared to the alloy with $0.5 \mathrm{wt} \% \mathrm{Ni}(257.5 \pm 2.1 v s .210 .5 \pm 2.5)$. The IPF 
maps show the grain orientation of the samples. The pronounced subgrains in the alloys exhibit slight variations in orientation. Laves phase has been primarily identified as $\mathrm{Fe}_{2} \mathrm{Zr}$ _C14 in the alloys. Despite the observation of some $\mathrm{Fe}_{2} \mathrm{Zr}$ _C15 in the alloy with $4 \mathrm{wt} \% \mathrm{Ni}$, it may have not been well identified at this magnification. Further EBSD characterization at higher magnificantions is currently ongoing to reveal the effect of $\mathrm{Ni}$ content on the presence of $\mathrm{Fe}_{2} \mathrm{Zr} \_\mathrm{C} 15$ Laves phase.
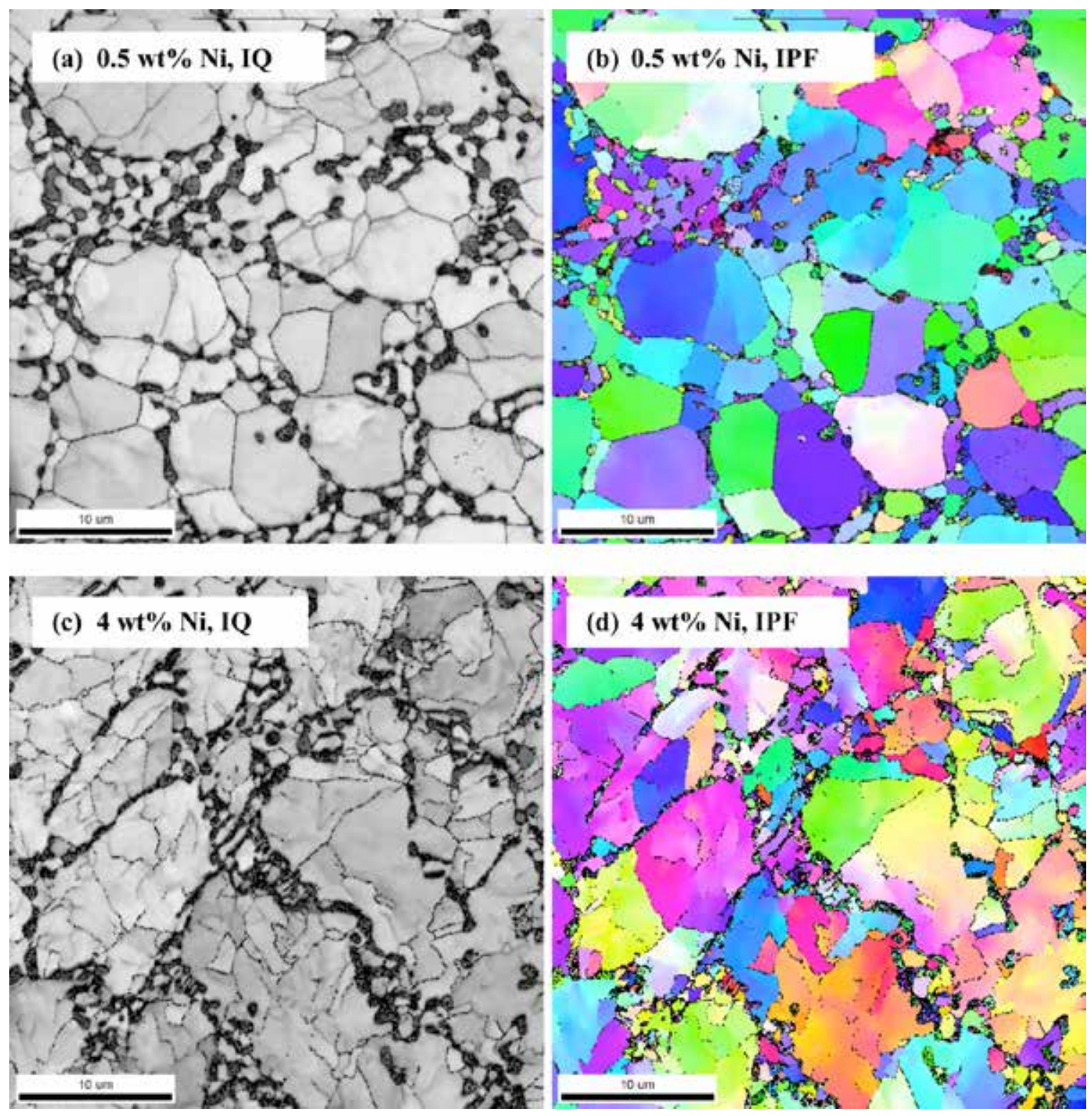

Figure 25. EBSD IQ and IPF maps of Fe-12Cr-6Zr alloys with (a-b) 0.5 and (c-d) 4 wt\% Ni.

The composition of phases was analyzed by EDS mapping. As shown in Figure 26, the $\mathrm{Fe}_{2} \mathrm{Zr}$ phase in the eutectic zone of the alloy with $0.5 \mathrm{wt} \% \mathrm{Ni}$ has lower Fe and $\mathrm{Cr}$ but enriched $\mathrm{Zr}$ content than the matrix ferrite phase that is enriched with Fe and Cr. Noticeable Ni enrichment was not observed in this alloy sample, which suggests uniform distribution. For the alloy with $4 \mathrm{wt} \% \mathrm{Ni}$ as shown in Figure 27, enrichment of $\mathrm{Ni}$ is consistent with the $\mathrm{Zr}$ site at the Laves phase. This is in agreement with the thermodynamically calculated solubility of $\mathrm{Ni}$ in the Laves phase in Figure 23. Depletion of $\mathrm{Cr}$ is consistent with $\mathrm{Fe}$ at the Laves phase and is similar to the alloy with $0.5 \mathrm{wt} \% \mathrm{Ni}$. 


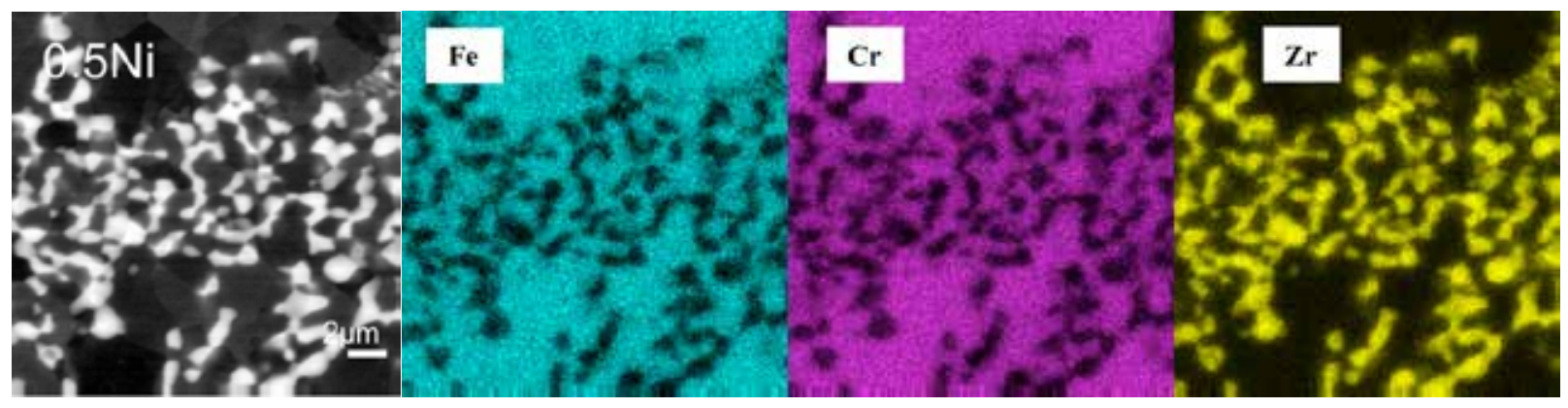

Figure 26. EDS maps of $\mathrm{Fe}, \mathrm{Cr}$ and $\mathrm{Zr}$ in the alloy with $0.5 \mathrm{wt} \% \mathrm{Ni}$.
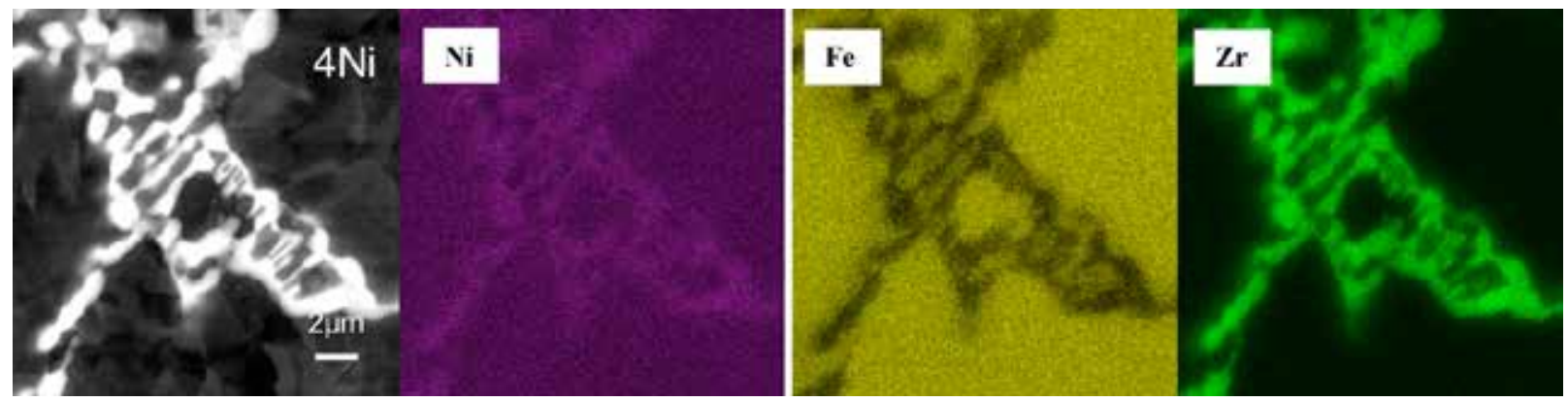

Figure 27. EDS maps of $\mathrm{Ni}, \mathrm{Fe}$, and $\mathrm{Zr}$ in the alloy with $4 \mathrm{wt} \% \mathrm{Ni}$. 


\section{RADIATION RESISTANCE EVALUATED BY ION IRRADIATION}

\subsection{ION IRRADIATION}

\subsubsection{Sample preparation}

Prior to ion irradiation, all alloys were cut into $5 \times 5 \mathrm{~mm}^{2}$ size and metallographically prepared and 3$\mathrm{mm}$ diameter disks were punched out of these samples and cleaned ultrasonically (Figure 28). The metallographic sample preparation consisted of three steps: grinding, polishing, and chemical cleaning. Grinding procedure was accomplished by progressively using SiC paper (procured from Allied) of 400, $600,800,1200$ grit size. When manually polishing, the samples were rotated 90 degrees between each grit paper and polished until all previous scratches are removed. Following the grinding steps, the samples were polished using a diamond suspension. A PLAN-B Rigid Back Magnetic System Disc, Diamat Rigid Magnetic Disc, and Final-POL Magnetic Disc from Allied with 9, 3, and $1 \mu \mathrm{m}$ diamond polish was used. The last part of the polishing process uses the CHEM-POL Rigid Magnetic Disc from Allied with a 0.3 and $0.05 \mu \mathrm{m}$ aluminum suspension followed by a $0.02 \mu \mathrm{m}$ colloidal silica suspension. Finally, in order to remove any deposits, the samples were ultrasonically in an acetone bath for 15 minutes.

After polishing, the surface roughness of each sample was measured by Zygo, and samples with surface roughness above $50 \mathrm{~nm}$ for proton-irradiation and around $30 \mathrm{~nm}$ for Fe-irradiation were repolished until the desired surface finish was achieved. Zygo measurements for all samples were made with the same parameters, which are outlined in Table 5. For each alloy five measurements were taken at slightly different locations in the central region of the samples, and then the average was recorded.

Table 5. Zygo parameters for surface roughness measurements of samples prior to ion irradiation.

\begin{tabular}{cc}
\hline Parameter & Zygo settings \\
\hline Objective & $20 \mathrm{x}$ \\
Zoom & $2 \mathrm{x}$ \\
Min-Mod & $5 \%$ \\
Scan Length & $150 \mu \mathrm{m}$ bipolar $(12 \mathrm{~s})$ \\
Camera Mode & $640 \times 480200 \mathrm{~Hz}$ \\
Surface Correction & Sphere \\
\hline
\end{tabular}

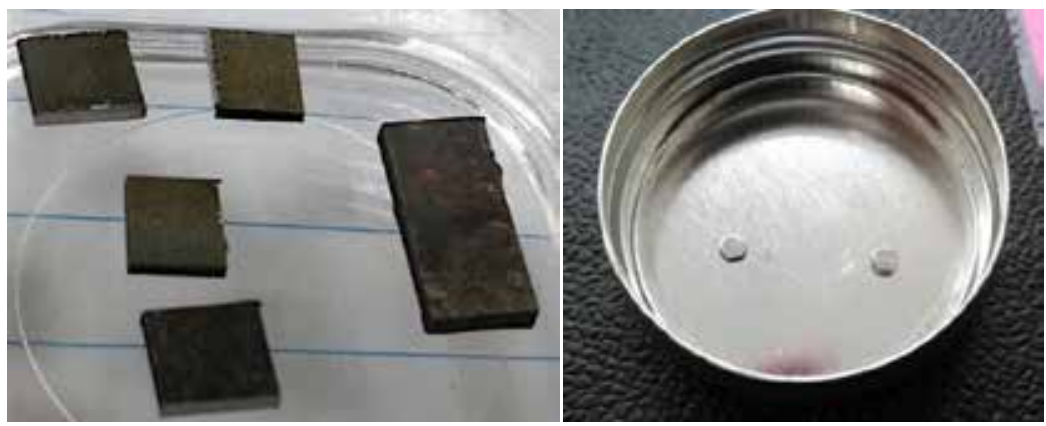

Figure 28. As received ferritic steel samples (left) and after polishing and punching into 3-mm disks (right). 


\subsubsection{MeV proton-irradiation}

All 12 experimental alloys (two L-, six Z-, and four T-alloys) were irradiated by $2 \mathrm{MeV}$ protons at the University of Wisconsin-Madison's 1.7 MV tandem ion beam accelerator (see Table 6). The 3-mm diameter samples were attached to a stainless steel sample holder using water-soluble carbon paste. The incident ion beam, normal to the sample surface, was rastered across a well-defined aperture exposing the samples uniformly to the $\mathrm{H}$ ions (protons). The beam current ranged between 10-13 $\mu \mathrm{A}$ resulting in a proton flux of about $3 \times 10^{13} \mathrm{p} /\left(\mathrm{cm}^{2} \mathrm{~s}\right)$ and dpa rate $3 \mathrm{e}-6 \mathrm{dpa} / \mathrm{s}$. The sample temperature of $420 \pm 20{ }^{\circ} \mathrm{C}$ was maintained through a combination of beam heating and air cooling on the back side of the samples, and recorded on the right and left sides of the sample holder using two type-K thermocouples (see Figure 29). The irradiation chamber pressure was at or below $1 \times 10^{-6}$ Torr before and during the irradiation. The implantation with $2.0 \mathrm{MeV}$ protons corresponding to a projected range $R_{\mathrm{p}}=19 \mu \mathrm{m}$ (see Figure 30) was performed to fluences of $1.1 \times 10^{18}$ and $1.1 \times 10^{19} \mathrm{p} / \mathrm{cm}^{2}$ (see Figure 31), which correspond to damage levels of 0.1 and $1 \mathrm{dpa}$ at the depth of $15 \mu \mathrm{m}$, respectively.

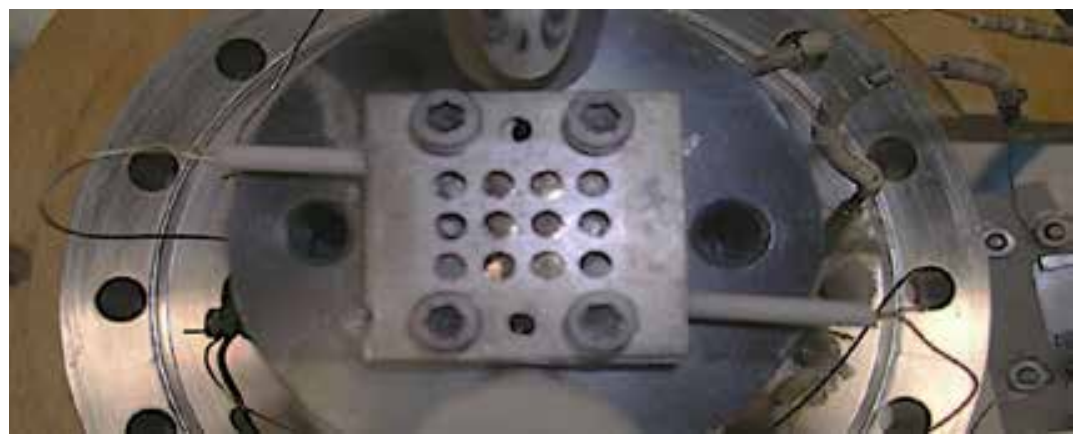

Figure 29. Sample and thermocouple arrangement in the irradiation stage with 6 samples ready for $2 \mathrm{MeV}$ proton irradiation at $420^{\circ} \mathrm{C}$ up to $1 \mathrm{dpa}$.

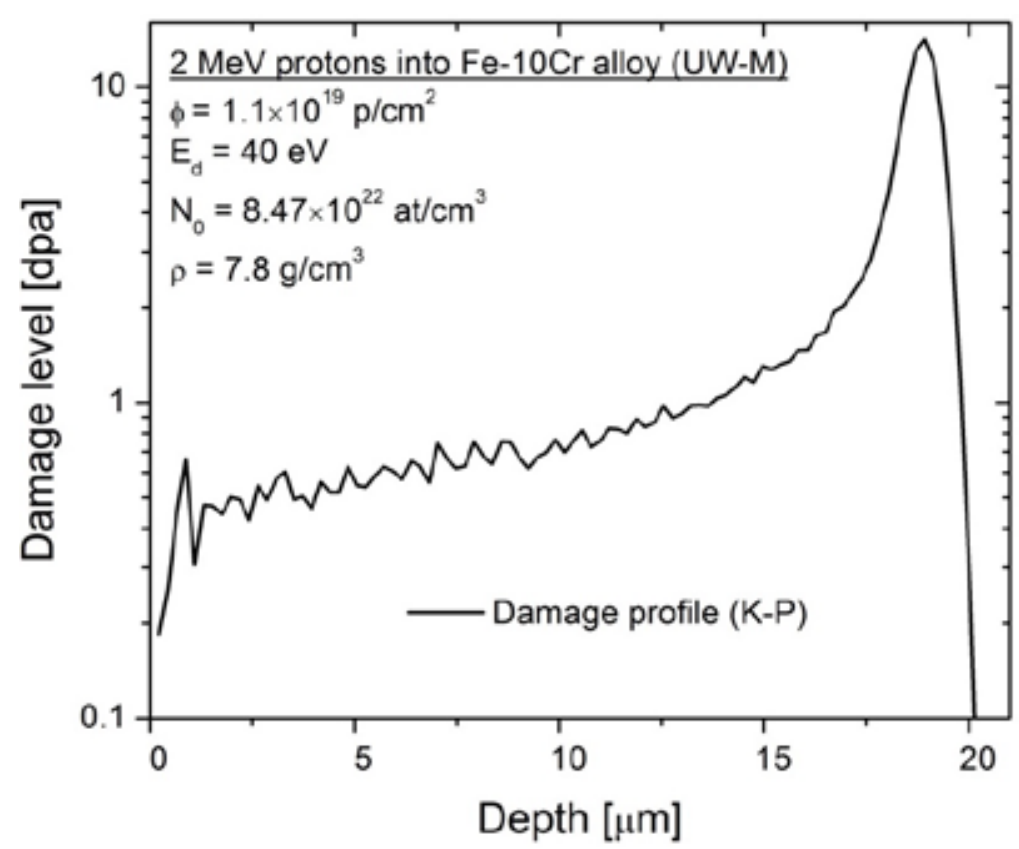

Figure 30. Damage depth profile in Fe-10Cr irradiated with $2 \mathrm{MeV}$ protons to a level of $1 \mathrm{dpa}$ at $15 \mu \mathrm{m}$. Calculation was performed using SRIM-2012.03 assuming the displacement threshold energies to be $40 \mathrm{eV}$ for all elements. 
Table 6. Matrix of samples irradiated by $2 \mathrm{MeV}$ protons at $420^{\circ} \mathrm{C}$. Numbers in columns indicate the number of samples for each condition.

\begin{tabular}{lccc}
\hline \multirow{2}{*}{ Alloy ID } & \multicolumn{4}{c}{$\mathbf{2} \mathbf{~ M e V}$ protons at $\mathbf{4 2 0}^{\circ} \mathbf{C}$} \\
\cline { 2 - 4 } & $0 \mathrm{dpa}$ & $0.1 \mathrm{dpa}$ & $1 \mathrm{dpa}$ \\
\hline LT1 & 1 & 3 & 3 \\
LTZ1 & 1 & 3 & 3 \\
Z3 & 1 & 1 & 1 \\
Z4 & 1 & 1 & 1 \\
Z6 & 1 & 1 & 1 \\
Z7 & 1 & 1 & 1 \\
Z8 & 1 & 1 & 1 \\
Z9 & 1 & 1 & 1 \\
T1b & 1 & 1 & 1 \\
TTZ1NT2 & 1 & 1 & 1 \\
TT1NT2 (T12) & 1 & 1 & 1 \\
TT2NT2 (T22) & 1 & 1 & 1 \\
\hline
\end{tabular}

Note: The additional letters such as $\mathrm{b}$ and NT2 after the alloy IDs denote the samples taken from the bottom section and the alloy subjected to secondary normalization and tempering, respectively.
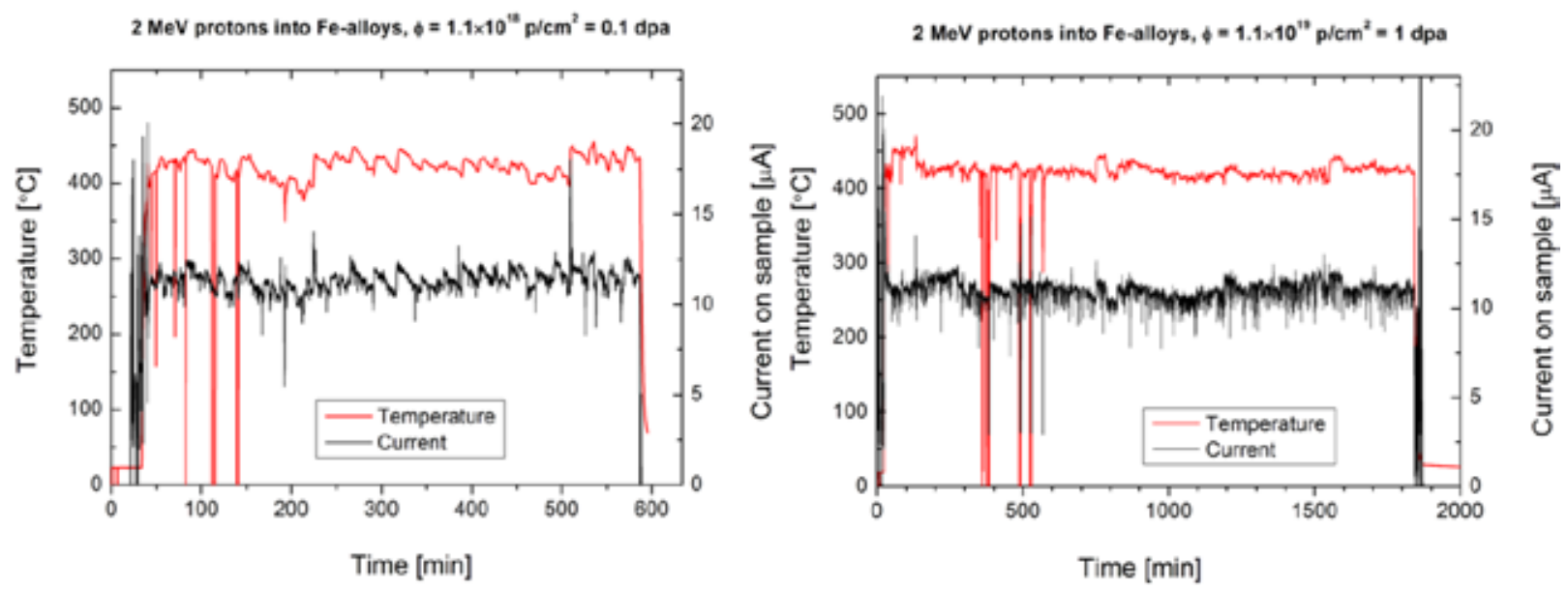

Figure 31. Temperature and current profile for $2 \mathrm{MeV}$ proton-irradiation up to $1.1 \mathrm{e} 18 \mathrm{p} / \mathrm{cm}^{2}(0.1 \mathrm{dpa})$ and $1.1 \mathrm{e} 19 \mathrm{p} / \mathrm{cm}^{2}(1 \mathrm{dpa})$ at $420{ }^{\circ} \mathrm{C}$.

\subsubsection{MeV iron-irradiation}

Iron-irradiation of 8 alloys listed in Table 7 was performed using the $1.7 \mathrm{MV}$ tandem accelerator located at UW-Madison under the following conditions: $4.0 \mathrm{MeV} \mathrm{Fe}^{2+}$ (projected range $\mathrm{Rp}=1.2 \mu \mathrm{m}$, see Figure 32) up to a fluence of $5.0 \times 10^{16} \mathrm{Fe} / \mathrm{cm}^{2}$ which corresponds to $50 \mathrm{dpa}$ at the peak, assuming threshold 
displacement energies of $40 \mathrm{eV}$ for all elements. For damage level calculation, the method proposed by Stoller et al. [23] was employed. The maximum Fe concentration was about 1.3 at.\% with a majority of the Fe interstitials located beyond the depth of $0.8 \mu \mathrm{m}$ (see Figure 32). The average current was about $0.65 \mu \mathrm{A}$ (see Figure 33), and the flux was maintained at a level of $2.34 \times 10^{12} \mathrm{Fe} /\left(\mathrm{cm}^{2} \mathrm{~s}\right.$ ), resulting in a damage rate of $8.3 \mathrm{dpa} / \mathrm{s}$. The beam was rastered ( $64 \mathrm{~Hz}$ horizontally, $517 \mathrm{~Hz}$ vertically) over the entire irradiation area, and its uniformity was controlled by an infrared camera. Sample temperature, controlled by two thermocouples attached diagonally to the sample holder, was attained by external $(95 \%)$ and beam heating with fluctuations of $\pm 10 \mathrm{~K}$. The background pressure during irradiation was maintained at about $10^{-6}$ Torr.

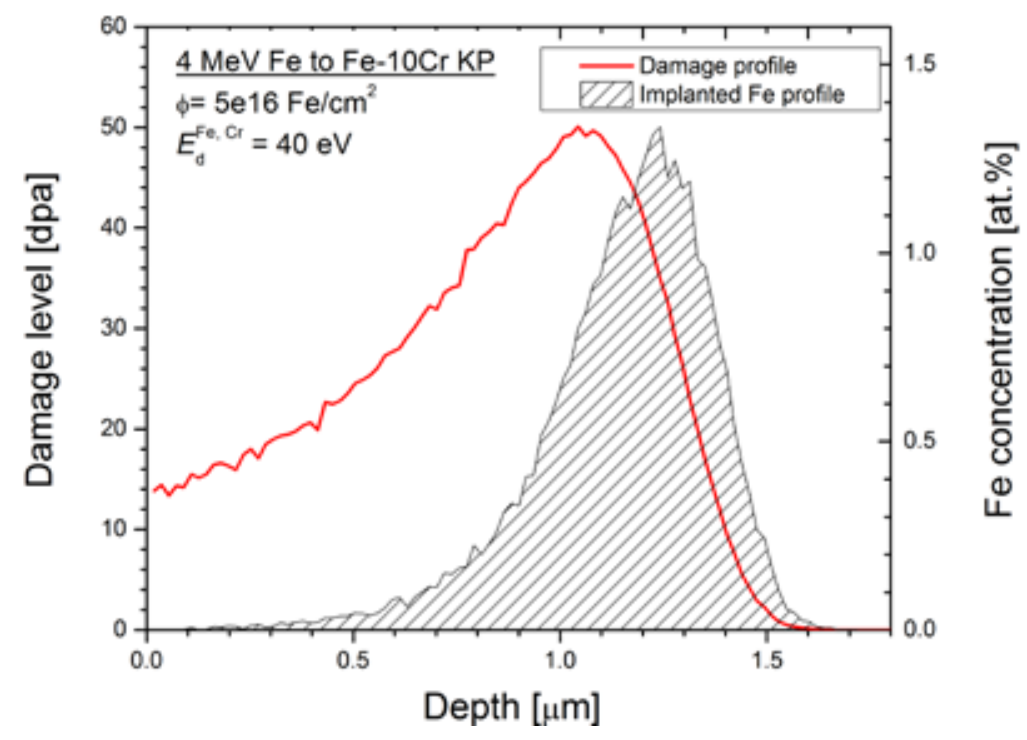

Figure 32. Damage and Fe-implantation profile of $4 \mathrm{MeV} \mathrm{Fe}{ }^{2+}$-irradiated $\mathrm{Fe}-10 \mathrm{Cr}$ alloy up to $5 \mathrm{e} 16 \mathrm{Fe} / \mathrm{cm}^{2}=$ $50 \mathrm{dpa}_{\text {peak }}$. The damage level was calculated using SRIM 2012-03, assuming $E_{d}(\mathrm{Cr}, \mathrm{Fe})=40 \mathrm{eV}$ under the Kinchin-Pease model.

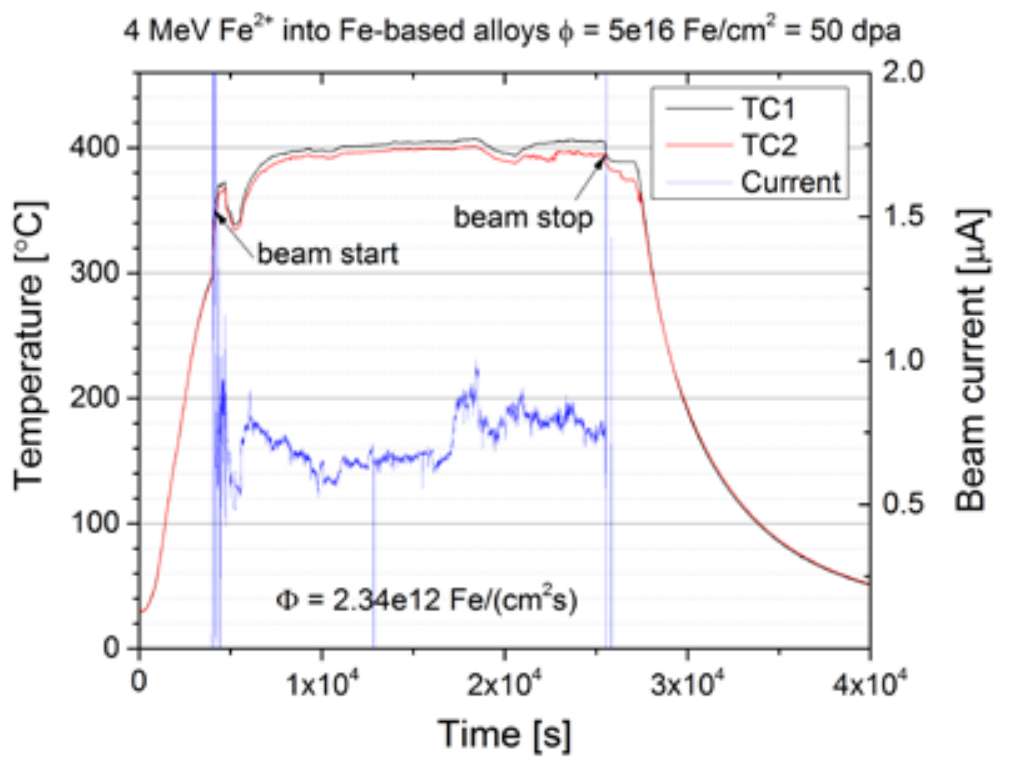

Figure 33. Temperature and current profile for $4 \mathrm{MeV} \mathrm{Fe}$-irradiation up to $5 \mathrm{e} 16 \mathrm{Fe} / \mathrm{cm}^{2}$ at $400^{\circ} \mathrm{C}$. 
Table 7. Samples selected for the $4 \mathrm{MeV}$ Fe-irradiation at $400{ }^{\circ} \mathrm{C}$ up to $50 \mathrm{dpa}$. In most cases, the surface roughness increased by a factor of two after irradiation.

\begin{tabular}{lcc}
\hline & \multicolumn{2}{c}{ Surface roughness [nm] } \\
\hline Sample ID & Before Fe-irradiation & After Fe-irradiation \\
\hline Z3_Fe & $34.8 \pm 4.1$ & $51.6 \pm 4.6$ \\
Z4_Fe & $11.6 \pm 3.4$ & $24.8 \pm 8.5$ \\
Z6_Fe & $30.8 \pm 3.4$ & $36 \pm 8.2$ \\
Z7_Fe & $15.2 \pm 4.2$ & $22.6 \pm 3.8$ \\
Z9_Fe & $26 \pm 5.2$ & $59.2 \pm 26.2$ \\
T12_Fe & $110.6 \pm 6.7$ & $57.8 \pm 9.7$ \\
T1b_Fe & $31.2 \pm 3.9$ & $45 \pm 7.7$ \\
TTZ2m_Fe & $31.6 \pm 4.2$ & $43.8 \pm 5.1$ \\
\hline
\end{tabular}

\subsection{POST-IRRADIATION EXAMINATION}

\subsubsection{X-ray diffraction analysis}

XRD analysis of all alloys was performed on Bruker D8 Discovery, at $50 \mathrm{~kW}$ and $1000 \mu \mathrm{A}$, using $\mathrm{Cu}$ anode with $\lambda=1.54184 \AA, 0.5-\mathrm{mm}$ incident slit and $0.5-\mathrm{mm}$ collimator in combination with the Montel mirror and Soller mount. The 2D Vantec 500 detector was located $200 \mathrm{~mm}$ from the sample. Standard $2 \theta-\theta$ scans were taken at the range between $20^{\circ}-85^{\circ}$ with 3 steps $(300 \mathrm{~s} / \mathrm{step})$ starting at $2 \theta=25^{\circ}$ and increment of $25^{\circ}$. In order to include the maximum number of grains (size of a couple of hundreds of micrometers for L-alloys) in the XRD analysis, the x-y rastering ( $1 \mathrm{~mm}$ by $1 \mathrm{~mm}$, x-speed: $0.1 \mathrm{~mm} / \mathrm{s}, \mathrm{y}-$ speed: $0.2 \mathrm{~mm} / \mathrm{s})$ with simultaneous phi rotation $\left(360^{\circ}\right.$, speed $\left.72^{\circ} / \mathrm{s}\right)$ was performed. The same parameters were used for all samples and 1-3 samples per each condition [0 (reference), 0.1 , and $1 \mathrm{dpa}$ ] for all alloys were measured.

X-ray penetration depth was calculated to determine the thickness of the damage zone being investigated. The mass absorption coefficients for $\mathrm{Fe}$ and $\mathrm{Cr}$ for the $\mathrm{Cu}-\mathrm{K} \alpha$ radiation are 302 and 247 $\mathrm{cm}^{2} / \mathrm{g}$. The $\mathrm{Fe}-15 \mathrm{Cr}$ alloy's density is $7.77 \mathrm{~g} / \mathrm{cm}^{3}$ and the mass absorption coefficient of the alloy is expressed as follows:

$$
\left(\frac{\mu}{\rho}\right)_{F e-15 C r}=0.85 \times 302+0.15 \times 247=294\left(\mathrm{~cm}^{2} / \mathrm{g}\right)
$$

The linear absorption coefficient is then:

$$
\mu_{F e-15 C r}=294 \times 7.77=2284\left(\mathrm{~cm}^{-1}\right)
$$

Therefore, the half value layer is:

$$
x=\frac{0.693}{2284}=3 \mu m
$$

which is much shorter than the implantation depth (about $20 \mu \mathrm{m}$ ). 


\subsubsection{Hardness}

Low load Vicker's microhardness tests involving indentations into the top surface of the samples were performed at $25 \mathrm{gf}$ load with two indents being made per sample. Indent depth varied between $1.9-$ $2.6 \mu \mathrm{m}$ depending on the alloy and dpa level. This approach was only applied to proton irradiated samples because of the extended irradiation damage depth achieved by this irradiation.

Irradiation-induced changes in nano-hardness of Zr-containing FM steel samples were studied by an instrumented nanoindenter, TI 950 by Hysitron, Inc. Alloys were indented by a high-load transducer (OmniProbe) under displacement control. For the proton-irradiated samples, maximum displacements of $2,4,6,8,10$, and $12 \mu \mathrm{m}$ were imposed as triangular functions with constant loading and unloading rates (Figure 34A).

Berkovich tip compatible with the high-load transducer was used in the experiments (Figure 34B). All the nanoindentation measurements were conducted in ambient conditions $\left(22^{\circ} \mathrm{C}, 45 \% \mathrm{RH}\right)$. Ten measurements were made for each indentation depth.
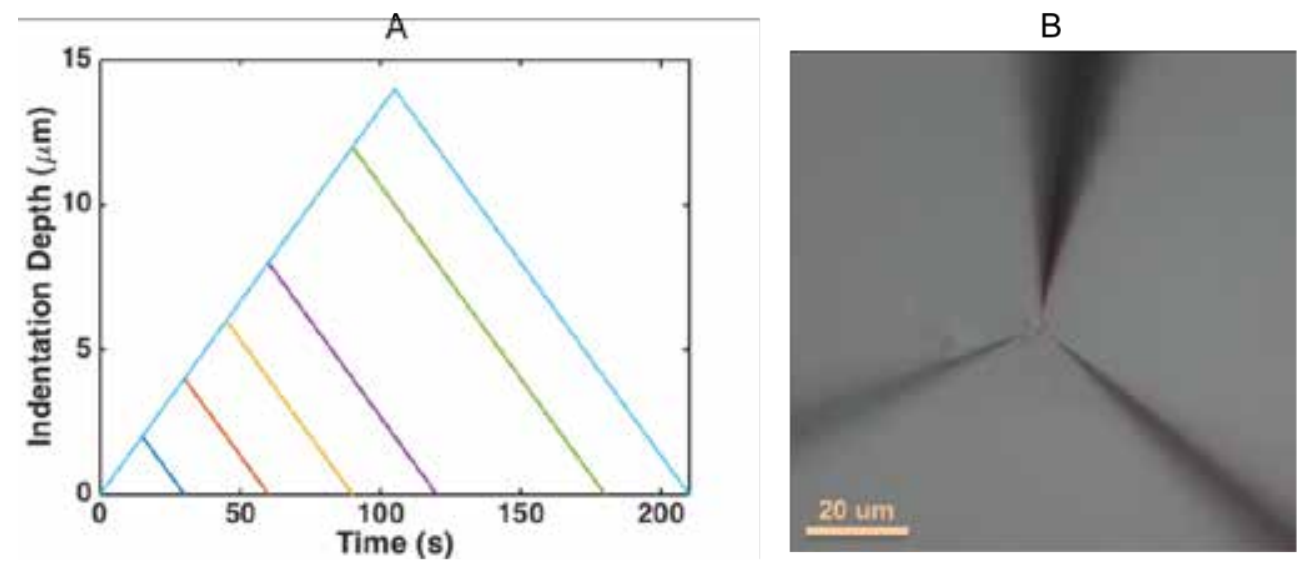

Figure 34. Indentation depths (left, $A$ ) and a photograph of the indenter (right, B) used in this study.

In analyzing the nano-indentation results, Oliver-Pharr method is adopted here [24], where the hardness is calculated as

$$
H=\frac{P_{\max }}{A_{c}}
$$

where $A_{c}$ is the projected contact area and $P_{\max }$ is the maximum load. For Berkovich tip, $A_{c}$ can be linked to the actual indentation depth $h_{c}$ as [25]

$$
A_{c}=24.5 h_{c}^{2}
$$

The actual indentation depth $h_{c}$ can be computed as

$$
h_{c}=h_{m}-\frac{h_{e}}{2}-1.96 R_{q}
$$


where $h_{m}$ is the maximum indentation depth imposed by the transducer, $h_{e}$ is the displacement recovered elastically, and $R_{q}$ is the rms roughness. Elastic recovery component, $h_{e}$ is calculated by subtracting the measured residual depth from the maximum indentation depth. The last term in Eq.(3) subtracts the effect of flattening behavior from the indentation depth measured and thus, provides correction for the roughness related compliance [26].

\subsubsection{TEM analysis}

TEM analyses were conducted on L-alloys, proton-irradiated Z6 and T12 samples as well as Feirradiated Z6 and T12 samples.

\section{L-alloys}

TEM samples from L-alloys were prepared in a Zeiss 1500XB focused ion beam (FIB) system. Platinum coating was deposited to protect the oxide surface before cutting. TEM lamellae were created by coarse trenching to produce samples $20 \mu \mathrm{m} \times 15 \mu \mathrm{m} \times 1 \mu \mathrm{m}$ in dimensions using the FIB technique. The samples were then welded to a copper TEM grid for final thinning and thinned to a final thickness of roughly 100-200 nm using $30 \mathrm{kV}$ gallium ions and further polished using $5 \mathrm{kV}$ gallium ions. The TEM lamellae were finally cleaned with a Fischione's Model 1040 Nanomill with $900 \mathrm{eV}$ Ar ions for 30 min at each side.

\section{Proton-irradiated samples}

FIB was used to prepare samples for a cross-sectional TEM. The original sample surface was firstly covered with Pt-C stripe deposited using electron-beam $(5 \mathrm{kV})$. A thin slice with thickness $<500 \mathrm{~nm}$ was then cut out using $\mathrm{Ga}^{+}$ion beam $(30 \mathrm{kV})$ and lifted out in situ onto a TEM grid. Final polishing until thickness $<200 \mathrm{~nm}$ was performed using $\mathrm{Ga}^{+}$ion beam $(5 \mathrm{kV}, 200 \mathrm{pA})$. A Titan scanning transmission electron microscope (STEM) with CEOS probe aberration corrector operated at $200 \mathrm{kV}$, equipped with a high-angle angular-dark-field (HAADF) detector and EDS system was used for microstructure and composition analysis of the proton-irradiated Z6 and T12 samples. The probe size for EDS line-scan was less than $1 \mathrm{~nm}$ and step size was about $1 \mathrm{~nm}$.

\section{Fe-irradiated samples}

TEM samples were prepared employing conventional FIB lift-out technique. Final cleaning procedure included low voltage $(5 \mathrm{kV}$ followed by $2 \mathrm{kV})$ and low current $(100 \mathrm{pA})$ polishing of the sample at $\mathrm{a} \pm 6^{\circ}$ with respect to the gallium beam. This was done in order to minimize the damage caused by previous steps. TEM and Annular Bright Field Scanning-TEM (ABF-STEM) analysis was performed on the Tecnai TF30, while high resolution (HR)-STEM and STEM-EDS analysis was performed on the Titan. A high angle annular dark field (HAADF) detector was employed for observation on the Titan. A small camera length was used for high resolution imaging, while for radiation induced segregation (RIS) analysis, images were acquired at bigger camera length, because bigger camera lengths shows a stronger diffraction contrast (therefore grain boundaries are more easily visible). Images acquired in this mode are usually referred to as annular dark field (ADF)-STEM images. For the acquisition of EDS spectra, a bigger probe size, as compared to the high resolution imaging was used, in order to improve the EDS signal on the detector. Line scans were performed by collecting point EDS spectra for each single nanometer, across the grain boundaries.

Imaging of dislocation loops in transmission electron microscope (TEM) were mostly performed using the $\boldsymbol{g} \cdot \boldsymbol{b}$ invisibility criteria. However, because STEM significantly reduces the elastic contrast in the background by smearing out thickness-dependent contrast, it can be performed on thicker samples, and because of the fact that the traditional invisibility criterion $\boldsymbol{g} \cdot \boldsymbol{b}$ can remain applicable [27], 
dislocation imaging via STEM is a viable option [28]. In this study therefore, ABF-STEM imaging of the grains of both the un-irradiated and irradiated samples, on the [100], [110] and [111] poles were performed. The individual dislocation loop types were identified by comparing their morphologies with those predicted by Yao et al. [29]. Dislocation loop size was determined by manual counting and sizing with the software imageJ, and their densities were calculated by determining the sample thickness with the log-log ratio technique.

\subsection{RESULTS}

\subsubsection{L-alloys}

All L-alloys underwent discoloration (see Figure 35) after proton-implantation. TEM analysis appeared to indicate the formation of a $1 \mu \mathrm{m}$ thick titanium oxide layer on the surface (see Figure 39, Figure 40).
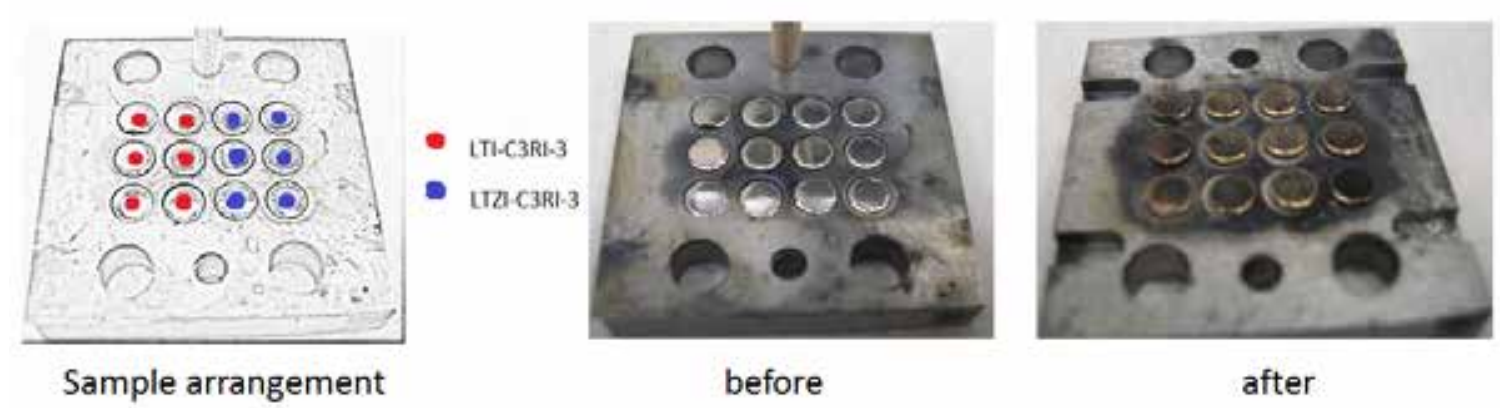

Figure 35. L-alloy sample arrangement and appearance before and after $2 \mathrm{MeV}$ proton irradiation at $420^{\circ} \mathrm{C}$ up to $0.1 \mathrm{dpa}$. Discoloration of the samples was observed after irradiation.

XRD data for LTZ1 alloy shown in Figure 36 indicate the evolution of certain new phases as a result of irradiation, particularly at 1 dpa damage levels. Those were speculated to be Ti-rich phases and their stoichiometry was confirmed TEM (see Figure 39 and Figure 40). To more accurately confirm these phases as well as their morphology and spatial distribution, TEM samples were prepared using focused ion bean technique to minimize any aberrations due to the magnetic nature of the samples.

The as-received LTZ1 steel was denuded of precipitates at grain boundary (GB) and a high density of dislocations was found in the samples (Figure 37). After irradiation at a damage level of $0.1 \mathrm{dpa}$, the Ti, $\mathrm{W}$ rich phases were found at GBs (Figure 38). As the damage level reached $1 \mathrm{dpa}$, a film of Ti-rich phase (likely titanium-dioxide) formed on the the sample surface (Figure 39 and Figure 40). A similar layer was also observed to form on the LT1 sample.

Irradiation hardening was clearly observed in all alloys (see Figure 41) however, L-alloys performed worst with $120 \%$ of increase in hardness at $1 \mathrm{dpa}$ compared to $0 \mathrm{dpa}$, which is probably due to the buildup of the Ti- dioxide layer on its surface. 


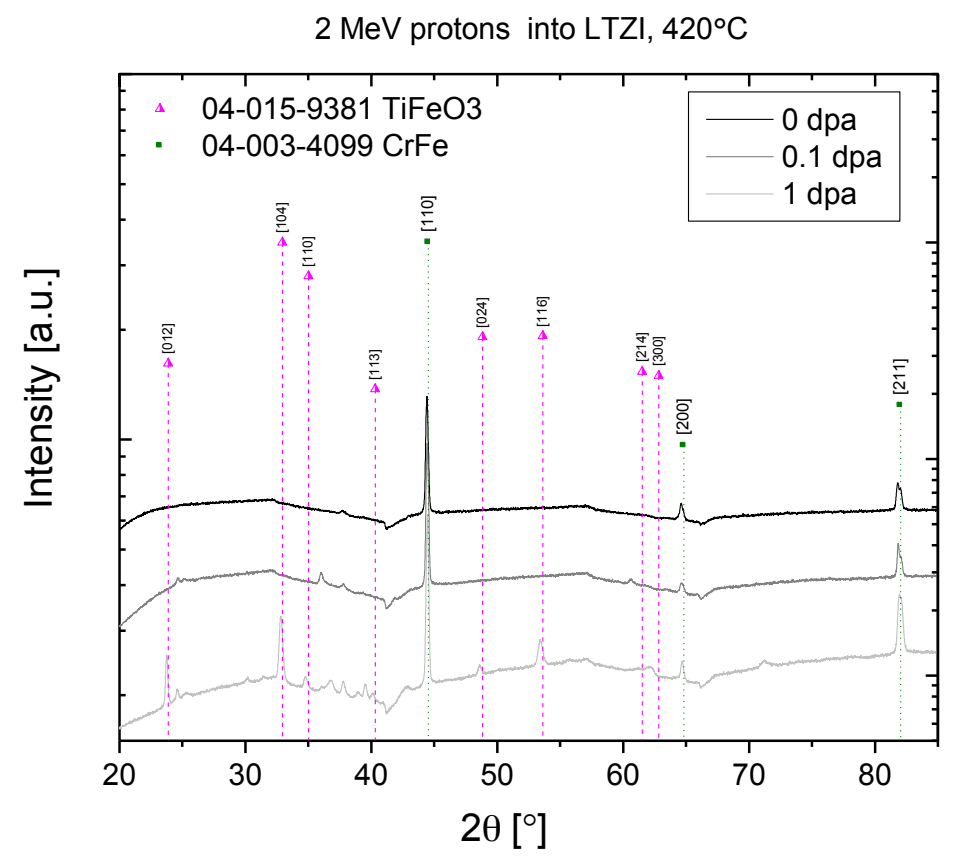

Figure 36. XRD patterns of LTZ1 alloy at various proton damage levels. The possible Ti-rich peaks are marked in magenta.

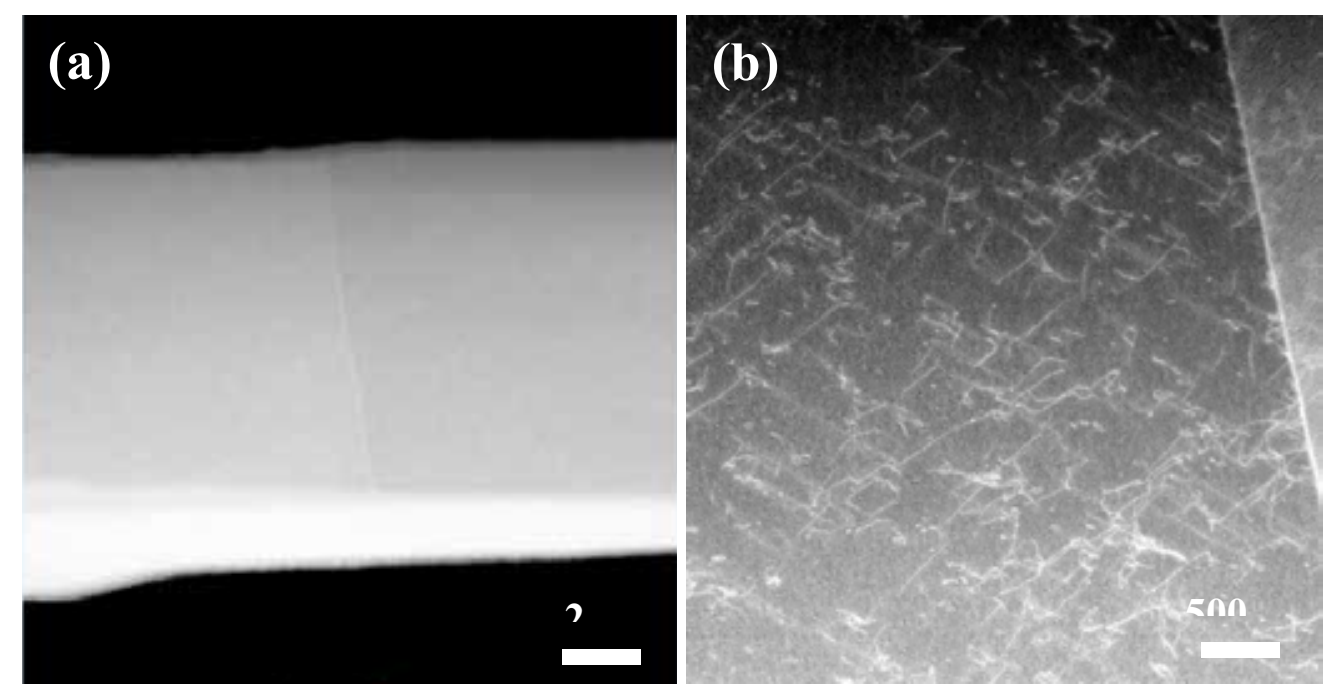

Figure 37. STEM image of LTZ1 alloy before proton irradiation at (a) low and (b) high magnifications. 


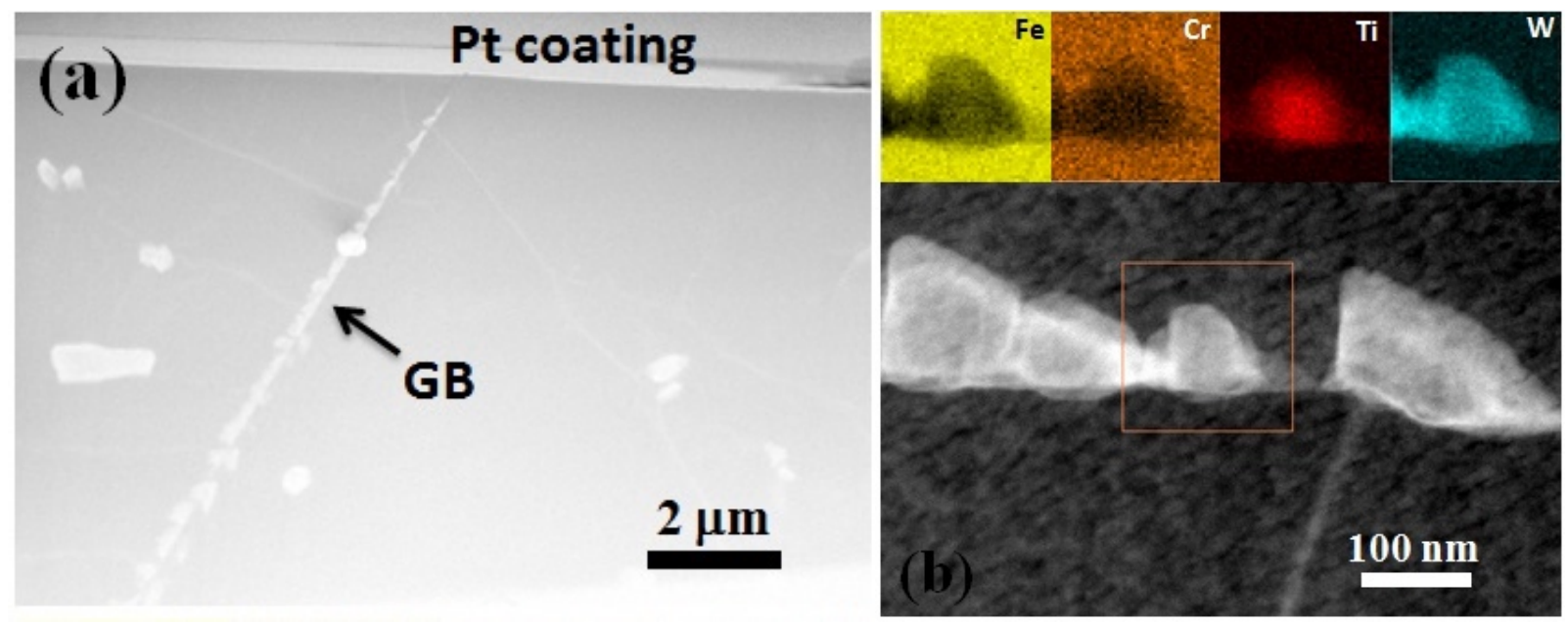

Figure 38. (a) STEM image and (b) EDS mapping of LTZ1 alloy irradiated with protons up to 0.1 dpa.

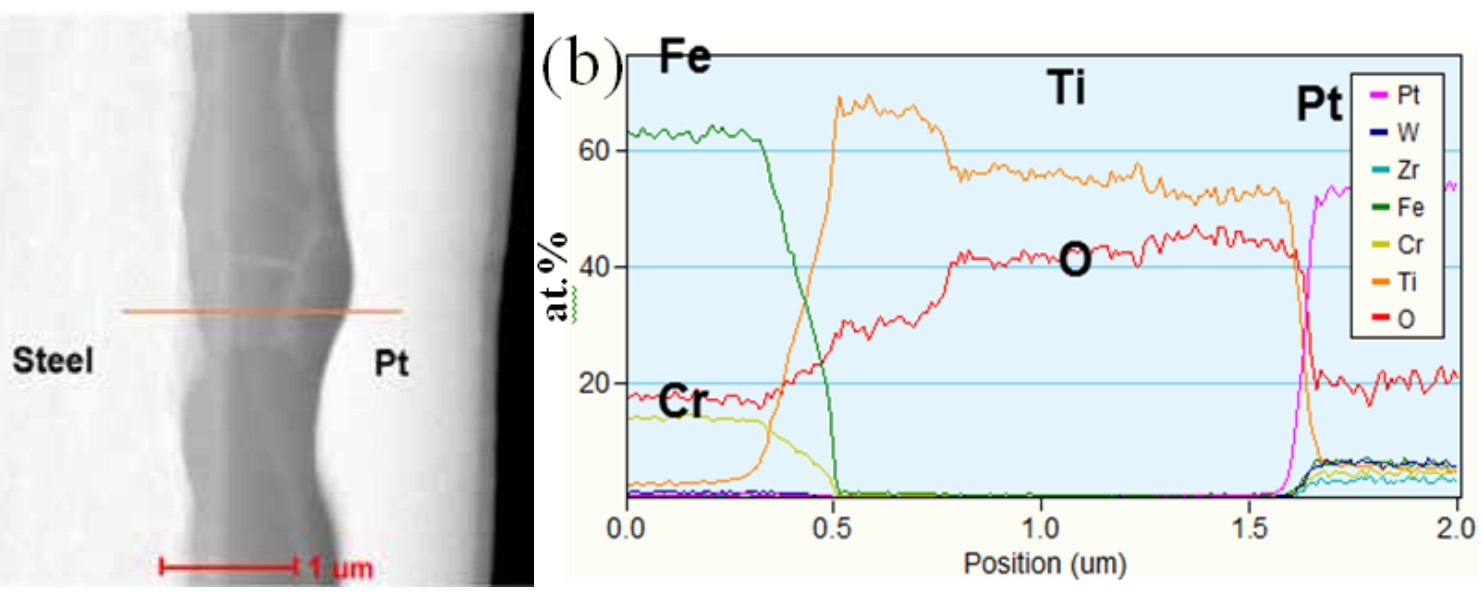

Figure 39. (a) STEM image and (b) EDS line scan of LTZ1 alloy irradiated with protons up to $1 \mathrm{dpa}$.

(a)
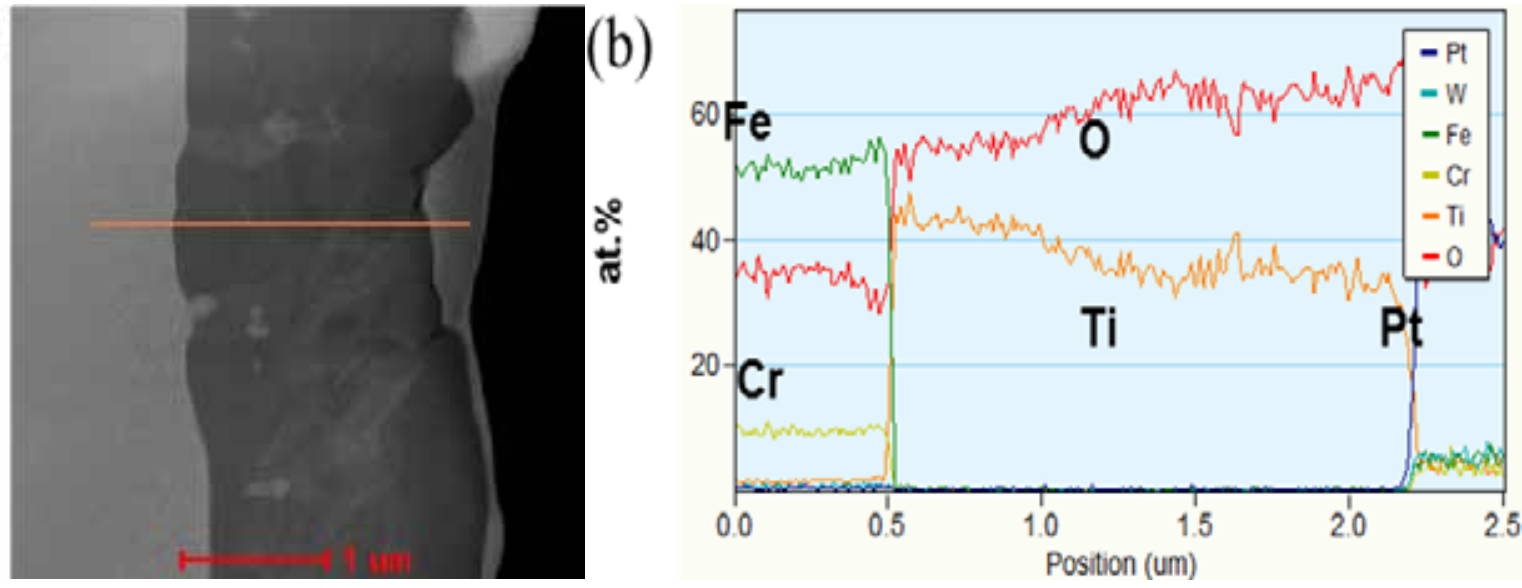

Figure 40. (a) STEM image and (b) EDS line scan of LT1 sample irradiated with protons up to 1 dpa. 


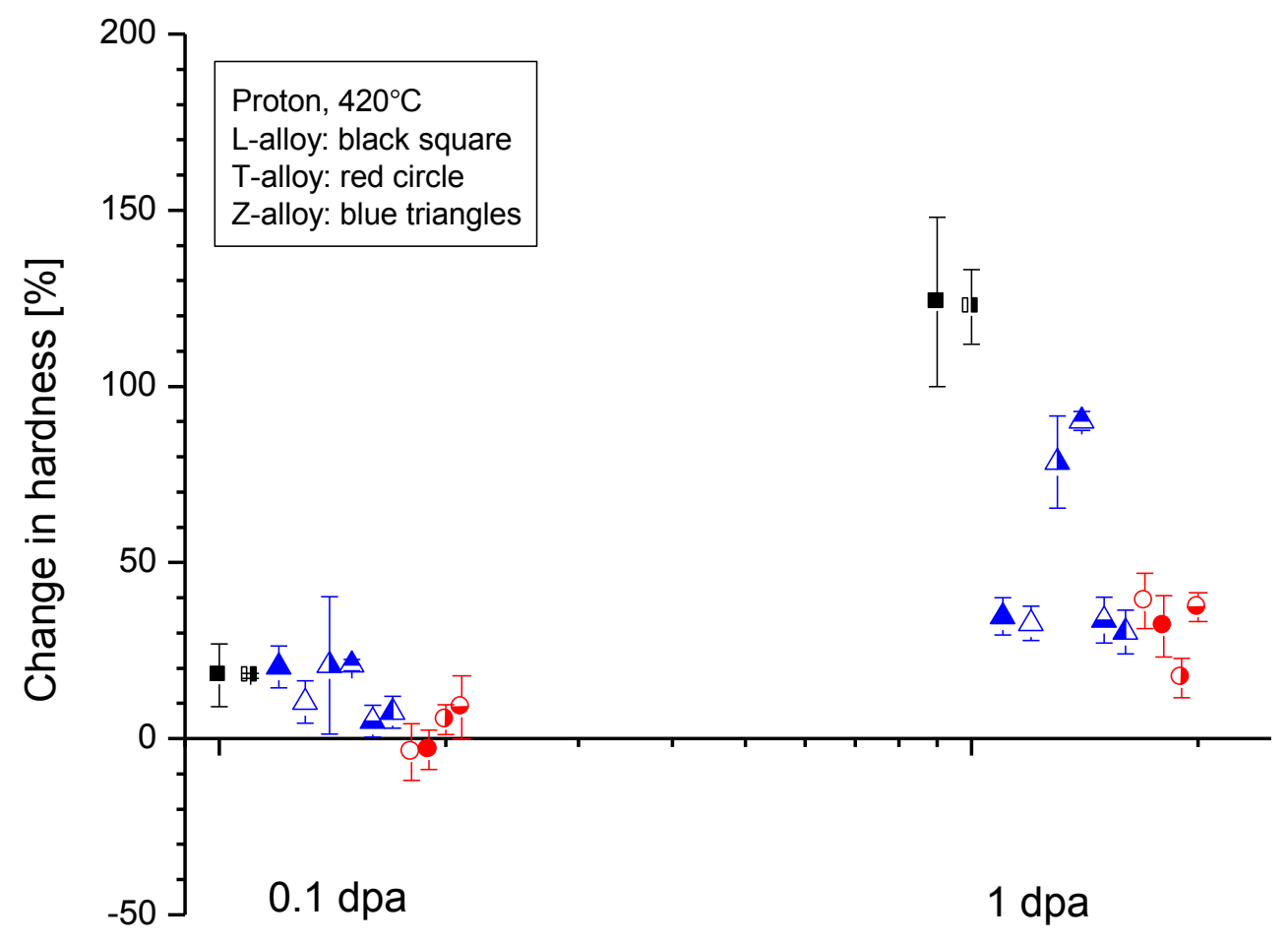

Figure 41. Change of Vickers microhardness ( $25 \mathrm{gf})$ as compared to the non-implanted ( 0 dpa) counterparts for advanced alloys as a function of proton-irradiation damage level.

\subsection{2 $Z$ - and $T$-alloys after proton-irradiation}

No post-irradiation discoloration was observed on the surface of the proton-irradiated $\mathrm{T}$ - and Zalloys. All T-alloys seem to be resistant to precipitate formation/phase changes due to proton-irradiation (see Figure 42, Figure 43). Almost no change in XRD spectra is observed between various damage levels which also results in the best micro-hardness performance (see Figure 41 ): only up to $10 \%$ of hardness increase at $0.1 \mathrm{dpa}$ and less than $40 \%$ at $1 \mathrm{dpa}$. No $\mathrm{Ti}_{\mathrm{x}} \mathrm{O}_{\mathrm{y}}$ layer build-up was observed in these alloys despite the fact they had Ti content similar to L-alloys.

Z-alloys underwent some phase change during proton-irradiation at various damage levels (see Figure 44) however not as drastic as L-alloys. $\mathrm{Fe}_{2} \mathrm{Zr}$ hexagonal phase could be clearly identified, especially in the samples with a higher $\mathrm{Zr}$ content (see Figure 45). In almost all Z-alloys and some Talloys a new peak at $2 \theta \sim 26^{\circ}$ appeared after proton-irradiation however it was not possible to identify its origin. In terms of micro-hardness, Z-alloys appear to harden a bit more than T-alloys, however this trend has to be confirmed for Fe-irradiated samples which experienced very high dpa levels. 


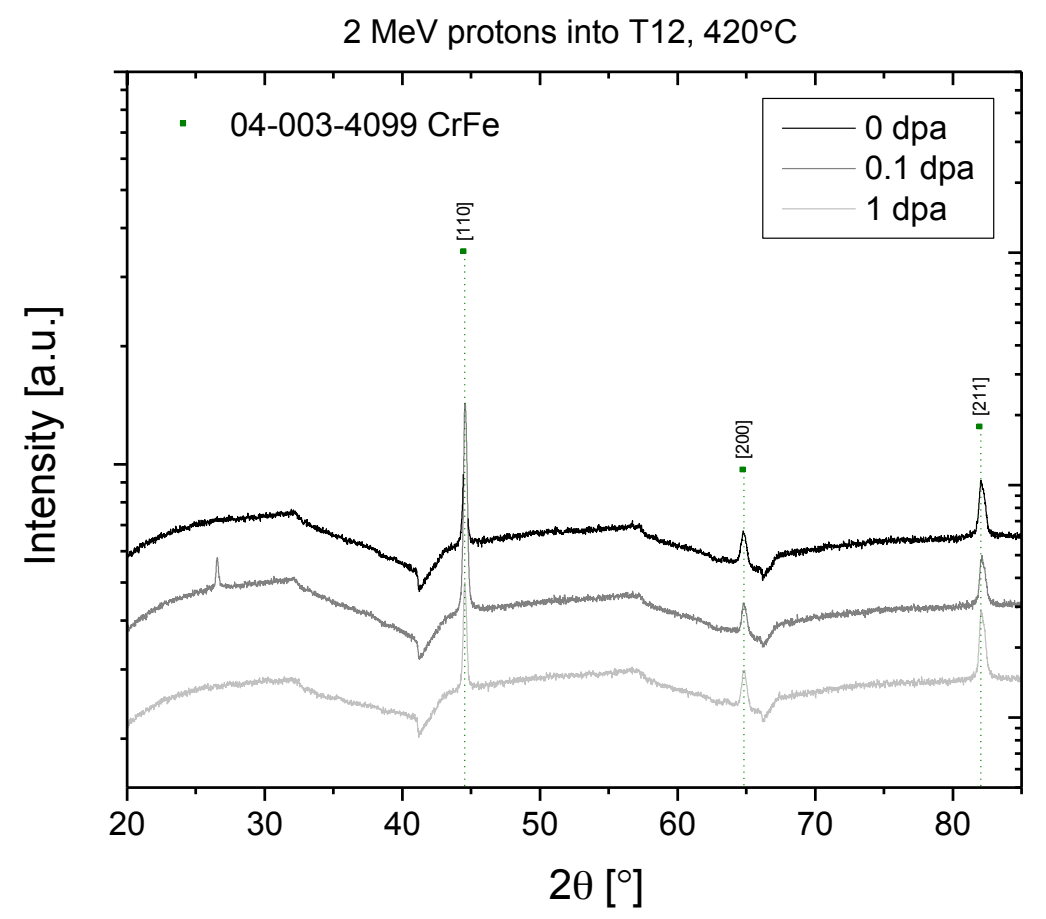

Figure 42. XRD patterns for T12 alloy at various proton damage levels.

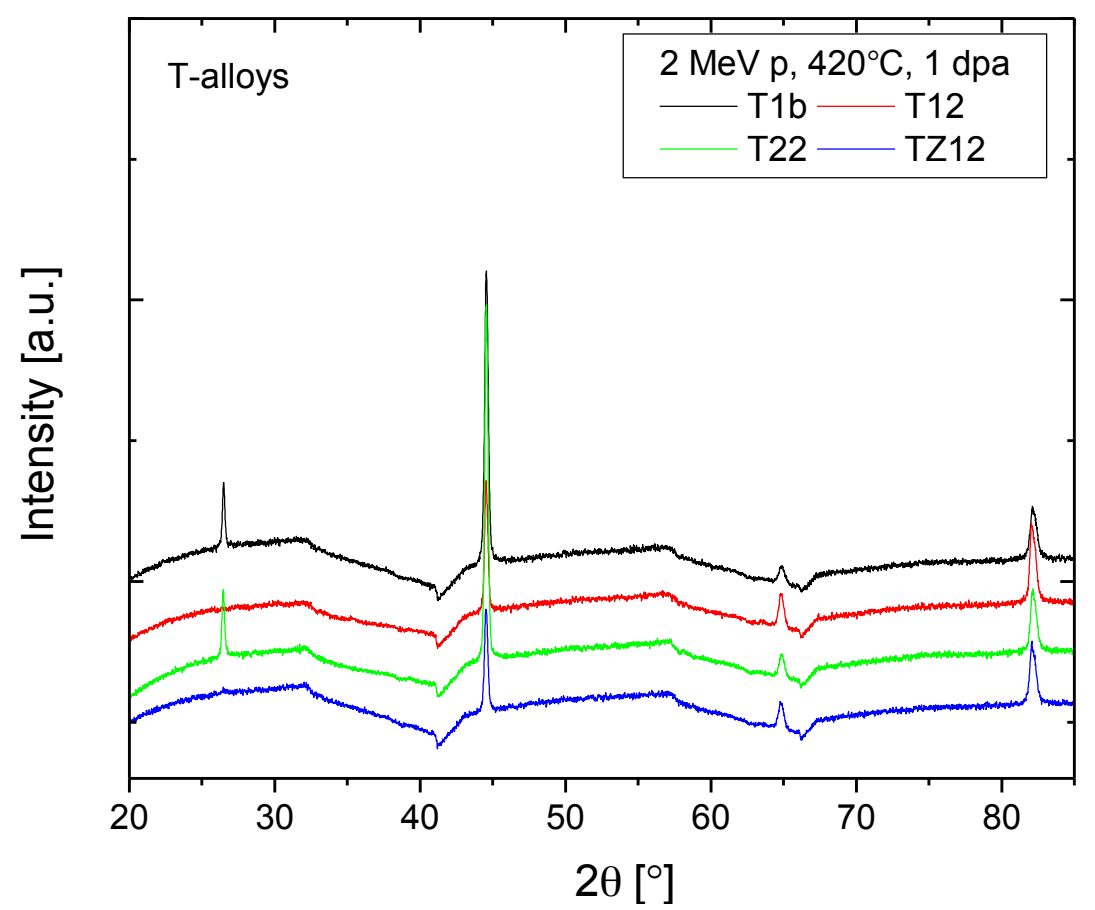

Figure 43. XRD patterns of $\mathrm{T}$-alloys irradiated with $2 \mathrm{MeV}$ protons at $420^{\circ} \mathrm{C}$ up to 1 dpa. Main peaks at $2 \theta \sim$ $45^{\circ}, 6^{\circ}$, and $82^{\circ}$ correspond to diffraction from $\mathrm{CrFe}(\mathrm{PDF04-033-4099).}$ 


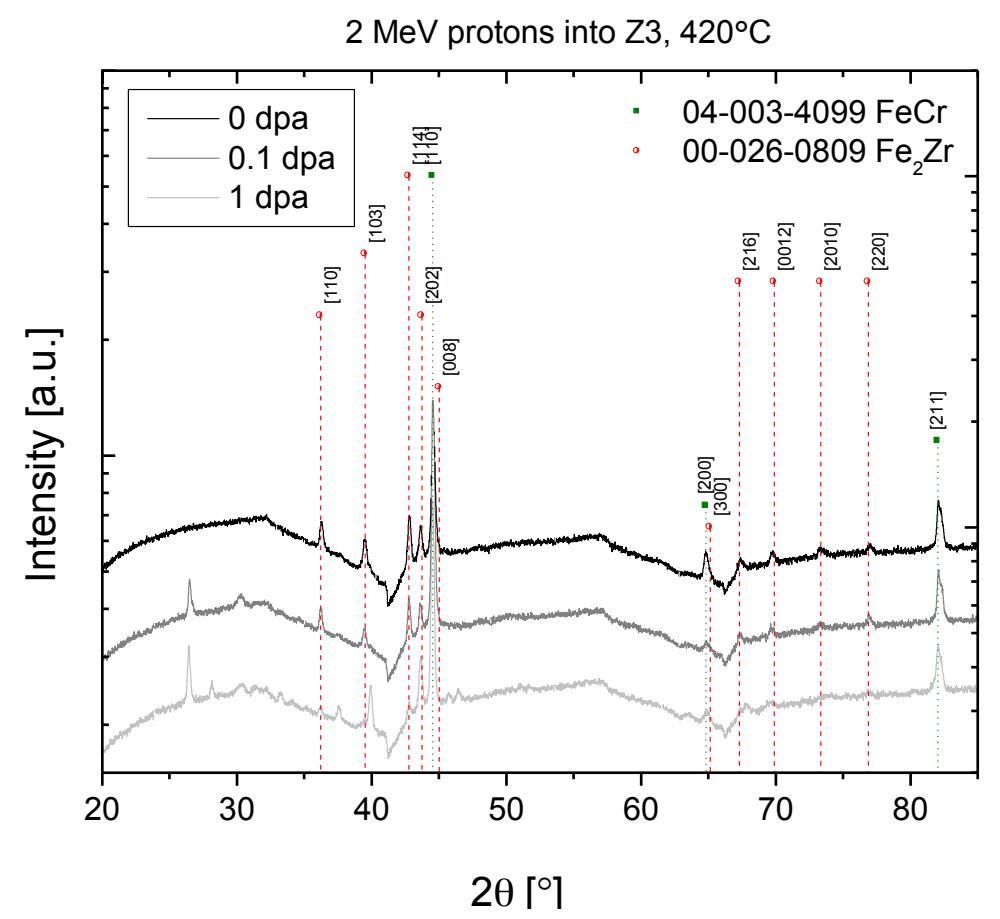

Figure 44. XRD patterns of $\mathrm{Z3}$ alloy at various proton damage levels. The possible $\mathrm{Zr}$-rich peaks are marked in red.

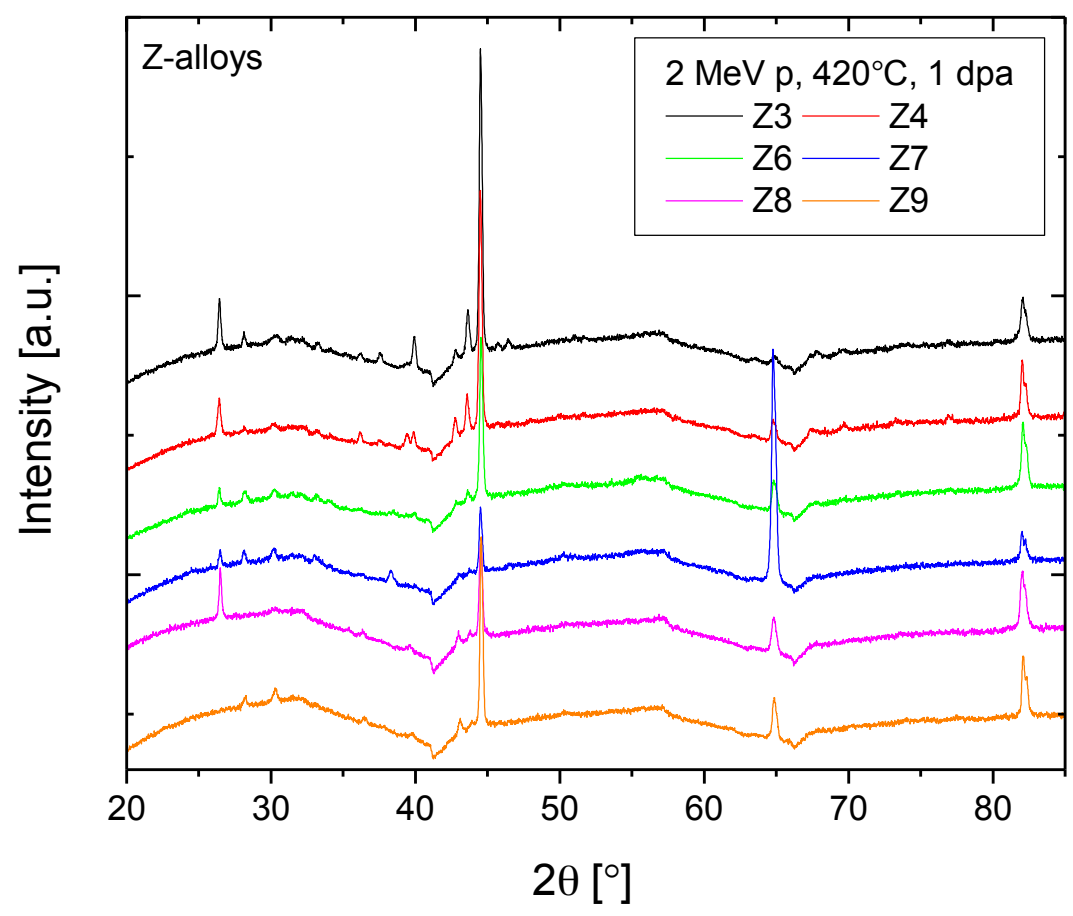

Figure 45. XRD patterns of $\mathrm{Z}$-alloys irradiated with $2 \mathrm{MeV}$ protons at $420^{\circ} \mathrm{C}$ up to 1 dpa. Main peaks at $2 \theta \sim$ $45^{\circ}, 6^{\circ}$, and $82^{\circ}$ correspond to diffraction from $\mathrm{CrFe}$ (PDF04-033-4099).

Nano-hardness of five proton-irradiated $(\mathrm{Z7}, \mathrm{Z8}, \mathrm{Z9}, \mathrm{T} 12, \mathrm{~T} 22)$ and their un-irradiated counterparts was measured (see Table 8 ). 
Table 8. Samples selected for the nano-hardness measurements based on XRD and TEM observations.

\begin{tabular}{lcc}
\hline Sample ID & $\begin{array}{c}0 \text { dpa } \\
\text { (reference) }\end{array}$ & $\begin{array}{c}1 \mathrm{dpa} \\
\text { (protons, } 420^{\circ} \mathrm{C} \text { ) }\end{array}$ \\
\hline Z7_p1420 & & $\times$ \\
Z8_p1420 & & $\times$ \\
Z9_p1420 & $\times$ \\
T12_p1420 & & $\times$ \\
T22_p1420 & & $\times$ \\
Z7 & $\times$ & \\
Z8 & $\times$ & \\
Z9 & $\times$ & \\
T12 & $\times$ & \\
T22 & $\times$ & \\
\hline
\end{tabular}

The proton irradiated samples showed considerable roughness due to sputtering, nevertheless nanohardness values for unirradiated and irradiated samples were similar with the exception of steel T22 where the irradiated samples exhibited a lower hardness. We view this as an anomalous result. Irradiation-induced changes in microstructure, defect density, and roughness is well documented [30]. Optical microscope images in Figure 46 suggest significant increase in roughness for the irradiated sample. In-situ scanning probe microscopy (SPM) provided in the TI 950 testing suite was used to quantify roughness changes due to irradiation. Figure 47 shows the surface heights obtained by the SPM. After eliminating surface slopes with spatial wavelengths larger than indentation lengths $(>100 \mu \mathrm{m})$, rootmean-square ( $\mathrm{rms}$ ) roughness, $R_{\mathrm{q}}$, values for the un-irradiated and irradiated samples range as 40-50 and 40-300 $\mathrm{nm}$ (see Table 9), respectively. While Table 9 details the rms values close to where the indentation was performed, other areas of the samples can range from 100-300 nm typically, and in some extreme cases up to $1 \mu \mathrm{m}$ in variance.

Contact depths larger than approximately ten times the rms roughness are known to eliminate roughness effects [31]. Therefore, tests on the un-irradiated sample are not expected to contain roughness effects. In contrast, irradiated sample exhibits more compliant response due to roughness, and hardness estimates will be influenced directly, especially at 2 and $4 \mu \mathrm{m}$ indentation depths. Following analysis will consider roughness effect in hardness estimations.

Example raw indentation load and depth responses are presented in Figure 48. Several noticeable responses were noted for all samples at the $2 \mu \mathrm{m}$ indentation depth, which was due to roughness caused by the irradiation. Observations both with optical microscopy and the in-situ scanning probe microscopy (SPM) feature in the TI 950 testing suite reveal a significant change in the surface roughness of irradiated samples. 


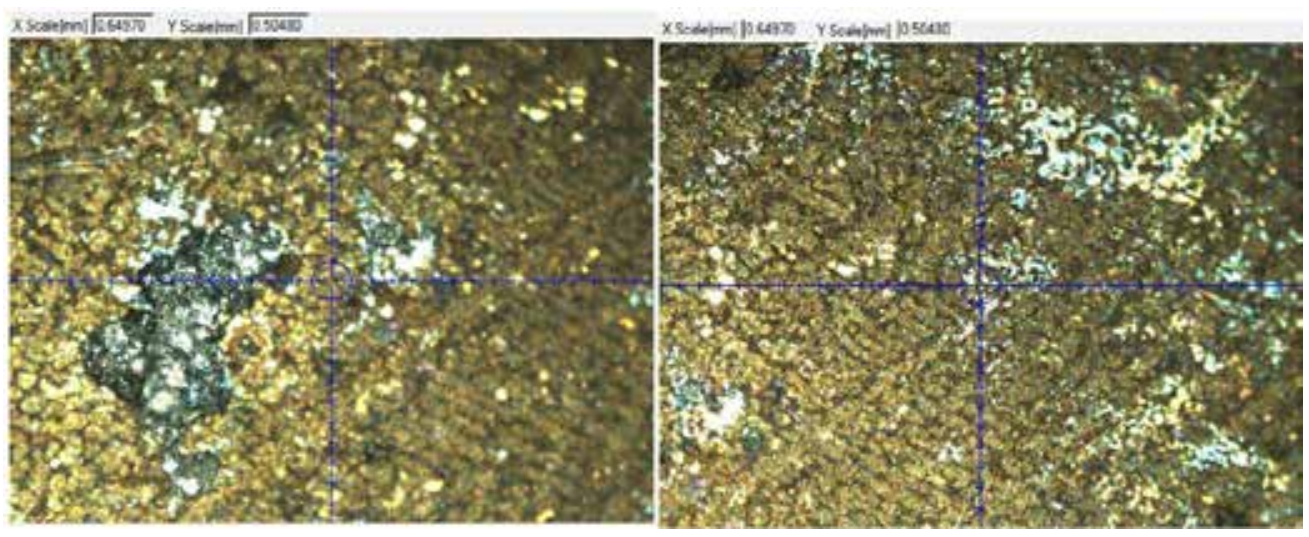

Figure 46. Surface images of proton-irradiated Z8 ferritic steel.

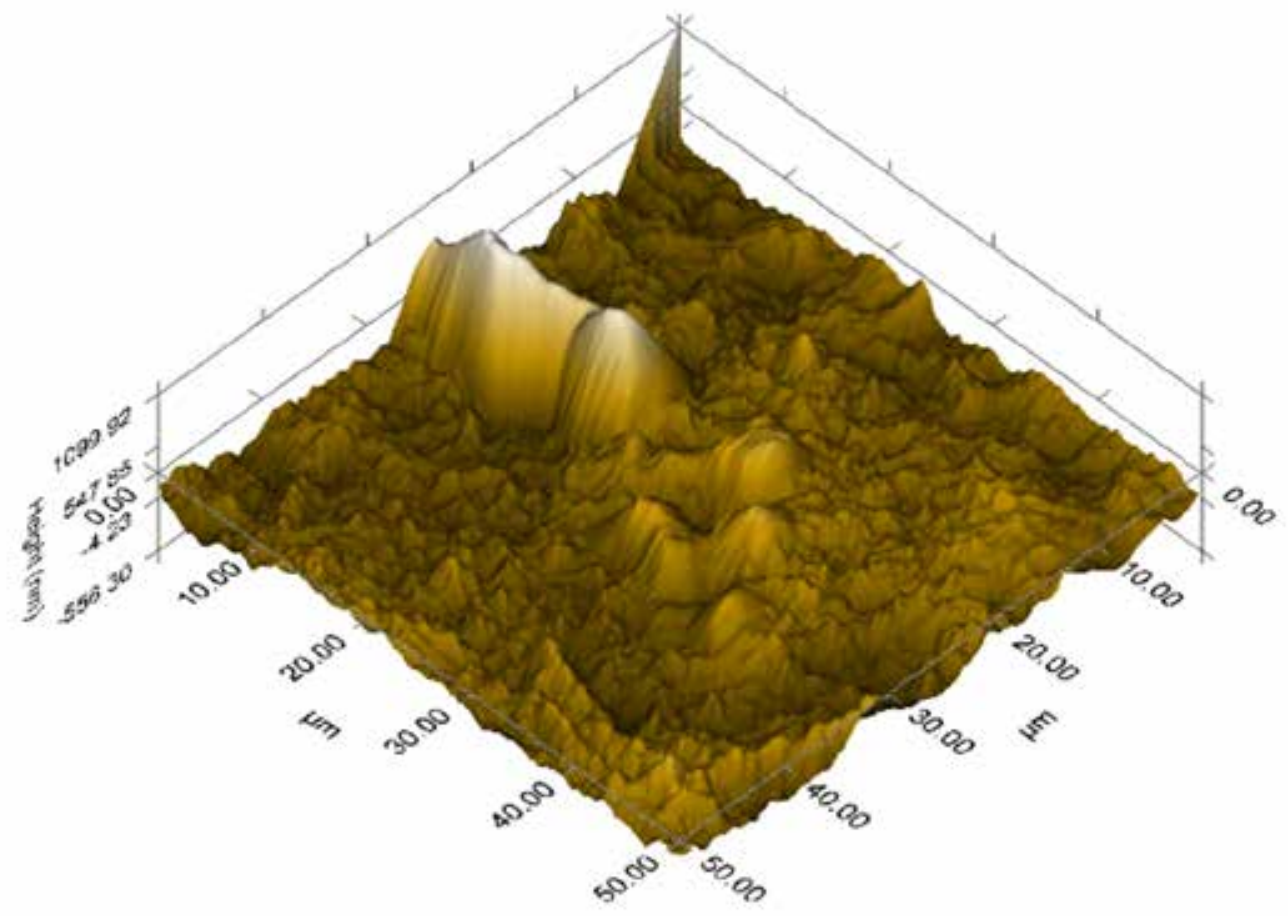

Figure 47. Surface heights of the proton-irradiated T22 sample obtained by the in-situ SPM imaging.

Table 9. Root-Mean-Squared (RMS) roughness values for proton-irradiated steel samples.

\begin{tabular}{cc}
\hline Sample Name & RMS Roughness [nm] \\
\hline Z7 & 104.11 \\
Z8 & 308.27 \\
Z9 & 138.02 \\
T22 & 174.28 \\
T12 & 42.84 \\
\hline
\end{tabular}




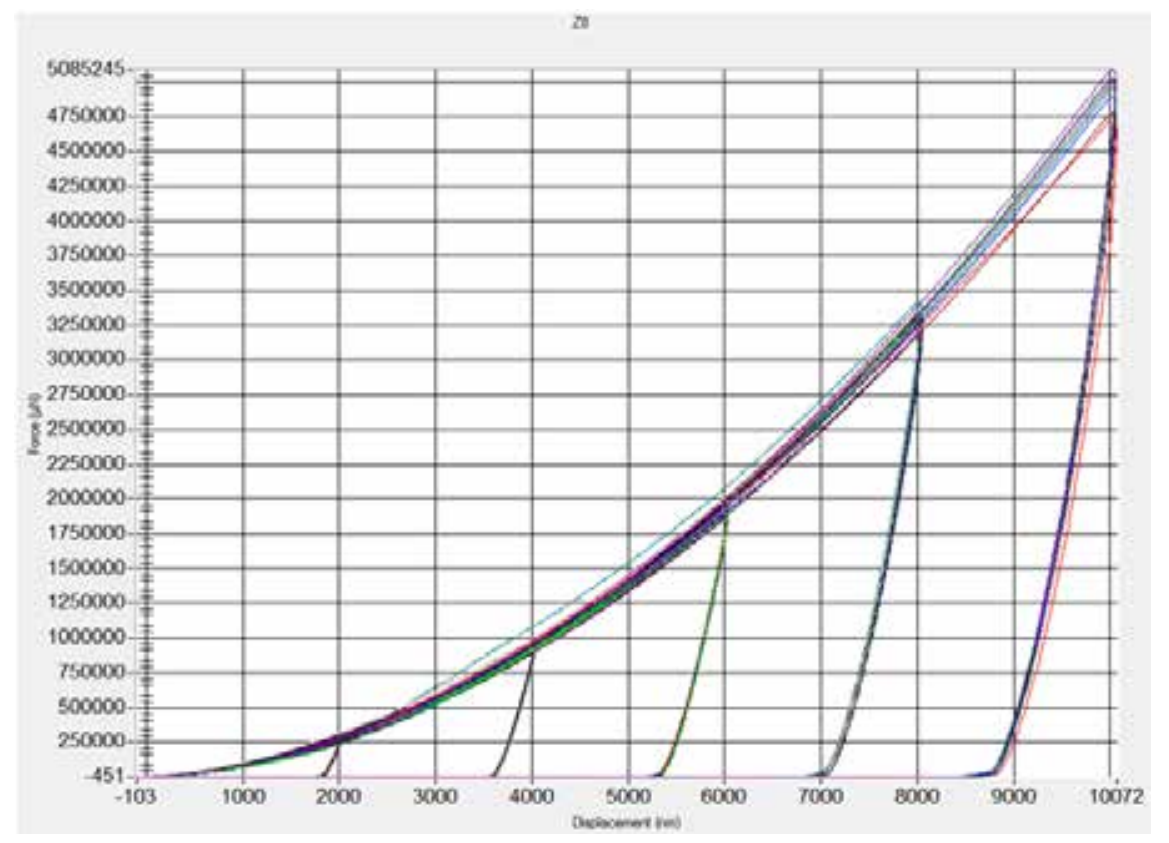

Figure 48. Raw indentation and depth responses for un-irradiated Z8 steel (shown here as an example).
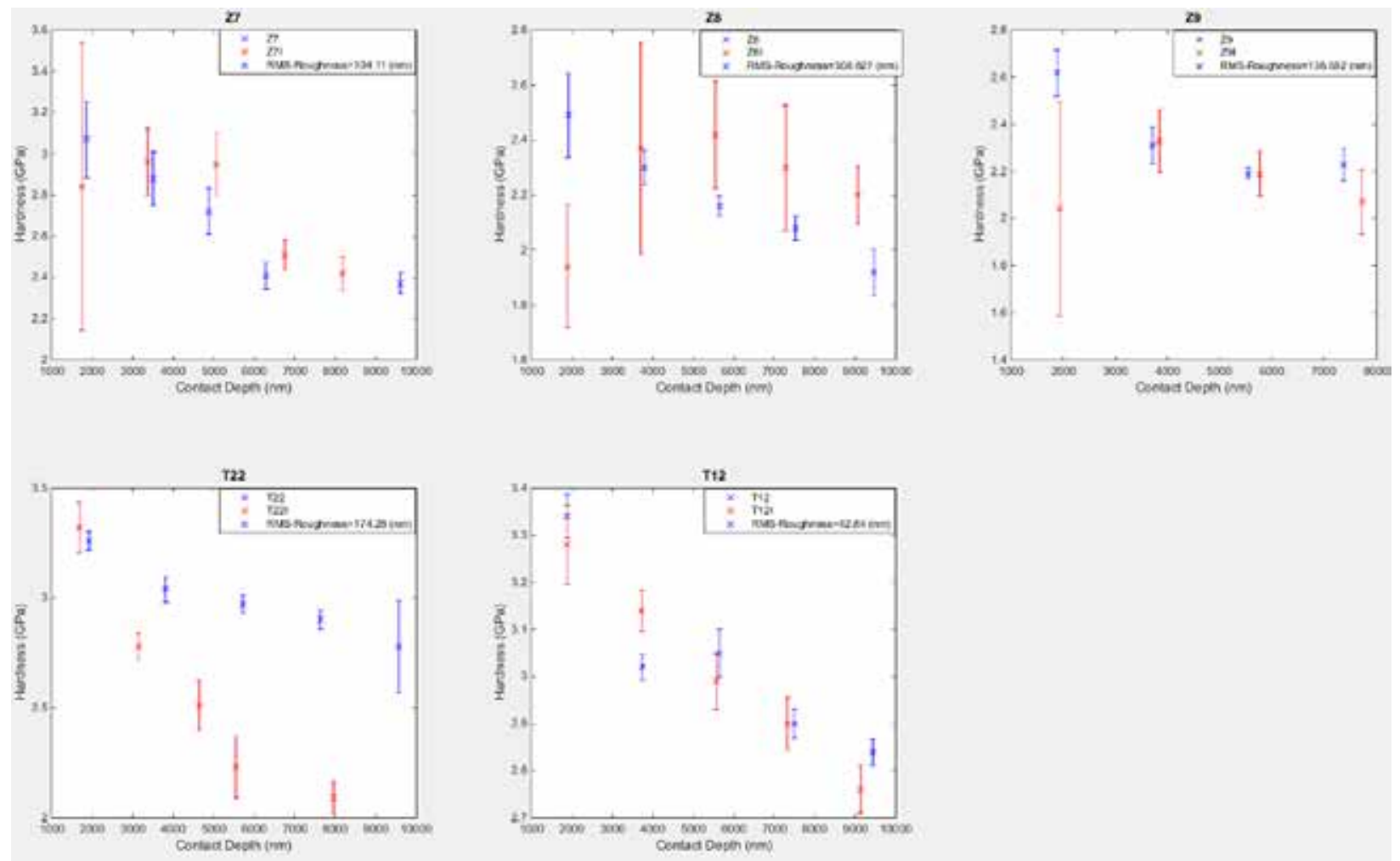

Figure 49. Projection for hardness vs. contact depth for proton-irradiated steel samples (red) as compared to un-irradiated base material (blue). 
As seen in Figure 46 several different parts of the same irradiated sample reveal several different surface morphologies. Indentation was restricted to areas that showed a mostly consistent surface. Figure 49 shows the hardness vs. indentation depth for of all the irradiated samples as compared to the unirradiated counterparts.

The hardness values for nearly all irradiated samples had a significant increase in standard deviation at the $2 \mu \mathrm{m}$ mark. These increases can be attributed to the roughness values of the sample. Some correction for this roughness can be applied using the advanced non-linear Oliver-Pharr method [24]. T22 irradiated steels also oddly showed a weakening in the steel that may be attributed to the large amount of variance in the surface roughness of the sample caused by large voids. These voids could attribute to the softening of the sample.

\subsubsection{TEM analysis of proton-irradiated samples}

\section{Microstructure of un-irradiated Z6 Alloy}

Figure 50(a) and Figure 50(b) are SEM images that show representative surface morphology of unirradiated Z6 alloy. This alloy has a dual-phase microstructure. The "brighter" phase is homogeneously dispersed in the "darker" phase with a length scale over $50 \mu \mathrm{m}$, consisting of eutectic structure; while single-phase ("darker") regions are occasionally observed, being the primary phase of the alloy. Some black spots are noticed in Figure 50(b) and are suggested to be carbon according to EDS, but these features are trivial to the microstructure and are not observed in cross-sectional TEM specimens. Figure 50(c) shows EDS spectrum measured over full area of Figure 50(a), and the inset shows quantification of the global composition of this alloy. Figure 50(d) further compares two EDS spectra obtained respectively from the "brighter" and "darker" phases in Figure 50(b). It is clearly shown that the "brighter" phase is rich of $\mathrm{Zr}$ and $\mathrm{W}$, while the "darker" phase has a higher content of $\mathrm{Cr}$.
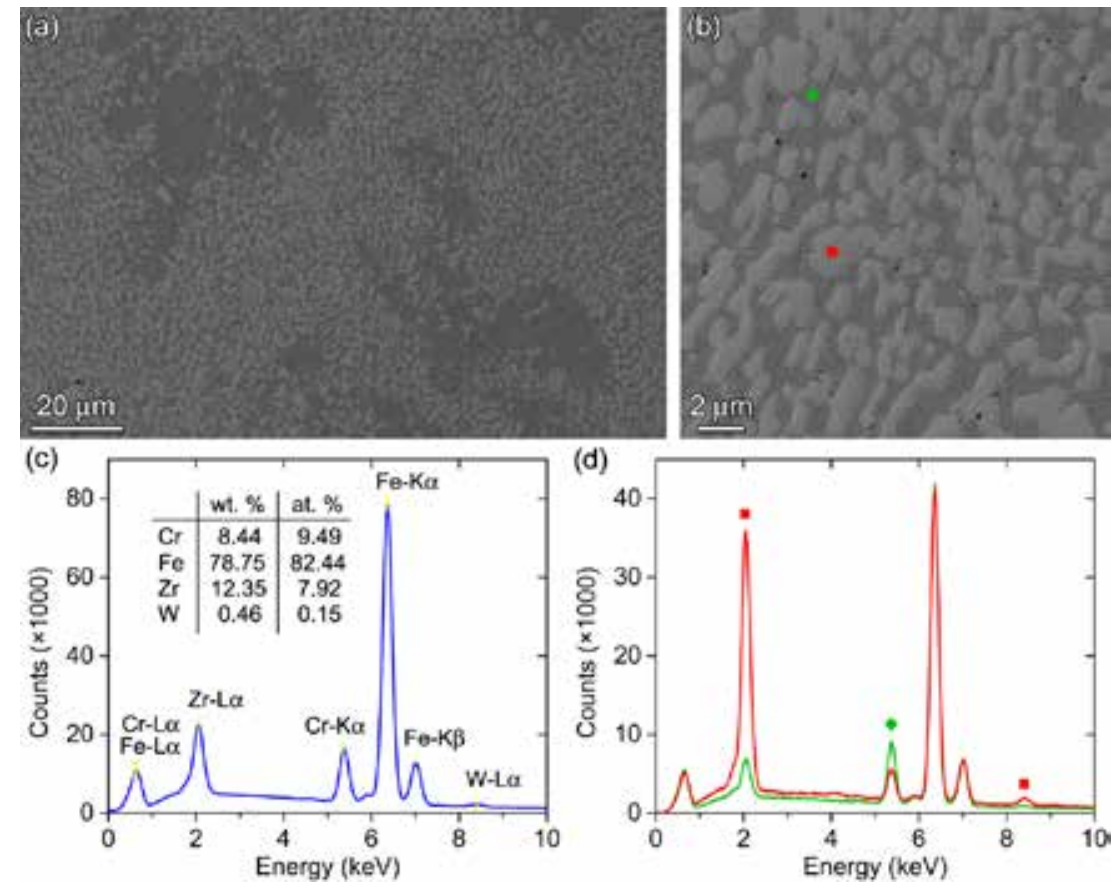

Figure 50. SEM characterization of un-irradiated Z6 alloy: (a) low-magnification secondary-electron image overview; (b) high-magnification secondary-electron image of the eutectic zone; (c) EDS spectrum from full area of (a) and quantification results (error $< \pm 0.1 \%$ ); (d) EDS spectra from the "brighter" (red square) and "darker" (green diamond) phases in (b), all with beam voltage of $20 \mathrm{kV}$. 
Figure 51(a) shows overview of the cross-sectional specimen extracted from the eutectic zone, which was imaged under HAADF-STEM mode with atom mass (Z)-sensitive contrast. This, along with composition profiles measured across a phase interface (see Figure 51(b) and Figure 51(c)), confirms the dual-phase eutectic microstructure of un-irradiated Z6 alloy, with a Zr/W-rich phase homogeneously dispersed in a $\mathrm{Fe}-\mathrm{Cr}$ matrix. Both phases form equiaxed or slightly elongated grains with grain sizes of $0.5 \sim 2 \mu \mathrm{m}$. Table 10 further shows composition of the two phases, determined from quantification of EDS spectra. Notice that $\mathrm{Zr}$ content is even lower than $\mathrm{W}$ content in $\mathrm{Fe}-\mathrm{Cr}$ matrix, which can be reasonably attributed to their different lattice types (Zr: HCP; W, Fe, Cr: BCC). Figure 51(d) shows representative composition profiles across a grain boundary of matrix, with no detectable segregation of $\mathrm{Cr}$ or $\mathrm{W}$ observed (the contrast is related to the high density of defects near the boundary, since HAADF is also contributed by diffraction contrast).
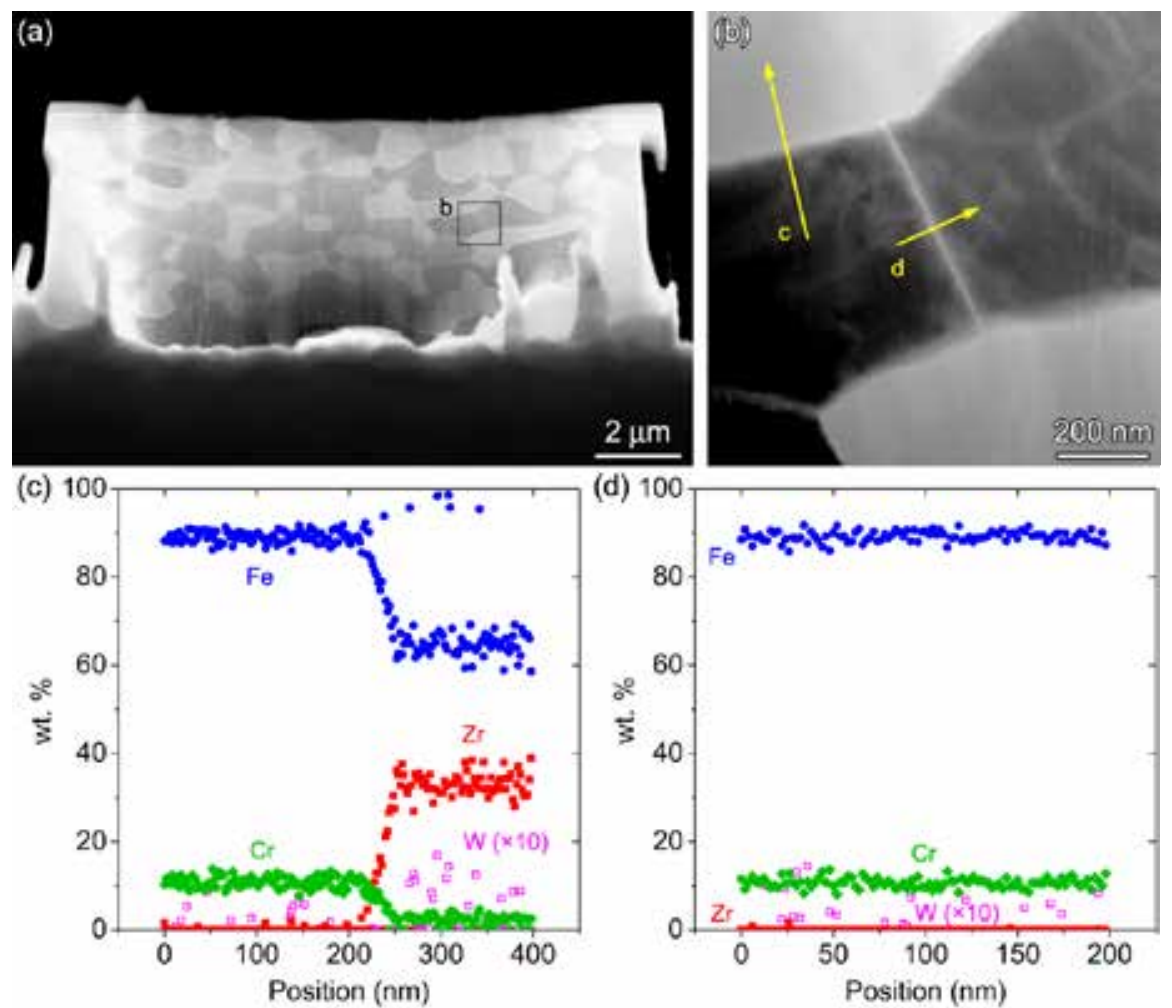

Figure 51. Cross-sectional TEM of un-irradiated $\mathrm{Z6}$ alloy in the eutectic zone: (a) low-magnification STEMHAADF image; (b) zoom-in image of box b in (a) showing phase interface and grain boundary; (c, d) EDS line-scan profiles along arrows $\mathrm{c}$ and $\mathrm{d}$ in (b), respectively.

Table 10. Summary of eutectic microstructure of Z6 alloy.

\begin{tabular}{ccccc}
\hline Eutectic component & \multicolumn{2}{c}{ Fe-Cr matrix } & \multicolumn{2}{c}{$\mathrm{Zr} / \mathrm{W}$-rich phase } \\
\hline Crystal structure & \multicolumn{2}{c}{$\alpha$-Fe (BCC) } & \multicolumn{2}{c}{$\beta / \beta^{\prime}-\mathrm{Fe}_{2} \mathrm{Zr}$ (faulted Laves) } \\
\hline Composition & wt. \% & at. \% & wt. \% & at. \% \\
$\mathrm{Cr}$ & 10.64 & 11.37 & 2.19 & 2.78 \\
$\mathrm{Fe}$ & 88.83 & 88.47 & 59.52 & 70.04 \\
$\mathrm{Zr}$ & $<0.01$ & $<0.01$ & 37.04 & 26.73 \\
$\mathrm{~W}$ & 0.53 & 0.15 & 1.24 & 0.45 \\
\hline
\end{tabular}


Figure 52 to Figure 54 show more details of defect microstructure within a representative $\mathrm{Fe}-\mathrm{Cr}$ grain of the eutectic zone. Figure 52(a) is HAADF image viewed along [111] zone axis, which reveals contrast of all defects due to increased scattering. Figure 52(b) and Figure 52(c) shows the grain boundary studied in Figure 51, which is a low-angle tilt boundary close to (611). We notice that the majority of grain boundaries are found to be low-angle type with misorientation angle $<10^{\circ}$, and the absence of $\mathrm{Cr}$ or W segregation might be related to grain boundary characters. Long (and sometimes tangled) lines and short threads are widely spread within the grain, and weak-beam dark-field (WBDF) TEM images (see Figure 53(d-f)) using different reflection vectors (g) suggest these features to be dislocation lines with Burgers vectors (b) of $<111>/ 2$ or $<100>$, though unambiguous identification of these dislocations requires contrast analysis under additional imaging conditions. The long dislocation lines are mostly nucleated from matrix grain boundaries or phase interfaces, which might be related to the thermal history of this alloy. Meanwhile, the short dislocation threads $(10 \sim 100 \mathrm{~nm})$ are uniformly dispersed throughout the grain, and, more intriguingly, approximately parallel with each other (in this grain, also parallel with the grain boundary that is close to (100)). We further notice that all short dislocation threads are without contrast in Figure 52(b) and Figure 53(f) with $\mathbf{g}=(01 \overline{1})^{*}$. Taken as a whole, all current results support these short threads to be edge dislocations with Burgers vector of $<100>$.

Figure 53(d-f) also presents substantial amount of defects shown as white spots, which resemble the dislocation loops and/or clusters that are commonly observed in ion-irradiated materials. However, we have no clear evidence yet regarding whether these defects are generated by FIB processing.

Nonetheless, the short dislocation threads are believed to be native to the alloy microstructure. EDS linescans across dislocation threads and white-spot defects show hardly detectable (if any) change of composition (see Figure 54g-j), i.e., a slight segregation of W, which might explain the contrast observed. However, this still needs to be verified with more careful measurements.
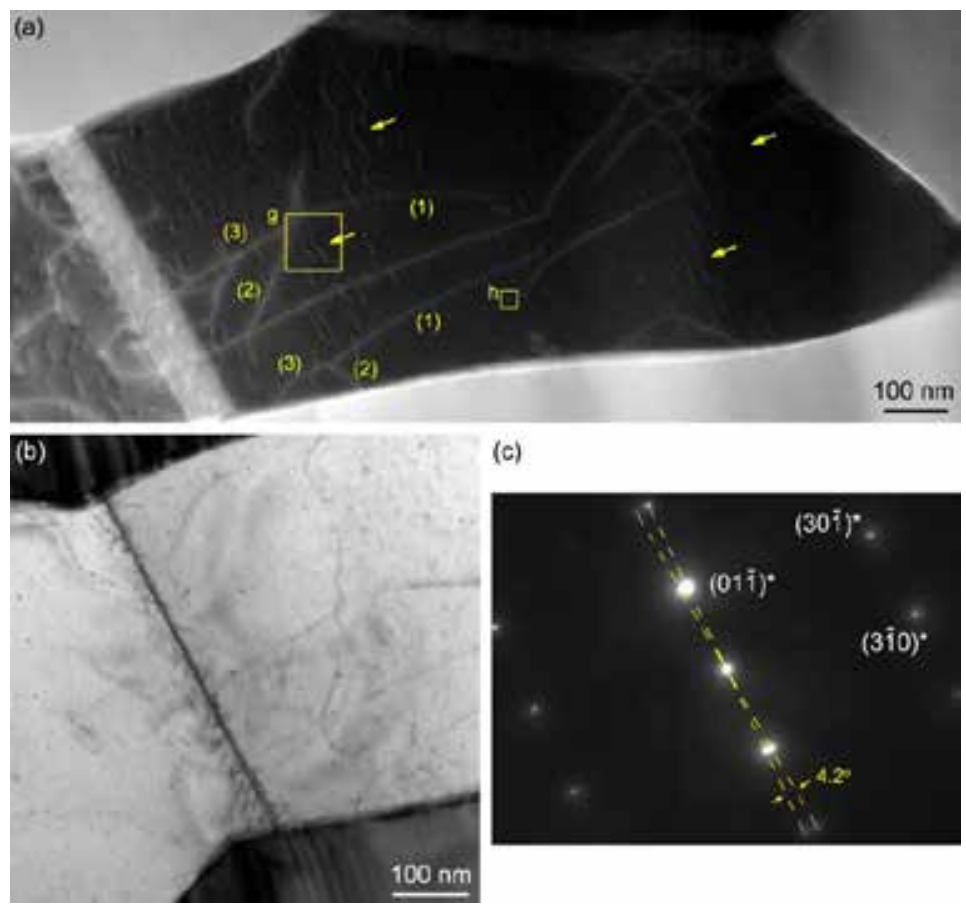

Figure 52. Microstructure of the Fe-Cr phase in the eutectic zone of the un-irradiated Z6 alloy: (a) HAADF image viewed along [111] zone axis with (1-3) representing a few long dislocation lines and arrows pointing to short dislocation threads; (b) bright-field TEM image of the grain boundary shown in Figure 51(b) with defects and/or strain field noticed near the boundary; (c) diffraction pattern shows a small misorientation angle of the boundary. 

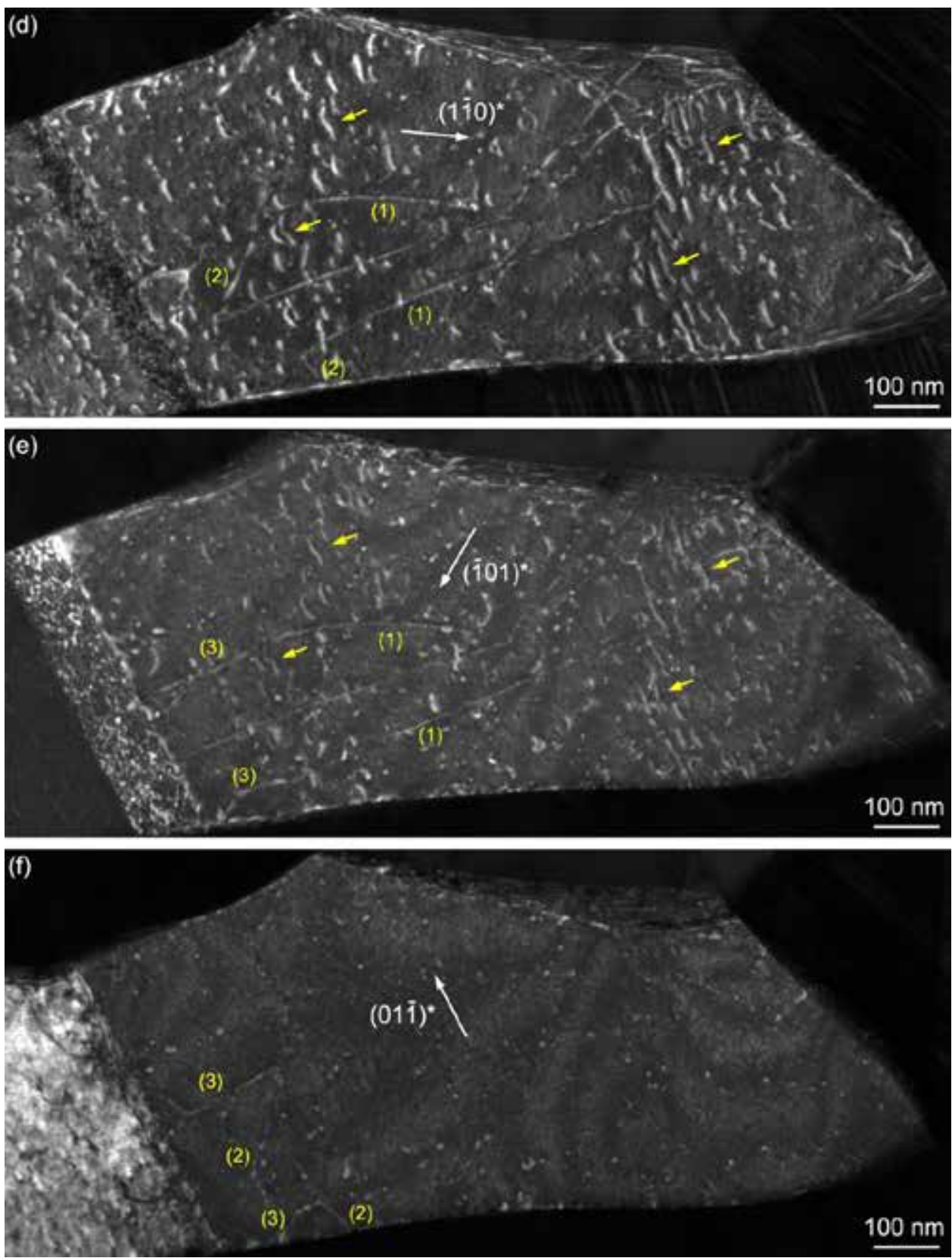

Figure 53. (d-f) WBDF TEM images of the same grain in (a) using different g vectors. All images were recorded in (g, 3.1g) condition. One possible combination of Burgers vectors of the dislocation lines shown as (1), (2), and (3) is: $\mathbf{b}^{(1)}=[1 \overline{1} 1] / 2, \mathbf{b}^{(2)}=[0 \overline{1} 0]$, and $\mathbf{b}^{(3)}=[111] / 2$, allowing $\mathbf{b}^{(1)}=\mathbf{b}^{(2)}+\mathbf{b}^{(3)}$. 

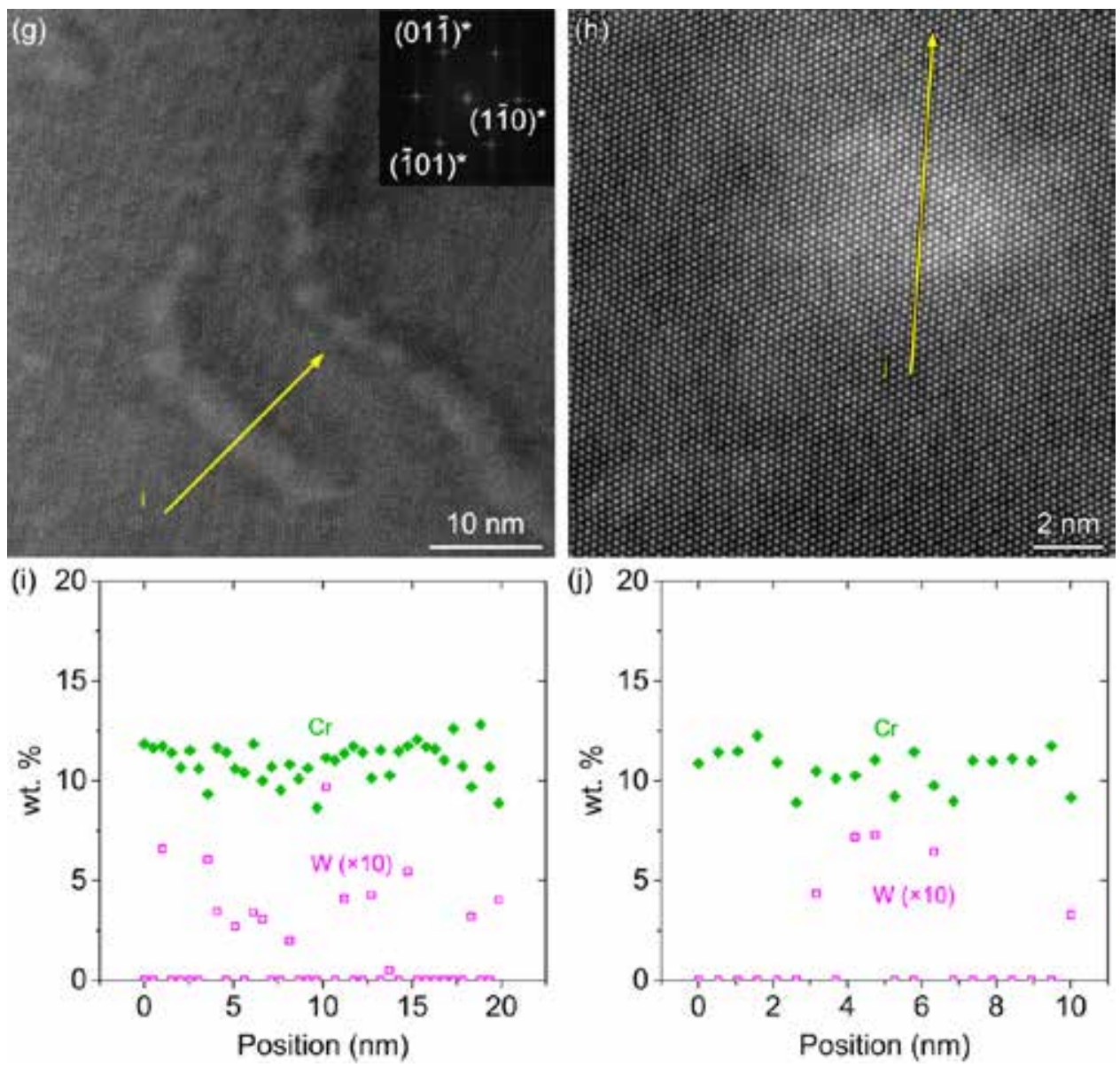

Figure 54. (g) HRSTEM image of short dislocation threads with an inset FFT pattern suggests no extra phase relates with the dislocation. The interplanar spacing $d_{(110)}=1.97 \AA$ accords with that of $\alpha-F e(B C C)$. (h) HRSTEM image of a white-spot. (i, j) EDS line-scan profiles along arrows in (g) and (h), respectively.

Figure 55(a) shows a representative $\mathrm{Zr} / \mathrm{W}$-rich grain in the eutectic zone, which was slightly titled away from its edge-on orientation, thus revealing high density of planar defects within this grain. These planar defects are not uniformly distributed, instead, a bunch of severely faulted bands are divided by defect-free bands with width ranging from $\sim 100 \mathrm{~nm}$ to $\sim 10 \mathrm{~nm}$. Figure 55(b) and Figure 55(c) show selected area diffraction patterns obtained from the severely faulted and defect-free regions, respectively. Pattern (b) agrees quantitatively well with [1 $\overline{2} 10]$ zone axis of $\beta-\mathrm{Fe}_{2} \mathrm{Zr}$, a C36 type $\left(\mathrm{P}_{3} / \mathrm{mmc}\right)$ Laves phase. Notice that $(0001)^{*},(0002)^{*}$, and $(0003)^{*}$ spots are forbidden in kinematic approximation but not in dynamic diffraction, while the satellite spots along $\mathrm{c}^{*}$ axis (see inset) indicate ordered stacking faults in (0001) planes. By contrast, pattern (c) agrees with [1 $\overline{2} 10]$ zone axis of a $\mathrm{C} 14$ type $\left(\mathrm{P}_{3} / \mathrm{mmc}\right)$ Laves phase, though this phase (namely $\beta$ '- $\mathrm{Fe}_{2} \mathrm{Zr}$ ) has not been reported in $\mathrm{Fe}-\mathrm{Zr}$ system before. Further, atomic structure of the two regions are directly revealed by aberration-corrected HRSTEM images (see Figure 56(d) and Figure 56(e)). The stacking order of structural units shown in these atom-resolved images agree perfectly with the structure models of faulted C36 and pristine C14 Laves phases (see Figure 56(f) and Figure 56(g)). 

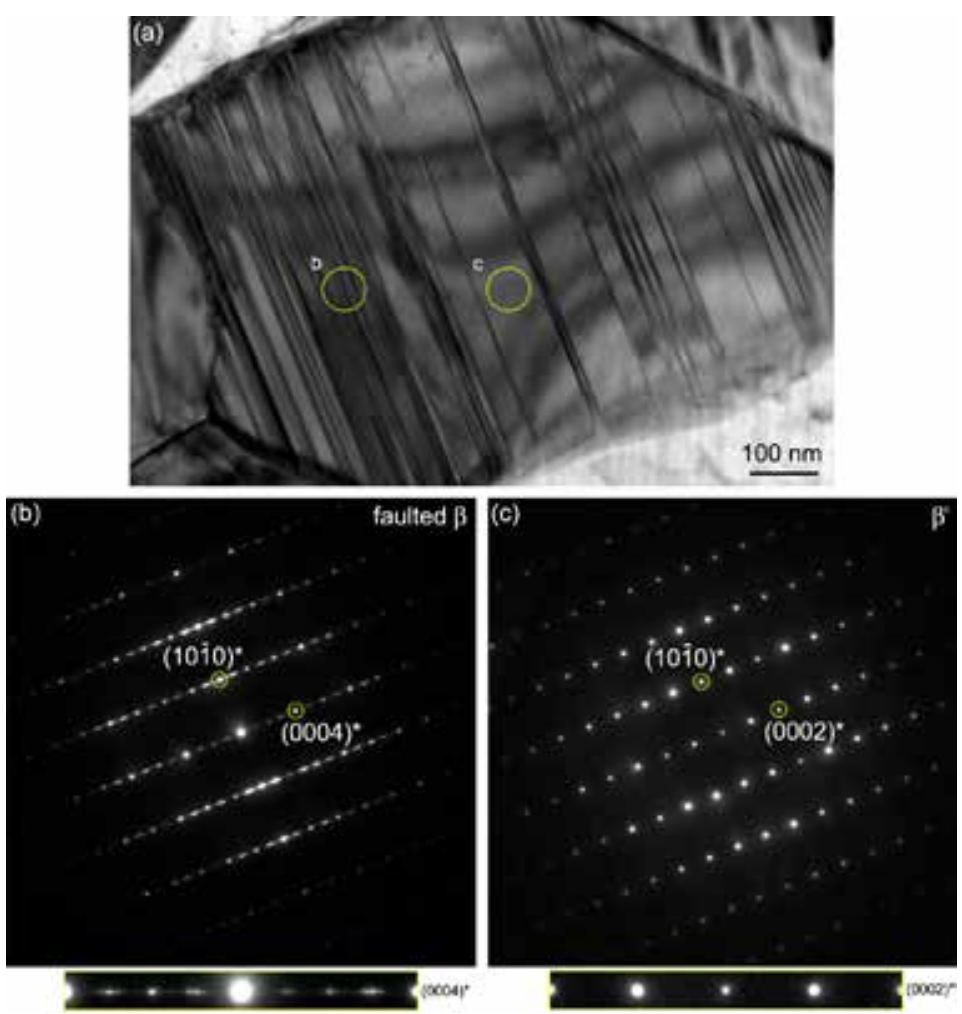

Figure 55. Microstructure of $\mathrm{Zr} / \mathrm{W}$-rich Laves phase in the eutectic zone of the un-irradiated $\mathrm{Z6}$ alloy: (a) bright-field TEM image shows severely faulted bands divided by defect-free bands; $(b, c)$ selected area diffraction patterns from circles $b$ and $c$ in (a), respectively, together with enlarged view of diffraction patterns along $\mathrm{c}^{*}$ axis.

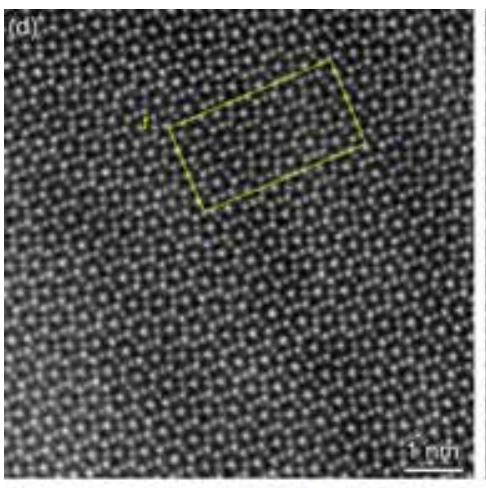

(f)

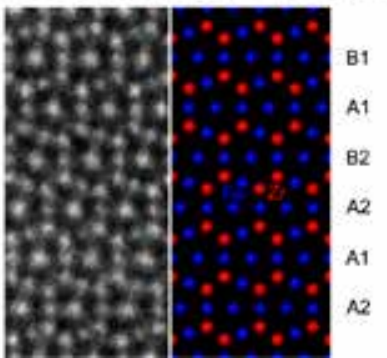

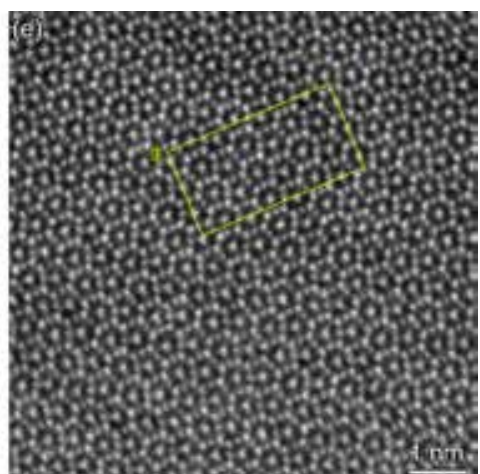

(g)

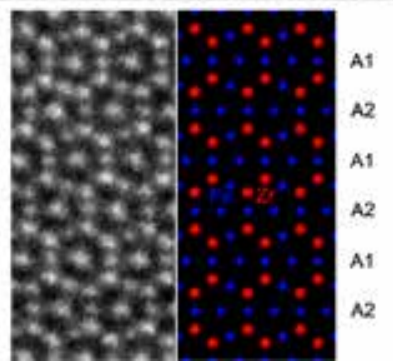

Figure 56. (d, e) Aberration-corrected HRSTEM images of faulted and defect-free region, respectively. (f, g) Enlarged atom-resolved images and structural model of faulted $\beta-\mathrm{Fe}_{2} \mathrm{Zr}$ and pristine $\beta$ '- $\mathrm{Fe}_{2} \mathrm{Zr}$ phases, respectively. 


\section{Microstructure of un-irradiated T12 Alloy}

Figure 57(a) shows representative surface morphology of un-irradiated T12 alloy. This alloy has a single phase microstructure, while a few precipitates with brighter contrast are sparsely dispersed in the matrix. The structure and composition of these precipitates will be later investigated in cross-sectional TEM specimens. Similar to the Z6 alloy, some black spots are also noticed on surface and are suggested to be carbon according to EDS. Figure 57(b) shows EDS spectrum measured over full area of Figure 57(a), and Table 11 shows quantification of the global composition of this alloy.

Table 11. Global composition of T12 alloy (error $< \pm 0.1 \%)$.

\begin{tabular}{lccccc}
\hline & $\mathrm{Ti}$ & $\mathrm{Cr}$ & $\mathrm{Fe}$ & $\mathrm{Ta}$ & $\mathrm{W}$ \\
\hline wt. \% & 0.13 & 8.92 & 89.33 & 0.21 & 1.41 \\
at. \% & 0.15 & 9.62 & 89.73 & 0.07 & 0.43 \\
\hline
\end{tabular}
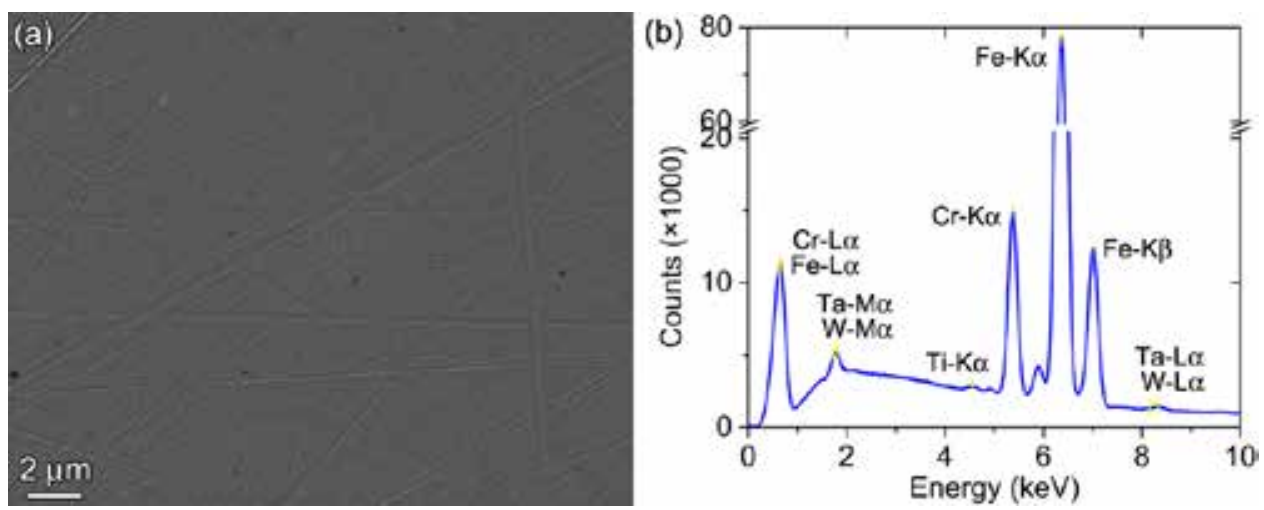

Figure 57. Microstructure of un-irradiated T12 alloy: (a) secondary-electron image with the same magnification as Figure 50(b); (b) EDS spectrum from full area of (a) with beam voltage of $20 \mathrm{kV}$.

Microstructure of T12 alloy is further investigated for a cross-sectional TEM specimen, as shown in Figure 58(a). Although a single phase (Fe-Cr matrix, $\mathrm{BCC}$ ) is found to be dominant, this alloy still shows complex microstructure characterized by elongated (sometimes lenticular) grains and high density of dislocations. The majority of grains have width of $0.2 \sim 1 \mu \mathrm{m}$ and length of $2 \sim 10 \mu \mathrm{m}$. Figure 58(b) further shows tangled dislocation lines within a grain as well as dislocation arrays along grain boundaries, which resemble the defect microstructure in the Fe-Cr matrix of Z6 alloy. Also, EDS line-scans across these dislocation lines (see Figure 58(c) and Figure 58(d)) show hardly detectable segregation of W, which still needs verification.

A few precipitates are also observed in cross-sectional TEM specimens of T12 alloy, and Figure 59(a) shows representative enlarged view of a near-spherical precipitate with diameter of $\sim 130 \mathrm{~nm}$, which is embedded within a Fe-Cr grain. Long dislocation lines are nucleated from the interface, indicating such precipitates to be incoherent with the matrix. EDS line-scan across interface (see Figure 59(b)) suggests these precipitates to be composed of $\mathrm{Ti}, \mathrm{Ta}, \mathrm{C}$, while the matrix grain is simply $\mathrm{Fe}-\mathrm{Cr}$ ( $\mathrm{C}$ signal may come from contamination). Careful quantification of EDS spectrum of the precipitates yields a composition close to $\left(\mathrm{Ta}_{0.34} \mathrm{Ti}_{0.66}\right) \mathrm{C}_{1.13}$, and the lattice image of precipitate (see Figure 59(c)) accord well with $\mathrm{TiC}$ or $\mathrm{TaC}$, both with a rocksalt $(\mathrm{Fm} 3 \mathrm{~m})$ structure and having similar lattice constants. We notice that precipitates with other structures and/or compositions are not observed yet in the un-irradiated T12 alloy. 

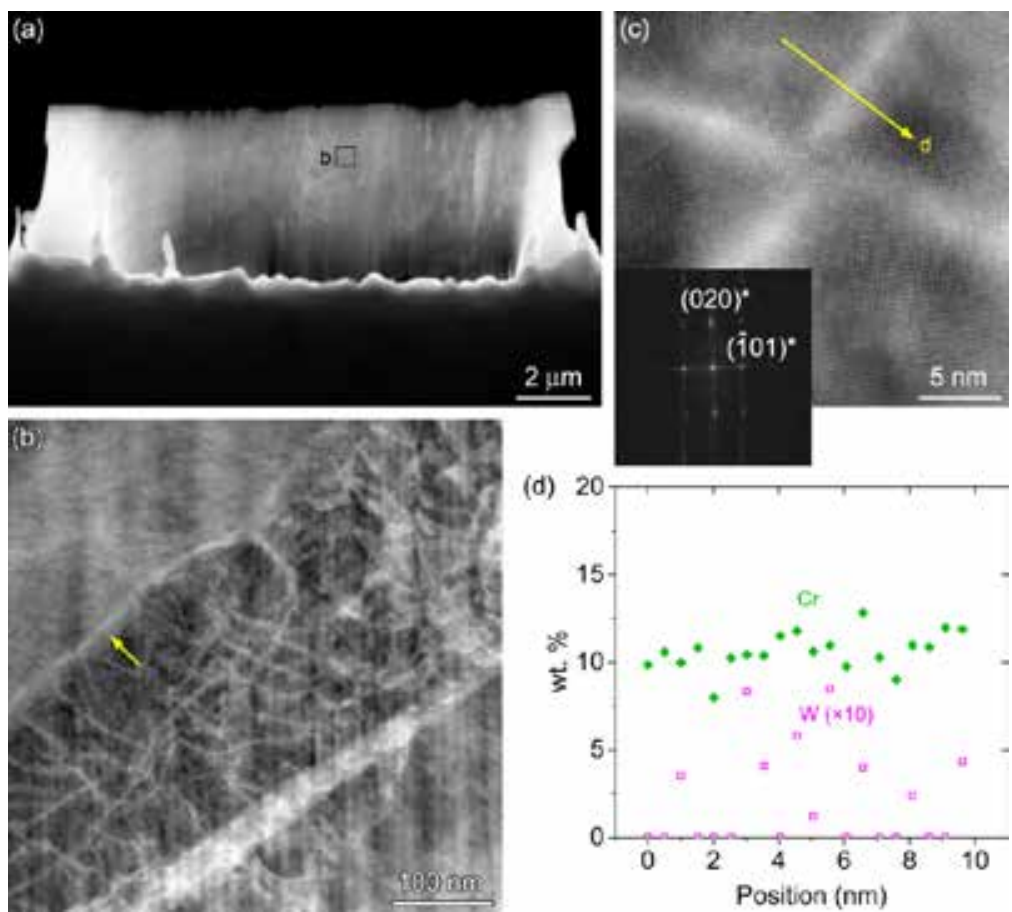

Figure 58. Cross-sectional TEM of un-irradiated T12 alloy: (a) low-magnification STEM-HAADF image; (b) zoom-in image of box $b$ in (a) showing tangled dislocation lines in an elongated subgrain with an arrow pointing to dislocation arrays on a boundary; (c) HRSTEM image of dislocation lines with an inset FFT pattern suggesting no extra phase relates with the dislocation. The interplanar spacing $d_{(110)}=2.06 \AA$ and $d_{(002)}=1.41 \AA$ accords with that of $\alpha-F e(B C C)$. (d) EDS line-scan profiles along arrow in (c).
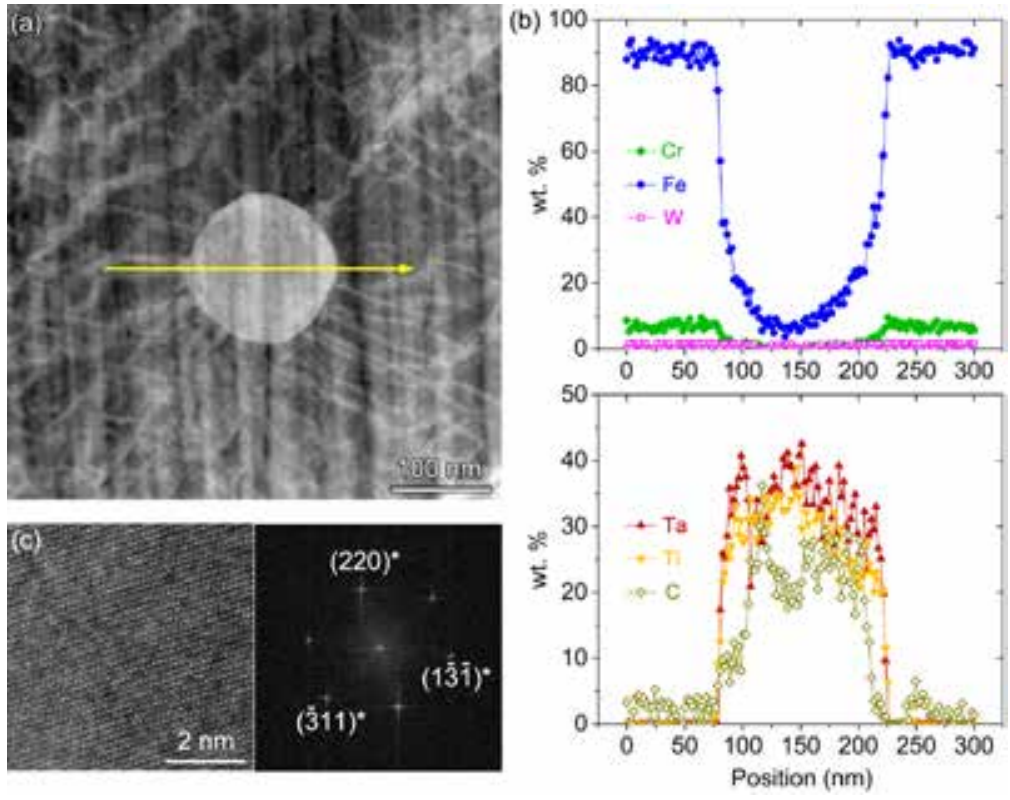

Figure 59. Characterization of precipitates in un-irradiated T12 alloy: (a) STEM-HAADF image of a precipitate; (b) EDS line-scan profiles along arrow in (a); (c) HRSTEM image and corresponding FFT pattern of the precipitate in (a). The interplanar spacing $d_{(22)}=1.59 \AA$ and $d_{(311)}=1.35 \AA$ accords well with that of TiC or TaC (rocksalt). 


\section{Microstructure of proton-irradiated Z6 Alloy}

Figure 60(a1) and Figure 60(b1) show representative surface morphology of Z6 alloy after protonirradiation $\left(420{ }^{\circ} \mathrm{C}, 1 \mathrm{dpa}\right)$. The imaged region is $\sim 1.5 \mathrm{~mm}$ off center of the $3 \mathrm{~mm}$ disk. A large portion of surface shows very rough morphology formed by uniformly distributed oxide islands with sizes of $1 \sim 2$ $\mu \mathrm{m}$, while some smaller, discrete areas are covered by relatively dense, granular oxide films. This morphology is similar to Figure 50, corresponding to the large portion of eutectic zone with some discrete zones of Fe-Cr primary phase. Meanwhile, Figure 60(a2) and Figure 60(b2) show surface morphology at the center of the $3 \mathrm{~mm}$ disk, where large portion of surface is covered by crystallite oxide particles with sizes of 200 500 $\mathrm{nm}$. Such inhomogeneous behavior of surface oxidation may indicate the side effect of irradiation, i.e., local heating and thermal gradient, to influence the microstructure. Furthermore, we notice even dramatic distinction of internal microstructure as viewed in cross-sectional TEM specimens (see Figure 60(c)). The volume within at least $\sim 10 \mu \mathrm{m}$ under surface is composed of predominant lamellar structure (characterized as $\mathrm{Fe}-\mathrm{Fe}_{2} \mathrm{Zr}$ eutectic structure) decorated with a few large globular "darker" phase (Fe-Cr primary phase), which is completely different from the initial dual-phase microstructure of the eutectic zone (see Figure 51(b)), suggesting the presence of microstructural inhomogeneity of the eutectic structures.
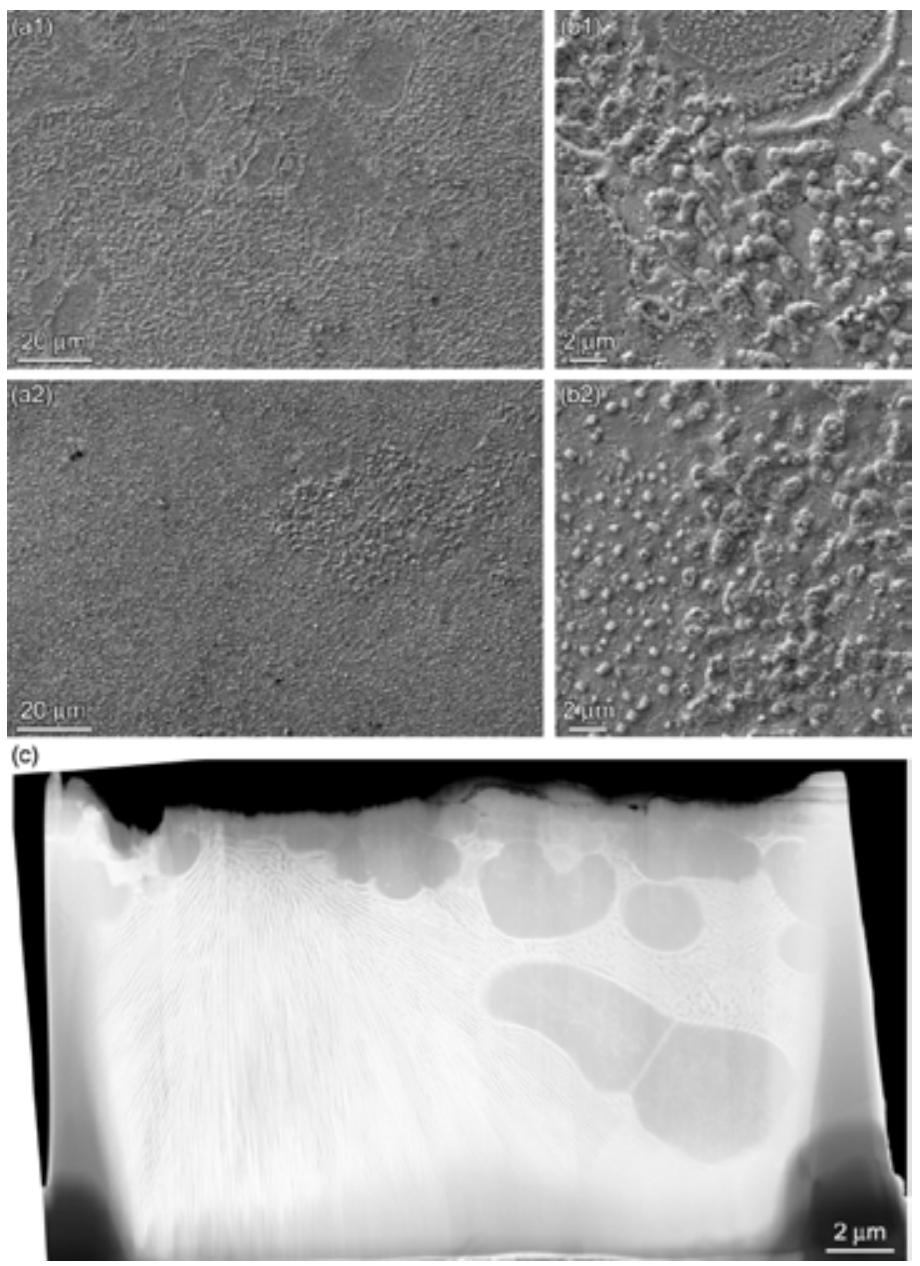

Figure 60. Surface morphology and cross-sectional microstructure of irradiated Z6 alloy: (a1,a2) lowmagnification secondary-electron image; (b1,b2) high-magnification secondary-electron image; (c) lowmagnification STEM-HAADF image of cross-sectional specimen. Notice that (a), (b), and (c) have the same magnifications as of Figure 50(a), Figure 50(b), and Figure 50(a), respectively. 
Figure 61(a) shows representative morphology of the eutectic structure away from surface. Figure 60(c) shows that eutectic structure is also found near surface, but these involve selective oxidation of the $\mathrm{Fe}_{2} \mathrm{Zr}$ phase and will not be discussed here. Figure 61(b) shows EDS line-scans perpendicular to the phase interface. Similar to the eutectic zone of the un-irradiated Z6 alloy (see Figure 51(c)), the two phases forming eutectic structure are Fe-Cr matrix (with slight $\mathrm{W}$ content) and $\mathrm{Zr} / \mathrm{W}$-rich phase, while oxidation in both phases are homogeneous and weak. Figure 61(c) and Figure 61(d) show atom-resolved images of the two phases, which are indexed as $\alpha-\mathrm{Fe}(\mathrm{BCC})$ and $\beta-\mathrm{Fe}_{2} \mathrm{Zr}\left(\mathrm{P}_{3} / \mathrm{mmc}\right)$, respectively. As in un-irradiated Z6 alloy, stacking faults in (0001) plane are also occasionally found in $\beta-\mathrm{Fe}_{2} \mathrm{Zr}$ lamellar (not shown here). An approximate orientation relationship of $(200)_{\alpha} / /(0002)_{\beta}$, and $[001]_{\alpha} / /[11 \overline{2} 0]_{\beta}$ is observed for the region investigated in Figure 61, though this needs further verification in other regions. Nonetheless, the eutectic structure form large colonies with length scale over $\sim 10 \mu \mathrm{m}$, and the two lamellar phases in each colony are expected to preserve similar orientation relationship. Moreover, they show very uniform lamellar thickness of $\mathrm{Fe}: \sim 70 \mathrm{~nm}$ and $\mathrm{Fe}_{2} \mathrm{Zr}: \sim 50 \mathrm{~nm}$. The lamellar eutectic structure formed during cooling of the alloy, which was not destroyed during the following hot rolling process. This type of structure is not a dominant type of eutectic structure as compared to the one shown in Figure 51(a). Additional TEM characterization will be conducted on elucidate the effect of proton-irradiation on the other type of eutectic structure as shown in Figure 51(a).
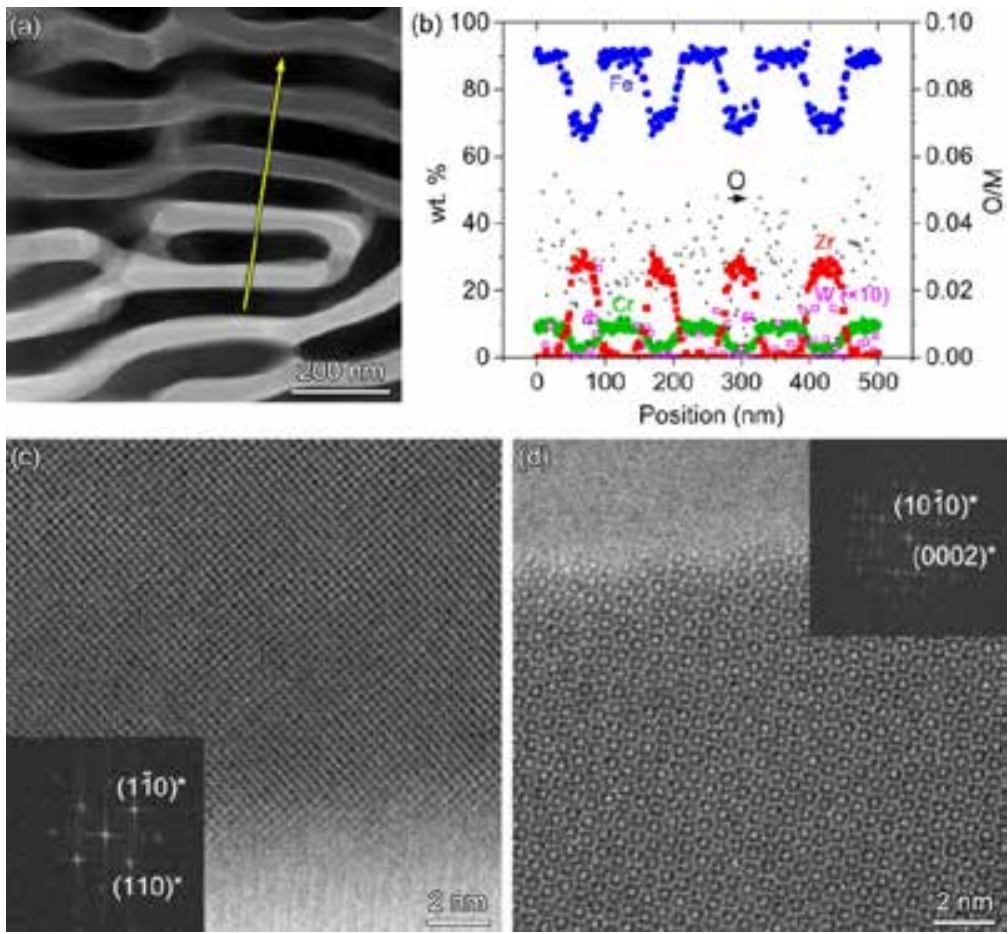

Figure 61. Characterization of eutectic structure in proton-irradiated Z6 alloy: (a) STEM-HAADF image; (b) EDS line-scan profiles along arrow in (a) with left axis as weight percent of $\mathrm{Cr}, \mathrm{Fe}, \mathrm{Zr}$, and $\mathrm{W}$ and right axis as atomic ratio between $\mathrm{O}$ and $(\mathrm{Cr}+\mathrm{Fe}+\mathrm{Zr}+\mathrm{W})$; (c, d) HRSTEM images and corresponding FFT patterns of $\mathrm{Fe}-\mathrm{Cr}$ phase and $\mathrm{Zr} / \mathrm{W}$-rich phase in (a).

Figure 62(a) shows HAADF-STEM image of two adjacent Fe-Cr matrix grains and their boundary. Similar to the un-irradiated microstructure, most grain boundaries are also found to be low-angle type with misorientation angle $<10^{\circ}$. EDS line-scans across this grain boundary (see Figure 62(b)) clearly shows a slight segregation of $\mathrm{Zr}$ (and depletion of $\mathrm{W}$ ), though $\mathrm{Fe}_{2} \mathrm{Zr}$ phase is not yet grown at grain 
boundary since the segregation is relatively weak. Long and tangled dislocation lines are also observed inside grains, however, the large amount of short dislocation threads as seen in un-irradiated grains (see Figure 52) no longer exist. Instead, substantial amount of polyhedron-shaped defects, with uniform sizes of $30 \sim 50 \mathrm{~nm}$, are newly formed by irradiation. These defects are always of contrast when imaged using with bright-field and weak-beam dark-field mode at variant diffraction conditions (see Figure 62(c) and Figure 62(d) for example), which likely preclude them to be dislocation loops. EDS line-scans across one of these defects (see Figure 62(e)) also shows a weak segregation of Zr. These defects may be new phase such as zirconium hydrides, carbides, or even octahedron voids with (111) facets, which need to be confirmed by further investigations. Besides, a denuded zone of these defects is clearly seen near grain boundaries (and phase interfaces), with a width of $\sim 500 \mathrm{~nm}$.
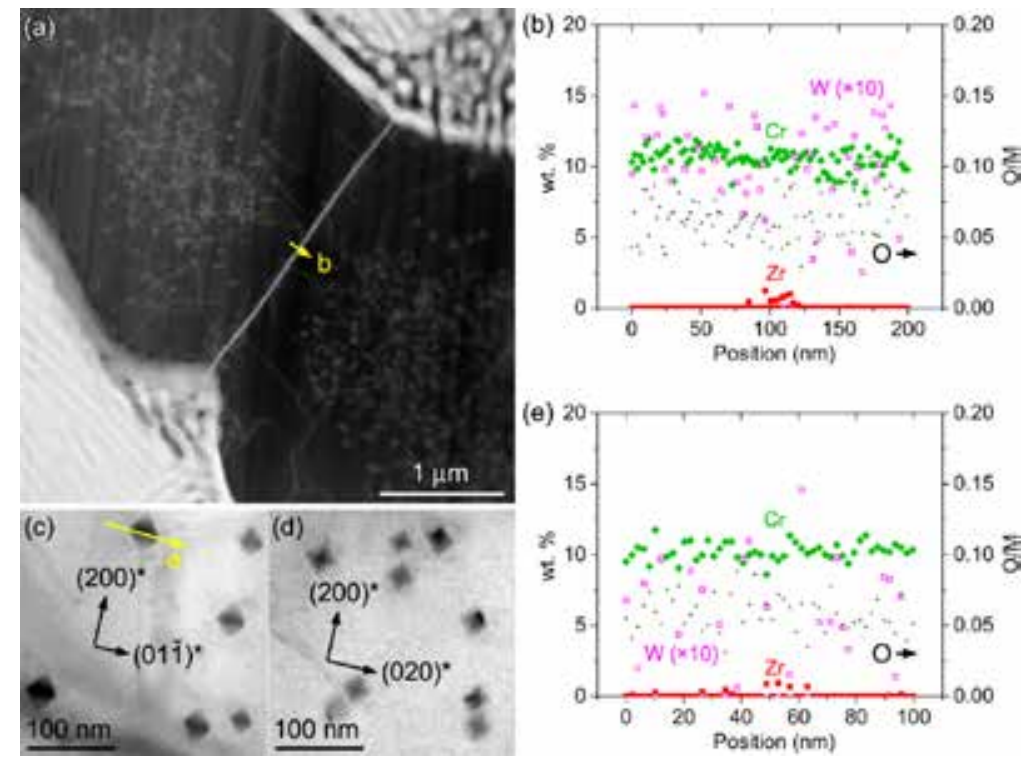

Figure 62. Characterization of defect microstructure in Fe-Cr matrix grains of proton-irradiated Z6 alloy: (a) STEM-HAADF image of a grain boundary and defects inside grains; (b) EDS line-scan profiles along arrow in (a); (c, d) bright-field TEM images of unknown defects using beam directions slightly off [011] and [002] zone axes, respectively; (e) EDS line-scan profiles along arrow in (c).

Figure 63 represents our preliminary effort to characterize the surface oxidation (unintended consequence of long-term high temperature irradiation) of Z6 alloy during irradiation. We notice that such oxidation layer, with thickness of $1 \sim 2 \mu \mathrm{m}$ under surface, is composed of oxides with variant morphology, structure, and composition, and it is not clear yet regarding whether (and how) the distribution of oxides is influenced by the initial phase structure near surface as well as the irradiation and heating condition. For the first example, Figure 63(a) shows eutectic structure near surface. Unlike the uniform composition of $\beta-\mathrm{Fe}_{2} \mathrm{Zr}$ away from surface, the $\mathrm{Zr}$-rich lamellar phase closer to surface shows both higher $\mathrm{Zr}$ content and higher $\mathrm{O} / \mathrm{M}$ ratio (see Figure 63(c)), suggesting that $\beta-\mathrm{Fe}_{2} \mathrm{Zr}$ phase in eutectic structure is preferentially oxidized. Also, the variation of $\mathrm{Cr}$ content between $\mathrm{Fe}-\mathrm{Cr}$ matrix and $\mathrm{Zr}$-rich phase is quite suppressed, indicating preferential loss of $\mathrm{Cr}$ from $\mathrm{Fe}-\mathrm{Cr}$ matrix. Figure 63(d) further shows that the oxidized Zr-rich phase is no longer single-crystalline, and the lattice structure can be indexed as pseudo-cubic $\mathrm{ZrO}_{2}$. Figure 63(b) shows oxidation of another surface region, where spherical particles inside Fe-Cr matrix is also pseudo-cubic $\mathrm{ZrO}_{2}$, while the debris on top surface is indexed as $\mathrm{Cr}_{2} \mathrm{O}_{3}$, according to atom-resolved images and EDS spectra. The latter may correspond to the islandshape asperities as seen in surface morphology Figure 60(b), however, a systematic correlation between surface morphology and oxides distribution in cross-sectional views is still uncovered. 

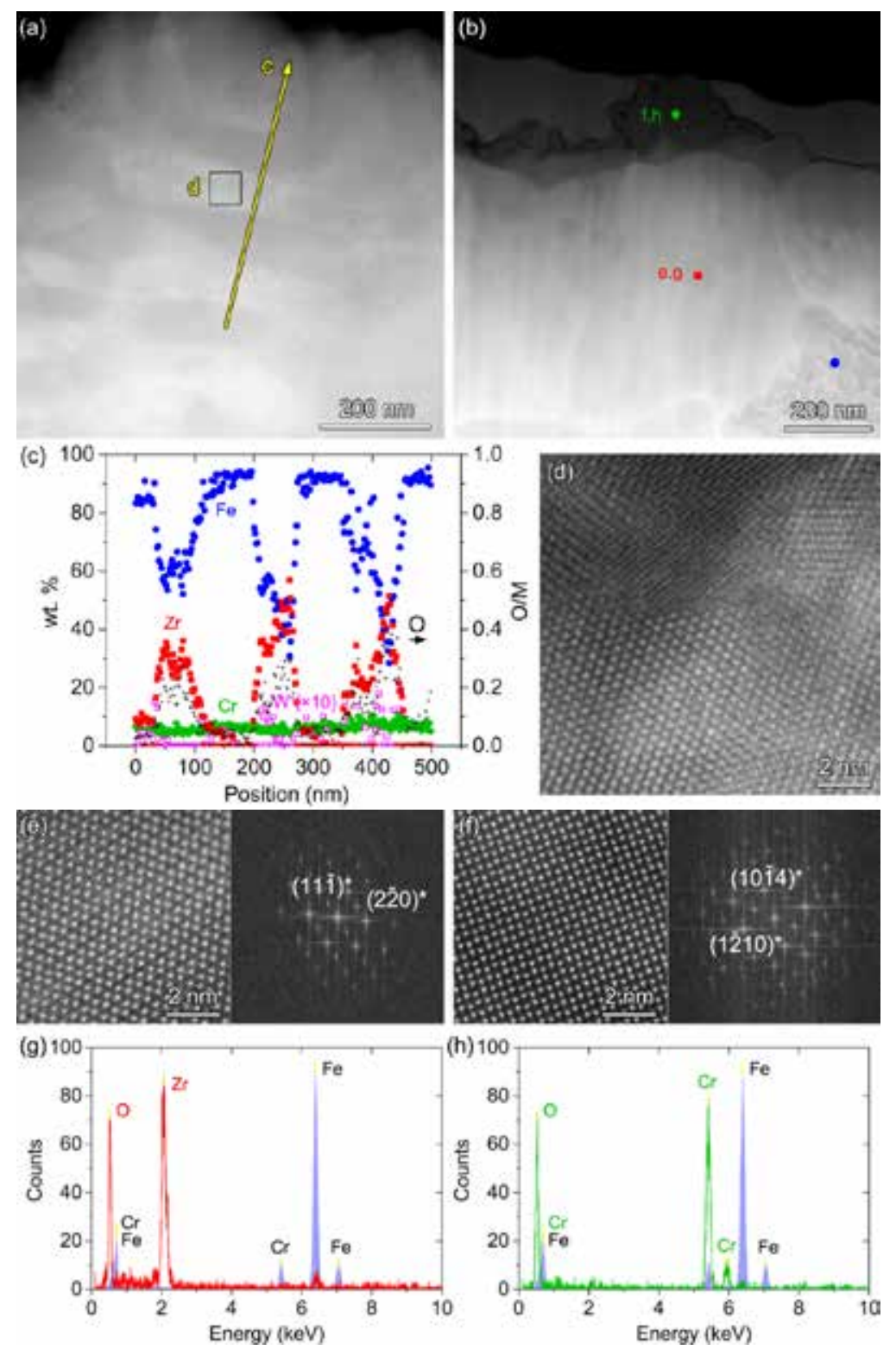

Figure 63. Preliminary characterization of surface oxidation of proton-irradiated Z6 alloy: (a) STEMHAADF image of eutectic structure near surface; (b) STEM-HAADF image of surface with multiple types of oxides; (c) EDS line-scan profiles along arrow in (a); (d) HRSTEM image of oxidized Zr-rich phase; (e) HRSTEM image and FFT pattern of a $\mathrm{ZrO}_{2}$ particle within $\mathrm{Fe}-\mathrm{Cr}$ matrix grain in (b); (f) HRSTEM image and FFT pattern of a $\mathrm{Cr}_{2} \mathrm{O}_{3}$ debris on surface in (b); (g, h) EDS point spectra measured from phases (e) and (f), respectively with the spectrum of Fe-Cr matrix grain in blue.

\section{Microstructure of proton-irradiated T12 Alloy}

Figure 64(a) shows representative surface morphology of $\mathrm{T} 12$ alloy after proton-irradiation under the same condition as Z6 alloy $\left(420^{\circ} \mathrm{C}, 1 \mathrm{dpa}\right)$. While the un-irradiated $\mathrm{T} 12$ alloy has a single-phase microstructure with few surface features, the irradiated $\mathrm{T} 12$ alloy shows widely dispersed asperities on surface. However, the surface roughness is much lower than irradiated Z6 alloy, and the (global) homogeneity of surface morphology is much better. Furthermore, the internal microstructure of T12 alloy is hardly influenced by irradiation, as to the overview of cross-sectional TEM specimens (see Figure 
64(b)). The topmost surface region is not preserved during sample preparation process by FIB, nonetheless, no remarkable oxidation layer is found beyond $\sim 500 \mathrm{~nm}$ under surface.
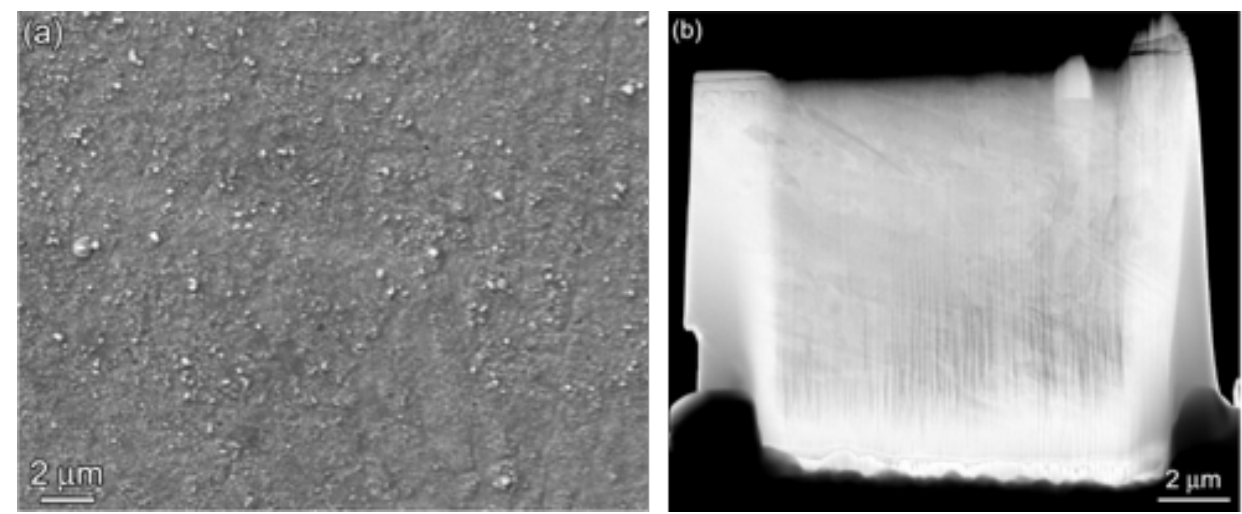

Figure 64. Surface morphology and cross-sectional microstructure of proton-irradiated T12 alloy: (a1) secondary-electron image with the same magnification as Figure 60(b); (b) low-magnification STEM-HAADF image of cross-sectional specimen with the same magnification as Figure 58(a).

Figure 65(a) shows representative microstructure of irradiated T12 alloy, which is characterized by elongated grains, high density of tangled dislocations, and spherical precipitates. We notice that these microstructural features, even very close to surface, are almost identical to those before irradiation. Moreover, grain sizes are almost not changed after irradiation. Also, segregation or depletion are not found in EDS line-scans across the grain boundary between elongated grains (see Figure 65(b)).
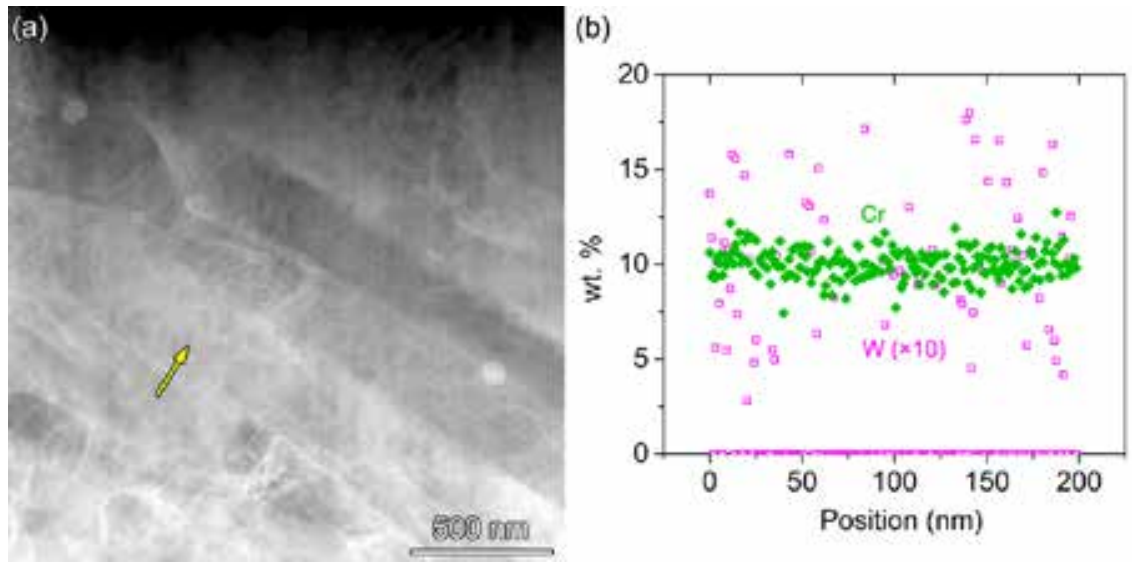

Figure 65. Cross-sectional TEM of proton-irradiated T12 alloy: (a) STEM-HAADF image showing elongated subgrains and sparse precipitates; (b) EDS line-scan profiles along the arrow in (a).

It can be seen above (Figure 65(a)) that the precipitates in irradiated T12 alloy have relatively uniform diameter of $60 \sim 70 \mathrm{~nm}$, which is remarkably smaller than that before irradiation $(120 \sim 150 \mathrm{~nm})$. Figure 66 shows further characterization of these precipitates. As shown in Figure 66(a), Figure 66(c), and Figure 66(e), the spherical precipitates located within $\mathrm{Fe}-\mathrm{Cr}$ matrix grains, as before irradiation, can be still indexed as $\left(\mathrm{Ta}_{\mathrm{x}} \mathrm{Ti}_{1-\mathrm{x}}\right) \mathrm{C}(\mathrm{x} \sim 0.3)$ with a rocksalt structure. In addition, some new precipitates with distinct polyhedron shape are newly generated at the grain boundaries, and are found to be rich of $\mathrm{C}, \mathrm{Cr}$, and W (see Figure 66(f)). However, their crystal structure has not been successfully determined, as the HRSTEM image (Figure 66(d)) cannot accord with typical structural models of carbides $\left(\mathrm{M}_{23} \mathrm{C}_{6}, \mathrm{M}_{7} \mathrm{C}_{3}\right.$, $\mathrm{M}_{5} \mathrm{C}_{2}, \mathrm{M}_{3} \mathrm{C}$, etc.), and this will be carefully examined in future experiments. We also notice a few 
spherical precipitates located on grain boundaries, which are rich of $\mathrm{C}, \mathrm{Ti}, \mathrm{Ta}$, and $\mathrm{Cr}$, and are also formed due to irradiation. This, along with the decreased size of (TaTi)C precipitates within grains, indicated enhanced diffusion towards grain boundary due to irradiation (and heating). However, $\mathrm{Cr}$ depletion is not observed at grain boundaries, though this also needs to be confirmed at different locations.
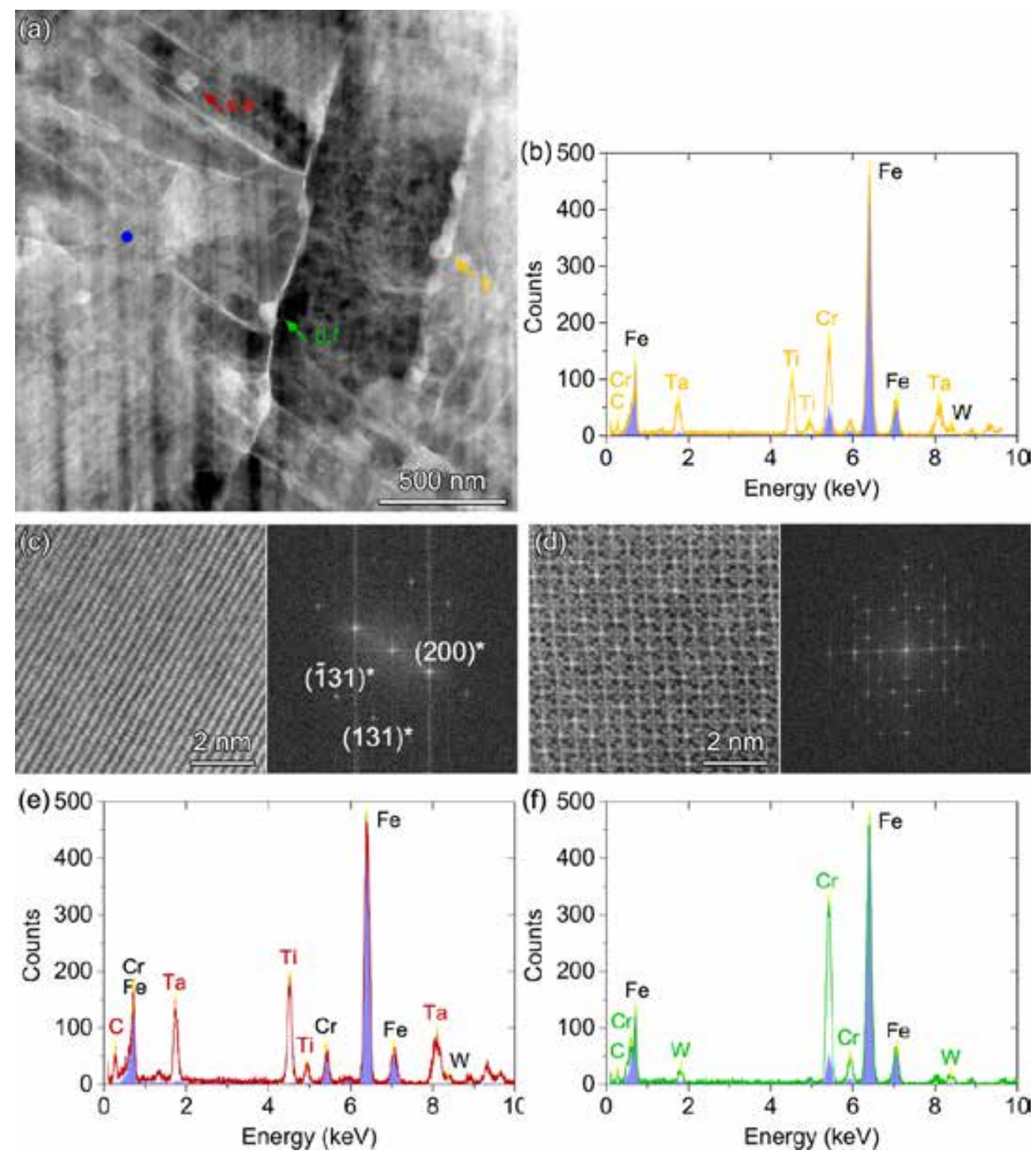

Figure 66. Characterization of precipitates in proton-irradiated T12 alloy: (a) STEM-HAADF image of elongated subgrain, with several precipitates within subgrain and on grain boundary; (b) EDS spectrum from a precipitate pointed by arrow b in (a); (c, e) HRSTEM image, FFT pattern, and EDS spectrum from a (TaTi)C precipitate pointed by arrow c,e in (a); (d, f) HRSTEM image, FFT pattern, and EDS spectrum from a $(\mathrm{CrW}) \mathrm{C}$ precipitate pointed by arrow d,f in (a). Blue: spectrum of $\mathrm{Fe}-\mathrm{Cr}$ matrix grain. 


\section{Summary}

Microstructure of two alloys, Z6 and T12 before and after proton irradiation, has been thoroughly characterized using TEM. The following knowledge of these alloys can be obtained at the current point:

1) Un-irradiated $\mathrm{Z6}$ alloy is composed of predominant eutectic structure of $\mathrm{Fe}-\mathrm{Cr}$ matrix $(\alpha-\mathrm{Fe})$ and $\mathrm{Zr} / \mathrm{W}$-rich Laves phase $\left(\beta-\mathrm{Fe}_{2} \mathrm{Zr}\right)$, together with some $\mathrm{Fe}-\mathrm{Cr}$ primary phase. The ferrite matrix grains contain substantial amount of tangled dislocation lines and small dislocation threads. The Laves phase contains bunches of stacking faults.

2) Un-irradiated T12 alloy is composed of single phase (Fe-Cr) matrix. The significantly elongated subgrains contain a high density of dislocations inside and on grain boundaries. Spherical (TaTi)C precipitates were found inside matrix grains.

3) The TEM specimens extracted from the proton-irradiated sample of Z6 alloy showed distinct surface morphology and internal microstructure, which had lamellar eutectic structure different from the the predominant type of eutectic structure characterized in the un-irradiated Z6 alloy. In general, proton-irradiation did not result in noticeable changes to the eutectic structure, but resulted in the formation of large amount of polyhedron-shaped defects within $\mathrm{Fe}-\mathrm{Cr}$ ferrite grains, together with slight segregation of $\mathrm{Zr}$ at boundaries and the defects. Additionally, noticeable preferential oxidation of $\mathrm{Fe}_{2} \mathrm{Zr}$ was observed near surface.

4) Microstructure of T12 alloy is not significantly changed after proton-irradiation, except for the formation of Cr-rich carbide precipitates along grain boundaries.

\subsubsection{Z- and T-alloy after Fe-irradiation}

No post-implantation discoloration was observed on the surface of the iron-irradiated $\mathrm{T}$ - and Z-alloys because of the relatively short duration of irradiation. All $\mathrm{Z}$ - and $\mathrm{T}$-alloys seem to be resistant to precipitate formation/phase changes due to iron-irradiation (see Figure 67, Figure 68).

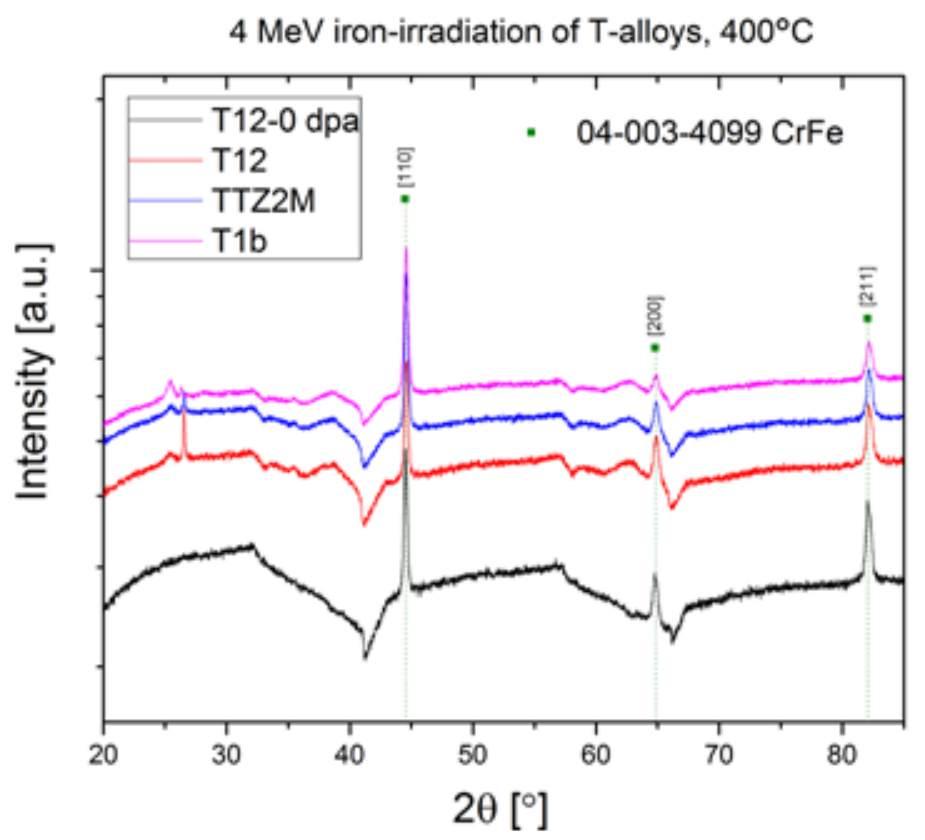

Figure 67. X-ray diffraction patterns of Fe-irradiated T-alloys at $400^{\circ} \mathrm{C}$ up to 50 dpa. Main peaks at $2 \theta \sim 45^{\circ}$, $65^{\circ}$, and $82^{\circ}$ correspond to diffraction from $\mathrm{CrFe}$ (PDF04-033-4099). 


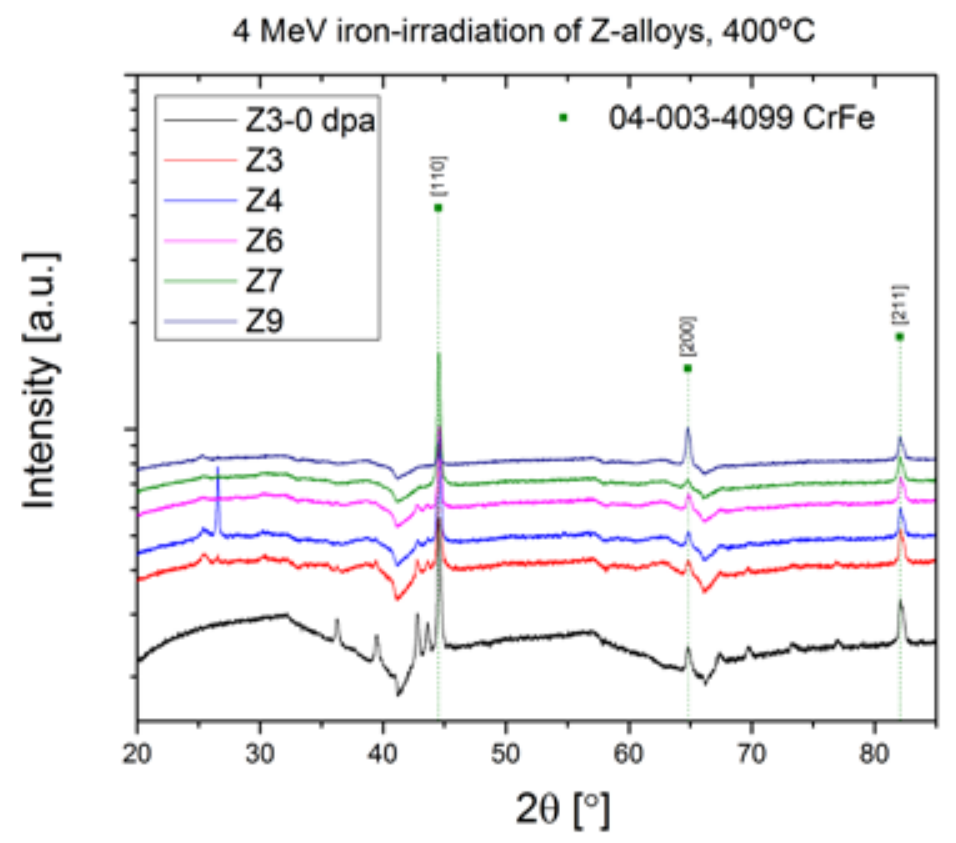

Figure 68. X-ray diffraction patterns of Fe-irradiated $\mathrm{Z}$-alloys at $400^{\circ} \mathrm{C}$ up to 50 dpa. $M$ ain peaks at $2 \theta \sim 45^{\circ}$, $65^{\circ}$, and $82^{\circ}$ correspond to diffraction from CrFe (PDF04-033-4099).

Iron-irradiated (Z6, T12) and un-irradiated of the same type samples were each indented on their surface using a high-load transducer under displacement control settings. Maximum displacements of 2, $4,6,8,10$, and $12 \mu \mathrm{m}$ are indented onto the surface with constant loading and unloading rates. As seen in Figure 69, the topography of the iron-irradiated T12 was roughened to the point where the microscopy was not entirely in focus due to large changes in the peaks and valleys. Because of that we were not able to obtain reliable hardness data for the Fe-Irradiated T12 sample.
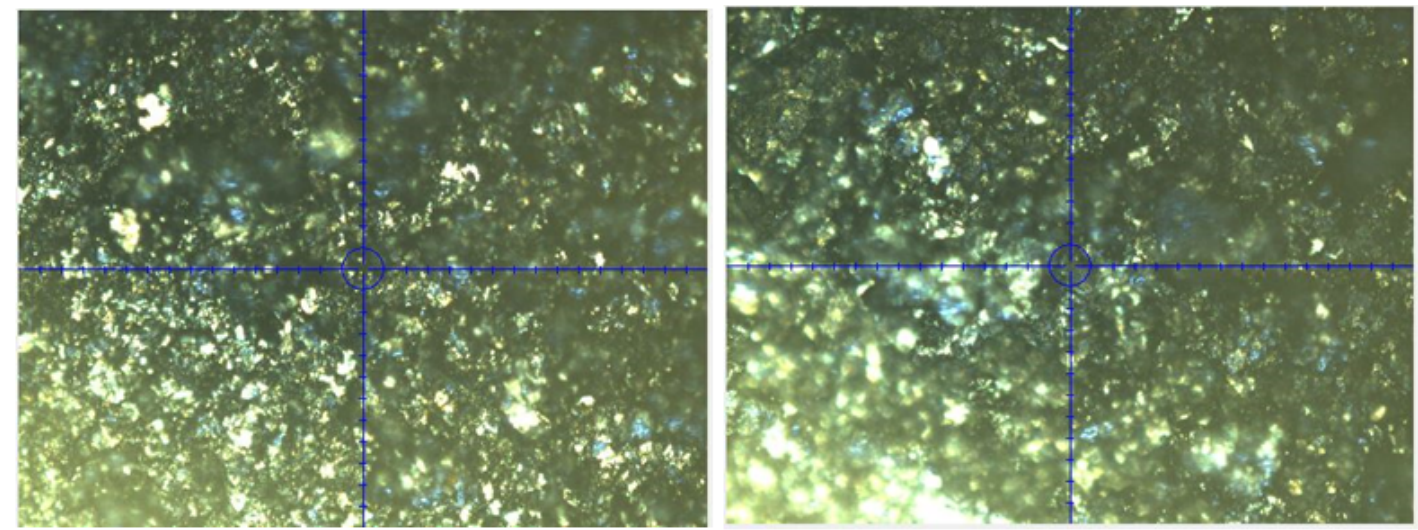

Figure 69. Sample surface images taken of Fe-irradiated T12 alloy.

The hardness value for the Fe-irradiated Z6 sample has a significant increase in standard deviation at the $2 \mu \mathrm{m}$ mark as shown in Figure 70. This increase can be attributed to the roughness values of the sample. Some correction for this roughness can be applied using the advanced non-linear Oliver-Pharr method. Except for the $2 \mu \mathrm{m}$ indent, the Fe-irradiated Z6 sample shows a slight increase in hardening compared to its un-irradiated counterpart. 


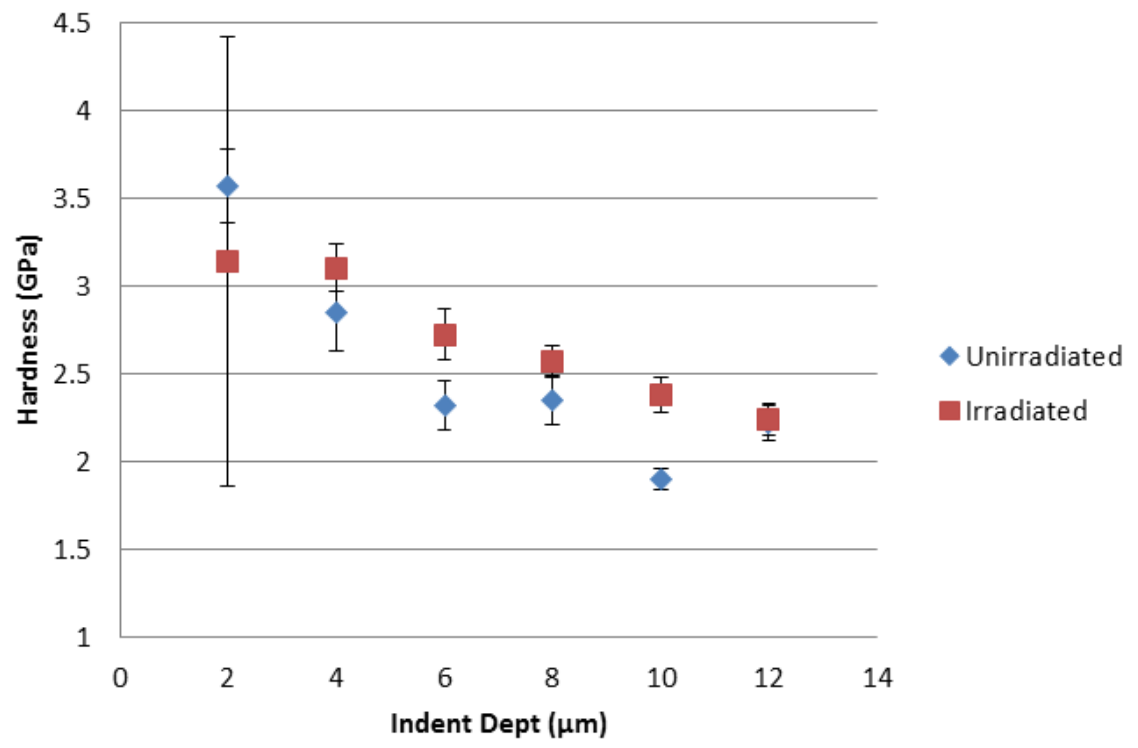

Figure 70. Projection for hardness vs contact depth for Fe-irradiated Z6 alloy (red) as compared to unirradiated base material (blue).

\subsubsection{TEM analysis of Fe-irradiated samples}

\section{Microstructure of un-irradiated Z6 Alloy}

Conventional TEM as well as ABF-STEM imaging were used in order to analyze the as received Z6 sample. The sample results as made up of two different phases: bcc ferrite and $\mathrm{Fe}_{2} \mathrm{Zr}$ Laves phase.

Figure 71 shows a STEM-HAADF image of the as received alloy. The different contrast of the grains arises from a different average $\mathrm{Z}$-number (HAADF is a Z-contrast imaging technique), and therefore is caused by a different chemical composition: darker grains correspond to the ferrite phase, brighter grains correspond to the Laves phase. EDS points scans performed on 10 different grains of each phase gave an average atomic composition of $88.12 \%$ and $11.69 \%$ for $\mathrm{Fe}$ and $\mathrm{Cr}$, respectively, in the ferrite phase, and $70.39 \%, 2.80 \%$ and $26.80 \%$ for $\mathrm{Fe}, \mathrm{Cr}$ and $\mathrm{Zr}$, respectively, in the Laves phase.

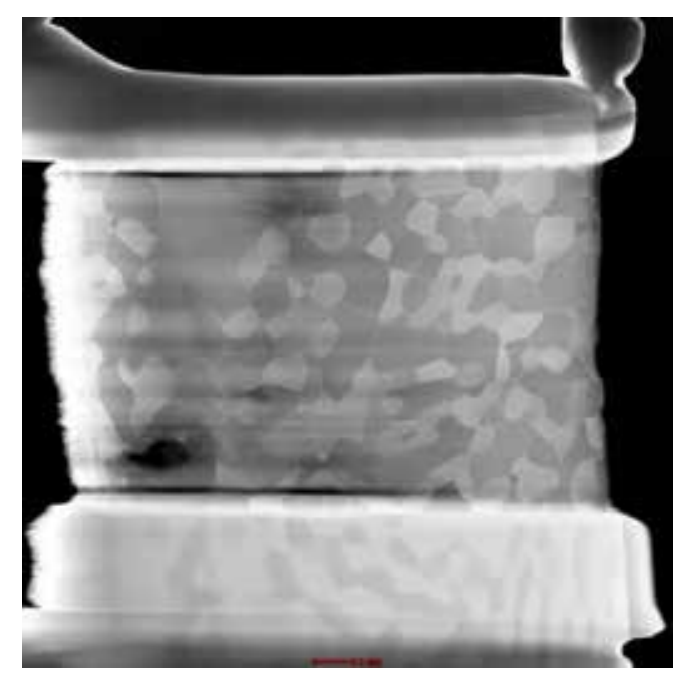

Figure 71. Low magnification STEM-HAADF image of the as received Z6 alloy, showing an overview of the sample: darker grains correspond to the ferrite phase, brighter grains correspond to the Laves phase. 
Native structure of the bcc grains is characterized by a small size $(\sim 1 \mu \mathrm{m})$ and the presence of native dislocation lines. STEM-ABF images of 1 grain of the as received Z6 alloy sample imaged along the [100] zone axis (ZA) is shown in Figure 72.

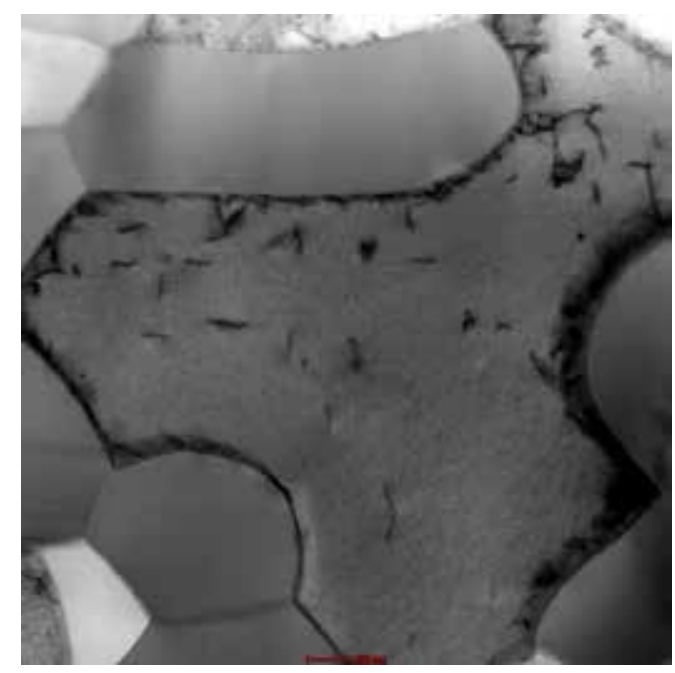

Figure 72. STEM-ABF micrograph of the one grain of the as received $\mathrm{Z6}$ alloy imaged along the [100] zone axis. Dislocation lines are visible at the center of the grain as well as close to grain boundaries.

Two different grains were analyzed and the density of the dislocation was estimated to be $0.09 \times 10^{22}$ $\mathrm{m}^{-3}$, with an average size of $40 \pm 18 \mathrm{~nm}$. Figure 73 shows the size distribution for the dislocation lines in the un-irradiated $\mathrm{Z} 6$ alloy.

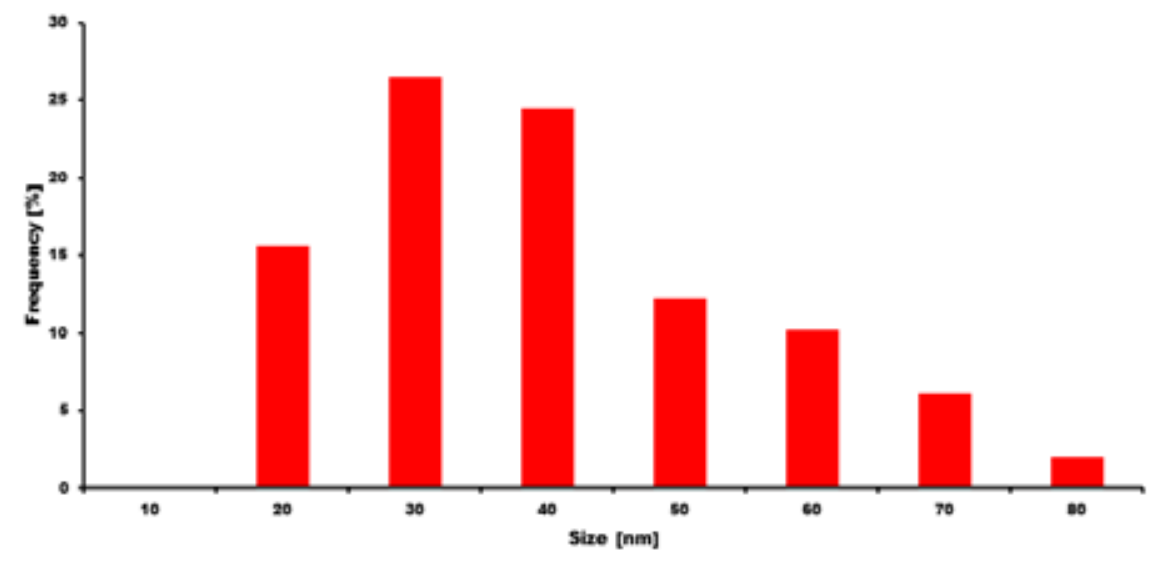

Figure 73. Size distribution of the dislocation lines in the $\mathrm{Z6}$ as received alloy.

\section{Microstructure of Fe-irradiated Z6 Alloy}

Heavy ions at the energy of few $\mathrm{MeV}$ have only a limited range (on the order of single $\mu \mathrm{m}$ ) inside metals and alloys, and therefore this limits the regions of the sample that can be investigated. Two different grains were analyzed and the defects present were counted and sized. The position inside the sample of the two grain chosen for the analysis is shown in Figure 74. 

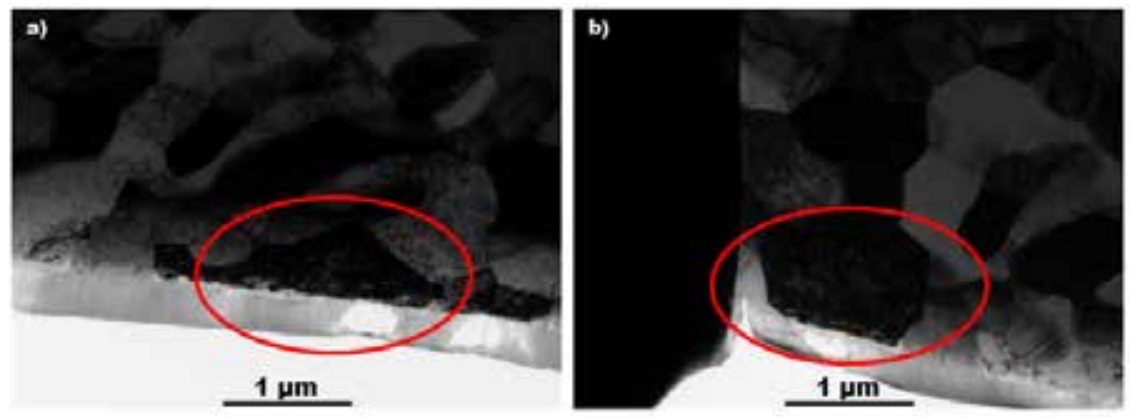

Figure 74. TEM-BF micrographs of the two grains (circled in red) used for defect analysis in the Feirradiated Z6 alloy.

For the analysis, each grain was imaged in ABF-STEM mode on the [100] and [110] zone axis. Although the [110] zone axis is sufficient for imaging all the possible dislocation loops present in irradiated bcc alloys, imaging along the [100] ZA is useful for distinguishing some of the different loop morphologies. Figure 75 shows a typical ABF-STEM micrographs of the grain shown in Figure 74(b), imaged along the [110] ZA. Because of the high density of loops in some regions of the grain and in order to further distinguish some of the loops observed, the same region was imaged also on the [100] $\mathrm{ZA}$, because this is an ideal orientation to differentiate $<100>\{100\}$ dislocation loops from $1 / 2<111>\{111\}$ loops.

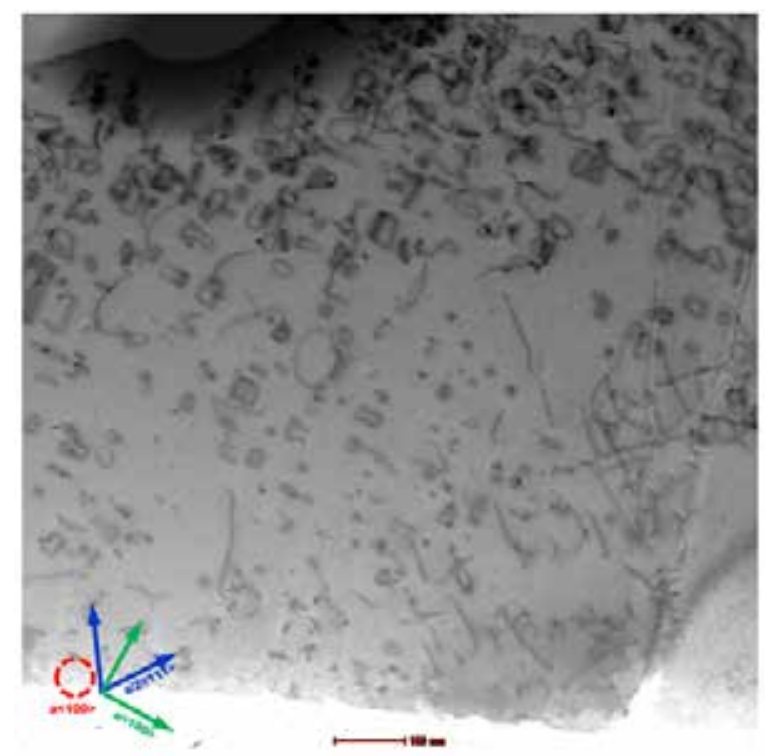

Figure 75. STEM-ABF micrograph of one grain of the Fe-irradiated Z6 alloy imaged along the [110] ZA. On the bottom left corner the habit planes of the loops, as viewed in this imaging condition is shown, as taken from Yao et al. [29]. 

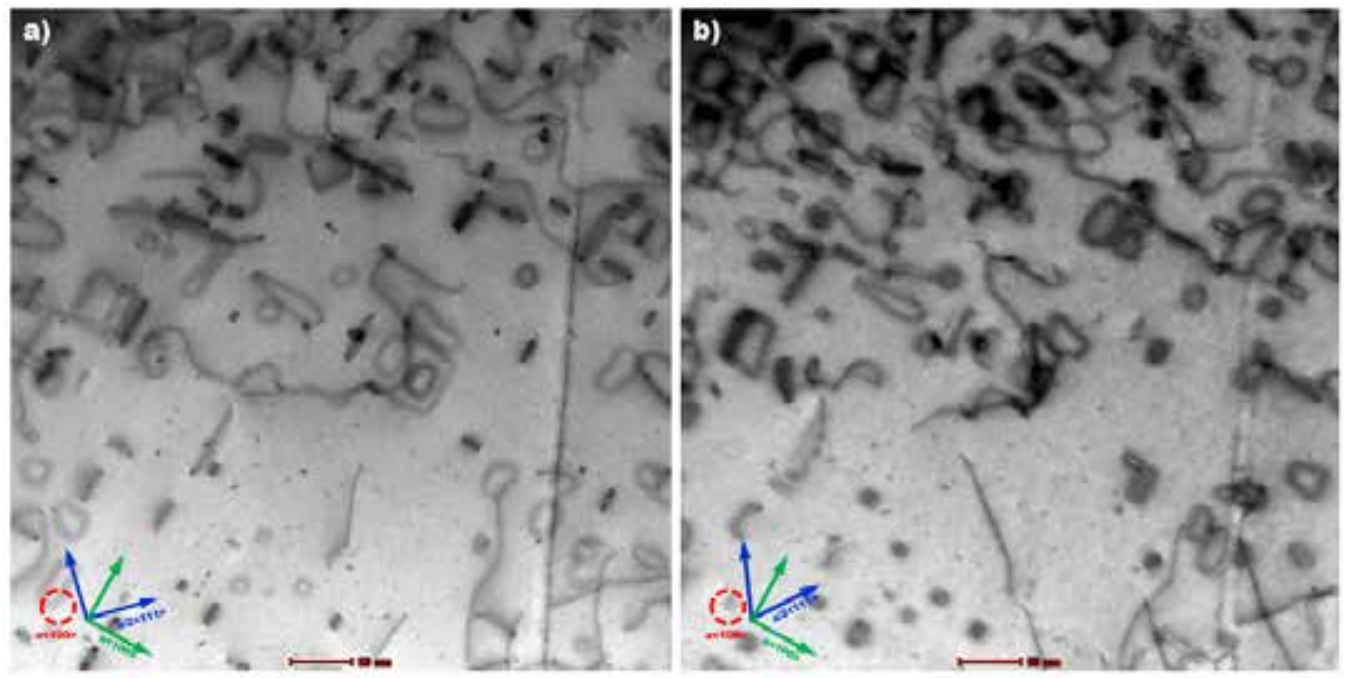

Figure 76. STEM-ABF micrographs (the same region and grain) of the Fe-irradiated Z6 alloy imaged around a) $[100]$ and b) $[110]$ zone axes.

As seen from Figure 76, almost only loops of the $<100>$ types are visible. It was already seen in some reports that after irradiation at high temperature $\left(\sim 400^{\circ} \mathrm{C}\right.$ and higher $),<100>$ loop type becomes predominant over the $<111>$ ones [32,33,34]; this is also confirmed by theoretical calculations for pure $\alpha-\mathrm{Fe}$ [32]. Two different grains were analyzed and the defects were count; their density was estimated to be $0.86 \times 10^{22} \mathrm{~m}^{-3}$ and the size was estimated to be $18.06 \pm 10.69 \mathrm{~nm}$. The size distribution is also presented in Figure 77. It must be noted however, that the great variance in dislocation loops size is due to the fact the damage profile caused by heavy ions is characterized by a steep function, and therefore the damage caused to the sample varies substantially over small depths (there is a great variability of dpa inside one single grain). Additionally, HRSTEM images were acquired on a dislocation loop and a dislocation line of the irradiated sample, as shown in Figure 78.

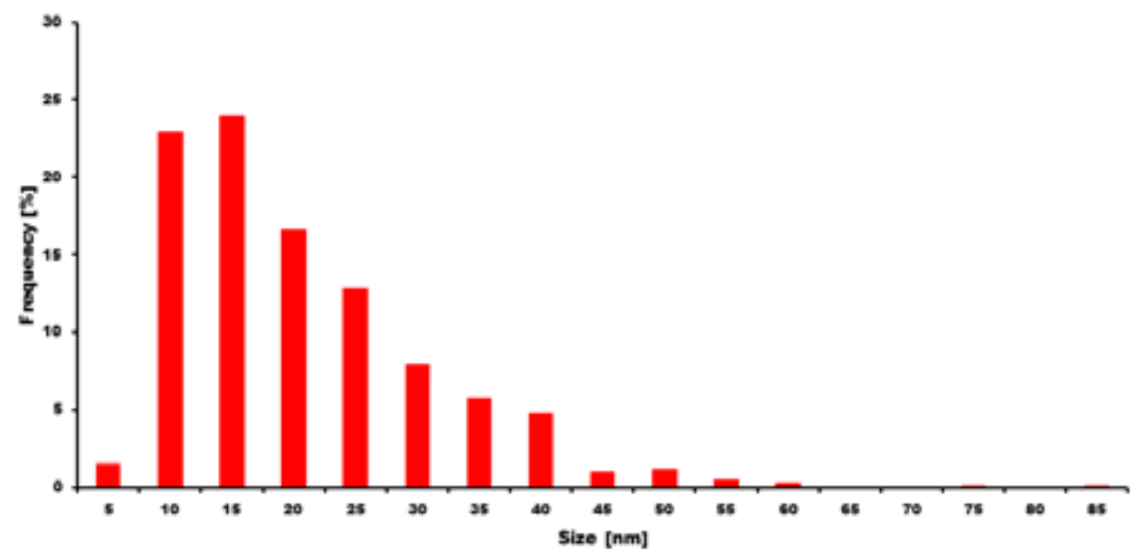

Figure 77. Size distribution for dislocation loops formed in Fe-irradiated Z6 alloy. 

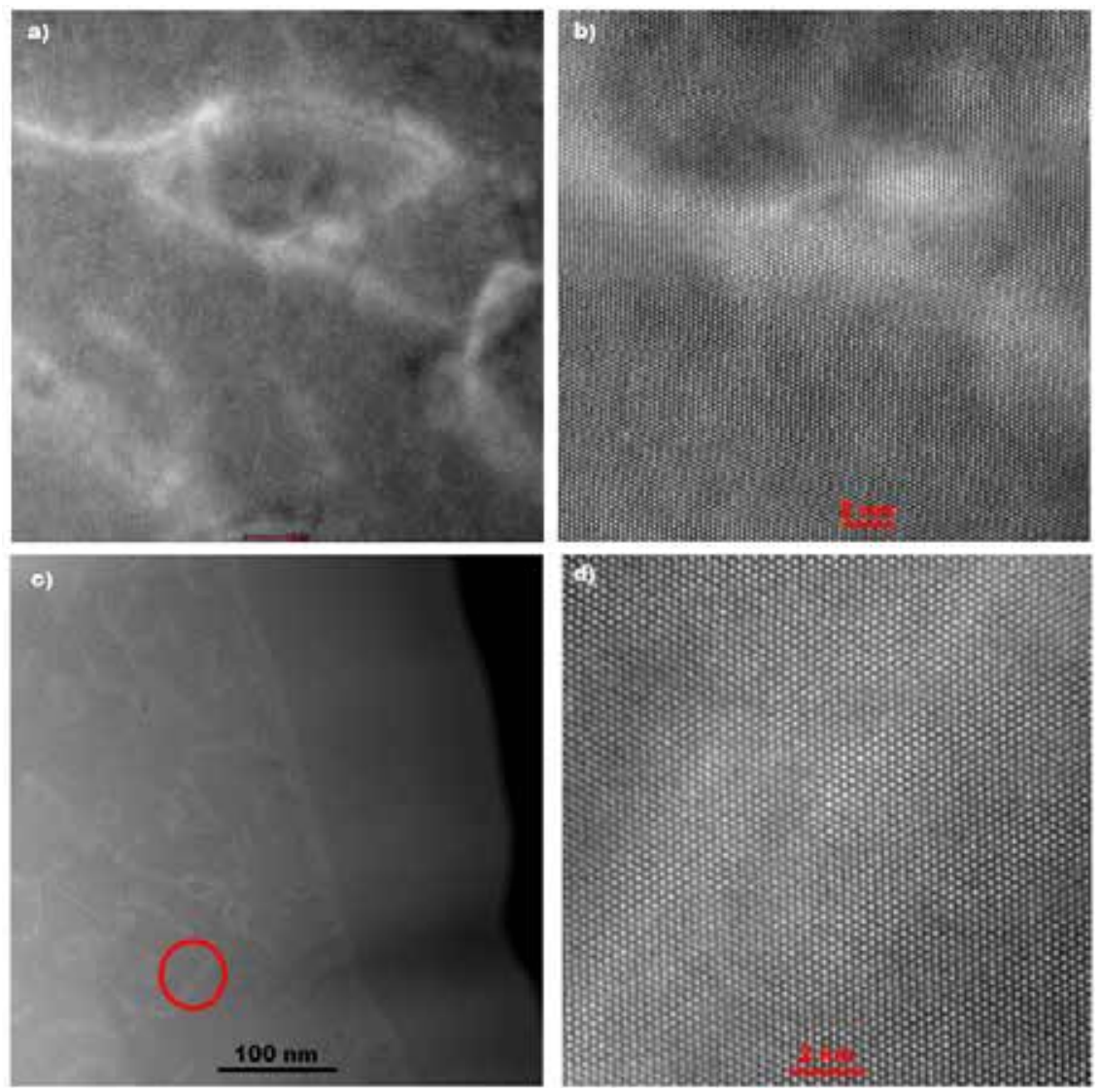

Figure 78. HRSTEM images acquired on dislocation lines and a loop found in the Fe-irradiated Z6 alloy, when the grain was oriented along the [111] ZA. No significant structural rearrangement was observed.

Finally, no evidence of radiation induced segregation was found across grain boundaries between ferrite grains. Three different grains were analyzed and no significant segregation was observed in any of these grains. Figure 79 shows a typical profile across the grain boundaries.

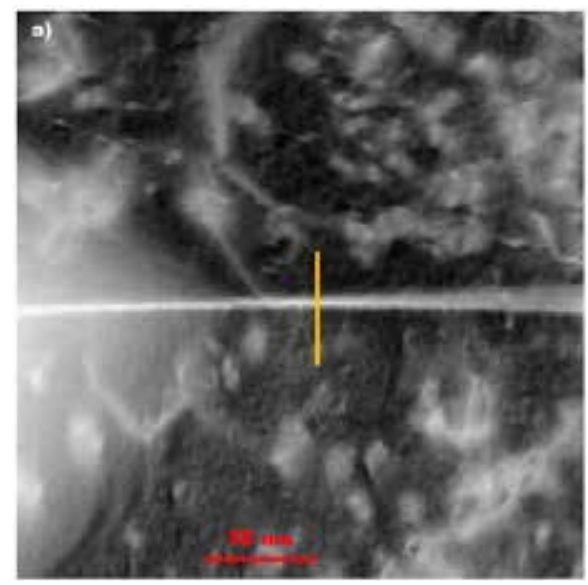

b)

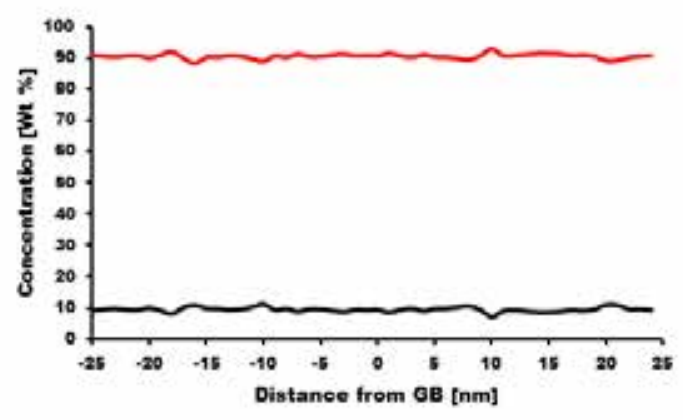

Figure 79. Typical RIS profile across a grain boundary separating two ferritic grains in the Fe-irradiated Z6 alloy: a) STEM-ADF image; b) EDS compositional profile following the orange line in a) with red and black lines denoting $\mathrm{Fe}$ and $\mathrm{Cr}$, respectively. 
Depending on the damage dose to which they were exposed, some of grains of the Laves phases were seen to undergo amorphization. This happened at depths in the range of 0.8 to $1.7 \mu \mathrm{m}$ from the sample surface. Grains of the Laves phase found outside this region (closer to the surface or deeper inside the sample, but still within the irradiation range), remained crystalline. Figure 80 shows a series of STEM$\mathrm{ABF}$ images and selected area diffraction patterns (SADP) of the Fe-irradiated Z6 alloy.
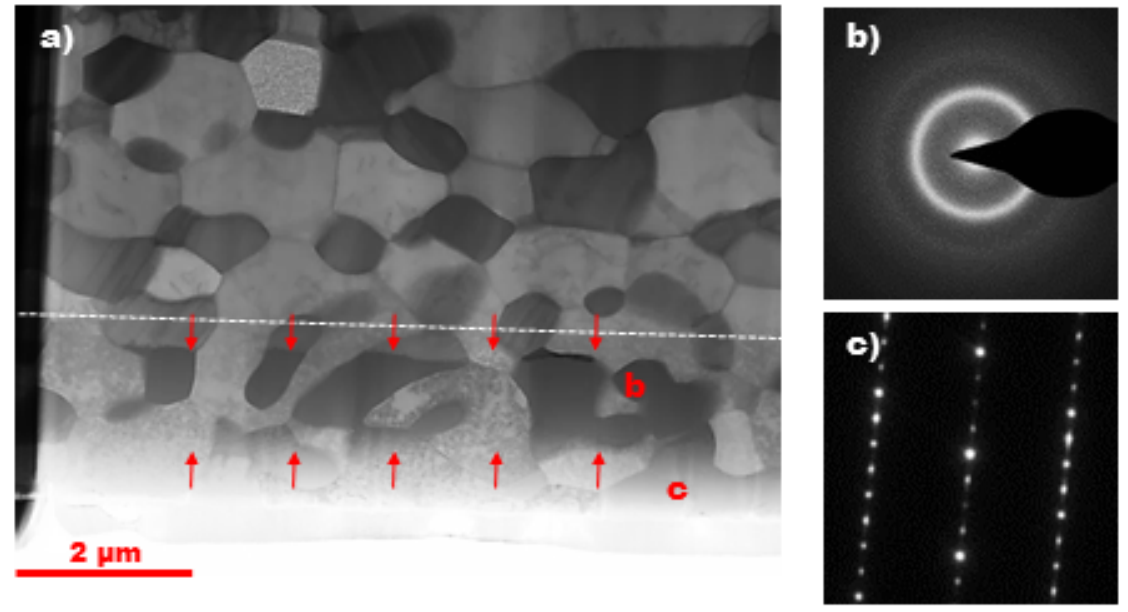

Figure 80. Overview of the Fe-irradiated Z6 alloy and Laves phase: a) low magnification STEM-ABF micrograph with a dashed white line representing the approximate depth after which defects caused by irradiation are not visible anymore, corresponding to the maximum damage range of $\sim 2.1 \mu \mathrm{m}$. Grains of the Laves phase within the region bounded by red arrows $(0.8-1.7 \mu \mathrm{m})$ underwent amorphization. $b)$ and c) are the SADP corresponding to the grains indicated by $b$ and $c$ in the STEM micrograph.

As can be seen from Figure 80(a), the grains of the Laves phase which underwent amorphization can also be identified by a slight change in contrast. It is also worth noting that in some cases amorphization occurred only in a fraction of a grain, leaving the remaining part of it crystalline (careful observation of Figure 80(a) shows that the contrast sometimes changes within a single grain). HRSTEM images of the non-amorphous regions of the Laves phases (Figure 81) showed that no particular atomic rearrangement occurred inside the grains, as compared with the as received sample.
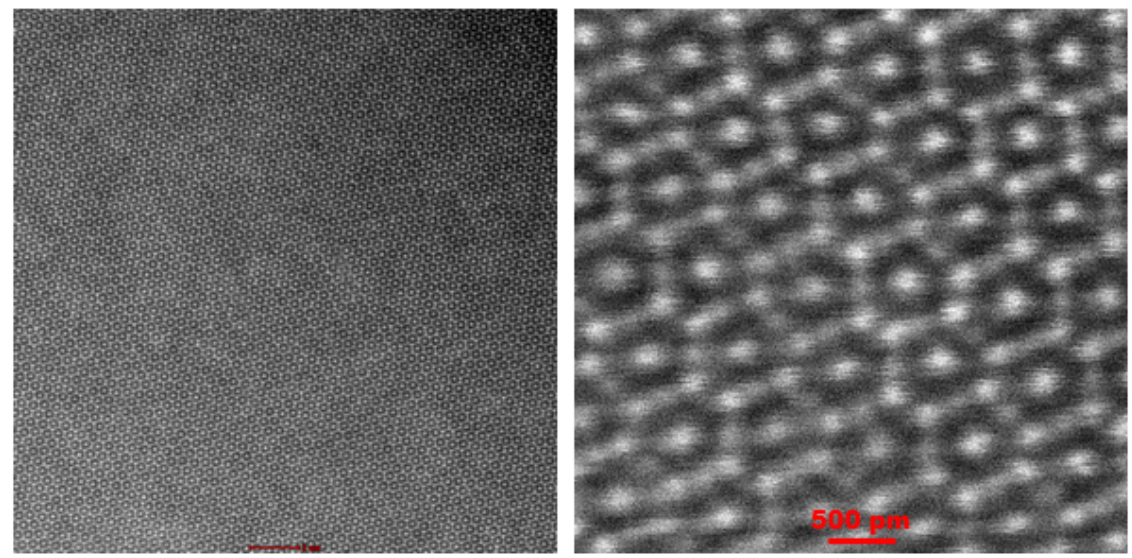

Figure 81. HRSTEM image of one crystalline grain of the Laves phase close to the top surface of the Feirradiated $\mathrm{Z6}$ alloy. 
Finally, a STEM-ABF micrograph of one Laves phase grain (imaged a little bit off axis, to decrease the contrast given by the faulted planes) shows some features that might look like defects caused by radiation (Figure 82). Defects that look like dislocation loops are visible and appear to be aligned with the faults plane.
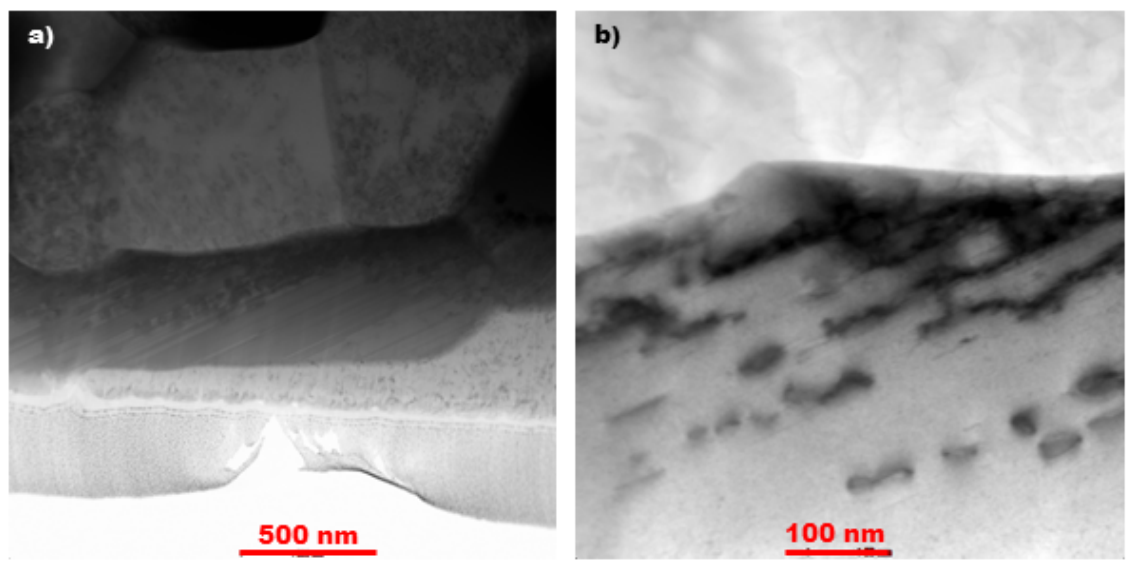

Figure 82. STEM-ABF micrographs of a crystalline Laves phase grain in the Fe-irradiated Z6 alloy.

\section{Microstructure of un-irradiated T12 Alloy}

Figure 83 shows a low magnification TEM image of the as-received sample of T12 alloy. The asreceived martensite phase has a very complicated microstructure including lath boundaries, a very high density of dislocation lines, dislocation networks, and different types of precipitates. Figure 84 shows two STEM micrographs of the as received sample, showing the dislocation networks inside the martensite laths, lath boundaries, and some of the precipitates found in the sample.

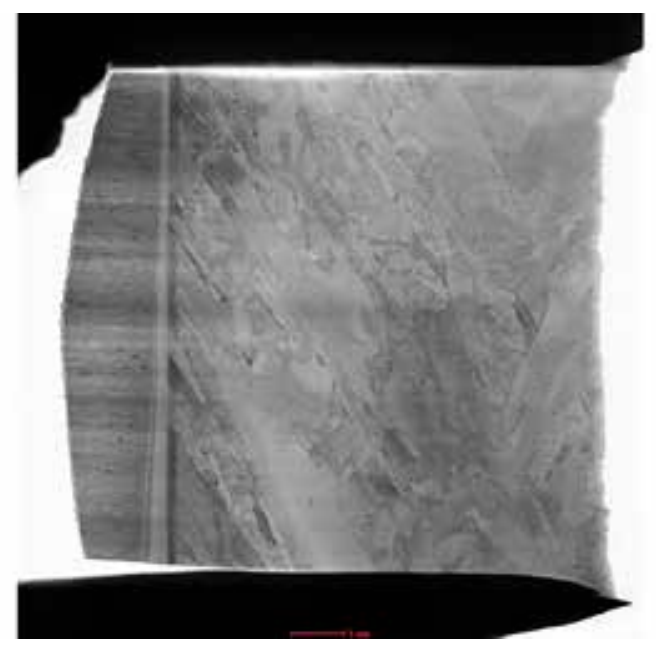

Figure 83. Low magnification STEM-ABF image of the as received T12 alloy, showing an overview of the sample with the martensitic structure. 


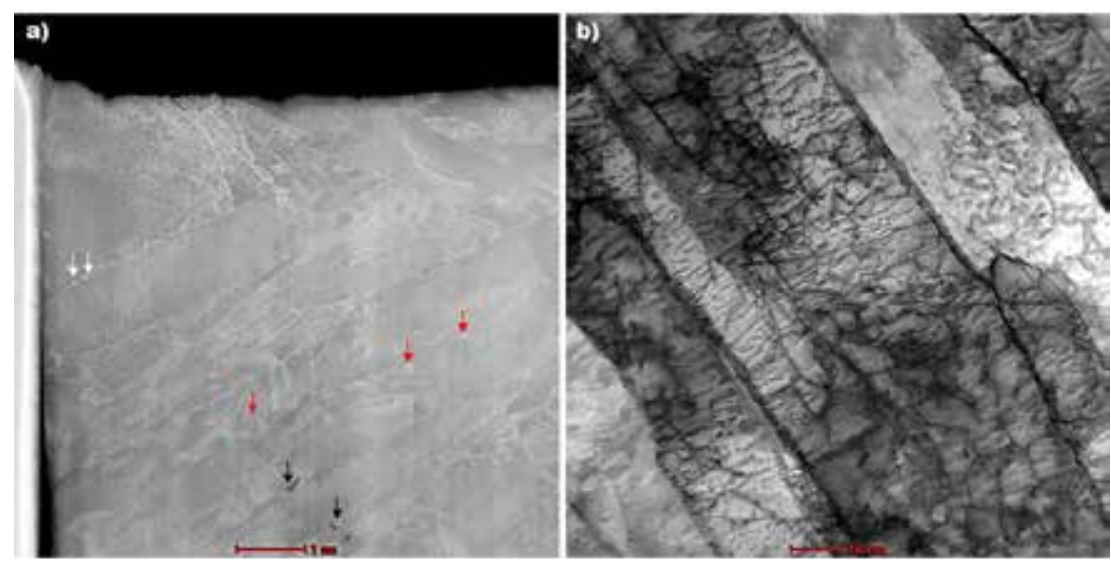

Figure 84. STEM micrographs of the as received T12 alloy: a) HAADF image showing different precipitates found in the as received alloy (arrows of different colors indicated precipitates with different composition) found in the sample; b) BF-ABF STEM micrograph of dislocations line inside a lath (imaged on the $[100] \mathrm{ZA})$.

Different types of precipitates were found dispersed inside the matrix of the as received alloy. Many precipitates displayed a brighter contrast as respect to the matrix when imaged in STEM-HAADF and STEM-ADF mode (STEM-HAADF is a Z-contrast imaging method, meaning that brighter particles contain heavier elements as respect to the surrounding matrix, while STEM-ADF, while still sensitive to Z-contrast, is also sensitive to a diffraction contrast); the particles were therefore enriched in heavier elements as compared to the matrix. Of these particles, some of them were found to be dispersed homogenously inside the grains; typically these precipitates have a size of $\sim 10 \mathrm{~nm}$ and they are enriched in $\mathrm{Ta}, \mathrm{Ti}$ (and most probably also $\mathrm{C}$ ) as compared to the surrounding matrix. Figure 85 shows a low magnification STEM-HAADF micrograph showing some of these precipitates along with an EDS of one of precipitates.
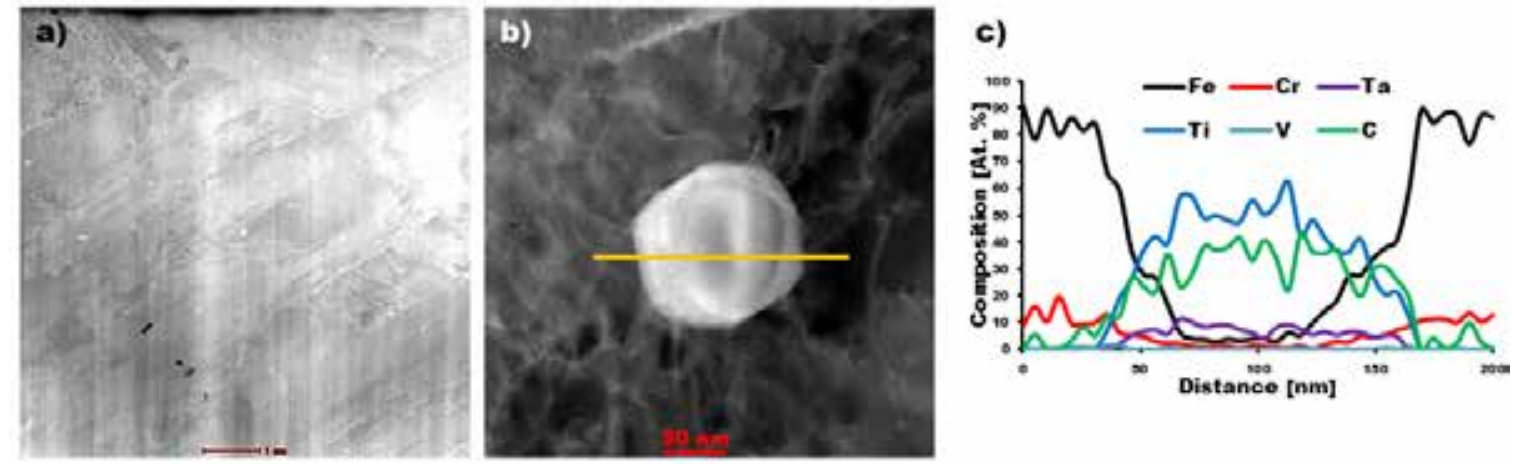

Figure 85. STEM-EDS analysis of the bright precipitates in the as received T12 alloy: a) STEM-HAADF image showing different precipitates dispersed inside the grain of the steel matrix; b) STEM-HAADF at higher magnification of one precipitates; c) EDS line-scan profiles showing $\mathrm{C}$, Ta and Ti enrichment in the precipitate.

The composition of the single particles was found to be variable, in particular the $\mathrm{C}$ content and the $\mathrm{Ti} / \mathrm{Ta}$ ratio, which was found to vary between 2.2 and 4 in different precipitates of this kind. Other bright precipitates were found at the grain boundaries. These precipitates, as opposed to the bright precipitates found inside the grains, were not enriched in $\mathrm{Ti}$ and $\mathrm{Ta}$, but in $\mathrm{W}$, and they also showed a significant 
amount of $\mathrm{Cr}$ in excess, as compared to the nominal value of the matrix. The value of the $\mathrm{Fe} / \mathrm{Cr}$ ranges in this particles between 1 and 2.5, and an average $\mathrm{W}$ concentration of 2\%. Figure 86 shows these types of precipitates, found on grain boundaries and giving a brighter contrast as respect to the matrix.

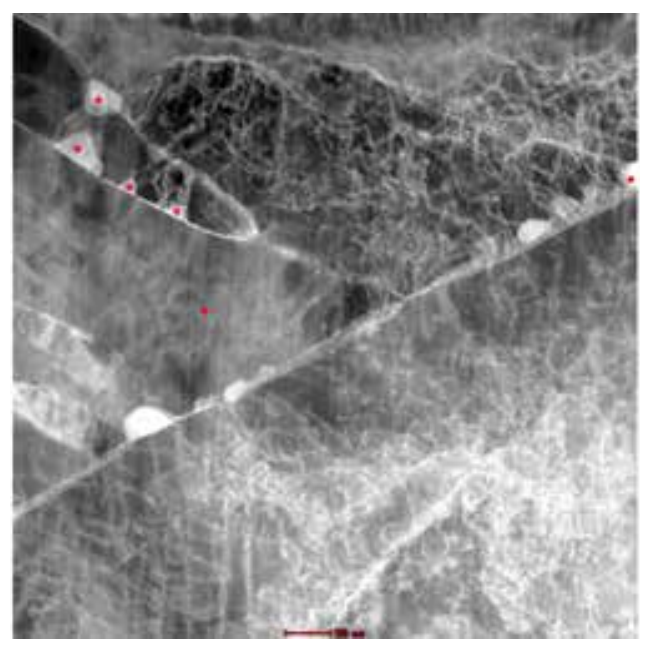

Figure 86. STEM-ADF images of bright precipitates at gain boundary of the as received T12 alloy, which are enriched with $\mathrm{W}$ and $\mathrm{Cr}$, as compared to the matrix. Red dots represent the point from which EDS signals were acquired.

Different types of precipitates, indicated by black arrows in Figure 84 are shown in Figure 87. Only 4 precipitates of this kind were found in the entire lamella. The darker contrast exhibited by these particles indicated they are enriched with elements which are lighter than the matrix. Table 12 shows their average composition.

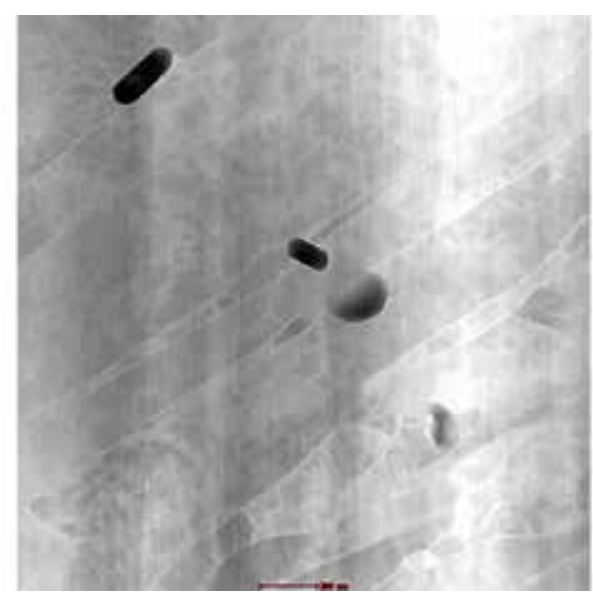

Figure 87. STEM-HAADF image of the precipitates indicated by black arrows in Figure 84. Those precipitate are heavily enriched in titanium and carbon and only slightly in tantalum.

Table 12. Atomic percent composition of the black precipitates observed in the T12 as received alloy.

\begin{tabular}{ccccccccc}
\hline $\mathrm{C}[\%]$ & $\mathrm{O}[\%]$ & $\mathrm{Ti}[\%]$ & $\mathrm{V}[\%]$ & $\mathrm{Cr}[\%]$ & $\mathrm{Mn}[\%]$ & $\mathrm{Fe}[\%]$ & $\mathrm{Ta}[\%]$ & $\mathrm{W}[\%]$ \\
\hline 18.01 & 0.6275 & 49.9725 & 0.2 & 2.1225 & 0 & 24.515 & 4.525 & 0 \\
\hline
\end{tabular}




\section{Microstructure of Fe-irradiated T12 Alloy}

Heavy ions at the energy of few $\mathrm{MeV}$ have only a limited range (on the order of few single $\mu \mathrm{m}$ ) inside metals and alloys, and therefore this limits the volume of the sample that can be investigated. Two different grains were analyzed and the defects present were counted and sized. The position inside the sample of the two grain chosen for the analysis is shown in Figure 88.
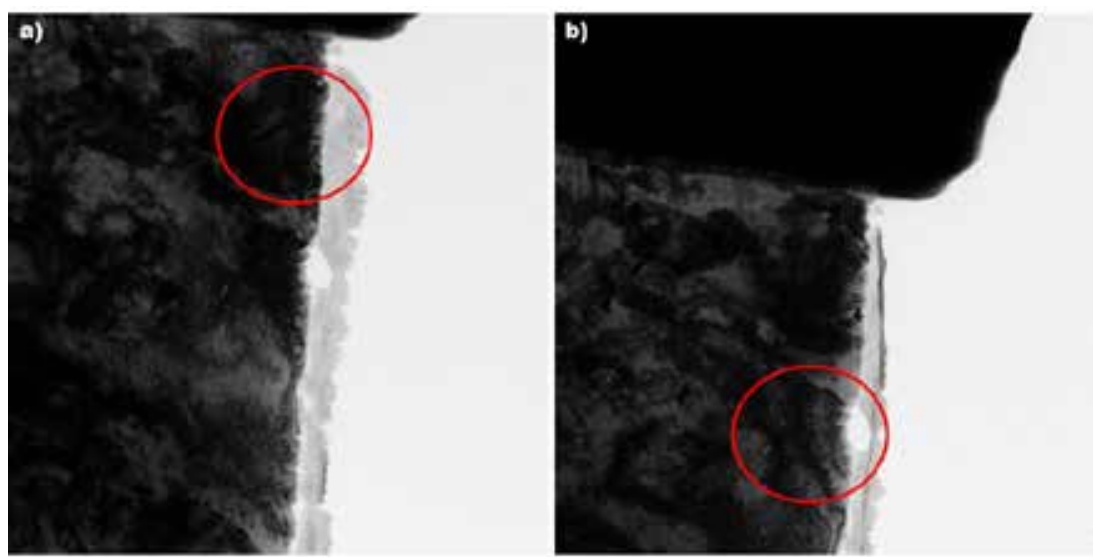

Figure 88. TEM-BF micrographs of the two grains (circled in red) used for defect analysis in the Feirradiated $\mathrm{T} 12$ alloy.

For the analysis, each grain was imaged in ABF-STEM mode on the [100] Zone Axis. The starting microstructure of the steel was complicated and most of the dislocation lines and dislocation networks observed were still present after radiation and made the observation of the defects formed due to irradiation challenging. Figure 89 shows a STEM-ABF image of one grain of the irradiated sample and the resulting loops observed in the grain. The density of loops observed was estimated to be $5.0 \times 10^{22}$ loops $/ \mathrm{m}^{3}$ and the average size was $6.57 \pm 3.67 \mathrm{~nm}$. The size distribution is also presented in Figure 90.
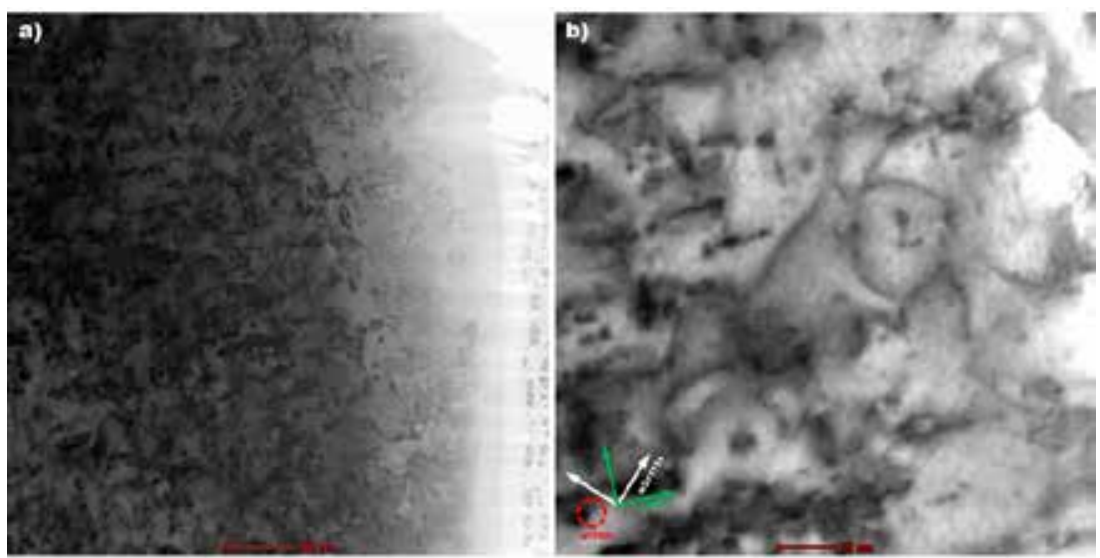

Figure 89. ABF-STEM images of dislocation loops in a grain of the Fe-irradiated T12 alloy, imaged on the [100] ZA. Similar to the case of Fe-irradiated Z6 alloy, loops are determined to be of the $<100>\{100\}$ type. 


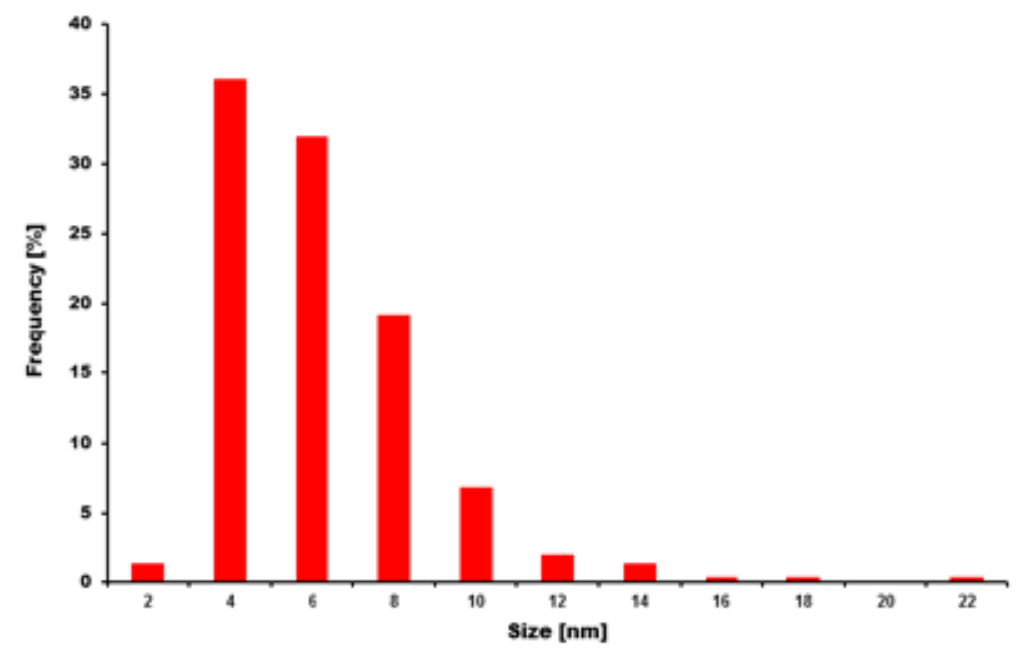

Figure 90. Size distribution for dislocation loops formed in Fe-irradiated T12 alloy.

Irradiated samples showed the same types of precipitates as the as-received alloy samples. It appears that the distribution of precipitates changes primarily because of high temperature exposure. Figure 91 shows regions of the samples with a high density of precipitates. These regions were not exposed to the irradiating ions, as they were found deep inside the lamella (well beyond the irradiation range). Regions with such high density of precipitates were not found in the as-received alloy. Figure 92 shows precipitate particles just inside and outside the ion range.
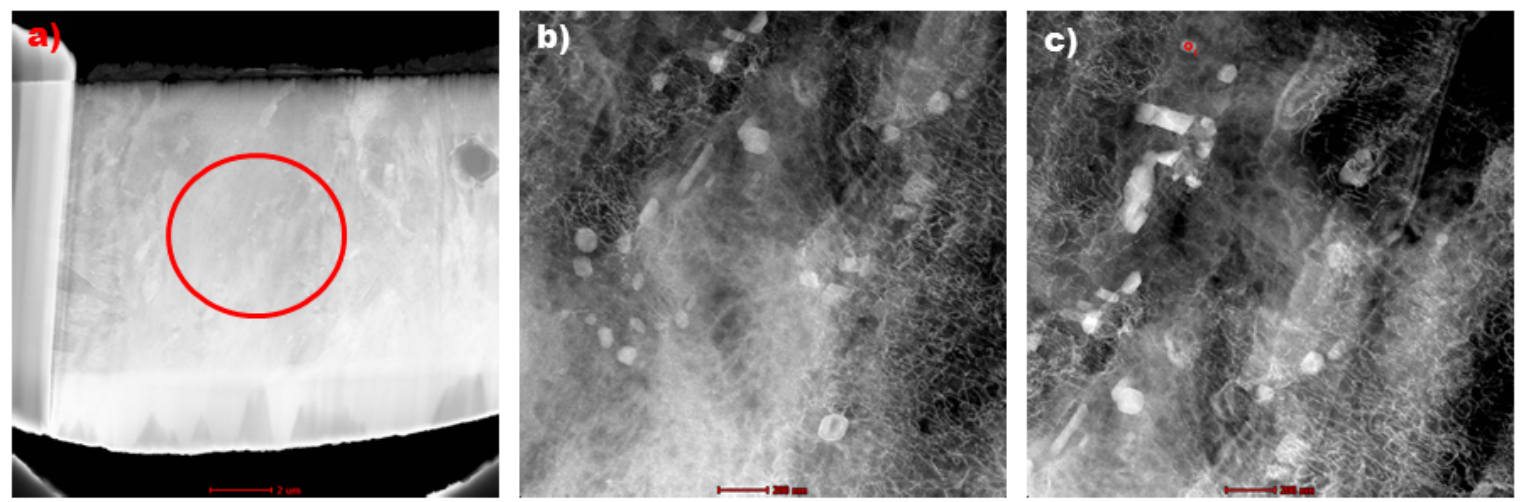

Figure 91. STEM-HAADF micrographs of the Fe-irradiated T12 alloy at (a) low magnification and (b,c) high magnification of the region encircled in (a). High density of precipitate particles was observed and their composition varied considerably. Typically, precipitates inside grains were enriched in Ti and Ta, while precipitates on grain boundaries were enriched in $\mathrm{W}$ and $\mathrm{Cr}$. 

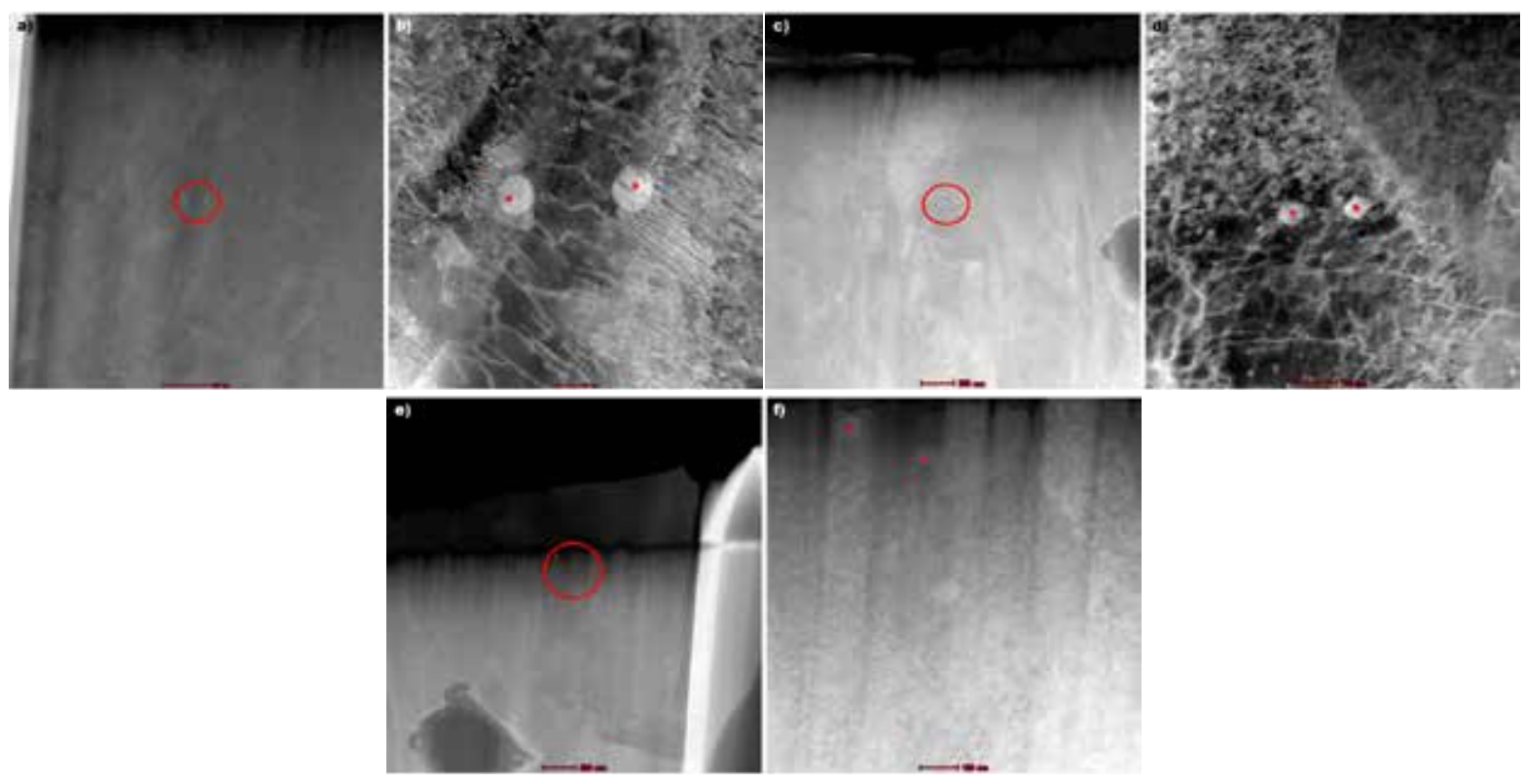

Figure 92. STEM-HAADF micrograph showing different precipitates at various depths inside the Feirradiated T12 alloy.

For both inside and outside the ion range, precipitates found within grains, were generally enriched in $\mathrm{Ti}$ and $\mathrm{Ta}$, while precipitates found at grain boundaries (see Figure 93), are generally enriched in $\mathrm{Cr}$ and $\mathrm{W}$. The precipitates at the lath boundaries were enriched in $\mathrm{W}$ (approximately $2 \%$ ) and in $\mathrm{Cr}$ ( $\mathrm{ratio} \mathrm{Fe} / \mathrm{Cr}$ ranging between 0.5 and 2).
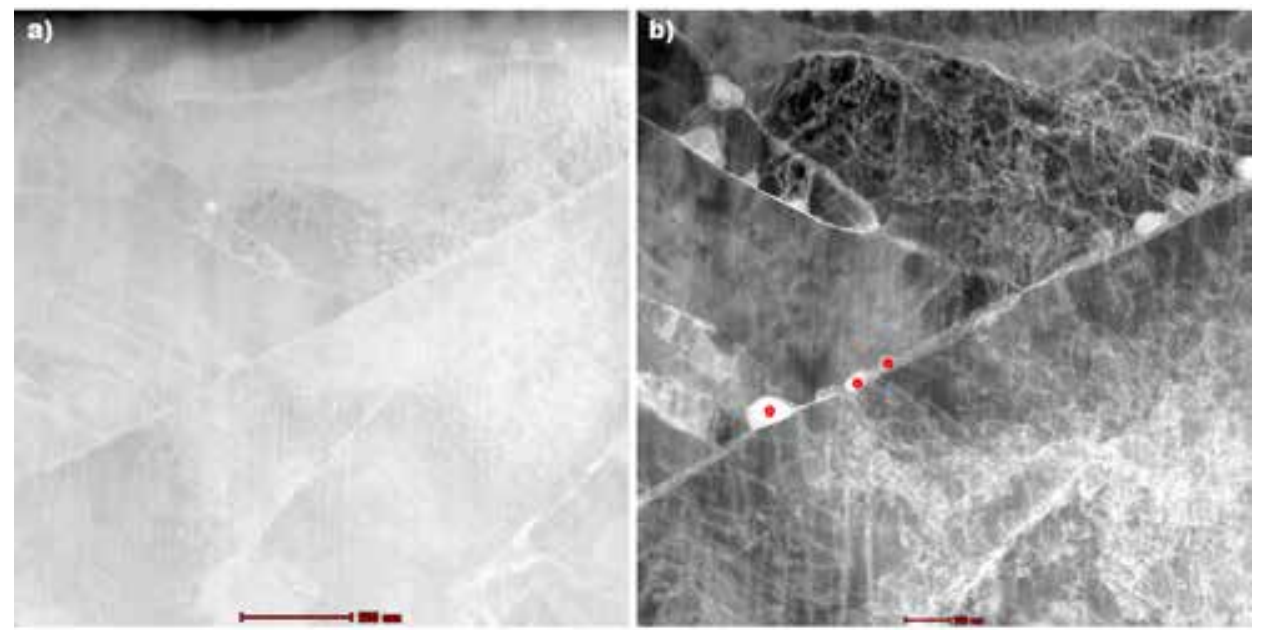

Figure 93. STEM-HAADF micrograph of different precipitates found at grain boundaries in the Feirradiated T12 alloy. Red dots represent the point from which EDS signals were acquired.

A typical example of a line scan ran across a precipitate at grain a boundary (outside the ion range) is shown in Figure 94. As can be seen from Figure 94, particles at these grain boundaries are enriched in W and in $\mathrm{Cr}$ as compared to the matrix. No elemental Ti or Ta were detected inside the particles. 


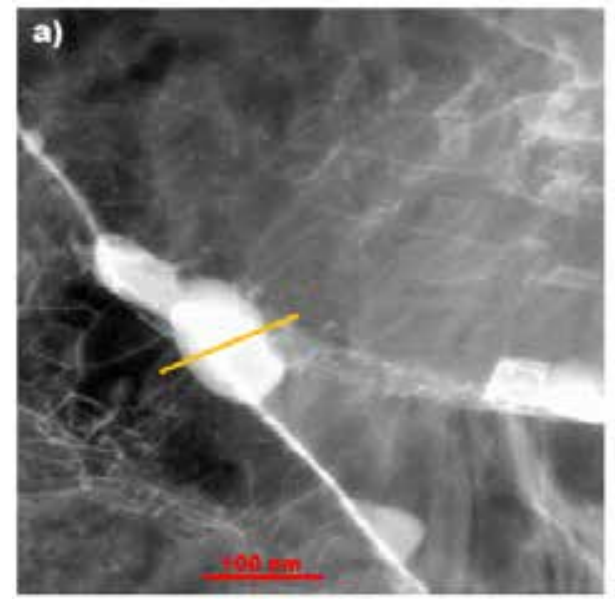

b)

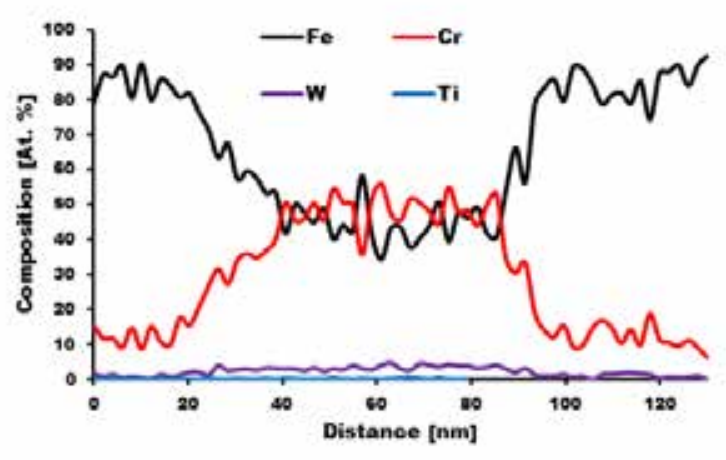

Figure 94. STEM-EDS analysis of precipitates at grain boundaries outside the Fe-irradiation range: a) STEM-ADF image and b) EDS line-scan profile showing the particle enriched in $\mathrm{W}$ and $\mathrm{Cr}$ without the presence of Ti or Ta. 


\section{SUMMARY}

Three groups of advanced ferritic alloys were developed with the aid of computational alloy thermodynamics using the Zr-bearing alloy database developed in this work. The three groups advanced alloys include T-alloys (i.e., 9Cr ferritic-martensitic (FM) steels), Z-alloys (i.e., intermetallicstrengthened $\mathrm{Fe}-\mathrm{Cr}-\mathrm{Zr}$ alloys), and $\mathrm{L}$-alloys (i.e., high-Cr ferritic steels). As compared to the $\mathrm{T}$-alloys, the $\mathrm{Z}$ - and L-alloys do not have the ferrite-austenite phase transformation during heating and cooling, leading to simplified alloy fabrication and possible capability of higher temperature use. Recently, effect of $\mathrm{Ni}$ alloying on phase stability in $\mathrm{Fe}-\mathrm{Cr}-\mathrm{Zr}-\mathrm{Ni}$ system, specifically on the stability of polymorphic Laves phase, was preliminarily assessed by computational alloy thermodynamics, coupled with selected experiments.

The designed alloys were fabricated using arc-melting and drop-casting, followed by hot rolling and conventional heat treatments. The control capability of impurities such as $\mathrm{S}, \mathrm{O}, \mathrm{N}$, and $\mathrm{C}$, especially for the presence of $\mathrm{Zr}$, Ti, and $\mathrm{Ta}$ in alloys, was confirmed by a larger heat of $\mathrm{L}$-alloy production using vacuum-induction melting from a commercial vendor. A comprehensive experimental studies have been conducted on the developed alloys to evaluate their hardness, tensile properties, creep resistance, Charpy impact toughness, and aging resistance, as well as resistance to proton and heavy ion $\left(\mathrm{Fe}^{2+}\right)$. Relevant microstructure characterization was conducted using optical microscopy, SEM, EBSD, XRD, TEM, and EDS. Vicker's microhardness and nanoindentation technique were employed to measure radiation hardening. The project has been primarily focused on the $\mathrm{T}$ - and $\mathrm{Z}$-alloys because the $\mathrm{L}$-alloys exhibited the lowest strength and the highest radiation hardening among the three groups of alloys.

As compared to P91, the T-alloys exhibited $\sim 300$ to $100 \mathrm{MPa}$ increases in yield/tensile strength from room temperature to $\sim 750^{\circ} \mathrm{C}$. The Z-alloys showed comparable or slightly lower yield strength than P91 at temperatures below $\sim 600^{\circ} \mathrm{C}$, above which the $\mathrm{Z}$-alloys exhibited higher yield strength approaching the T-alloys. Microstructural characterization and the modeling of strengthening elements suggest that the notable strength increase of the $\mathrm{T}$-alloys is primarily attributable to the significantly increased amount of ultrafine $\mathrm{MX}(\mathrm{M}=$ metal, $\mathrm{X}=\mathrm{C} / \mathrm{N})$ type nanoprecipitates. In contrast, the $\mathrm{Z}$-alloys are primarily strengthened by the network of eutectic structure. The T-and Z-alloys had increased creep lives by 2 to 4 times of the $\mathrm{P} 91$ tested at $650^{\circ} \mathrm{C}$ and $110 \mathrm{MPa}$. The increased amount of MX nanoprecipitates in the Talloys helped pin the subgrains during creep. Many ultrafine particles $(\sim 10 \mathrm{~nm})$ were randomly formed in the Z-alloys during the creep test, which helped improve creep life without impairing creep ductility. Thermal aging at 600 and $700^{\circ} \mathrm{C}$ for up to $10,200 \mathrm{~h}$ indicated that aging-induced softening in $\mathrm{T}$-alloys, but slight aging hardening in $\mathrm{Z}$-alloys. The higher aging temperature resulted in greater softening in $\mathrm{T}-$ alloys, but less hardening or becoming softening in Z-alloys. Alloying Ta in T-alloys exhibited greater aging resistance. The minor $\mathrm{Zr}$ alloying in $\mathrm{T}$-alloys showed trivial beneficial effect on aging resistance. The decreasing amount of Laves phase in $\mathrm{Z}$-alloys resulted in the change of aging hardening to softening. Charpy V-notch impact tests showed the significant improvement in impact toughness of T-alloys as compared to P91. However, the impact toughness of Z-alloys was significantly lower, which needs to be further investigated and developed.

Ion irradiation experiments using proton and heavy ion $\left(\mathrm{Fe}^{2+}\right)$ have been conducted on the developed alloys to $\sim 1 \mathrm{dpa}$ at $420^{\circ} \mathrm{C}$ and $\sim 50 \mathrm{dpa}$ at $400^{\circ} \mathrm{C}$, respectively. Vicker's microhardness measurements indicated the largest radiation hardening of the L-alloys $(\sim 120 \%)$ and the smallest hardening of the $\mathrm{T}-$ alloys $(\sim 15-40 \%)$ after $\sim 1$ dpa irradiation. The Z-alloys exhibited a large variation in hardening ( $\sim 30-$ $90 \%$ ), suggesting a strong microstructure effect. XRD and STEM/EDS investigations suggested the formation of a large amount of radiation-induced precipitates in the L-alloys and a small amount in the $\mathrm{Z}$-alloys, but negligible in the T-alloys, which is qualitatively consistent with the largest hardening of the 
L-alloys and the smallest hardening of the T-alloys. Detailed microstructural characterization was conducted on the Z6 and T12 alloys as representatives of the Z- and T-alloys. Proton-irradiation resulted in the disappearance of pre-existing large amount of short dislocation threads and the formation of many unknown polyhedron-shaped defects within the ferritic grains, but did not result in phase and chemistry changes to Laves phase in Z6 alloy. In contrast, Fe-irradiation resulted in predominant $<100>$ type dislocation loops in ferrite grains and amorphization of Laves phase within the zone of $>\sim 25 \mathrm{dpa}$. The effect of Laves phase amorphization on mechanical properties is not clear, but which may be beneficial radiation resistance improvement. Unlike the radiation-induced segregation (RIS) of slight Zr-enrichment at popular low-angle boundaries of the ferritic grains in proton-irradiated Z6 alloy, Fe-irradiation did not result in detectable RIS. Additionally, interrupted $\mathrm{Cr}_{2} \mathrm{O}_{3}$ islands or layers were observed at the protonirradiated surface of $\mathrm{Z6}$ alloy, which led to preferential oxidation of $\mathrm{Fe}_{2} \mathrm{Zr}$-type Laves phase in the eutectic structure. Similar studies are needed to see if continuous protective $\mathrm{Cr}_{2} \mathrm{O}_{3}$ layer is formed at surface of Z-alloys with higher $\mathrm{Cr}$ content (e.g., $12 \mathrm{Cr}$ in $\mathrm{Z7}$ to Z9). Proton-irradiation did not result in significant changes to the microstructure of $\mathrm{T} 12$ alloy, except for the formation of $(\mathrm{Cr}, \mathrm{W})$-rich carbides with undefined crystal structure at grain boundaries. Fe-irradiation mainly resulted in a high density of predominant $<100>$ type dislocation loops in T12 alloy, which are about $1 / 3$ in size but one order of magnitude higher in density than the loops in the Fe-irradiated Z6 alloy. RIS was not detected in the proton- and Fe-irradiated T12 alloy.

According to the experimental results, the TT-series alloys and Z-alloys showed promising mechanical properties and radiation resistance. The TT-series alloys exhibited superior strength and impact toughness with excellent microstructure stability under the ion irradiation experiments. Despite the superior high temperature strength and decent (or superior) radiation resistance of $Z$-alloys, this group of alloys requires further development to have balanced mechanical properties and radiation resistance, as well as to understand underlying mechanisms. 


\section{REFERENCES}

[1] N. Baluc, "On the potentiality of using ferritic/martensitic steels as structural materials for fusion reactors," FT/1-1Rb, International Atomic Energy Agency.

[2] H. Mimura, M. Ohgami, H. Naoi, T. Fujita, "Properties of $9 \mathrm{Cr}-1.8 \mathrm{~W}$ steel with high creep strength for USC boiler piping and tubing applications," in: D. Coutsouradis (Eds.), Materials for Advanced Power Engineering, Kluwer Academic Publishers, The Netherlands, 1994, pp. 361.

[3] B. Raj, M. Vijayalakshmi, "Ferritic steels and advanced ferritic-martensitic steels," in: R.J.M. Konings, T.R. Allen, R.E. Stoller, S. Yamanaka, Comprehensive Nuclear Materials, Elsevier, 2012.

[4] K. Maruyama, K. Sawada, J. Koike, "Strengthening mechanisms of creep resistant tempered martensitic steel," ISIJ Inter. 41 (2001) 641-653.

[5] L. Tan, T.S. Byun, Y. Katoh, L.L. Snead, "Stability of MX-type strengthening nanoprecipitates in ferritic steels under thermal, stress and ion irradiation," Acta Mater. 71 (2014) 11-19.

[6] D.G. Morris, M.A. Munoz-Morris, L.M. Requejo, Acta Mater. 54 (2006) 2335-2341.

[7] N. Shigenaka, S. Ono, Y. Isobe, T. Hashimoto, H. Fujimori, S. Uchida, "Effect of zirconium addition to austenitic stainless steels on suppression of radiation induced chromium segregation at grain boundaries under ion irradiation," J. Nucl. Sci. Tech. 33 (1996) 577-581.

[8] M.J. Hackett, J.T. Busby, M.K. Miller, G.S. Was, "Effects of oversized solutes on radiation-induced segregation in austenitic stainless steels," J. Nucl. Mater. 389 (2009) 265-278.

[9] L. Tan, Y. Yang, K. Sridharan, B. Tyburska-Püschel, Optimization and Testing Results of Zr-bearing Ferritic Steels, ORNL/TM-2014/440, UT-Battelle, LLC, Oak Ridge National Laboratory, September 2014.

[10] L. Tan, Y. Yang, Progress Report on the Mechanical Testing and Thermal Aging of Zr-bearing Ferritic Steels, ORNL/TM-2013/360, UT-Battelle, LLC, Oak Ridge National Laboratory, September 2013.

[11] L. Kaufman, B. Uhrenius, D. Birnie, K. Taylor, "Coupled pair potential, thermochemical and phasediagram data for transition-metal binary-systems .7.," CALPHAD 8 (1984) 25-66.

[12] N. Saunders and A.P. Miodownik, CALPHAD (Calculation of Phase Diagrams): A Comprehensive Guide ( $1^{\text {st }}$ Ed.), Elsevier, New York, 1998.

[13] Muggianu, Yves M., Michele Gambino, and Jean P. Bros, Enthalpies of formation of liquid alloys bismuth-gallium-tin at 723.deg.K. Choice of an analytical representation of integral and partial excess functions of mixing, Journal de Chimie Physique et de Physico-Chimie Biologique 72 (1975) $83-91$.

[14] http://www.computherm.com

[15] Y. Yang, L. Tan, H. Bei, J.T. Busby, “Thermodynamic modeling and experimental study of the FeCr-Zr system," J. Nucl. Mater. 441 (2013) 190-202.

[16] L. Tan, Y. Yang, Progress report on the mechanical testing and thermal aging of Zr-bearing ferritic steels, ORNL/TM-2013/360, September 2013.

[17] NIMS Creep Data Sheet No. 43A, National Institute for Materials Science, Japan, 2014.

[18] Y. Yang, L. Tan, H. Bei, J.T. Busby, "Thermodynamic modeling and experimental study of the FeCr-Zr system," J. Nucl. Mater. 441 (2013) 190-202.

[19] L. Tan, J.T. Busby, "Formulating the strength factor $\alpha$ for improved predictability of radiation hardening," J. Nucl. Mater. 465 (2015) 724-730.

[20] L. Tan, Y. Yang, "Microstructure and mechanical properties of Laves phase-strengthened $\mathrm{Fe}-\mathrm{Cr}-\mathrm{Zr}$ alloys," Metall. Mater. Trans. A 46 (2015) 1188-1195.

[21] W.R. Corwin, A.M. Hougland, "Effect of specimen size and material condition on the Charpy impact properties of 9Cr-1Mo-V-Nb steel," in: W.R. Corwin, G.E. Lucas (Eds.), The Use of SmallScale Specimens for Testing Irradiated Material, ASTM STP 888, American Society for Testing and Materials, Philadelphia, 1986, pp. 325-338. 
[22] M.A. Sokolov, R.K. Nanstad, "On impact testing of subsize Charpy V-notch type specimens," in: D.S. Gelles, R.K. Nanstad, A.S. Kumar, E.A. Little (Eds.), Effects of Radiation on Materials: $17^{\text {th }}$ International Symposium, ASTM International, STP 1270, 1996, pp. 384.

[23] R. Stoller, M. Toloczko, G. Was, A. Certain, S. Dwaraknath, F. Garner, Nucl. Instrum. Meth. Phys, Res. B 310 (2013) 75.

[24] W.C. Oliver, G.M. Pharr, "An improved technique for determining hardness and elastic modulus using load and displacement sensing indentation experiments," J. Mater. Res. 7 (1992) 1564-1583.

[25] A.C. Fischer-Cripps, Nanoindentation, Springer 2002.

[26] J.-Y. Kim, J.-J. Lee, Y.-H. Lee, J. Jang, D. Kwon, "Surface roughness effect in instrumented indentation: A simple contact depth model and its verification," J. Mater. Res. 21 (2006) 2975-2978.

[27] C.M. Parish, K.G. Field, A.G. Certain, J.P. Wharry, "Application of STEM characterization for investigating radiation effects in BCC Fe-based alloys," J. Mater. Res. 30 (2015) 1275-1289.

[28] P.J. Phillips, M.C. Brandes, M.J. Mills, M. De Graef, "Diffraction contrast STEM of dislocations: imaging and simulations," Ultramicroscopy 111 (2011) 1483-1487.

[29] B. Yao, D.J. Edwards, R.J. Kurtz, "TEM characterization of dislocation loops in irradiated bcc Febased steels," J. Nucl. Mater. 434 (2013) 402-410.

[30] W. Jäger, H. Trinkaus, "Defect ordering in metals under irradiation," J. Nucl. Mater. 205 (1993) 394-410.

[31] K.L. Johnson, Contact Mechanics, Cambridge University Press 1987.

[32] S.L. Dudarev, R. Bullough, P.M. Derlet, Effect of the phase transition on the stability of dislocation loops in bcc iron, Phys. Rev. Lett. 100 (2008) 1-4.

[33] G.S. Was, Microstructure and Property Evolution in Advanced Cladding and Duct Materials under Long-term Irradiation at Elevated Temperature: Critical Experiments, DOE-NEUP final report project no. 10-678 (2013).

[34] Z. Yao, M.L. Jenkins, M. Hernández-Mayoral, M.A. Kirk, "The temperature dependence of heavyion damage in iron: A microstructural transition at elevated temperatures," Philos. Mag. 90 (2015) $4623-4634$. 